University of Sao Paulo

School of Pharmaceutical Sciences of Ribeirao Preto

Development of a DNA microarray platform for the detection of viruses transmitted by small mammals and arthropods

Mohd Jaseem Khan

Ribeirao Preto

2015 


\section{University of Sao Paulo}

School of Pharmaceutical Sciences of Ribeirao Preto

Development of a DNA microarray platform for the detection of viruses transmitted by small mammals and arthropods

Doctorate thesis presented to the Postgraduate Program of Biosciences Applied to Pharmacy to obtain the title of Doctor of Sciences.

Field: Biosciences Applied to Pharmacy

Student: Mohd Jaseem Khan

Supervisor: Victor Hugo Aquino Quintana

Ribeirao Preto

2015 
I AUTHORIZE THE REPRODUCTION AND DISTRIBUTION OF WHOLE OR PARTIAL PART OF THIS WORK, BY EITHER CONVENTIONAL OR ELECTRONIC WAY, FOR THE AIM OF STUDY OR RESEARCH, WHEN THE SOURCE IS CITED.

Khan, Mohd Jaseem

Development of a DNA microarray platform for the detection of viruses transmitted by small mammals and arthropods. Ribeirao Preto, 2015.

168 p. : il. ; $30 \mathrm{~cm}$.

Doctorate thesis, presented at the School of Pharmaceutical Sciences of Ribeirao Preto/USP - Field: Biosciences Applied to Pharmacy.

Supervisor: Aquino Quintana, Victor Hugo.

1. Virus. 2. Small mammals. 3. Arthropods. 4. DNA microarray. 


\section{APPROVAL SHEET}

Mohd Jaseem Khan

Development of a DNA microarray platform for the detection of viruses transmitted by small mammals and arthropods.

Doctorate thesis presented to the Postgraduate Program of Biosciences Applied to Pharmacy to obtain the title of Doctor of Sciences.

Field: Biosciences Applied to Pharmacy

Student: Mohd Jaseem Khan

Approved in:

\section{Evaluation Committee}

Dr.

Institution: Signature:

Dr.

Institution: Signature:

Dr.

Institution: Signature:

Dr.

Institution: Signature:

Dr. Signature: 


\section{DEDICATED}

\section{TO MY PARENTS AND BROTHERS}




\section{ACKNOWLEDGEMENT}

I would like to deeply express my sincere gratitude to my mentor Dr. Victor Hugo Aquino Quintana, under whose guidance and supervision this work was made possible. I am extremely thankful to him in believing in me and giving me an opportunity of being trained under him.

I would like to thanks to funding agencies, especially Foundation for the Support of Research in the State of Sao Paulo (FAPESP) for financial support for this study with process numbers 2011/02045-6 (scholarship support), Coordination for the Improvement of Higher Education Personnel, Ministry of Higher Education federal government (Brazil) CAPES (process \# XX) and National Council for Scientific and Technology Development (CNPq) Brazilian federal government under Ministry of Science and Technology (process \# 167634/2014-3 and 141878/2015-0) for my scholarship supports. The administrative and nonadministrative persons from department for their amicable help and valuable time. 


\begin{abstract}
Khan, M. J. Development of a DNA microarray platform for the detection of viruses transmitted by small mammals and arthropods. 197p. Thesis (Doctoral). School of Pharmaceutical Sciences of Ribeirao Preto - University of Sao Paulo, 2015.

Human activities have being responsible for the global environmental changes, resulting in an increase number of incident of vector- and rodent-borne diseases worldwide. Rodents and arthropods-borne viruses are important globally emerging and re-emerging viruses and most of them are RNA viruses. Efficient and early diagnosis of these infections are very important to prevent their spread, to improve clinical management of the patients, as wells to protect livestock and domestic animals. Currently, available diagnostic methods such as immunoassays, polymerase chain reaction and virus isolation can detect only one or few viruses in a single assay. The DNA microarray platform has emerged as diagnostic tool suitable for high throughput screening of pathogenic agents. The aim of this study was to develop a DNA microarray platform (RoboArboVirusChip) for detecting rodent- and arthropod-borne viruses, which belong to seven families: Bunyaviridae (genera Orthobunyavirus, Nairovirus and Phlebovirus), Flaviviridae (genus Flavivirus), Togaviridae (genus Alphavirus), Reoviridae (genera Orbivirus, Seadornavirus and Coltvivirus), Rhabdoviridae (genera Vesiculovirus and Ephemerovirus), and Asfarviridae (genus Asfarvirus). Specific oligonucleotide probes of 60 -mer $(n=4209)$ targeting 412 virus species and generic probes of $25-35$-mer $(n=87)$ targeting viruses at the genus level were designed. A total of 17 reference viruses belonging to the Bunyaviridae, Flaviviridae, Rhabdoviridae and Togaviridae families were used to standardize RoboArboVirusChip. All reference viruses were specifically detected without any cross hybridization; however, the generic probes were not able to identify the viruses at the genus level. The RoboArboVirusChip was able to specifically identify four viruses contained in three different mixtures: i) virus of different families, ii) virus of the Flavivirus genus, and iii) the Dengue virus (DENV) serotypes. The four DENV serotypes were use to evaluate the sensitivity of the RoboArboVirusChip, which was able to detect a minimum of $25 \mathrm{RNA}$ copies $/ \mathrm{mL}$ of the viruses, confirming its high sensitivity. The applicability of the RoboArboVirusChip to detect viruses in clinical samples was tested with serum samples obtained from dengue suspected cases (four positive cases and 40 negative cases). DENV was detected in the four positive serum samples, while in the 40 negative serum samples, it was not detected any virus. The results obtained in this study suggest that the RoboArboVirusChip platform could be a useful tool for early diagnosis of robovirus and arbovirus infections during epidemic outbreaks, helping in the rapid implementation of disease containment strategies.
\end{abstract}

Keywords: Virus, small mammals, arthropods, DNA microarray. 


\section{RESUMO}

Khan, M. J. Desenvolvimento de uma plataforma de microarranjo de DNA para detecção de vírus transmitidos por pequenos mamíferos e artrópodes.. 197f. Tese (Doutorado). Faculdade de Ciências Farmacêuticas de Ribeirão Preto - Universidade de São Paulo, Ribeirão Preto, 2015.

As atividades humanas têm sido responsável por mudanças ambientais globais, resultando num aumento do número de casos de doenças transmitidas por vetores e roedores em todo o mundo. Os vírus transmitidos por roedores e artrópodes são vírus emergentes e re-emergentes de importância global, sendo que a maioria deles são vírus de RNA. O diagnóstico eficiente e precoce dessas infecções são muito importantes para evitar a sua propagação, para melhorar o manejo clínico dos pacientes e também, para proteger o gado e os animais domésticos. Atualmente, os métodos de diagnóstico disponíveis, tais como os imunoensaios, a reação em cadeia da polimerase e o isolamento viral podem detectar apenas um ou poucos vírus em um único ensaio. A plataforma de microarranjo de DNA tem surgido como uma ferramenta de diagnóstico apropriada para o monitoramento em larga escala de agentes patogênicos. O objetivo deste estudo foi desenvolver uma plataforma de microarranjo de DNA (RoboArboVirusChip) para a detecção de vírus transmitidos por roedores e artrópodes, os quais pertencem a sete famílias: Bunyaviridae (gêneros Orthobunyavirus, Nairovirus e Phlebovírus), Flaviviridae (gênero Flavivirus), Togaviridae (gênero Alphavirus), Reoviridae (gênero Orbivirus, Seadornavirus e Coltvivirus), Rhabdoviridae (géneros Vesiculovirus e Ephemerovirus), e Asfarviridae (gênero Asfarvirus). Sondas oligonucleotídicas de 60-mer $(\mathrm{n}=4209)$ específicas contra 412 espécies virais, e sondas genéricas de 25-35-mer $(\mathrm{n}=87)$ para detecção de vírus a nível do gênero foram desenhados. Um total de 17 vírus de referência, pertencentes às famílias Bunyaviridae, Flaviviridae, Rhabdoviridae e Togaviridae foram utilizados para padronizar o RoboArboVirusChip. Todos os vírus de referência foram detectados especificamente sem apresentação de hibridação cruzada, porem as sondas genéricas não foram capazes de detectar os vírus a nível do gênero. O RoboArboVirusChip foi capaz de identificar especificamente quatro vírus contidos em diferentes misturas: i) vírus de diferentes famílias, ii) vírus pertencentes ao gênero a Flavivirus, e iii) os sorotipos do vírus da dengue (DENV). Os quatro sorotipos do DENV foram utilizados para determinar a sensibilidade do RoboArboVirusChip, o qual foi capaz de detectar um mínimo de 25 copias de RNA/mL. A aplicabilidade do RoboArboVirusChip para detectar vírus em amostras clínicas foi avaliada testando amostras de soro de pacientes com suspeita de dengue (quatro casos positivos e 40 casos negativos). Os resultados obtidos neste estudo sugerem que o RoboArboVirusChip poderá ser uma ferramenta útil para o diagnóstico precoce da infecção causada por robovírus e arbovírus, auxiliando na rápida implementação de estratégias de contenção das doenças causadas por esses vírus.

Palavras chaves: Vírus, pequenos mamíferos, artrópodes, microarranjo de DNA. 


\section{RESUMEN}

Khan, M. J. Desarrollo de una plataforma de microarreglo de DNA para detección de virus transmitidos por pequeños mamíferos y artrópodos. 2015. 197h. Tesis (Doctorado). Facultad de Ciencias Farmacéuticas de Ribeirao Preto - Universidad de San Pablo, Ribeirao Preto, 2015.

Las actividades humanas han sido responsables por cambios ambientales globales, resultando en un aumento del número de casos de enfermedades transmitidas por vectores y roedores en todo el mundo. Los virus transmitidos por roedores e artrópodos son virus emergentes e re-emergentes de importancia mundial, siendo que la mayoría son virus de RNA. El diagnóstico eficiente y rápido de esas infecciones son muy importantes para evitar su propagación, para mejorar la atención clínica de los pacientes y también, para proteger el ganado y a los animales domésticos. Actualmente, los métodos de diagnóstico disponibles, tales como los imunoensayos, la reacción en cadena de la polimerasa y el aislamiento viral pueden detectar solo un o pocos virus en un único examen. La plataforma de microarreglo de DNA ha surgido como una herramienta de diagnóstico apropiada para monitorizar en larga escala de agentes patogénicos. El objetivo de este estudio fue desenvolver una plataforma de microarreglo de DNA para la detección de virus transmitidos por roedores e artrópodos, los cuales pertenecen a siete familias: Bunyaviridae (géneros Orthobunyavirus, Nairovirus e Phlebovírus), Flaviviridae (género Flavivirus), Togaviridae (genero Alphavirus), Reoviridae (género Orbivirus, Seadornavirus y Coltvivirus), Rhabdoviridae (géneros Vesiculovirus y Ephemerovirus), y Asfarviridae (género Asfarvirus). Sondas oligonucleotídicas de 60mer $(n=4209)$ específicas contra 412 especies virales y sondas genéricas de 25-35-mer $(\mathrm{n}=87)$ para la detección de virus a nivel del género fueron diseñados. Un total de 17 virus de referencia, pertenecientes a las familias Bunyaviridae, Flaviviridae, Rhabdoviridae y Togaviridae fueron utilizados para estandarizar el RoboArboVirusChip. Todos los virus de referencia fueron específicamente detectados sin la presencia de hibridación cruzada, sin embargo, las sondas genéricas no fueron capaces de detectar los virus a nivel del género. El RoboArboVirusChip fue capaz de identificar específicamente cuatro virus contenidos en diferentes mezclas: i) virus de diferentes familias, ii) virus pertenecientes al género Flavivirus, y iii) los serotipos del virus del dengue (DENV). Los cuatro serotipos del DENV fueron utilizados para determinar la sensibilidad del RoboArboVirusChip, el cual fue capaz de detectar un mínimo de 25 copias de RNA/mL. La aplicabilidad del RoboArboVirusChip para detectar virus en muestras clínicas fue evaluada analizando muestras de suero de pacientes con sospecha de dengue (cuatro casos positivos y 40 casos negativos). El DENV fue detectado en las cuatro muestras positivas, mientras que ningún virus fue detectado en las muestras negativas. Los resultados obtenidos en este estudio sugieren que el RoboArboVirusChip podrá ser una herramienta útil para el diagnóstico rápido de la infección causada por robovirus e arbovirus, ayudando en la rápida implementación de estrategias para la contención de las enfermedades causadas por esos virus.

Palabras claves: Virus, pequeños mamíferos, artrópodos, microarreglo de DNA. 


\section{LIST OF FIGURES}

Figure 1. WORK PLAN. .36

Figure 2. Indirect immunofluorescence demonstrating infection in C6/36 cells with DENV-2 (B), (C) SLEV, (D) YFV,(E) OROV, and (F) PIRY. (A) Negative control.

Figure 3. Electrophoresis on $1.8 \%$ agarose gel showing the DNA bands with the molecular-weight marker as well as negative, positive controls and viruses lane1Marker, lane-2 DENV-2 (band size 316bp), lane-3 DENV-3 (659bp), lane 4 DENV4(222bp), lane-5 Busuquara (388bp), lane-6 YFV(253bp), lane -7 Ilheus (474bp). Lane-8 Rocio (230bp), lane -9 SLEV (232bp), lane-10 Negative control-1(during RNA extraction), lane-11 Negative control and lane- 2 Positive control (Rocio virus).

Figure 4. Microarray control slide with 8 arrays scanned at $532 \mathrm{~nm}$. 1. DENV-3 (PCR); 2. DENV-3 (PCR); 3. DENV-2 (cDNA); 4. DENV-3 (cDNA); 5. YFV (cDNA); 6. BUSV (cDNA); DENV-2 (cDNA); and 7. YFV (cDNA).

Figure 5. Visualization of probes fluorescence intensity of control slide hybridized with DENV-3 (genomic region: 1-950 bp). Data were sorted by family, genus and species levels.

Figure 6. Visualization of probes fluorescence intensity of control slide hybridized with DENV-3 (genomic region 8800-10707 bp). Data were sorted by family, genus and species levels.

Figure 7. Visualization of probes fluorescence intensity of control slide hybridized with DENV-2 (5 $\mu \mathrm{L}$ cDNA). Data were sorted by family, genus and species levels. .....59

Figure 8. Visualization of probes fluorescence intensity of control slide hybridized with DENV-2 (10 $\mu$ L cDNA). Data were sorted by family, genus and species levels. ...61

Figure 9. Visualization of probes fluorescence intensity of control slide hybridized with BUSQV. Data were sorted by family, genus and species levels. 
Figure 10. Visualization of probes fluorescence intensity of control slide hybridized with YFV (5 $\mu \mathrm{L}$ cDNA). Data were sorted by family, genus and species levels. .65

Figure 11. Visualization of probes fluorescence intensity of control slide hybridized with DENV-2 (5 $\mu \mathrm{L}$ cDNA). Data were sorted by family, genus and species levels. .....67

Figure 12. Visualization of probes fluorescence intensity of control slide hybridized with YFV ( $5 \mu \mathrm{L}$ cDNA). Data were sorted by family, genus and species levels.

Figure 13. Microarray control slide with 8 arrays scanned at $532 \mathrm{~nm}$. DENV-2, DENV-3, YFV, BUSV, DENV-4, ILHEV, SLEV and OROV. .70

Figure 14. Microarray RoboArboVirusChip slide with 8 arrays scanned at $532 \mathrm{~nm}$. 1DENV-2, DENV-3, YFV, BUSV, DENV-4, ILHEV, SLEV and OROV. .70

Figure 15. Visualization of probes fluorescence intensity of control slide hybridized with OROV. Data were sorted by family, genus and species levels. .72

Figure 16. Visualization of probes fluorescence intensity of control slide hybridized with BUSQV. Data were sorted by family, genus and species levels. 74

Figure 17. Visualization of probes fluorescence intensity of control slide hybridized with SLEV. Data were sorted by family, genus and species levels. 76

Figure 18. Visualization of probes fluorescence intensity of control slide hybridized with YFV. Data were sorted by family, genus and species levels. .78

Figure 19. Visualization of probes fluorescence intensity of control slide hybridized with ILHV. Data were sorted by family, genus and species levels. .80

Figure 20. Visualization of probes fluorescence intensity of control slide hybridized with DENV-3. Data were sorted by family, genus and species levels. .82

Figure 21. Visualization of probes fluorescence intensity of control slide hybridized with DENV-4. Data were sorted by family, genus and species levels. .84

Figure 22. Visualization of probes fluorescence intensity of control slide hybridized with DENV-2. Data were sorted by family, genus and species levels. .86 
Figure 23. Visualization of probes fluorescence intensity of control slide hybridized with OROV. Data were sorted by family, genus and species levels.

Figure 24. Visualization of probes fluorescence intensity of control slide hybridized with BUSQV. Data were sorted by family, genus and species levels. .91

Figure 25. Visualization of probes fluorescence intensity of control slide hybridized with SLEV. Data were sorted by family, genus and species levels. .93

Figure 26. Visualization of probes fluorescence intensity of control slide hybridized with YFV. Data were sorted by family, genus and species levels. .95

Figure 27. Visualization of probes fluorescence intensity of control slide hybridized with ILHV. Data were sorted by family, genus and species levels.

Figure 28. Visualization of probes fluorescence intensity of control slide hybridized with DENV-3. Data were sorted by family, genus and species levels. .99

Figure 29. Visualization of probes fluorescence intensity of control slide hybridized with DENV-4. Data were sorted by family, genus and species levels. 101

Figure 30. Visualization of probes fluorescence intensity of control slide hybridized with DENV-2. Data were sorted by family, genus and species levels. 103

Figure 31. Visualization of probes fluorescence intensity of RoboArboVirusChi v3 slide hybridized with DENV-3. Data were sorted by family, genus and species levels. 114

Figure 32. Visualization of probes fluorescence intensity of RoboArboVirusChi v3 slide hybridized with BUSQV. Data of virus species within the Flavivirus genus are shown.

Figure 33. Visualization of probes fluorescence intensity of RoboArboVirusChi v3 slide hybridized with CHIKV. Data were sorted by species of the Alphavirus genus levels. 116

Figure 34. Visualization of probes fluorescence intensity of RoboArboVirusChi v3 slide hybridized with DENV-1. Data of virus species within the Flavivirus genus are shown. 
Figure 35. Visualization of probes fluorescence intensity of RoboArboVirusChi v3 slide hybridized with DENV-2. Data of virus species within the Flavivirus genus are shown.

Figure 36. Visualization of probes fluorescence intensity of RoboArboVirusChi v3 slide hybridized with DENV-4. Data of virus species within the Flavivirus genus are shown.

Figure 37. Visualization of probes fluorescence intensity of RoboArboVirusChi v3 slide hybridized with GROV. Data of virus species within the Orthobunyavirus genus are shown.

Figure 38. Visualization of probes fluorescence intensity of RoboArboVirusChi v3 slide hybridized with IGUV. Data of virus species within the Flavivirus genus are shown.

Figure 39. Visualization of probes fluorescence intensity of RoboArboVirusChi v3 slide hybridized with ILHV. Data of virus species within the Flavivirus genus are shown.

Figure 40. Visualization of probes fluorescence intensity of RoboArboVirusChi v3 slide hybridized with MAYV. Data of virus species within the Alphavirus genus are shown.

Figure 41. Visualization of probes fluorescence intensity of RoboArboVirusChi v3 slide hybridized with OROV. Data of virus species within the Orthobunyavirus genus are shown.

Figure 42. Visualization of probes fluorescence intensity of RoboArboVirusChi v3 slide hybridized with PIRYV. Data of virus species within the Vesiculovirus genus are shown.

Figure 43. Visualization of probes fluorescence intensity of RoboArboVirusChi v3 slide hybridized with RIOMV. Data of virus species within the Hantavirus genus are shown. 
Figure 44. Visualization of probes fluorescence intensity of RoboArboVirusChi v3 slide hybridized with ROCV. Data of virus species within the Flavivirus genus are shown.

Figure 45. Visualization of probes fluorescence intensity of RoboArboVirusChi v3 slide hybridized with SLEV. Data of virus species within the Flavivirus genus are shown.

Figure 46. Visualization of probes fluorescence intensity of RoboArboVirusChi v3 slide hybridized with WNV. Data of virus species within the Flavivirus genus are shown.

Figure 47. Visualization of probes fluorescence intensity of RoboArboVirusChi v3 slide hybridized with YFV. Data of virus species within the Flavivirus genus are shown.

Figure 48. Visualization of probes fluorescence intensity of RoboArboVirusChi v3 slide hybridized with RNA of uninfected C6/36 cells. Data of virus species within the Flavivirus genus are shown. 131

Figure 49. Visualization of probes fluorescence intensity of RoboArboVirusChi v3 slide hybridized with MAYV, SLEV, BUSQV and PIRYV. Data of virus species within the Flavivirus genus are shown.

Figure 50. Visualization of probes fluorescence intensity of RoboArboVirusChi v3 slide hybridized with MAYV, SLEV, BUSQV and PIRYV. Data of virus species within the Alphavirus genus are shown.

Figure 51. Visualization of probes fluorescence intensity of RoboArboVirusChi v3 slide hybridized with MAYV, SLEV, BUSQV and PIRYV. Data of virus species within the Vesiculovirus genus are shown.

Figure 52. Visualization of probes fluorescence intensity of RoboArboVirusChi v3 slide hybridized with DENV-1, DENV-2, DENV-3 and DENV-4. Data of virus species within the Flavivirus genus are shown. 134 


\section{LIST OF TABLES}

Table 1. Summary of viruses belongs to Genera: Mammarenaviruses .............................

Table 2. Summary of Arenaviruses pathogenic for human. .........................................6

Table 3. Summary of genus Reptarenavirus .........................................................

Table 4. Taxonomic status of known and tentative arboviruses....................................

Table 5. Summary of arthropods-borne viruses of genus Orthobunyavirus ..................... 10

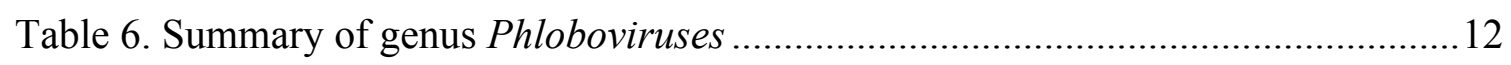

Table 7. Summary of genus Nairovirus.................................................................... 14

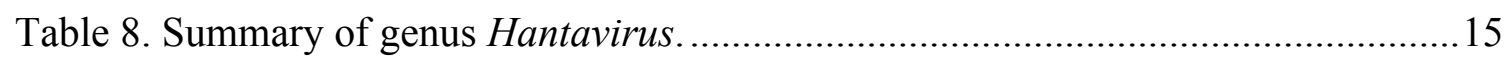

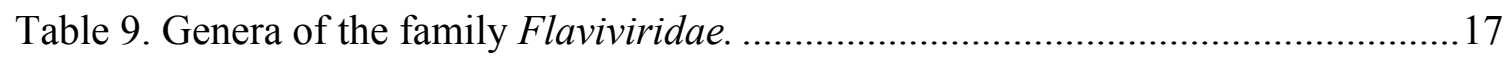

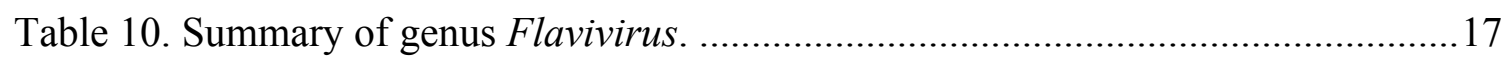

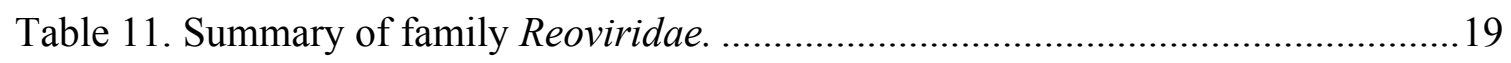

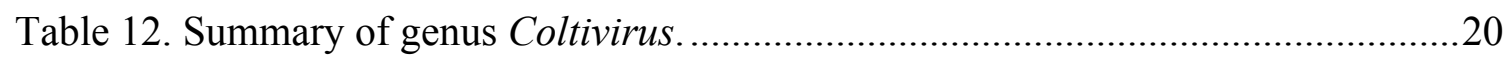

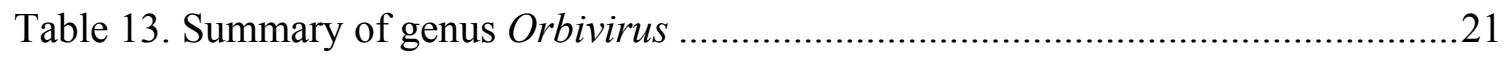

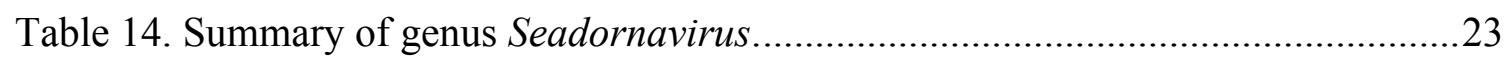

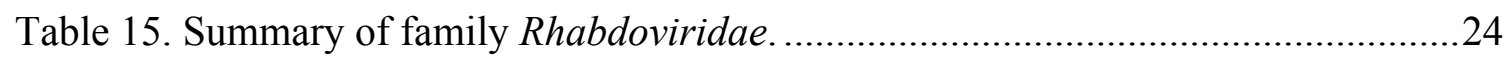

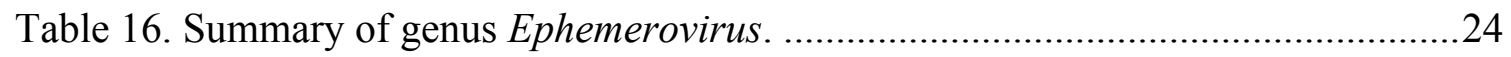

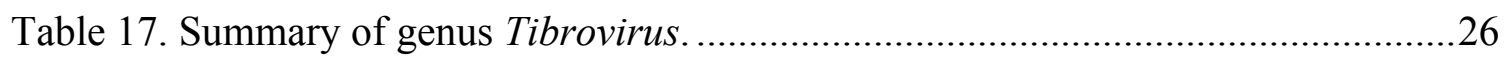

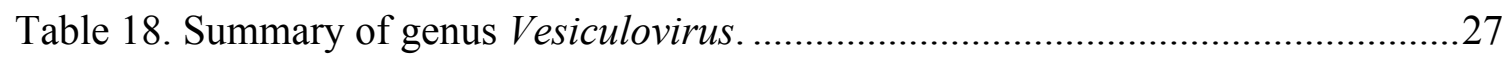

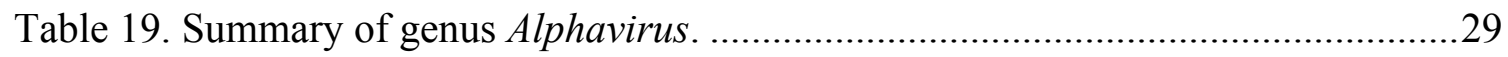

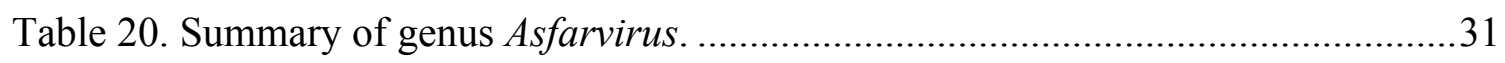


Table 21. Genome of roboviruses and arboviruses .32

Table 22. Reference viruses used in this study.

Table 23. Summary of viruses and sequences retrieved from GenBank. .39

Table 24. Reference virus titers. 52

Table 25. Significant analysis of array hybridized with DENV-3. The top 10 viruses with lowest $p$-values. .55

Table 26. Significant analysis of array hybridized with DENV-3. The top 10 viruses with lowest $p$-values.

Table 27. Significant analysis of array hybridized with DENV-2. The top 10 viruses with lowest $p$-values.

Table 28. Significant analysis of array hybridized with DENV-2. The top 10 viruses with highest $p$-values.

Table 29. Significant analysis of array hybridized with BUSQV. The top 10 viruses with lowest $p$-values.

Table 30. Significant analysis of array hybridized with YFV. The top 10 viruses with lowest $p$-values.

Table 31. Significant analysis of array hybridized with DENV-2. The top 10 viruses with lowest $p$-values.

Table 32. Significant analysis of array hybridized with YFV. The top 10 viruses with lowest $p$-values.

Table 33. Significant analysis of array hybridized with OROV. The top 10 viruses with lowest $p$-values.

Table 34. Significant analysis of array hybridized with BUSQV. The top 10 viruses with lowest $p$-values. .75

Table 35. Significant analysis of array hybridized with SLEV. The top 10 viruses with lowest $p$-values. 
Table 36. Significant analysis of array hybridized with YFV. The top 10 viruses with

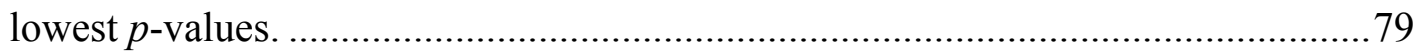

Table 37. Significant analysis of array hybridized with ILHV. The top 10 viruses with

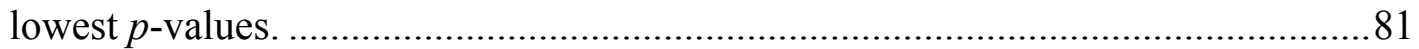

Table 38. Significant analysis of array hybridized with DENV-3. The top 10 viruses with

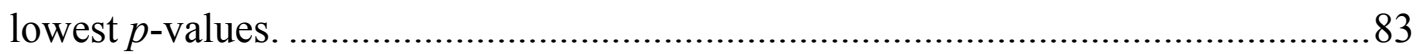

Table 39. Significant analysis of array hybridized with DENV-4. The top 10 viruses with lowest $p$-values.

Table 40. Significant analysis of array hybridized with DENV-2. The top 10 viruses with lowest $p$-values.

Table 41. Significant analysis of array hybridized with OROV. The top 10 viruses with lowest $p$-values.

Table 42. Significant analysis of array hybridized with BUSQV. The top 10 viruses with lowest $p$-values. .91

Table 43. Significant analysis of array hybridized with SLEV. The top 10 viruses with lowest $p$-values. .93

Table 44. Significant analysis of array hybridized with YFV. The top 10 viruses with lowest $p$-values. .95

Table 45. Significant analysis of array hybridized with ILHV. The top 10 viruses with lowest $p$-values.

Table 46. Significant analysis of array hybridized with DENV-3. The top 10 viruses with lowest $p$-values.

Table 47. Significant analysis of array hybridized with DENV-4. The top 10 viruses with lowest $p$-values. 101

Table 48. Significant analysis of array hybridized with DENV-2. The top 10 viruses with highest $p$-values. 103 
Table 49. Significant analysis of array hybridized with DENV-1. The top 10 viruses with lowest $p$-values.

Table 50. Significant analysis of array hybridized with DENV-2. The top 10 viruses with lowest $p$-values.

Table 51. Significant analysis of array hybridized with YFV. The top 10 viruses with lowest $p$-values. 105

Table 52. Significant analysis of array hybridized with DENV-1. The top 10 viruses with lowest $p$-values. 105

Table 53. Significant analysis of array hybridized with BUSQV. The top 10 viruses with lowest $p$-values. 105

Table 54. Significant analysis of array hybridized with OROV. The top 10 viruses with lowest $p$-values. 105

Table 55. Significant analysis of array hybridized with DENV-3. The top 10 viruses with lowest $p$-values. 106

Table 56. Significant analysis of array hybridized with DENV-4. The top 10 viruses with lowest $p$-values. 106

Table 57. Significant analysis of RoboArboVirusChip v2 hybridized with cDNA and PCR products of YFV. The top 10 viruses with lowest $p$-values. 107

Table 58. Significant analysis of arrays hybridized with pool of viruses. The top 10 viruses with lowest $p$-values 108

Table 59. Determination of sensitivity of the RoboArboChip v2 for DENV-2. 109

Table 60. Determination of sensitivity of the RoboArboChip for DENV-4. 111

Table 61. Significance analysis of arrays hybridized with DENV-3. The top 10 viruses with lowest $p$-values.

Table 62. Significance analysis of arrays hybridized with BUSQV. The top 10 viruses with lowest $p$-values. 
Table 63. Significance analysis of arrays hybridized with CHIKV. The top 10 viruses with lowest $p$-values

Table 64. Significance analysis of arrays hybridized with DENV-1. The top 10 viruses with lowest $p$-values.

Table 65. Significance analysis of arrays hybridized with DENV-2. The top 10 viruses with lowest $p$-values 118

Table 66. Significance analysis of arrays hybridized with DENV-4. The top 10 viruses with lowest $p$-values.

Table 67. Significance analysis of arrays hybridized with GROV. The top 10 viruses with lowest $p$-values

Table 68. Significance analysis of arrays hybridized with IGUV. The top 10 viruses with lowest $p$-values.

Table 69. Significance analysis of arrays hybridized with ILHV. The top 10 viruses with lowest $p$-values.

Table 70. Significance analysis of arrays hybridized with MAYV. The top 10 viruses with lowest $p$-values.

Table 71. Significance analysis of arrays hybridized with OROV. The top 10 viruses with lowest $p$-values

Table 72. Significance analysis of arrays hybridized with PIRYV. The top 10 viruses with lowest $p$-values

Table 73. Significance analysis of arrays hybridized with RIOMV. The top 10 viruses with lowest $p$-values. 126

Table 74. Significance analysis of arrays hybridized with ROCV. The top 10 viruses with lowest $p$-values.

Table 75. Significance analysis of arrays hybridized with SLEV. The top 10 viruses with lowest $p$-values. 128 
Table 76. Significance analysis of arrays hybridized with WNV. The top 10 viruses with lowest $p$-values.

Table 77. Significance analysis of array hybridized with YFV. The top 10 viruses with lowest $p$-values. 130

Table 78. Significance analysis of array hybridized with RNA of uninfected C6/36 cells. The top 10 viruses with lowest $p$-values.

Table 79. Significance analysis of array hybridized with a pool of MAYV, SLEV, BUSQV and PIRYV. The top 10 viruses with lowest $p$-values.

Table 80. Significance analysis of array hybridized with a pool of MAYV, SLEV, BUSQV and PIRYV. The top 10 viruses with lowest $p$-values.

Table 81. Determination of sensitivity of the RoboArboVirusChip v3 for DENV-1, DENV-2, DENV-3 and DENV-4.

Table 82. Significance analysis of array hybridized with RNA of serum samples of DENV uninfected cases. The top 10 viruses with lowest $p$-values. 136

Table 83. Significance analysis of array hybridized with RNA of serum samples of DENV infected cases. The top 10 viruses with lowest $p$-values. 137 


\section{List of Abbreviations of reference viruses}

$\begin{array}{ll}\text { BSQV } & \text { Bussuquara virus } \\ \text { CHIKV } & \text { Chikungunya virus } \\ \text { DENV-1 } & \text { Dengue virus type 1 } \\ \text { DENV-2 } & \text { Dengue virus type } 2 \\ \text { DENV-3 } & \text { Dengue virus type } 3 \\ \text { DENV-4 } & \text { Dengue virus type } 4 \\ \text { GUAV } & \text { Goaroa vírus } \\ \text { IGUV } & \text { Iguape vírus } \\ \text { ILHV } & \text { Ilheus virus } \\ \text { MAYV } & \text { Mayaro virus } \\ \text { OROV } & \text { Oropouche virus } \\ \text { PIRYV } & \text { Piry virus } \\ \text { RIOMV } & \text { Rio Mamore virus } \\ \text { SLEV } & \text { St.Louis encephalitis virus } \\ \text { WNV } & \text { West Nile virus } \\ \text { YFV } & \text { Yellow fever virus }\end{array}$

\section{List of Abbreviations other than viruses}

$\begin{array}{ll}\% & \text { Percentage } \\ > & \text { Greater than } \\ { }^{\circ} \mathrm{C} & \text { Degree centigrade } \\ \mathrm{Mg} & \text { Micro gram } \\ \mu \mathrm{r} & \text { Micro liter } \\ \mu \mathrm{M} & \text { Micrometer } \\ \mathrm{Ab} & \text { Antibody } \\ \mathrm{AmB} & \text { Amphotericin B } \\ \mathrm{BLAST} & \text { Basic local alignment search tool } \\ \mathrm{CDC} & \text { Centers for Disease Control and Prevention } \\ \text { cDNA } & \text { Complementary Deoxyribo Nucleic Acid } \\ \text { CLC } & \text { CLC Main Workbench }\end{array}$




\begin{tabular}{|c|c|}
\hline $\mathrm{CMC}$ & Carboxymethyl cellulose \\
\hline $\mathrm{CO}_{2}$ & Carbon dioxide \\
\hline CPE & Cytopathic effect \\
\hline Сy3 & Cyanine Dye 3 \\
\hline DNA & Deoxyribonucleic acid \\
\hline dNTPs & Deoxynucleotide triphosphate \\
\hline dsDNA & Double-strand DNA \\
\hline dsRNA & Double-strand RNA \\
\hline DTT & Dithiothreitol \\
\hline EDTA & Ethylene diamine tetra acetic acid \\
\hline FCS & Fetal calf serum \\
\hline FITC & Fluorescein isothiocyanate \\
\hline $\mathrm{G} / \mathrm{C}$ & Guanine/ Cytosine \\
\hline ICTV & International Committee on the taxonomy of viruses \\
\hline ICTVdB & International Committee on the taxonomy of viruses database \\
\hline IFA & Immunofluorescence assay \\
\hline $\operatorname{IgG}$ & Immunoglobulin G \\
\hline $\mathrm{KCl}$ & Potassium chloride \\
\hline L15 medium & Leibovitz's L-15 medium \\
\hline LLOD & Lower Limit of Detection \\
\hline MAbs & Monoclonal antibodies \\
\hline $\mathrm{Mg} 2 \mathrm{SO} 4$ & Magnesium sulfate \\
\hline $\mathrm{MgCl}$ & Magnesium chloride \\
\hline MIAF & Mouse immune ascetic fluid \\
\hline Min & Minutes \\
\hline $\mathrm{mL}$ & Milli liter \\
\hline MLS & Master Species List \\
\hline $\mathrm{mM}$ & Milli molar \\
\hline MMLV & Moloney murine leukemia virus \\
\hline MQ & MilliQ water \\
\hline NCBI & National Center for Biotechnology Information \\
\hline NH4 SO4 & Ammonium sulfate \\
\hline $\mathrm{Nm}$ & Nanometer \\
\hline NS3 & Non-structutral protien 3 \\
\hline ORF & Open reading frame \\
\hline PBS & Phosphate-buffered saline \\
\hline
\end{tabular}




\begin{tabular}{ll} 
PFU & Plaque forming unit \\
pH & Potential of hydrogen \\
RNA & Ribonucleic acid \\
rpm & Revolutions per minute \\
RT & Reverse Transcriptase \\
RT-PCR & Reverse Transcriptase Polymerase Chain Reaction \\
S1 & Segment-1 \\
S6 & Segment-6 \\
S10 & Segment-10 \\
SDS & Sodium dodecyl sulfate \\
SIA & Sequence-independent amplification \\
SSC & Saline-sodium citrate \\
ssRNA & Single-strand RNA \\
Taq & Thermus aquaticus DNA polymerase enzyme \\
TE & Tris EDTA \\
TAE & Tris Acetate EDTA \\
TPB & Tryptose phosphate broth \\
Tris-HCL & Tris- hydrogen cloride \\
Tris-SO4 & Tris-salfate \\
U & Unit \\
UV & Ultra Violet \\
VP2 & Viral Protien-2 \\
VP5 & Viral Protien-5 \\
WGA & Whole-genome amplification \\
\hline
\end{tabular}




\section{Table of contents}

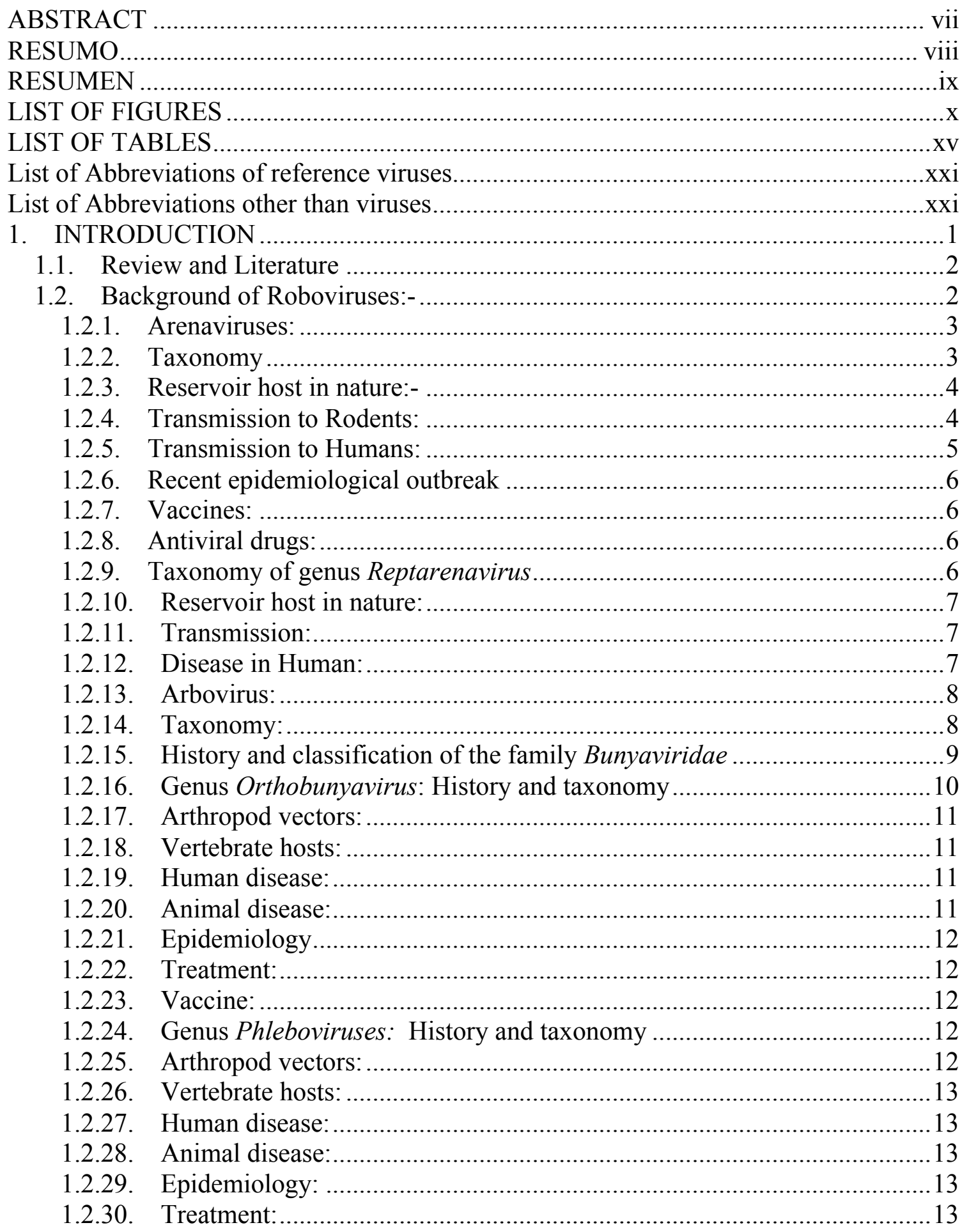




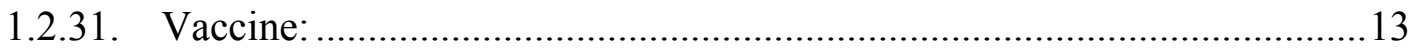

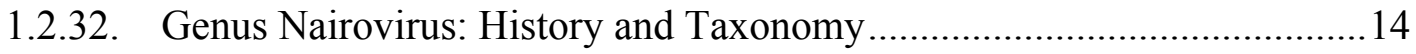

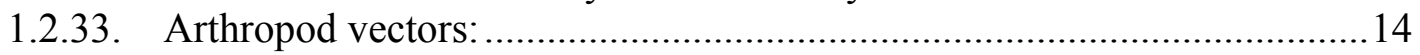

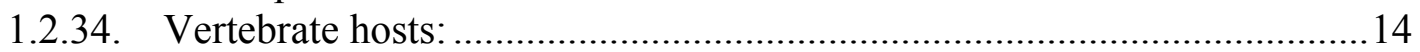

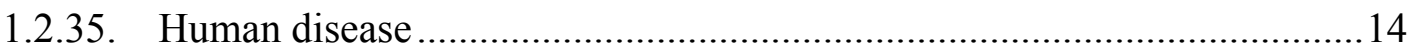

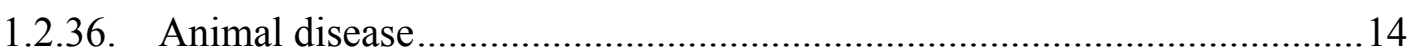

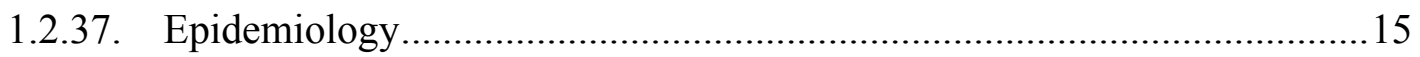

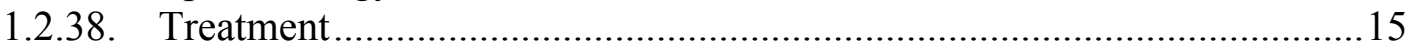

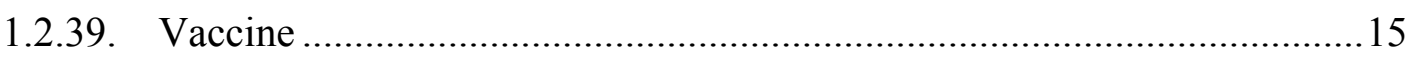

1.2.40. History and taxonomy of genus Hantavirus: ......................................... 15

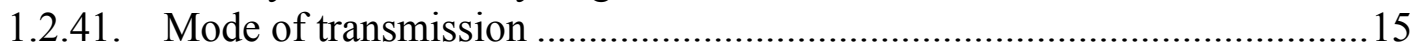

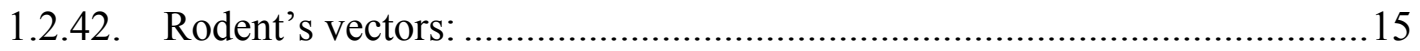

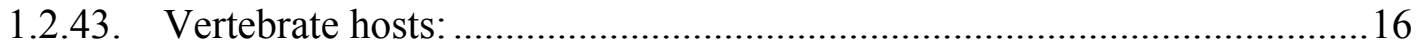

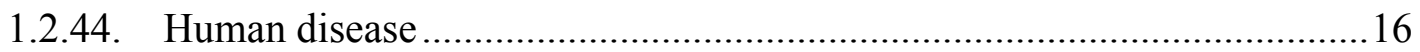

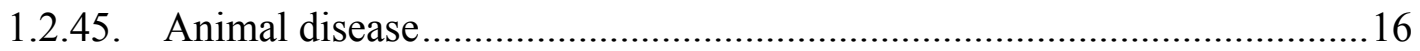

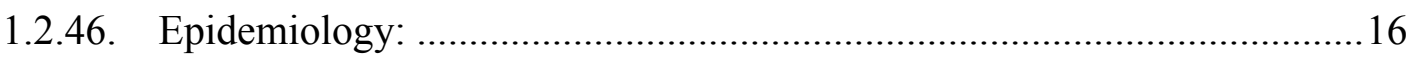

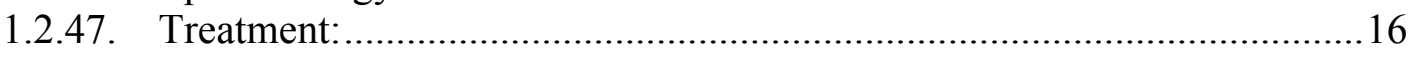

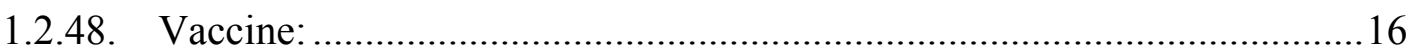

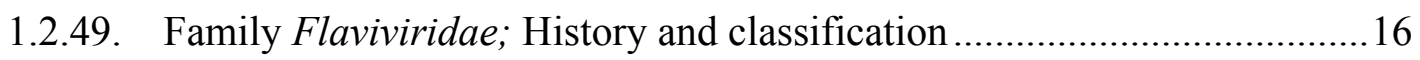

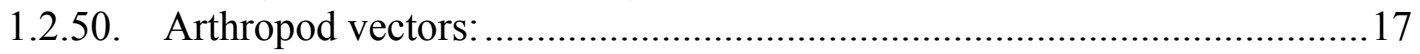

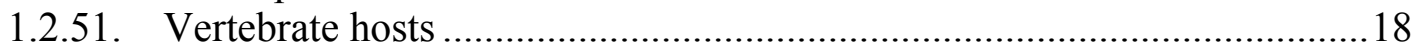

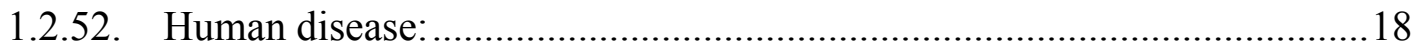

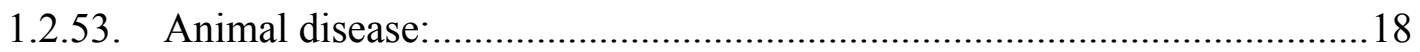

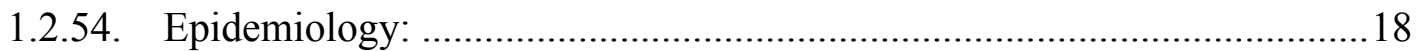

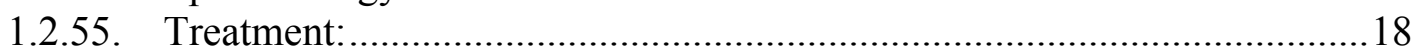

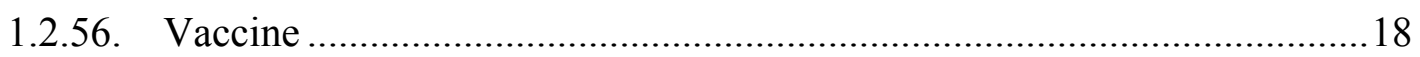

1.2.57. Family Reoviridae; History and classification ........................................ 19

1.2.58. History and taxonomy of genus coltivirus:............................................. 19

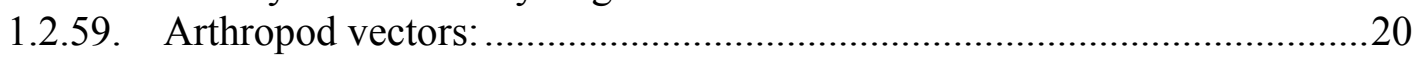

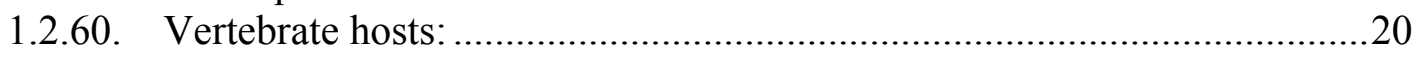

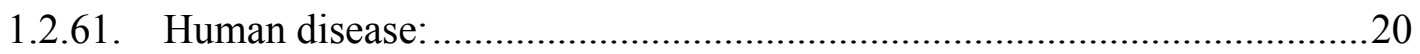

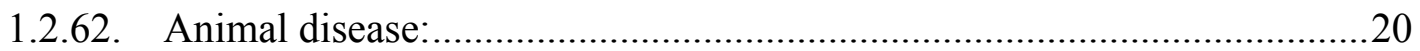

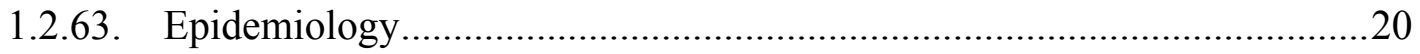

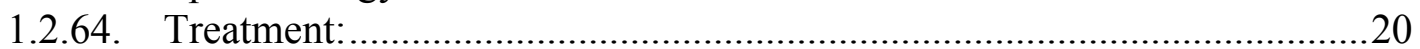

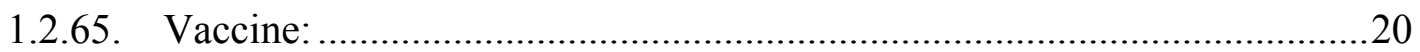

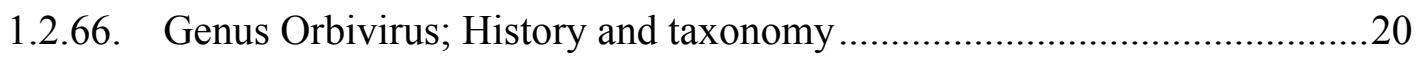

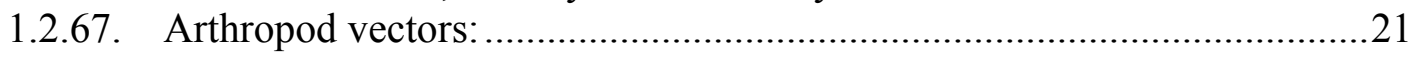

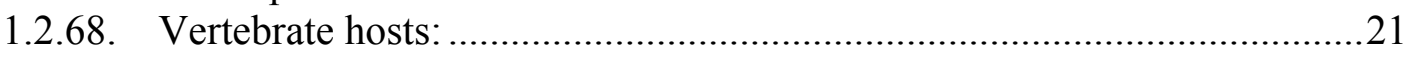

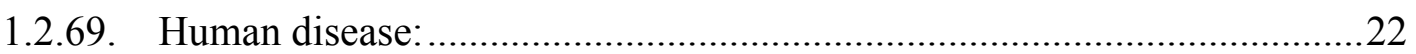

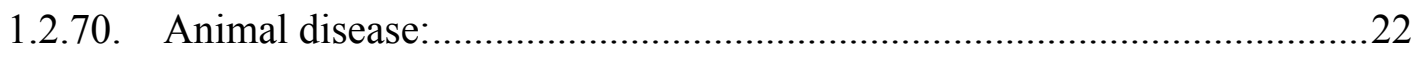

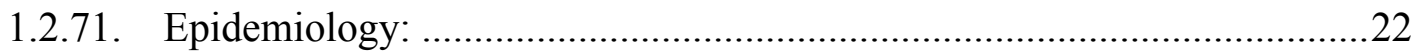

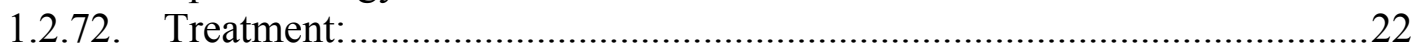

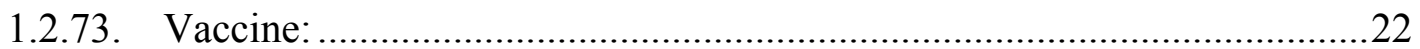

1.2.74. Genus Seadornavirus; History and taxonomy: ....................................22

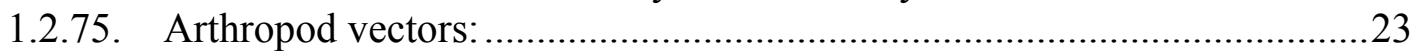

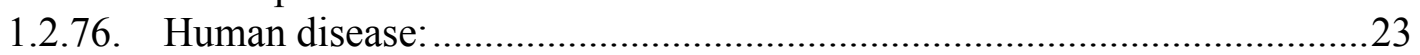

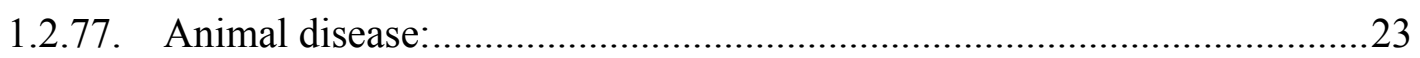

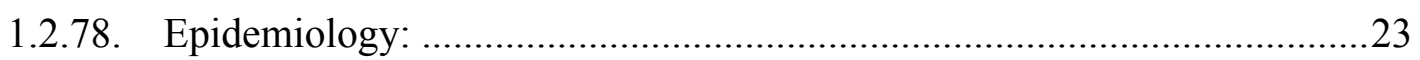

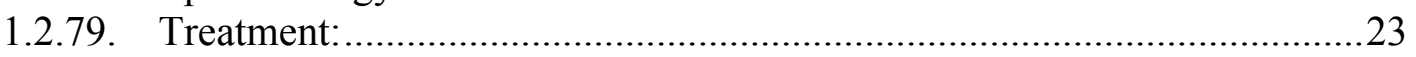

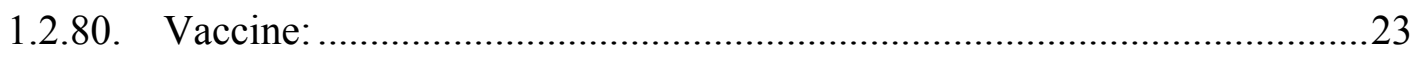


1.2.81. Family Rhabdoviridae; History and classification .................................23

1.2.82. Genus Ephemerovirus; History and taxonomy ......................................24

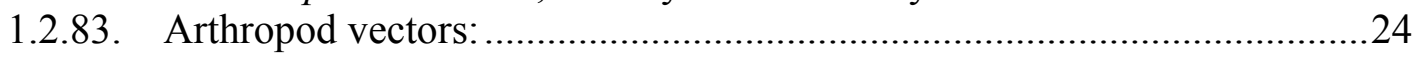

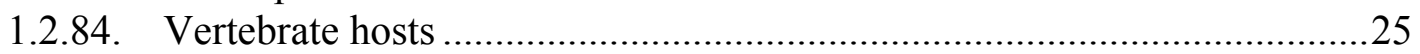

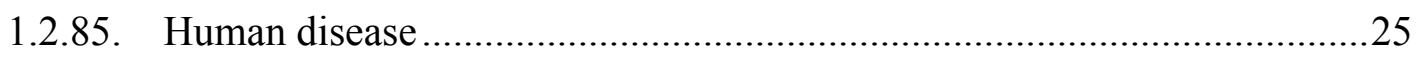

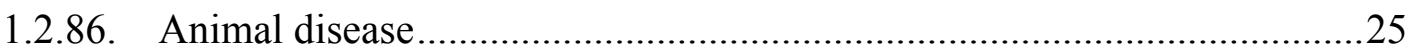

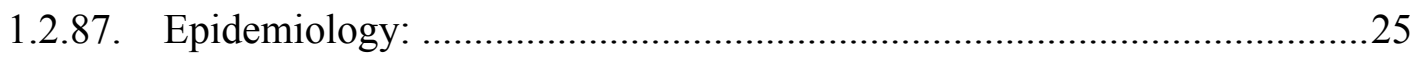

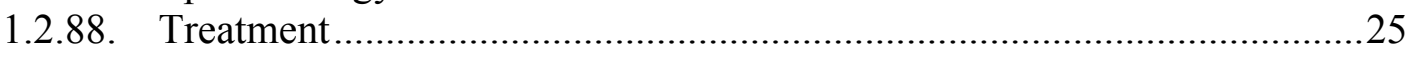

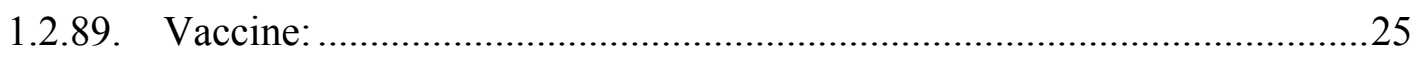

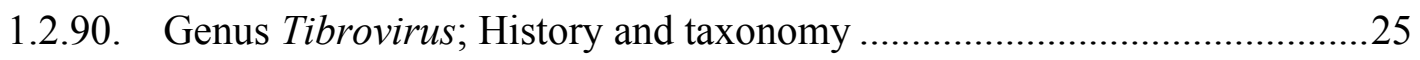

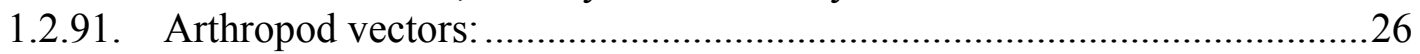

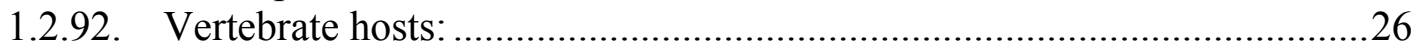

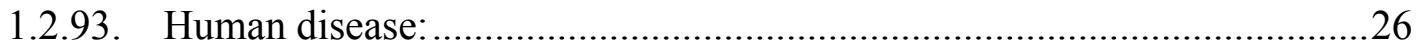

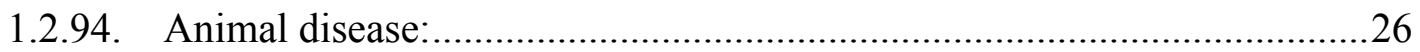

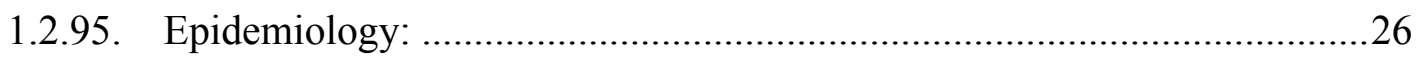

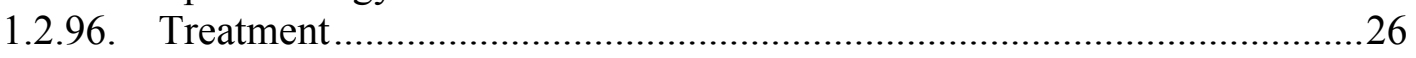

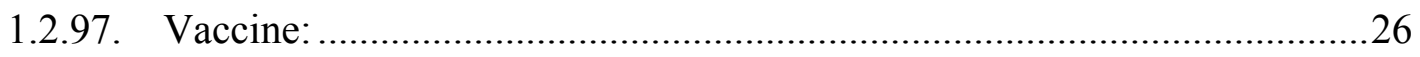

1.2.98. Genus Vesiculovirus; History and taxonomy ........................................26

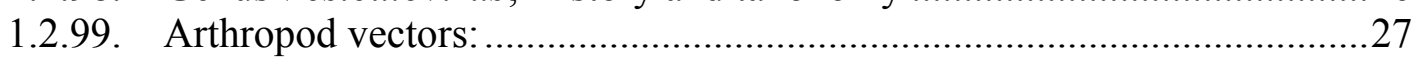

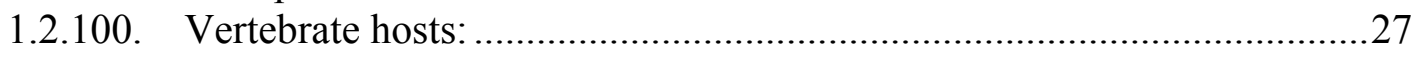

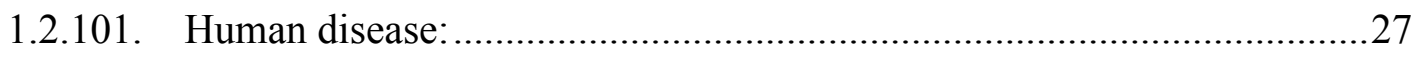

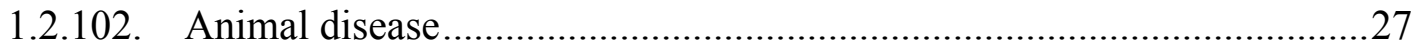

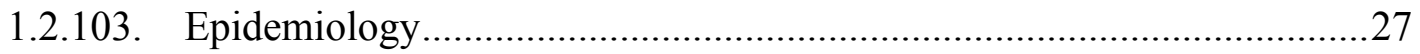

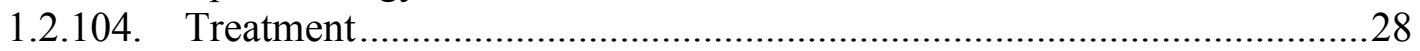

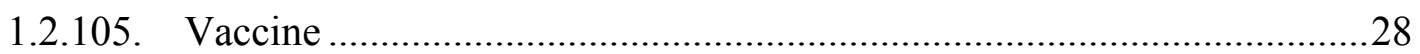

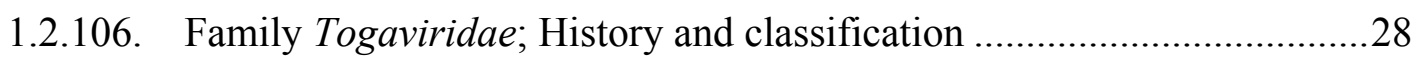

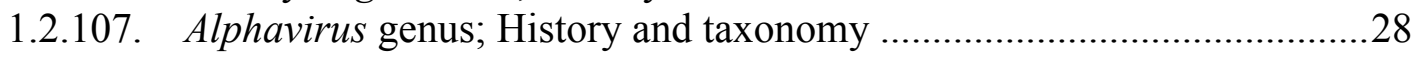

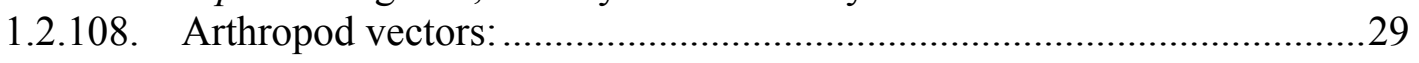

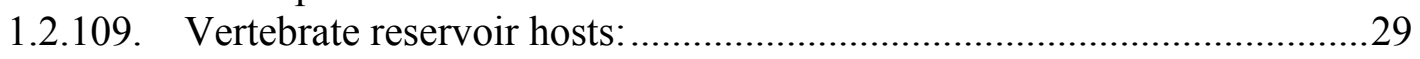

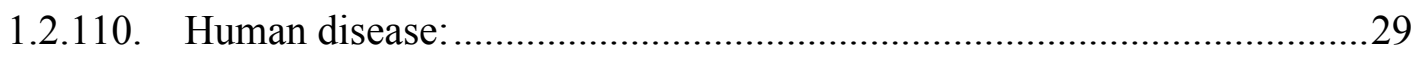

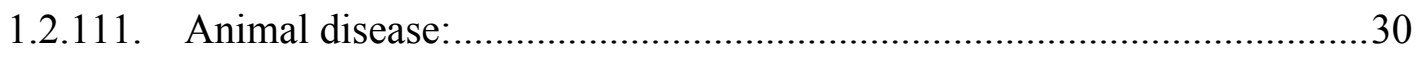

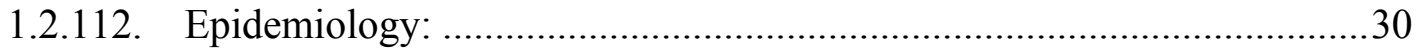

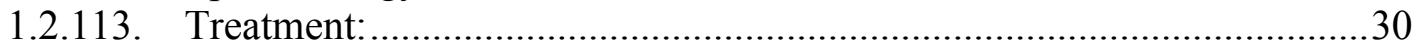

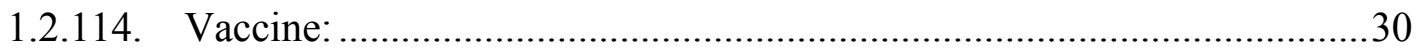

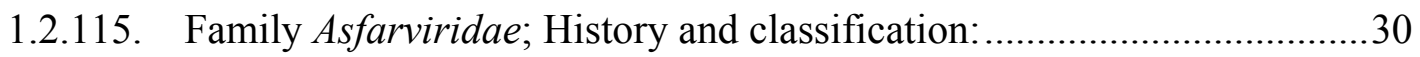

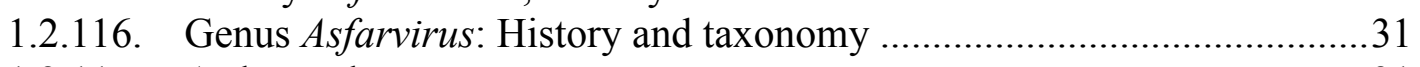

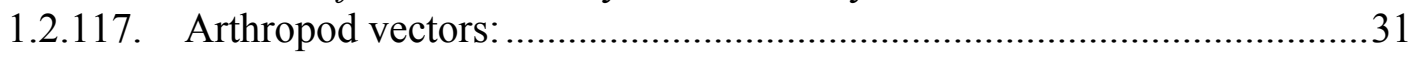

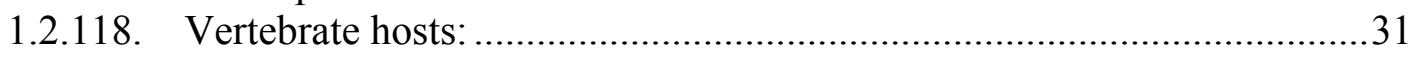

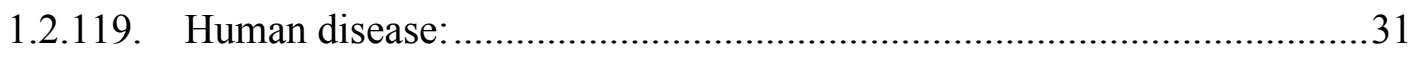

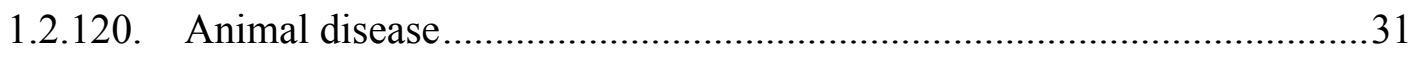

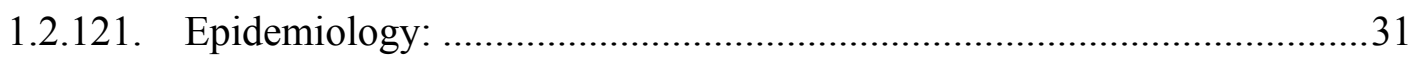

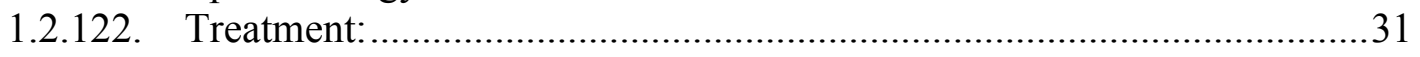

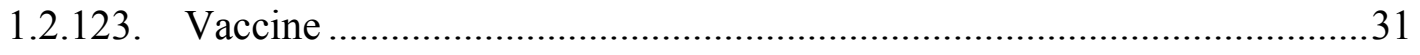

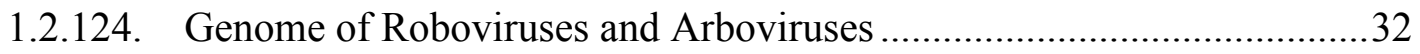

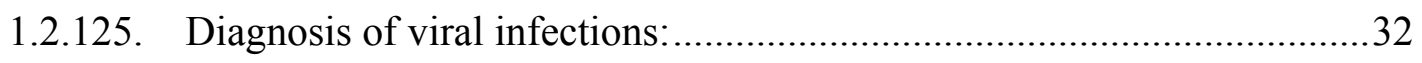

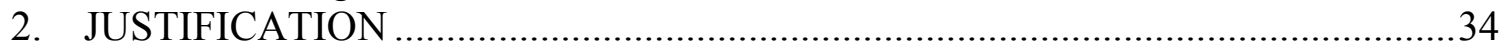

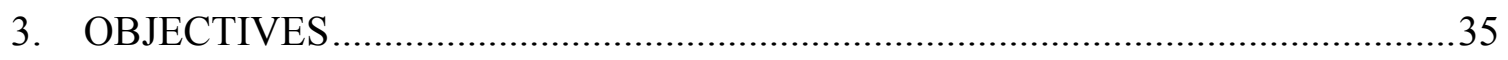

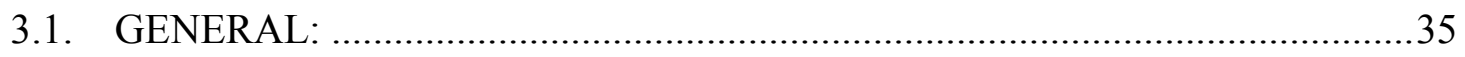

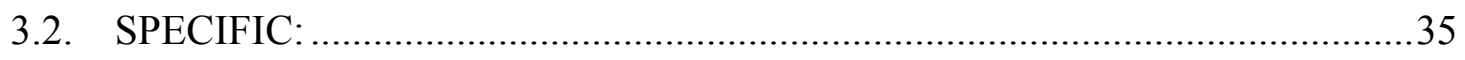

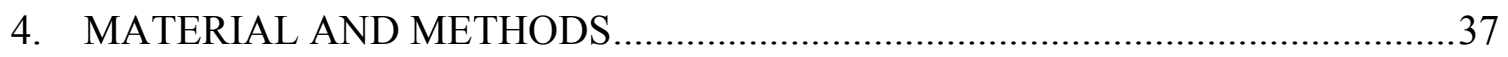


4.1. Viral reference Strains:

.37

4.2. Design of the DNA microarray slide for viruses transmitted by rodents and

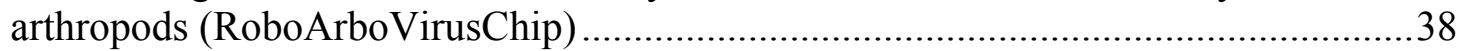

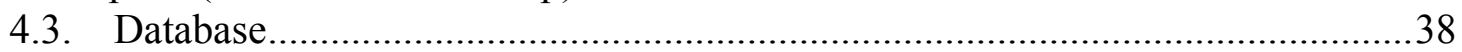

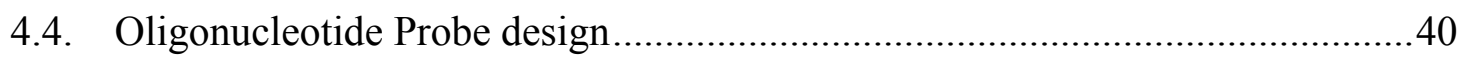

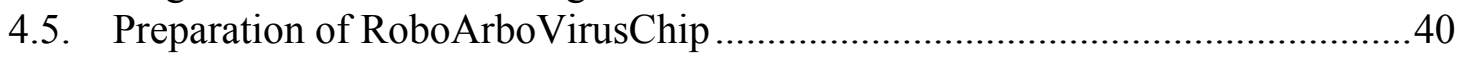

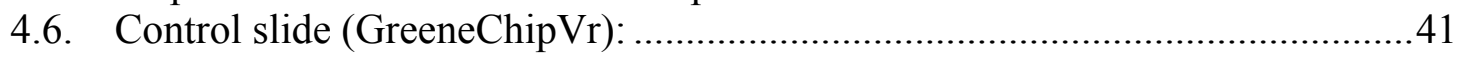

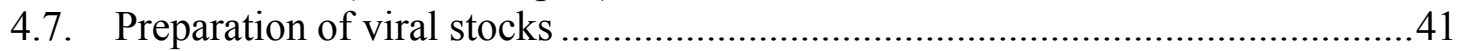

4.8. Confirmation of viral infection by indirect immunofluorescence ......................42

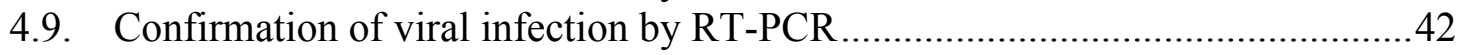

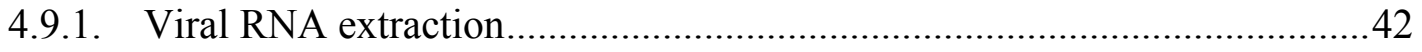

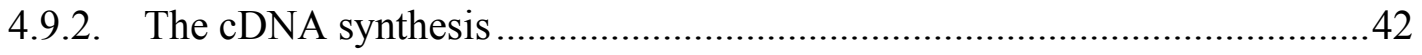

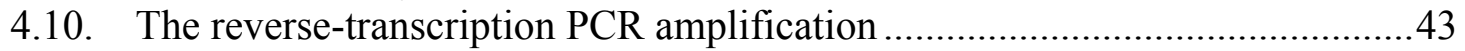

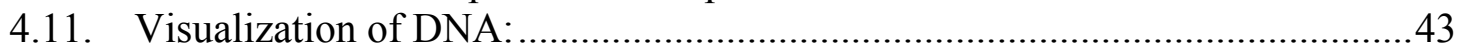

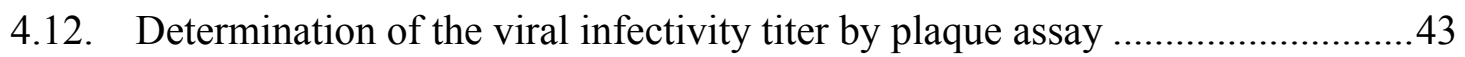

4.13. Dengue virus RNA detection and quantification: Quantitative real-time RT-

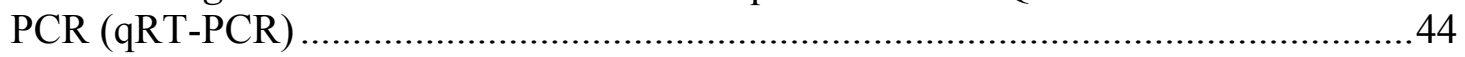

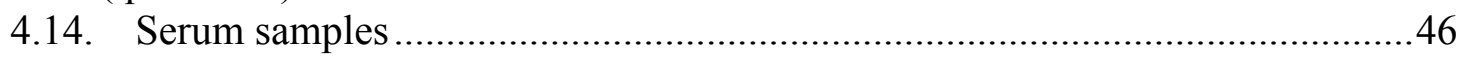

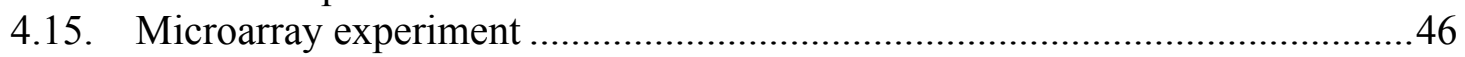

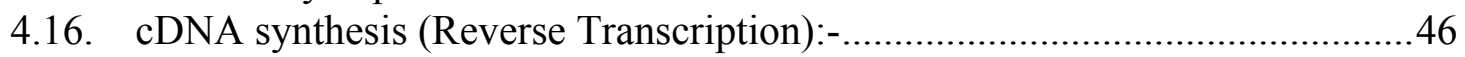

4.17. The polymerase chain reaction (PCR) amplification.....................................46

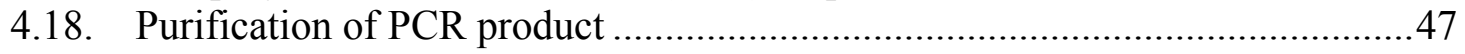

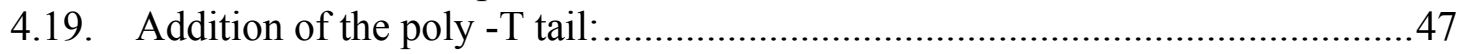

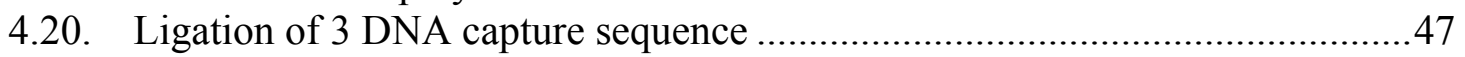

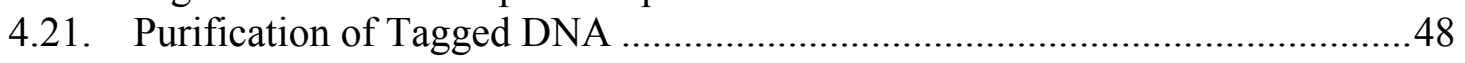

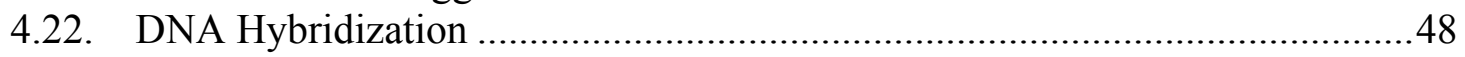

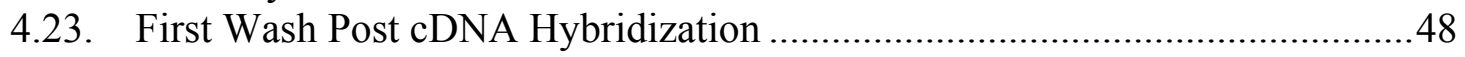

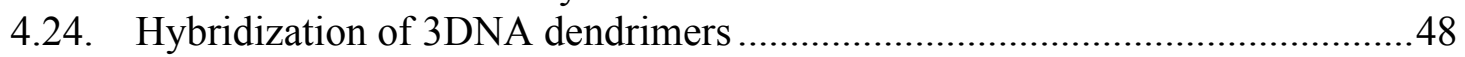

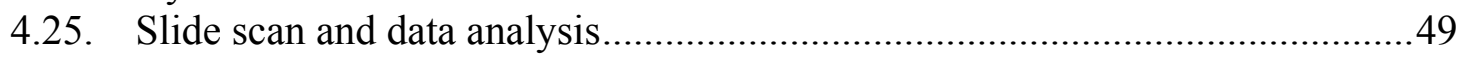

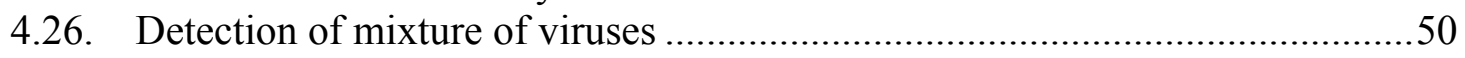

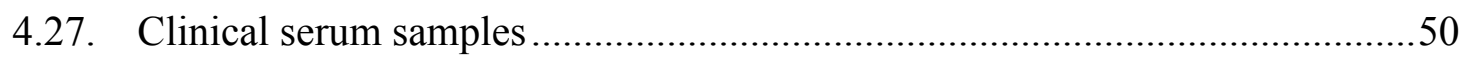

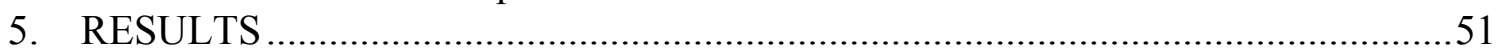

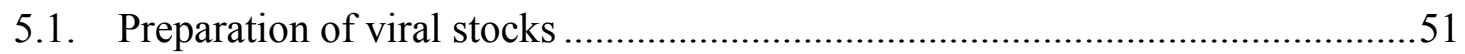

5.2. Confirmation of viral infection by indirect immunofluorescence ......................51

5.3. Determination of viral titer by plaque assay .................................................52

5.4. Design of probes for RoboArboVirusChip V1 (version 1) and control slides ...52

5.5. Implementation of microarray method: Control slide .....................................53

5.6. Microarray experiments with control and RoboArboVirusChip v1 slides..........70

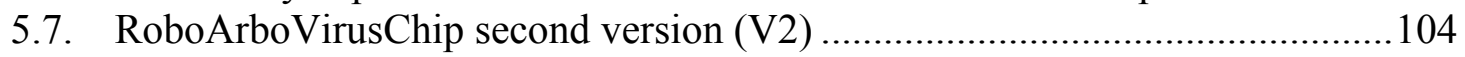

5.8. Comparison of cDNA and PCR products as target for the RoboArboVirusChip v2 107

5.9. Detection of mixture of viruses by the RoboArboVirusChip v2 ......................108

5.10. Determination of sensitivity of the RoboArboVirusChip v2 ..........................109

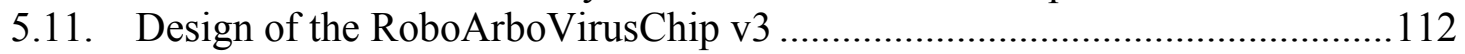

5.12. Detection of mixture of viruses by the RoboArboVirusChip v3 ...................131

5.13. Determination of sensitivity of the RoboArboVirusChip v3.........................135

5.14. Analysis of clinical samples with the RoboArboVirusChip v3 .......................135

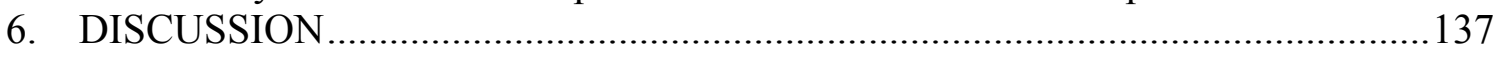

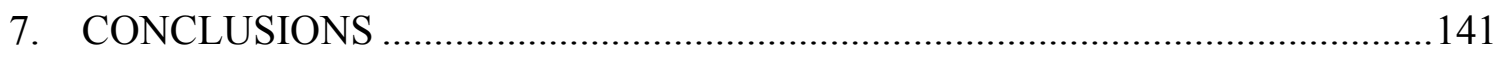

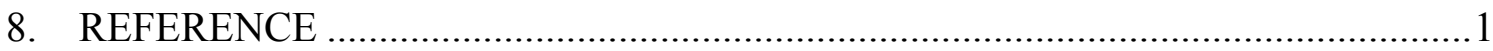




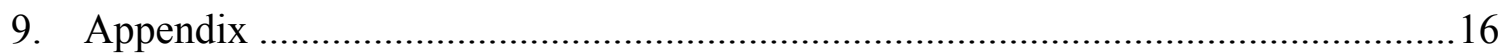




\section{INTRODUCTION}

Roboviruses (Rodent-borne viruses) belong to two different families: Arenaviridae (Mammarenavirus and Reptarenavirus genera) and Bunyaviridae (genera Hantavirus) (Gegúndez and Lledó, 2005). Approximately, ten mammarenaviruses are known to cause disease in human through natural or laboratory acquired infection. The clinical symptoms of four viruses (Guanarito, Junin, Lassa and Machupo) are mimic in several ways. Reptarenaviruses are Snake-infecting new arenavirus genera causes' fatal disease called Boid inclusion body disease (BIBD). There is no evidence of these viruses causing disease in human (Hetzel et al., 2014). About twenty Hantaviruses are responsible for in Asia and Europe "Hemorrhagic fever with Renal Syndrome" (HFRS) and in Americas Hantavirus Cardiopulmonary Syndrome (HCPS) (Zapata and Salvato, 2013; Kruger et al., 2014). They infect humans by the inhalation of aerosols contain virus, through ingestion of contaminated stored food or due to consumption contaminated rodents meat (Ter Meulen et al., 1996). Arboviruses (arthropod-borne viruses) are one of the most important emergence and re-emergance agents nearly worldwide. The arboviruses belong to seven famileis: Bunyaviridae (genus Orthobunyavirus, Nairovirus and Phlebovirus), Flaviviridae (genus Flavivirus) and Togaviridae (genus Alphavirus). In addition, a small group of arboviruses are included in the families Reoviridae (genus Orbivirus, Seadornavirus and Coltvivirus), Rhabdoviridae: (genres Vesiculovirus and Ephemerovirus), Orthomyxoviridae (gender Thogotovirus) and Asfarviridae (gender Asfarvirus) they cause a wide range of infections in humans, domestic and wild animals (Jones et al., 2008; Weaver and Reisen, 2010). There are currently more than 550 arboviruses have been identified, mostly belong to families above mentioned. More than 150 viruses are responsible for flu-like to fatal disease in humans and 50 viruses pathogenic animals (Gao et al., 2010; Cleton et al., 2012; Gan and Leo, 2014; Hubálek et al., 2014). For an example, only dengue (DENV) virus infections are at present roughly to cause over 100,000,000 clinical cases every year specific a re-emergence throughout the tropical and subtropical countries. Approximately 17 million human's deaths every year reported throughout the world. The arboviral infections are rapidly spreading and this is major public health issue. There are not specific and effective treatments are available for the roboviruses and arboviruses with deal for those symptoms supportive therapy has been used with exception of 
Yellow fever (YFV) and Japanese encephalitis (JEV) vaccines (Cleton et al., 2012; Bhatt et al., 2013; Dash et al., 2013). Mainly, the medically important bugs: Mosquitoes, ticks, midges and sandflies, are known vectors responsible for the inoculation of arboviruses during blood feed, through contaminated mouthparts they enter in the body of host (humans and animals). The viruses first amplify within the tissues salivary gland of arthropods to produce high concentration of virus and are then passed on to host (Gubler, 2001). Other, non-vector transmission through laboratory associated, organ transplantation, mother to child and breast feeding (Descloux, 2013). These viruses are mostly causing zoonosis in the wild and are maintained in nature in complex cycles involving birds, rodents, marsupials, primates and sloths as reservoirs and wild mosquitoes, which suck the blood of these animals as vectors. Among the animal reservoir, mostly migratory birds, are infected, and are important carriers of arboviruses to distant sites (Meslin, 1997). The introduction of humans or animals viremic at these sites could lead to the emergence of urban cycles. Regarding robovirus, their emergence is associated with environmental changes caused by intensive agriculture causing increased food availability, an increase in the population of wild rodents, including attracting these animals to living next to man, who is mainly virally infected, inhalation of fecal and urinary components excreted by these infected animals and some important factors are responsible for the arboviruses will continue to emerge in new regions: landscape composition, deforestation, floods, increasing surface temperatures, urbanization, travel and commerce like animals and their products (Zeier et al., 2005; Dash et al., 2013).

\subsection{Review and Literature}

\subsection{Background of Roboviruses:-}

The Robovirus term refers to Rodent-borne viruses (viruses transmitted by rodents) belonging to two families:

1. Family Arenaviridae (two genera Mammarenvirus and Reptarenavirus)

2. Family Bunyaviridae (only genus Hantavirus)

Both families of viruses are transmitted from rodents (natural reservoir host) to human beings (Gegúndez and Lledó, 2005). 
Note: The genus Hantavirus we discussed in arbovirus section.

\subsubsection{Arenaviruses: \\ 1.2.2. Taxonomy}

The first arenavirus prototype LCMV was isolated in 1933 by doing serial passage of SLEV virus infected material from 42 years old dead human body, in monkey's brain. Arenaviruses are the group of viruses that represents the family Arenaviridae and was named after the sandy (Latin, arenosus) appearance of the ribosomes originally seen in thin sections of virions (Armstrong, 1934).

The family Arenaviridae consists of two proposed genera Mammarenvirus and Reptarenavirus (Radoshitzky et al., 2015). The Mammarenavirus (referred to "mammals and arenaviruses") for the genus for all currently known mammalian viruses, which is currently subdivided into two major groups, New World (Tacaribe virus) and Old World (Lymphocytic choriomeningitis virus) mainly on the basis of geographical distribution (Old World, Eastern Hemisphere and New World, Western Hemisphere), serological and molecular properties (Charrel et al., 2008). Both groups of arenaviruses currently contains twenty five virus species recognized by the International Committee for Taxonomy of Viruses Master-Species list 2014 (MSL\#29) released on June, 2014 (Salvato et al., 2012) as well as many newly discovered viruses whose taxonomic status has not yet been confirmed by the ICTV.

The Old World arenaviruses contain a total of sixteen viruses; seven species and nine tentative virus species. Thirty viruses, eighteen species, one strain and eleven tentative belongs to The New World viruses that were further divided into four lineages designated clades A, B, C, and A/Rec. Five viruses belonged to clade A; Allpahuayo mammarenavirus (ALLV), Flexal mammarenavirus (FLEV), Parana mammarenavirus (PARV), Pichinde mammarenavirus (PICV) and Pirital mammarenavirus (PIRV). Clade B contained eight species Amapari mammarenavirus (AMAV), Chapare mammarenavirus (CHAPV), Cupixi mammarenavirus (CPXV), Guanarito mammarenavirus (GTOV), Junin mammarenavirus (JUNV), Machupo mammarenavirus (MACV), Sabia mammarenavirus (SABV) and Tacaribe mammarenavirus (TCRV). Clade $\mathrm{C}$ is composed of four viruses: two species and two unclassified Latino mammarenavirus (LATV) and Oliveros virus (OLVV) and unclassified; Pampa mammarenavirus (PAMV) and Pinhal mammarenavirus. The clade A/Rec contained 
total thirteen viruses Bear Canyon mammarenavirus (BCNV), Tamiami mammarenavirus (TAMV), Whitewater Arroyo mammarenavirus (WWAV); unclassified Big brushy tank mammarenavirus (BBTV), Black Mesa mammarenavirus (BMV),Catarina mammarenavirus (CTNV), North American mammarenavirus (NAAV), Ocozocoautla de Espinosa mammarenavirus (OCEV), Real de Catorce mammarenavirus (RDCV), Skinner Tank mammarenavirus (SKTV), Tonto Creek mammarenavirus (TTCV), Black Mesa mammarenavirus, Orogrande mammarenavirus and Arenavirus H0380005 mammarenavirus. The Rio Carcarana mammarenavirus virus status is still unclassified (see Table 1).

Table 1. Summary of viruses belongs to Genera: Mammarenaviruses

\begin{tabular}{|l|l|l|l|l|l|l|l|l|l|l|l|}
\hline Serogroup & Species & Strains & Tentative & Total & Mouse & Rat & Bat & N/D & HF & N/K & Others \\
\hline LASV- LCMV & 9 & - & 7 & 16 & 8 & 6 & - & 2 & 3 & 13 & - \\
\hline Tacribe & 18 & 1 & 11 & 30 & 8 & 19 & 1 & 2 & 6 & 24 & - \\
\hline Ungrouped & - & - & 1 & 1 & - & $? ?$ & $? ?$ & $? ?$ & $? ?$ & $? ?$ & - \\
\hline Total & $\mathbf{2 7}$ & $\mathbf{1}$ & $\mathbf{1 9}$ & $\mathbf{4 7}$ & $\mathbf{1 6}$ & $\mathbf{2 5}$ & $\mathbf{1}$ & $\mathbf{4}$ & $\mathbf{9}$ & $\mathbf{3 7}$ & - \\
\hline
\end{tabular}

\subsubsection{Reservoir host in nature:-}

Each virus is associated with either one species or a few closely related rodents with the exception of Tacaribe virus, which natural reservoir is bat. The New World rodents (rats and mice) belong to family Muridae, subfamily Sigmodontinae, while the Old World rodents belong to family Muridae, subfamily Murinae. Taken together, these types of rodents are located across the greater proportion of the earth's landmass, including Europe, Asia, Africa, and the Americas. One notable exception is Tacaribe virus, found in Trinidad in the Caribbean region, which was isolated from bats and mosquitoes during a rabies surveillance in Trinidad from, 1956 - 1958 (Downs et al., 1963). In 2012, several arenaviruses have been isolated from non-poisonous snakes: Boa constrictors (Boa constrictor), an annulated tree snake (Corallus annulatus) and python with inclusion body disease-associated arenaviruses (BIBDAV) (Stenglein et al., 2012). More recently, the re-isolation of the arenavirus from pool of one hundred host-seeking lone star ticks (Amblyomma americanus) was collected in a Florida in 2012 (Sayler et al., 2014).

\subsubsection{Transmission to Rodents:}


The rodents normally infected with arenaviruses; however, they are asymptomatic, with chronic viremia and viruria, thus spreading viruses to other noninfected rodents and other mammals. Infected reservoir host sheds virus into the environment via urine, feces and saliva. Some New World arenaviruses transmitted among adult rodents, via fighting and inflicting bites. In addition, Old World arenaviruses can pass from mother rodents to their offspring during pregnancy (Vitullo et al., 1987; Vitullo and Merani, 1988). New rodents in each host species infected with virus once, in many cases only in limited part of the geographical localization.

\subsubsection{Transmission to Humans:}

Arenaviruses infect humans by inhalation of aerosolized particles, through ingestion of contaminated stored food or consumption of their contaminated meat. (Ter Meulen et al., 1996). However, there are some risk factors involved in the virus spread; for example, human infection is associated with agricultural work, as the infected rodents prefers a field or agricultural habitat. In areas where the rodent species habitat includes human homes or other buildings, infection occurs in domestic settings. This may occur in a variety of ways. Person-to-person transmission is associated with direct contact with the blood, saliva, semen, stool, tissues, urine, vomits, and other secretions or via inhalation of aerosolized virus from clinical specimens. Patient infected with Lassa virus may shed virus in urine and semen for several weeks after recovery, and it is documented that sexual activity has resulted in secondary transmission (Mccormick et al., 1987). Mother to child transmission is well evidenced and may result in severe congenital malformation or death of the fetus or newborn ( $\mathrm{Cj}, 2000$;). Transmission of lymphocytic choriomeningitis virus by organ transplantation was recently described ( $\mathrm{Ja}, 2005$;). Nosocomial transmission also reported. Contact with objects contaminated with these materials, such as medical equipment, nursed in open wards where patient is not properly isolated also associated with transmission (Leparc-Goffart and Emonet, 2011; Atkinson et al., 2014). 
Table 2. Summary of Arenaviruses pathogenic for human.

\begin{tabular}{|l|l|l|l|l|}
\hline Virus & Type of disease & Annually incidence & Fatality rate & Reference \\
\hline LCMV & Lymphocytic choriomeningitis & $>5 \%$ & $<1 \%$ & $(\mathrm{Cj}, 2000 ;)$ \\
\hline Lassa virus & Lassa fever & $\approx 2000000$ & $15 \%$ & $($ Yun and Walker, 2012) \\
\hline Junin virus & AHF & 300 to 1000 & $15 \%-30 \%$ & (Enria et al., 2008) \\
\hline Machupo virus & Bolivian hemorrhagic fever & $>200$ & $20 \%$ & (Franz et al., 1997) \\
\hline Guanarito virus & Venezuelan hemorrhagic fever & $\approx 618$ & $23 \%$ & (Fulhorst et al., 2008) \\
\hline Sabia virus & Not yet named & 1 & fatal & (Lisieux et al., 1994) \\
\hline Whitewater Arroyo virus & Not yet named & $3 / 3$ & fatal & $\begin{array}{l}\text { (Charrel } \\
\text { and }\end{array}$ \\
& & & & De \\
\hline Lujo virus & Lujo hemorrhagic fever & $4 / 5$ & $80 \%$ & (Briese et al., 2009) \\
\hline Chapare virus & Not yet named & Unknown & Unknown & (Liu, 1974) \\
\hline
\end{tabular}

\subsubsection{Recent epidemiological outbreak}

In May 2015, fatal case of Lassa virus was reported the patient returning from Liberia to USA (Http://Www.Cdc.Gov/Vhf/Lassa, 2015).

\subsubsection{Vaccines:}

To date, there are no FDA approved vaccines are available to fight against arenavirus infections except Candid\#1 for Junin virus but licensed for use only in Argentina (Cheng et al., 2015; Rathbun et al., 2015).

\subsubsection{Antiviral drugs:}

Currently, only licensed partially effective drug nucleoside inhibitor ribavirin is available for treatment of arenavirus infection associated with side effects (Cheng et al., 2015).

\subsubsection{Taxonomy of genus Reptarenavirus}

In the 1970's, inclusion body disease first detected in the United States, where it was affecting many species of snakes in zoo and private museum. Based on cross-react by western blot with anti-Junín virus antibodies, comparison weak cross reactivity was 
noted with anti-Machupo virus and anti-LCMV antibodies. The snake viruses do not able to react with antisera from patients with Bolivian hemorrhagic fever in ELISA. These new snake viruses may be hold the Old World and New World complexes of this family (Mj., 2012; Stenglein et al., 2012; Hetzel et al., 2013). A total seven viruses identified in the genus, three confirm species and four of them are tentative (Table 3 ).

Table 3. Summary of genus Reptarenavirus

\begin{tabular}{|l|l|l|l|l|l|l|l|l|l|l|}
\hline Serogoup & Species & Strains & Tentative & Total & Mouse & Rat & Bat & N/K & HF & N/K \\
\hline $\begin{array}{l}\text { Alethinophid 1 } \\
\text { Reptarenavirus }\end{array}$ & 1 & - & - & 1 & - & - & - & 1 & - & 4 \\
\hline $\begin{array}{l}\text { Alethinophid 2 } \\
\text { Reptarenavirus }\end{array}$ & 1 & - & - & 1 & - & - & - & 1 & - & - \\
\hline $\begin{array}{l}\text { Alethinophid 3 } \\
\text { Reptarenavirus }\end{array}$ & 1 & - & - & 1 & - & - & - & 1 & - & - \\
\hline Ungrouped & - & - & 4 & 4 & - & - & - & 4 & - & - \\
\hline Total & 3 & - & 4 & 7 & & - & - & 7 & - & \\
\hline
\end{tabular}

\subsubsection{Reservoir host in nature:}

Not yet been confirmed (Hepojoki et al., 2015).

\subsubsection{Transmission:}

Snakes consume of rodents and bats, and both can be infected by arenaviruses and filoviruses (Zapata and Salvato, 2013).

\subsubsection{Disease in Human:}

To date, no disease was reported in human (Hepojoki, J.2015).

\section{Disease in Animals:}

Fatal disease called Boid inclusion body disease (BIDB) in boid Snakes (Hepojoki, J.2015)

\section{Epidemiology:}

The geographical area is not yet cleared (Hepojoki, J.2015).

\section{Treatment:}


Not treatment available

Vaccine:

No vaccine.

\subsubsection{Arbovirus:}

The origin of "Arbovirus" for first time was using in laboratory jargon at in early 1940s from the joke like “you can't see it, smell it, touch it, or culture it, but it can kill you". The Cuban Dr. Carlos Finlay, first time proposed mosquito-vector theory in 1881 and the US Army Yellow fever commission head Major Walter Reed discovered first arbovirus, Yellow fever virus in 1901 (Russell, 1934; Reeves, 2001; Chaves-Carballo, 2005). In 1930, six viruses (African swine fever, Blue tongue, Louping ill, Nairobi sheep disease, Vesicular stomatitis and Yellow fever) were known caused disease in human and transmitted by arthropods and today more than 550 known.

Arboviruses (an acronym for "arthropod-borne viruses") are one of the most important emergence and re-emergence agents nearly worldwide. They cause a wide range of infections in humans and domestic animals (Jones et al., 2008). They are able to replicate and transmitted by medically important bugs such as mosquitoes, ticks, midges and sand flies, are known vectors responsible for the inoculation of arboviruses during blood feed (Gubler, 2001). These arboviruses must replicate biologically in the arthropod vector prior to transmission (Weaver, 1997). As, mechanically transmitted, without replication in the vector, Biological transmission can be vertical, involving the passage of the virus from an infected female vector to both male and female offspring. Horizontal transmission can be venereal, from a vertically infected male directly to a female vector, as well as oral from a female vector to a vertebrate host via the saliva during blood feeding. The latter horizontal mode of transmission is most common for the majority of arboviruses and involves infection of the vector alimentary tract following a viremic blood meal, dissemination of the virus in the vector, and virus replication in the salivary glands, followed by the injection of infectious saliva during blood feeding (Weaver and Reisen, 2010).

\subsubsection{Taxonomy:}


The arboviruses belong to seven taxonomic families: Bunyaviridae (genera Orthobunyavirus, Nairovirus and Phlebovirus), Flaviviridae (genus Flavivirus) and Togaviridae (genus Alphavirus). In addition, a small group of arboviruses are included in the families Reoviridae (genera Orbivirus, Seadornavirus and Coltvivirus), Rhabdoviridae: (genera Vesiculovirus and Ephemerovirus), Orthomyxoviridae (genus Thogotovirus) and Asfarviridae (genus Asfarvirus) they cause a wide range of infections in humans, domestic and wild animals (Jones et al., 2008; Weaver and Reisen, 2010).

Table 4. Taxonomic status of known and tentative arboviruses

\begin{tabular}{|l|l|l|l|l|l|}
\hline Family & $\begin{array}{l}\text { Genera within } \\
\text { family }\end{array}$ & $\begin{array}{l}\text { Genera belongs } \\
\text { to Arboviruses }\end{array}$ & $\begin{array}{l}\text { Number of } \\
\text { viruses }\end{array}$ & $\begin{array}{l}\text { Number of viruses } \\
\text { pathogenic for } \\
\text { Human }\end{array}$ & $\begin{array}{l}\text { Number of viruses pathogenic } \\
\text { for Livestock's }\end{array}$ \\
\hline Bunyaviridae & 5 & 3 & 286 & 49 & 12 \\
\hline Flaviviridae & 4 & 1 & 76 & 38 & 13 \\
\hline Togaviridae & 2 & 1 & 36 & 16 & 9 \\
\hline Reoviridae & 15 & 3 & 171 & 8 & 8 \\
\hline Rhabdoviridae & 11 & 2 & 37 & 7 & 6 \\
\hline Orthomyxoviridae & 6 & 1 & 6 & 0 & 1 \\
\hline Asfarviridae & 1 & 1 & 1 & 0 & 1 \\
\hline Total & 44 & 12 & 613 & 118 & 50 \\
\hline
\end{tabular}

\subsubsection{History and classification of the family Bunyaviridae}

The family Bunyaviridae name derived from Bunyamwera virus (BUNV). This was isolated during an investigation of Yellow Fever in 1943 from Aedes spp. mosquitoes in the Semliki forest, Uganda. The family Bunyaviridae was officially recognized in 1975, which is the biggest and most diverse RNA viruses family (Elliott, 2014). According to the International Committee on Taxonomy of Virology (ICTV) currently this family is subdivided into five genera: Orthobunyavirus, Nairovirus, Phlebovirus, Hantavirus and Tospovirus. First three genera are pathogenic for humans and animals, fourth only for humans, Hantaviruses, which are mainly carried by small mammals. Genus Tospovirus are also transmitted by plant-feeding arthropods (thrips), but they infect plant, such as tomato and watermelon, in this case non-vertebrates (Briese et al., 2013). Approximately, 469 arboviruses are known, of which 381 strains/unclassified mainly representing from four genera are Orthobunyaviruses, Phleboviruses, Nairoviruses and Hantavirus. 


\subsubsection{Genus Orthobunyavirus: History and taxonomy}

To avoid confusion during discussion of any virus belonging to the family Bunyaviridae, the original Bunyavirus genus name it was changed to Orthobunyavirus in 1995 (Regenmortel, 2000). This genus is the largest genus within the family Bunyaviridae, with more than 170 viruses. Currently 48 viruses are species recognized by the ICTV, includes 122 viruses strain/ isolates, which is distributed throughout the world (Elliott, 2014). Most of the viruses are distributed into 18 different serogroups or left unclassified (Table 5). However, the historical term "serogroup" is not more useful for the viral taxonomy (Ladner et al., 2014).

Table 5. Summary of arthropods-borne viruses of genus Orthobunyavirus

\begin{tabular}{|c|c|c|c|c|c|c|c|c|c|c|c|c|c|}
\hline Serogroup & Species & Strains & Total & Tentative & Mosq & Sf & Ticks & $\mathbf{M}+\mathbf{S}$ & ND & Flu-like & Enc & HF & $\mathbf{N} / \mathbf{K}$ \\
\hline Anopheles A & 2 & 7 & 9 & - & 9 & - & - & - & - & - & - & - & 9 \\
\hline Anopheles B & 1 & 1 & 2 & - & 2 & - & - & - & - & - & - & - & 2 \\
\hline Bakau & 1 & 4 & 5 & - & 3 & - & - & - & 2 & - & - & - & 5 \\
\hline Bunyamwera & 5 & 24 & 29 & - & 27 & - & - & 2 & - & 8 & 1 & 1 & 19 \\
\hline Bwamba & 1 & 1 & 2 & - & 2 & - & - & - & - & 1 & - & - & 1 \\
\hline California & 1 & 15 & 16 & - & 16 & - & - & - & - & 3 & 4 & - & 9 \\
\hline Capim & 5 & 3 & 8 & - & 8 & - & - & - & - & - & - & - & 8 \\
\hline Gamboa & 2 & 2 & 4 & - & 4 & - & - & - & - & - & - & - & 4 \\
\hline Group C & 4 & 9 & 13 & - & 13 & - & - & - & - & 7 & - & - & 6 \\
\hline Guama & 5 & 7 & 12 & & 11 & - & - & - & 1 & 2 & - & - & 10 \\
\hline Koongol & 1 & 1 & 2 & - & 2 & - & - & - & - & - & - & - & 2 \\
\hline Minatitlan & 1 & 1 & 2 & - & 1 & - & - & - & 1 & - & - & - & 2 \\
\hline Nyando & 1 & 1 & 2 & - & 2 & - & - & - & - & - & - & - & 2 \\
\hline Olifantsvlei & 2 & 3 & 5 & - & 5 & - & - & - & - & - & - & - & 5 \\
\hline Patois & 3 & 4 & 7 & - & 5 & - & 1 & - & 1 & - & - & - & 7 \\
\hline Simbu & 12 & 22 & 34 & - & 16 & 6 & - & 5 & 7 & 1 & - & - & 33 \\
\hline Tete & 0 & 4 & 4 & - & - & 1 & 2 & - & 1 & - & - & & 4 \\
\hline Turlock & 0 & 1 & 1 & - & 1 & - & - & - & - & - & - & - & 1 \\
\hline Wyeomyia & 1 & 7 & 8 & - & 8 & - & - & - & - & 1 & 1 & - & 6 \\
\hline Unclassified & 0 & 5 & 5 & - & 2 & - & 1 & - & 2 & - & - & - & 5 \\
\hline Total & 48 & 122 & 170 & & 137 & 7 & 4 & 7 & 15 & 23 & 6 & 1 & 140 \\
\hline
\end{tabular}




\subsubsection{Arthropod vectors:}

The mosquitoes are main vector for this genus; mosquitoes transmit one hundred thirty seven viruses (137), sandflies (commonly referred to as " culicoid midges ") seven (7), mosquitoes and sandflies both are responsible for seven (7) virus, through ticks four (4) and for fifteen (15) viruses vectors are still unknown (Table 5 and suppementary Table 3).

\subsubsection{Vertebrate hosts:}

Rodents, ruminants, sloths primates and birds as reservoirs (Jfst, 1998; Blitvich et al., 2012).

\subsubsection{Human disease:}

At least 30 orthrbunyaviruses are responsible for flu-like to hemorrhagic fever disease and 140 viruses non-pathogenic for humans. A total 23 viruses, eight from Bunyamwera group, seven from group C, three from California group, two form Guama group, one from each Bwamba, Simbu and Wyeomyia groups are responsible for flu-like illness. Encephalitis viruses belong mainly to three groups: California 4, Bunyamwera 1 and one from Wyeomyia. Garissa virus (Ngari complex) that belongs to Bunyamwera group causes hemorrhagic fever.

\subsubsection{Animal disease:}

There are eight orthrobunyaviruses responsible for disease in animals. Two viruses from California group; La Cross virus caused encephalitis in dogs (Black et al., 1994) and Snowshoe hare virus known for equine encephalitis (Heath et al., 1989). The same number from Bunyamwera group; Cache Valley virus agent of an embryonic and fetal death of sheep, possibility of for all ruminants (Edwards, 1994) and Main Drain virus as a cause of equine encephalomyelitis (Emmons et al., 1983). Four viruses from Simbu group affects livestock's ; Akabane virus is an exotic agent for severe congenital defects (Kirkland, 2002), Aino virus is associated with fetal defects in sheep and cattle (Noda et al., 1998), Schmallenberg virus manifesting the CNS of sheep and cattle (Wu et al., 2014) and Shuni virus causes of neurological disorders in horses (Van Eeden et al., 2014). 


\subsubsection{Epidemiology}

Viruses of the Orthobunyaviruses are reported worldwide (Lowen and Elliott, 2005).

\subsubsection{Treatment:}

No specific therapies for the Orthobunyaviruses (Hollidge et al., 2012).

\subsubsection{Vaccine:}

No licensed vaccines are available for orthobunyaviruses those extremely effecting humans (Hollidge et al., 2012).

\subsubsection{Genus Phleboviruses: History and taxonomy}

The genera Phlebovirus name came from Phlebotomine sandflies because most of virus members are transmitted by phlebotomine except Uukuniemi and Bhanja serogroups (Tesh, 1988). The genera Phlebovirus contains more than 80 viruses, with 28 confirmed classified into 9 antigenic complexes groups and 32 as tentative and unclassified complexes.Before 1991, Uukuniemi-like group was in a separate genus. (Table 6).

Table 6. Summary of genus Phloboviruses

\begin{tabular}{|c|c|c|c|c|c|c|c|c|c|c|c|c|}
\hline Serogroups & Species & Strains & Tentative & Total & Sandflies & Mosq & $\mathbf{S F}+\mathbf{M}$ & Ticks & ND & Flu-like & $\mathbf{N} / \mathbf{K}$ & Others \\
\hline Bujaru & - & - & 5 & 5 & 5 & - & - & - & - & 1 & 4 & - \\
\hline Candiru & 1 & - & 6 & 7 & - & - & - & 7 & - & 4 & 2 & SFTS \\
\hline Chilibre & 1 & 5 & 7 & 13 & 4 & 1 & - & - & 8 & 1 & 12 & - \\
\hline Frijoles & 1 & 1 & - & 2 & 2 & - & - & - & - & - & 2 & - \\
\hline Punta Toro & - & 2 & - & 2 & - & - & 1 & - & 1 & - & 2 & - \\
\hline Rift Velley & 1 & 2 & 1 & 4 & 3 & 1 & - & - & - & 2 & 2 & - \\
\hline Salehabad & 4 & 5 & 21 & 30 & 17 & 3 & 1 & - & 9 & 4 & 24 & RVF,M \\
\hline SFNV & 1 & - & - & 1 & 1 & - & - & - & - & 1 & - & - \\
\hline Uukuniemi & 1 & 13 & - & 14 & - & - & - & 11 & 3 & - & 14 & - \\
\hline Unclassified & - & - & 2 & 2 & - & - & - & - & 2 & - & 2 & - \\
\hline Total & 10 & 28 & 42 & 80 & 32 & 5 & 2 & 18 & 23 & 13 & 64 & 3 \\
\hline
\end{tabular}

\subsubsection{Arthropod vectors:}


Genus can divide into two groups Sandfly fever (transmitted by Sandfly and mosquitoes) and Uukuniemi like virus (transmitted by ticks), as we know, the genus name came from Phlebotomine sandflies. Thirty-two viruses transmitted by sanflies, 18 viruses through ticks, and five by mosquitoes. Mosquitoes and sandflies are responsible for two viruses and 23 viruses by unknown vectors (Table 6).

\subsubsection{Vertebrate hosts:}

The ruminants, rodents and bat are main reservoir host in nature (Olive et al., 2012).

\subsubsection{Human disease:}

The fatal best-known virus from phlebovirus is Rift Valley fever virus and other three important pathogens include sandfly fever Neples, sandfly Sicilian and Toscana virus. Thirteen viruses are causes flu-like problem and 64 viruses still safe for human health.

\subsubsection{Animal disease:}

Rift Valley fever causes severe disease with more than $70 \%$ mortality rate in young animals like lamb and calf. The goat and buffaloes are also face problem with $10 \%$ mortality. Other Bhanja virus also pathogenic for the same animals and causes fever and meningoencephalitis.

\subsubsection{Epidemiology:}

Presente worldwide (Lantez et al., 2011).

\subsubsection{Treatment:}

No therapies against the phlebovirus disease (Sidwell, R. W 1992).

\subsubsection{Vaccine:}

No vaccine (Sidwell, R. W 1992). 


\subsubsection{Genus Nairovirus: History and Taxonomy}

The genus Nairovirus is named for Nairobi sheep disease (NSD), which was originally isolated near Nairobi, Kenya in 1910 as acute hemorrhagic gastroenteritis cases of sheep (Davies et al., 1978). There are thirty-six viruses, seven species confirmed and 29 strains. The genus Nairovirus is divided into seven serogroups (Table 7).

Table 7. Summary of genus Nairovirus.

\begin{tabular}{|l|l|l|l|l|l|l|l|l|l|l|l}
\hline Serogroups & Species & Strains & Total & Ticks & T+SF & T+SF+M & Mosq & ND & Flu-like & N/K & Others \\
\hline CCHF & 1 & 2 & 3 & 2 & 1 & - & - & - & - & 2 & CCF \\
\hline Dera Ghazi Khan & 1 & 5 & 6 & 5 & - & - & - & 1 & - & 6 & - \\
\hline Hughes & 1 & 9 & 10 & 10 & - & - & - & - & - & 10 & - \\
\hline Nairobi Sheep Dis & 1 & 3 & 4 & 4 & - & - & - & - & 2 & 2 & - \\
\hline Qalyub & 1 & 3 & 4 & 4 & - & - & - & - & - & 4 & - \\
\hline Sakhalin & 1 & 6 & 7 & 7 & - & - & - & - & - & 7 & - \\
\hline Thaifora & 1 & 1 & 2 & - & - & - & - & 2 & - & 2 & - \\
\hline Total & $\mathbf{7}$ & $\mathbf{2 9}$ & $\mathbf{3 6}$ & $\mathbf{3 2}$ & $\mathbf{1}$ & $\mathbf{0}$ & $\mathbf{0}$ & $\mathbf{3}$ & $\mathbf{2}$ & $\mathbf{3 3}$ & $\mathbf{1}$ \\
\hline
\end{tabular}

\subsubsection{Arthropod vectors:}

The ticks are main vector for Nairoviruses; thirty-two viruses are use ticks as main vector, one virus is involved with ticks and sandflies and the vector of three viruses still not confirmed.

\subsubsection{Vertebrate hosts:}

The goat, sheep, seabirds and rats are vertebrate hosts (Hubálek et al., 2014).

\subsubsection{Human disease}

Only three viruses from this genus have been identified as human pathogens, two viruses belong to Nairobi sheep disease virus serogroup causes flu-like symptoms and third Crimean-Congo hemorrhagic fever virus severe fatal with up to $50 \%$ mortality (Flusin et al., 2011).

\subsubsection{Animal disease}

Gunjan virus also known as Nairobi sheep disease virus an important disease of ruminants and other Soldado virus can affect young seabirds (Hubálek et al., 2014). 


\subsubsection{Epidemiology}

Worldwide (Hubálek et al., 2014).

\subsubsection{Treatment}

No effective treatment against these (Hubálek et al., 2014).

\subsubsection{Vaccine}

No vaccines are available for Nairoviruses (Hubálek et al., 2014).

\subsubsection{History and taxonomy of genus Hantavirus:}

The Hantavirus genus was name became from Hantaan river where Hantaan virus was discovered, previously known as Korean hemorrhagic fever, epidemic hemorrhagic fever was fist come to light during 1951 to 1953 , when approximately 3,200 cases reported among United Nations forces in Korea (Schmaljohn and Hjelle, 1997). This genus divided into four serotypes with total 97 viruses 38 viruses from OW and 59 reprehensive from NW. A twenty-four confirmed species, seven strains and sixtysix still are tentative (Table 8).

Table 8. Summary of genus Hantavirus.

\begin{tabular}{|l|l|l|l|l|l|l|l|l|l|l|l|}
\hline Serogroups & Species & Strains & Tentative & Total & OW & NW & HFRS & HCPS & Flu-like & N/K & Others \\
\hline Hantaan & 12 & 2 & 1 & 15 & 11 & 4 & 7 & 2 & - & 6 & - \\
\hline Puumala & 1 & 1 & - & 2 & 2 & - & - & - & 1 & 1 & - \\
\hline Sin Nombre & 8 & 4 & 11 & 23 & - & 23 & - & 15 & 1 & 6 & HARDS \\
\hline Thottapalayam & 1 & - & - & 1 & 1 & - & - & - & - & 1 & - \\
\hline Ungrouped & 2 & - & 54 & 56 & 24 & 32 & 3 & 6 & - & 47 & - \\
\hline Total & $\mathbf{2 4}$ & $\mathbf{7}$ & $\mathbf{6 6}$ & $\mathbf{9 7}$ & $\mathbf{3 8}$ & $\mathbf{5 9}$ & $\mathbf{1 0}$ & $\mathbf{2 3}$ & $\mathbf{2}$ & $\mathbf{6 1}$ & $\mathbf{1}$ \\
\hline
\end{tabular}

\subsubsection{Mode of transmission}

Mode of transmission is same like arenaviruses. Many Hantaviruses affect persons of low socioeconomic condition due to of poor housing conditions (Schmaljohn and Hjelle, 1997).

\subsubsection{Rodent's vectors:}


Hantaviruses are transmitted by various species of rodents (Khan and Khan, 2003).

\subsubsection{Vertebrate hosts:}

Small mammals specially, rodents are vertebrate hosts of Hantavirus (Jonsson et al., 2010).

\subsubsection{Human disease}

The Hantaviruses are causes two types of disease in humans, 10 viruses are known to haemorrhagic fever with renal syndrome (HFRS) in old world and 23 viruses are responsible for hantavirus pulmonary syndrome (HPS) in new world. Two viruses are show flu-like problem, one from Sin Nombre group causes Hantavirus Associated Respiratory Distress Syndrome (HARDS) and 61 viruses are non-pathogenic or unknown.

\subsubsection{Animal disease}

Not reported.

\subsubsection{Epidemiology:}

Hantaviruses are presents in Europe and Asia, and Americas (Escutenaire and Pastoret, 2000).

\subsubsection{Treatment:}

No specific treatment available (Bellomo et al., 2015).

\subsubsection{Vaccine:}

No licensed vaccines are available (Beltrán-Ortiz, C. E.2015).

\subsubsection{Family Flaviviridae; History and classification}

In 1881s, The Cuban Dr. Carlos Finlay first time suggested that mosquitoes were responsible to propagation of Yellow fever virus (an alternative name "vomito negro") in vertebrates host. The Walter Reed Yellow Fever Commission proved this hypothesis around 1900 (Chiong, 1989). This family currently includes four different genera. 
Table 9. Genera of the family Flaviviridae.

\begin{tabular}{|l|l|l|l|}
\hline Genus & Meaning in Latin/Greek & Mode of Transmission & Reference \\
\hline Flavivirus & Latin flavus "Yellow" & Arthropods & (Kuhn et al., 2002) \\
\hline Pestivirus & Latin pestis "Plague" & Direct contact & $\begin{array}{l}\text { (Lanyon and Reichel, } \\
2014)\end{array}$ \\
\hline Hepacivirus & Greek hepar, hepatos "Liver" & Blood-borne & $\begin{array}{l}\text { (Romero-Brey and } \\
\text { Bartenschlager, 2014) }\end{array}$ \\
\hline Pegivirus & Persistent GB virus & Blood-borne & Stapleton, J. T.2011 \\
\hline
\end{tabular}

The Flavivirus genus is the largest, composed of 76 species divided into 12 groups. Of these groups, the Japanese encephalitis group contains the largest number of viral species associated with human disease. The majority of human infections following exposure to a mosquito vector in this group of viruses include the Japanese encephalitis virus (JEV), Murray Valley encephalitis virus (MVEV), St. Louis encephalitis virus (SLEV), Dengue virus (DENV) and West Nile virus (WNV). Other important ticks-borne group causes encephalitis called mammalian tick-borne (Table 10).

Table 10. Summary of genus Flavivirus.

\begin{tabular}{|l|l|l|l|l|l|l|l|l|l|l|l|l|}
\hline Serogroup & Species & Strains & Tentative & Total & Ticks & Mosq & T+M & ND & Flu-like & Ence & HF & N/K \\
\hline Aroa virus & 1 & - & - & 1 & - & 1 & - & - & - & - & - & 1 \\
\hline Dengue virus & 5 & - & - & 5 & - & 5 & - & - & 4 & - & - & 1 \\
\hline Entebbe bat & 4 & - & - & 4 & - & - & - & 4 & - & 2 & - & 2 \\
\hline Japanese encephalitis & 8 & - & - & 8 & - & 8 & - & - & 1 & 4 & - & 2 \\
\hline Kokobera & 1 & - & 1 & 2 & - & 2 & - & - & 1 & - & - & 2 \\
\hline Mammalian tickborne & 8 & 8 & 3 & 19 & 18 & - & 1 & - & - & 14 & 1 & 4 \\
\hline Modoc virus & 3 & - & - & 3 & - & - & - & 3 & - & - & - & 3 \\
\hline Ntaya & 7 & 1 & - & 8 & - & 7 & - & 1 & 1 & 1 & - & 6 \\
\hline Rio Bravo & 6 & - & 1 & 7 & - & - & - & 7 & 2 & - & - & 5 \\
\hline Seabird tickborne & 4 & - & - & 4 & 3 & - & 1 & & 1 & - & - & 3 \\
\hline Spondweni & 1 & 1 & - & 2 & - & 2 & - & - & 2 & - & - & - \\
\hline Yellow fever & 9 & 1 & - & 10 & - & 8 & - & 2 & 3 & - & 1 & 6 \\
\hline Ungrouped & - & - & 3 & 3 & - & 2 & - & 1 & - & - & - & 3 \\
\hline Total & $\mathbf{5 7}$ & $\mathbf{1 1}$ & $\mathbf{8}$ & $\mathbf{7 6}$ & $\mathbf{2 1}$ & $\mathbf{3 5}$ & $\mathbf{2}$ & $\mathbf{1 8}$ & $\mathbf{1 5}$ & $\mathbf{2 1}$ & $\mathbf{2}$ & $\mathbf{3 8}$ \\
\hline
\end{tabular}

\subsubsection{Arthropod vectors:}


Responsible vectors for genus Flaviviruses transmitted to vertebrates are variety of mosquitoes and ticks. The major role play by infected mosquitoes with 35 viruses, ticks are known to transmit 21 viruses and two viruses are transmitted by both vectors. Also, non-vector-borne four flaviviruses have been isolated from bats and rodents.

\subsubsection{Vertebrate hosts}

The vertebrate amplifier hosts of flaviviruses are Birds, sheep, pigs, rodents, camels and primates (Rosen, 1986; Mlera et al., 2014).

\subsubsection{Human disease:}

Twenty-one flaviviruses are responsible for encephalitis and two viruses for hemorrhagic fever and 15 viruses are causes flu-like symptoms in humans (Table 10).

\subsubsection{Animal disease:}

Thirteen viruses have been reported to pathogenic for the animals, following viruses are infects animal; Yellow fever virus; monkeys, Japanese encephalitis virus; sows, boars and horses, Murray Valley encephalitis virus; horse and sheep, West Nile virus; equids and avian groups, Usutu virus; birds, Israel turkey meningoencephalitis virus; adult turkeys, Tembusu virus; ducks, Wesselsbron virus; sheep, goat, pig and horses, Louping ill virus; sheep, cattle, pig, dog and horses, Tick-borne encephalitis virus; birds, Omsk hemorrhagic fever virus; birds, Kyasanur Forest disease virus and Tyuleniy virus infect monkeys (Hubálek et al., 2014).

\subsubsection{Epidemiology:}

Worldwide except Antarctica (Huang et al., 2014).

\subsubsection{Treatment:}

No antiviral drugs are approved for use against the flaviviruses (Leyssen et al., 2008).

\subsubsection{Vaccine}

Licensed vaccines are available for YEV and JEV to protect human and WNV lineage 1 are for horses in the United States and in Europe (Hills et al., 2014; Beck and Barrett, 2015). 


\subsubsection{Family Reoviridae; History and classification}

Sabin first introduced family Reoviridae name derived from Respiratory Enteric Orphan viruses in 1959 and originally these viruses are classified as echo virus 10 (Urbano and Urbano, 1994). Currently, the family Reoviridae contains fifteen genera divided into two subfamilies Spinareovirinae and Sedoreovirinae bases rectified International Committee for Taxonomy of Virology (ICTV) in 2009. Viruses belong to three genera; Coltivirus, Orbivirus and Seadornavirus transmitted by arthropods and infect animals.

Table 11. Summary of family Reoviridae.

\begin{tabular}{|l|l|l|l|}
\hline Genus & Mode of transmission & Infect & Reference \\
\hline Aquareovirus & Water & Fish and Mollusks & (Mohd Jaafar et al., 2008) \\
\hline Cardoreovirus & Water & Crustaceans & (Fan et al., 2013) \\
\hline Coltivirus & Arthropods & Mammals & (Klasco, 2002) \\
\hline Cypovirus & Insect & Insects & (Li et al., 2006) \\
\hline Dinovernavirus & Arthropods & Insects & (Auguste et al., 2015) \\
\hline Fijivirus & Insect & Plant and Insects & (Soo et al., 1998) \\
\hline Idnoreovirus & Insect & Insects & (Miyazaki et al., 2008) \\
\hline Mimoreovirus & Water & Algae & (Attoui et al., 2006) \\
\hline Mycoreovirus & $? ?$ & Fungi & (Eusebio-Cope and Suzuki, 2015) \\
\hline Orbivirus & Arthropods & Mammals & (Drolet et al., 2015) \\
\hline Orthoreovirus & Fecal-oral route & Mammals, birds and reptiles & $\begin{array}{l}\text { (Thimmasandra Narayanappa } \text { et al., } \\
\text { 2015) }\end{array}$ \\
\hline Oryzavirus & Arthropods & & (Auguste et al., 2015) \\
\hline Phytoreovirus & Insect & Plants and Insects & (Ji et al., 2011) \\
\hline Rotavirus & Fecal-oral route & Mants and Insects & (Dennehy, 2015) \\
\hline Seadornavirus & Arthropods & Humans and Insects & (Attoui et al., 2005) \\
\hline
\end{tabular}

Viruses belong to three genera; Coltivirus, Orbivirus and Seadornavirus transmitted by arthropods and infect animals are consider arboviruses.

\subsubsection{History and taxonomy of genus coltivirus:}

The genus Coltivirus name has been derived from Colorado tick fever virus (Urbano and Urbano, 1994). Currently, genus contains two species (Table 12). 
Table 12. Summary of genus Coltivirus.

\begin{tabular}{|l|l|l|l|l|l|l|l|}
\hline Serogroup & Species & Strain & Tentative & Total & Ticks & Flu-like & N/K \\
\hline Colorado tick fever virus & 2 & - & - & 2 & 2 & 1 & 1 \\
\hline Total & 2 & 0 & 0 & 2 & 2 & 1 & 1 \\
\hline
\end{tabular}

\subsubsection{Arthropod vectors:}

Ticks are main vector for coltiviruses, Rocky Mountain wood tick is transmitted Colorado tick fever virus (Table 12)

\subsubsection{Vertebrate hosts:}

Viruses maintains in many animals like chipmunks, deer, squirrels, wild mice, wood rats, wild rabbits, rodents and sheep (Attoui et al., 2005).

\subsubsection{Human disease:}

Colorado ticks fever virus causes an acute systemic fever illness and Eaych virus

\subsubsection{Animal disease:}

Not reported yet.

\subsubsection{Epidemiology}

Colorado tick fever virus reported in USA and Eaych virus in Europe and Asia (Attoui et al., 1998; Charrel et al., 2004).

\subsubsection{Treatment:}

No antiviral treatment is available against coltiviruses except supportive care (Romero and Simonsen, 2008).

\subsubsection{Vaccine:}

No licensed vaccine available (Romero and Simonsen, 2008).

\subsubsection{Genus Orbivirus; History and taxonomy}

The genus currently, includes 166 viruses; 22 species (representing as serogroups), 132 strains and 12 unclassified (Table 13). 
Table 13. Summary of genus Orbivirus

\begin{tabular}{|c|c|c|c|c|c|c|c|c|c|c|c|}
\hline Serogroup & Species & Strains & Tentative & Total & Ticks & Mosq & Sandflies & $\begin{array}{l}\mathrm{N} \\
\mathrm{D}\end{array}$ & $\begin{array}{l}\text { Flu- } \\
\text { like }\end{array}$ & Ence & $\mathrm{N} / \mathrm{K}$ \\
\hline AHSV & 1 & 8 & - & 9 & - & - & 9 & - & - & - & 9 \\
\hline BTV & 1 & 25 & - & 26 & - & - & 26 & - & - & - & 26 \\
\hline Changuinola & 1 & 11 & - & 12 & 2 & 1 & 6 & 3 & 1 & - & 11 \\
\hline Chenuda & 1 & 6 & - & 7 & 7 & - & - & - & - & - & 7 \\
\hline $\begin{array}{l}\text { Chobar } \\
\text { Gorge }\end{array}$ & 1 & 1 & - & 2 & 2 & - & - & - & - & - & 2 \\
\hline Corriaparta & 1 & 5 & - & 6 & - & 6 & - & - & - & - & 6 \\
\hline EHD & 1 & 8 & - & 9 & - & - & 9 & - & - & - & 9 \\
\hline EEV & 1 & 6 & - & 7 & - & - & 7 & - & - & - & 7 \\
\hline Eubenangee & 1 & 2 & - & 3 & - & 3 & - & - & - & - & 3 \\
\hline Great Island & 1 & 35 & - & 36 & 36 & - & - & - & 1 & - & 35 \\
\hline Ieri & 1 & 2 & - & 3 & - & 3 & - & - & - & - & 3 \\
\hline Kemerovo & 1 & 1 & - & 2 & 2 & - & - & - & - & - & 2 \\
\hline Lebombo & 1 & - & - & 1 & - & 1 & - & - & - & - & 1 \\
\hline Orungo & 1 & 3 & - & 4 & - & 2 & - & 2 & 4 & - & - \\
\hline Palyam & 1 & 12 & - & 13 & 3 & 2 & 5 & 3 & - & - & 13 \\
\hline PHSV & 1 & - & - & 1 & - & 1 & - & - & - & - & 1 \\
\hline SCRV & 1 & - & - & 1 & 1 & - & - & - & - & - & 1 \\
\hline Umatilla & 1 & 3 & - & 4 & - & 4 & - & - & - & - & 4 \\
\hline WALV & 1 & 2 & - & 3 & - & - & 3 & - & - & - & 3 \\
\hline Warrego & 1 & 2 & - & 3 & - & - & 3 & - & - & - & 3 \\
\hline Wongorr & 1 & - & - & 1 & - & 1 & - & - & - & - & - \\
\hline YUOV & 1 & - & - & 1 & - & 1 & - & - & - & - & 1 \\
\hline Unclassified & - & - & 12 & 12 & 2 & 8 & - & 2 & - & - & 12 \\
\hline Total & 22 & 132 & 12 & 166 & 55 & 33 & 68 & 10 & 6 & - & 160 \\
\hline
\end{tabular}

\subsubsection{Arthropod vectors:}

Transmitted by range of hematophagus arthropods; mainly, 68 viruses by sandflies, 55 through ticks, mosquitoes responsible for 33 and 10 viruses with unknown vectors.

\subsubsection{Vertebrate hosts:}


The genus orbivirus has a wide vertebrate host range includes domestic and wild ruminants, equines, marsupials, sloths, bats, birds (Belaganahalli et al., 2015).

\subsubsection{Human disease:}

This genus not life threading for human, only six viruses associated with human health and causes flu-like problem and 160 viruses non-pathogenic (Table 13).

\subsubsection{Animal disease:}

Eight orbiviruses are pathogenic for animals; African horse sickness virus, equids manifest in three ways dunkop, dikkop and mixed form with $90 \%$ death rate. Kasba virus causes Chuzan disease in calves, Bluetongue virus responsible for "bluetongue or ovine catarrhal fever"or dancing disease in domestic and wild ruminants and Epizootic hemorrhagic disease virus also infect wild ruminants. The Ibaraki virus show symptoms like bluetongue-like in cattle, Equine encephalosis virus similar to American horse sickness virus in equine, Peruvian horse sickness virus with neurological disorders in horse up to $80 \%$ mortality and Yunnan virus also causes neurological disorders in donkey, cattle, sheep, and dog (Mellor and Hamblin, 2004; Kedmi et al., 2010; Maclachlan and Guthrie, 2010; Kim et al., 2011; Maclachlan, 2011; Cowled et al., 2012).

\subsubsection{Epidemiology:}

Orbivurses distributed worldwide (Hubálek et al., 2014).

\subsubsection{Treatment:}

None (Hubálek et al., 2014).

\subsubsection{Vaccine:}

Vaccines are available against two notable orbiviruses African swine fever virus and Bluetongue virus (Paton and Taylor, 2011).

\subsubsection{Genus Seadornavirus; History and taxonomy:}

Genus contains only three viruses (Table 14). 
Table 14. Summary of genus Seadornavirus.

\begin{tabular}{|l|l|l|l|l|l|l|l|l|l|l|l|}
\hline Serogroup & Species & Strains & Tentative & Total & Ticks & Mosq & Sandflies & N \\
D & Flu-like & Ence & N/K \\
\hline BANV & 1 & - & - & 1 & - & 1 & - & - & - & 1 & - \\
\hline KDV & 1 & - & - & 1 & - & 1 & - & - & - & - & - \\
\hline LNV & 1 & - & - & 1 & - & 1 & - & - & - & 1 & - \\
\hline
\end{tabular}

\subsubsection{Arthropod vectors:}

All three viruses transmitted by mosquitoes (Table 14).

\subsubsection{Human disease:}

Only Banna virus is causes encephalitis in human and other two viruses are nonpathogenic (Table 14)

\subsubsection{Animal disease:}

The only seadornaviruses isolated from human (Attoui et al., 2005).

\subsubsection{Epidemiology:}

The Seadornaviruses are only endemic in Southeast Asia (Attoui et al., 2005).

\subsubsection{Treatment:}

No specific treatment except relief of fever and pain (Attoui et al., 2005).

\subsubsection{Vaccine:}

None (Attoui et al., 2005).

\subsubsection{Family Rhabdoviridae; History and classification}

This family are currently composed of eleven genera based on antigenicity, phylogenetic analysis and structural properties (Bodewes et al., 2014). Eight that infect vertebrates (Ephemerovirus, Lyssavirus, Novirhabdovirus, Perhabdovirus, Sprivivirus, Tibrovirus, Tupavirus and Vesiculovirus), two genera responsible for plants (Cytrohabdovirus and Nucleorhabdovirus) and Sigmavirus found in invertebrates. Three of them genera are containing arthropods-borne agents Ephemerovirus, Tibrovirus and Vesiculovirus ((Table 15). 
Table 15. Summary of family Rhabdoviridae.

\begin{tabular}{|l|l|l|l|}
\hline Genus & Mode of transmission & Infect & Reference \\
\hline Cytrohabdovirus & Insect: Planthopper & Plants & (Jackson et al., 2005) \\
\hline Ephemeroviruses & Arthropods & Cattle & (Blasdell et al., 2014) \\
\hline Lyssaviruses & Bite by a rabid mammals & Humans & (Hicks et al., 2012) \\
\hline Novirhabdovirus & Waterborne & Fish & (Reichert et al., 2013) \\
\hline Nucleorhabdovirus & Insect: Leafhopper & Plants & (Jackson et al., 2005) \\
\hline Perhabdovirus & Waterborne & Fish & (Gadd et al., 2013) \\
\hline Sigma Virus & Vertically through eggs and sperm & Drosophila spp. & (Longdon et al., 2010) \\
\hline Sprivirus & Waterborne & Fish & (Ghasemi et al., 2014) \\
\hline Tibrovirus & Arthropods & Cattle & (Gubala et al., 2011) \\
\hline Tupavirus & $?$ & Mammals & (Allison et al., 2011) \\
\hline Vesiculovirus & Arthropods & Livestock and Humans & (Letchworth et al., 1999) \\
\hline Unassigned & - & - & -- \\
\hline
\end{tabular}

\subsubsection{Genus Ephemerovirus; History and taxonomy}

The origin of Bovine Ephemero Fever virus was first noticed as an infectious agent in East Africa in mid-nineteenth century (Nandi and Negi, 1999). The genus Ephemerovirus is one of eleven currently recognized genera in the family Rhabdoviridae. This genus divided into two serogroups with eight viruses, The BEFV group contains six virus five species and one tentative. Two viruses represented from second group MALV (Table 16).

Table 16. Summary of genus Ephemerovirus.

\begin{tabular}{|l|l|l|l|l|l|l|l|l|l|l|l|l|}
\hline Serogoup & Species & Strain & Tentative & Total & Ticks & Mosq & Sandflies & S+M & ND & Flu-like & Enc & N/K \\
\hline BEFV & 5 & - & 1 & 6 & - & 2 & 1 & 1 & 2 & 1 & - & 5 \\
\hline MALV & - & - & 2 & 2 & - & 1 & - & 1 & - & - & - & 2 \\
\hline Total & 5 & 0 & 3 & 8 & - & 3 & 1 & 2 & 2 & 1 & 0 & 7 \\
\hline
\end{tabular}

\subsubsection{Arthropod vectors:}


Principal vectors are mosquitoes for the genus Ephemerovirus. Mosquitoes transmitted virus two from BEFV group and one from MALV group. However, biting Sandflies also additional vector in BEFV group. Two vectors one from each group (Mosquitoes and sandflies) and two vectors still unknown from BEFV group (Table 16).

\subsubsection{Vertebrate hosts}

The ruminants are reservoir host (Hubálek et al., 2014).

\subsubsection{Human disease}

Viruses belong to this genus not pathogenic for humans (Table 16).

\subsubsection{Animal disease}

The Bovine ephemeral fever virus causes three days sickness in cattle and water buffaloes, dengue fever of cattle, stick sickness and bovine epizootic fever and second virus from this genus Kotonkan virus manifest an ephemeral fever-like illness in cattle (Tomori et al., 1974; Doherty, 1977; Nandi and Negi, 1999).

\subsubsection{Epidemiology:}

Bovine ephemeral fever is present throughout Africa, Middle East, northern Australia and Southeast Asia. Other virus from this genus Kotonkan distribute in Nigeria (Africa) (Hubálek et al., 2014).

\subsubsection{Treatment}

There is not any specific treatment available.

\subsubsection{Vaccine:}

Only an attenuated vaccine has been using in Australia and Japan against BEFV within genus (Uren et al., 1994).

\subsubsection{Genus Tibrovirus; History and taxonomy}

This genus is name as an adapted from the species Tibrogargan (TIBV) and it was first isolated in 1976 from a pool of sandflies in Australia (Queensland). The genus Tibrovirus newly recognized with two species, Tibrogargan virus (TIBV) and Coastal Plains virus (CPV) (Lauck et al., 2015) (Table 17 and sup Table 13). 
Table 17. Summary of genus Tibrovirus.

\begin{tabular}{|l|l|l|l|l|l|l|l|l|l|l|l|l|}
\hline Serogoup & Species & Strain & Tentative & Total & Ticks & Mosq & Sandflies & S+M & ND & Flu-like & Enc & N/K \\
\hline TIBV & 2 & - & - & 2 & - & - & 2 & - & - & - & - & 2 \\
\hline Total & 2 & - & - & 2 & 0 & 0 & 0 & 0 & 0 & 0 & 0 & 2 \\
\hline
\end{tabular}

\subsubsection{Arthropod vectors:}

Usually, both viruses are transmitted via biting of sandflies (TableXX).

\subsubsection{Vertebrate hosts:}

Bovine and water buffalos are vertebrate host (Gubala et al., 2011).

\subsubsection{Human disease:}

None of responsible for disease in human (Lauck et al., 2015).

\subsubsection{Animal disease:}

Not reported (Gubala et al., 2011).

\subsubsection{Epidemiology:}

Initially, Tibroviruses presence throughout Australia and New Guinea(Cybinski and Gard, 1986).

\subsubsection{Treatment}

Not required.

\subsubsection{Vaccine:}

No.

\subsubsection{Genus Vesiculovirus; History and taxonomy}

In 1916, first Vesiculovirus or Vesicular Stomatitis Virus (VSV) was reported in United States an epidemic in livestock (Hanson, 1952). The genus Vesiculovirus have total 27 viruses, nine of them are confirmed species and eighteen viruses are tentative (Table 18 and sup Table 14). 
Table 18. Summary of genus Vesiculovirus.

\begin{tabular}{|c|c|c|c|c|c|c|c|c|c|c|c|c|}
\hline Serogroup & Species & Strain & Tentative & Total & Ticks & Mosq & Sandflies & $\mathrm{M}+\mathrm{S}$ & $\begin{array}{l}\mathrm{N} \\
\mathrm{D}\end{array}$ & $\begin{array}{l}\text { Flu- } \\
\text { like }\end{array}$ & Enc & $\begin{array}{l}\mathrm{N} / \\
\mathrm{K}\end{array}$ \\
\hline Boteke & - & - & 1 & 1 & - & 1 & - & - & - & - & - & 1 \\
\hline Kwatta & - & - & 1 & 1 & - & 1 & - & - & - & - & - & 1 \\
\hline VSIV & 2 & - & - & 2 & - & - & 1 & 1 & - & 2 & - & - \\
\hline VSIJ & 1 & - & - & 1 & - & - & - & 1 & - & 1 & - & - \\
\hline VSV & 6 & - & 12 & 18 & - & 8 & 6 & & 4 & 3 & - & 15 \\
\hline Ungrouped & - & - & 4 & 4 & - & 4 & - & - & - & - & - & 4 \\
\hline Total & 9 & & 18 & 27 & - & 14 & 7 & 2 & 4 & 6 & - & 21 \\
\hline
\end{tabular}

\subsubsection{Arthropod vectors:}

Mosquitoes are main vector link with 14 viruses, seven viruses by Sandflies, four viruses are through both sandflies and mosquitoes and four viruses are transmitted with unknown vectors.

\subsubsection{Vertebrate hosts:}

There are several reservoir host like; Cattle, horse, pig, deer, rodents and bats (Hubálek et al., 2014).

\subsubsection{Human disease:}

A total six viruses causes flu-like symptoms in humans and other 21 viruses nonpathogenic for human (Table 18).

\subsubsection{Animal disease}

Four members of Vesiculovirus clinical disease presents in Livestock. The Cocal virus (Indiana-2), Vesicular stomatitis- New Jersey virus and Vesicular stomatitisIndiana virus causes vesicular stomatitis. Vesicular stomatitis Alagoas virus (Indiana-3) are pathogenic for cattle, equids cause tongue vesicles and fever causes (Letchworth et al., 1999).

\subsubsection{Epidemiology}


Vesiculoviruses are present only in the Americas especially south Mexico, Central America and some regions of South America (Hubálek et al., 2014).

\subsubsection{Treatment}

No specific treatment still available against Vesiculoviruses (Jadi et al., 2011).

\subsubsection{Vaccine}

No vaccine (Jadi et al., 2011).

\subsubsection{Family Togaviridae; History and classification}

This family name come from the Roman Cloak (in Latin = toga) for this reason called togaviruses. The family togaviridae is categorized into two genera: Alphavirus and Rubivirus. The Rubivirus genus is containing of a single member its Rubella virus (also called German measles) mode of transmission by droplet spread or direct contacts (Jose et al., 2009; Mangala Prasad et al., 2013).

\subsubsection{Alphavirus genus; History and taxonomy}

In 1930, first Alphavirus was isolated as Western Equine Encephalitis virus by Dr. Karl Friedrich Meyer with very interesting story. During encephalitis in horse at San Joaquin Valley (California, USA), Scientist team tried to get head of horse symptomatic for encephalitis and owner of horse threatened team “ I won't sell the horse, and you try to do anything to the horse I shoot you". But, Dr. Meyer deal with former wife when he was asleep in exchange horse head for USD 20, the team successfully isolated virus from the brain tissue (Sabin, 1980). The genus Alphavirus generally referred to; the viruses responsible for rheumatic disease in humans (Old World) and viruses especially associated with encephalitis disease in the Americas (New World) (Suhrbier et al., 2012). The Alphavirus genus consists of about 36 different viruses divided antigenically into seven serogroups and some viruses are still unclassified they not have their yet confirm serogroup status (Table 19). 
Table 19. Summary of genus Alphavirus.

\begin{tabular}{|c|c|c|c|c|c|c|c|c|c|c|c|c|c|}
\hline Serogroup & Species & Strains & Tentative & $\begin{array}{l}\text { Tota } \\
\text { I }\end{array}$ & Ticks & Mosq & Sandflies & $\mathbf{M}+\mathbf{S}$ & ND & $\begin{array}{l}\text { Flu- } \\
\text { like }\end{array}$ & Enc & R.A & $\mathbf{N} / \mathbf{K}$ \\
\hline BFV & 1 & - & - & 1 & - & 1 & - & - & - & 1 & - & - & - \\
\hline EEEV & 2 & - & - & 2 & - & 1 & - & - & 1 & - & 1 & - & 1 \\
\hline MIDV & 1 & - & - & 1 & - & 1 & - & - & - & - & - & - & 1 \\
\hline NDUV & 1 & - & - & 1 & - & 1 & - & - & - & - & - & - & 1 \\
\hline SFV & 9 & 1 & - & 10 & - & 9 & - & - & 1 & - & 1 & 5 & 4 \\
\hline VEEV & 9 & - & - & 9 & - & 9 & - & - & - & 2 & 3 & - & 4 \\
\hline WEEV & 8 & 3 & - & 11 & - & 9 & - & - & 2 & - & 1 & 2 & 8 \\
\hline Ungrouped & - & - & 1 & 1 & - & - & - & - & 1 & - & - & - & 1 \\
\hline Total & 31 & 4 & 1 & 36 & $\mathbf{0}$ & 31 & $\mathbf{0}$ & $\mathbf{0}$ & 5 & 3 & 6 & 7 & 20 \\
\hline
\end{tabular}

\subsubsection{Arthropod vectors:}

The mosquitoes are main vector for the genus Alphavirus with approximately 31 viruses and 5 viruses are transmitted through unknown vectors (Table 19).

\subsubsection{Vertebrate reservoir hosts:}

The vertebrate reservoir hosts are generally mammals, birds and primates (Weaver and Barrett, 2004).

\subsubsection{Human disease:}

Twenties viruses are non-pathogenic for humans from all serogroups except Barmah forest (BFV) virus. A total sixteen viruses are able to infect humans and causes flu-like to encephalitis except from three complexes Middleburg virus (MID), Ndumu virus (NDU) and one from ungrouped. Seven viruses are causes Rash and Arthritis (R.A), five viruses are from Semeliki forest (SF) and two from Western Equine Encephalitis virus (WEEV). Six viruses are responsible for encephalitis, one from EEEV, one from SF, also one from WEEV and three viruses are from VEEV. About flulike, one virus from (SF) and two viruses are from VEEV (Table 19). 


\subsubsection{Animal disease:}

There are nine exotic Alphaviruses significant on health of animals, the members within the sero-complex Western equine encephalitis virus is contains four viruses; Buggy Creek virus has little impact on house sparrows (O'brien and Brown, 2011), Highland $\mathrm{J}$ virus cause encephalitis in horses and recognized pathogenic for various avian species (Weaver et al., 1997). Sindbis virus cases encephalitis in horses and notable virus in this group Western Equine Encephalitis virus encephalomyelitis (Calisher et al., 1986). One viruses from Eastern Equine Encephalitis (EEEV) serogroup and one Venezuelan Equine Encephalitis (VEEV) causes encephalitis in equines (Zacks and Paessler, 2010). From Semiliki forest virus group; two viruses Getah virus pathogenic for racehorse and causes fever and other semiliki forest virus responsible for encephalitis in horses (Robin et al., 1974; Fukunaga et al., 2000) . One virus from Middelburg serocomplex (Middelburg virus) also responsible for encephalitis in equines (Attoui et al., 2007).

\subsubsection{Epidemiology:}

Alphaviruses are dispersed globally (Go, Y. Y.2014).

\subsubsection{Treatment:}

Currently, there are no licensed specific treatment available except symptoms supportive drugs for any Alphavirus (Phillips et al., 2013).

\subsubsection{Vaccine:}

We are still waiting licensed vaccines for humans use, but some (EEEV, VEEV and WEEV) unlicensed vaccines are available to protect at-high risk laboratory personnel (Hoke, 2005). For the veterinary use, vaccines (EEEV,VEEV and WEEV) are available for routine use to control infection in endemic areas (Barber et al., 1978).

\subsubsection{Family Asfarviridae; History and classification:}

In 1910, R.E Montgomery discovered first African swine fever virus (African swine fever and related viruses) from an ill pig in Kenya (at Kabete, Kiambu County). It was observed that the occurrence of cases appear when domestic pigs come into close 
contact with wildlife species, specially warthogs (Costard et al., 2009). There is a unique genus Asfarvirus in family Asfarviridae.

\subsubsection{Genus Asfarvirus: History and taxonomy}

This genus has only one species and its called African swine fever virus (Table 20).

Table 20. Summary of genus Asfarvirus.

\begin{tabular}{|l|l|l|l|l|l|l|l|l|l|l|l|l|}
\hline Serogroup & Species & Strains & Tentative & Total & Ticks & Mosq & Sandflies & ND & Flu-like & Ence & R.A & N/K \\
\hline ASF & 1 & - & - & 1 & 1 & - & - & - & - & - & - & 1 \\
\hline Total & $\mathbf{1}$ & $\mathbf{0}$ & $\mathbf{0}$ & $\mathbf{1}$ & $\mathbf{1}$ & $\mathbf{0}$ & $\mathbf{0}$ & $\mathbf{0}$ & $\mathbf{0}$ & $\mathbf{0}$ & $\mathbf{0}$ & $\mathbf{1}$ \\
\hline
\end{tabular}

\subsubsection{Arthropod vectors:}

Ticks are main arthropods vector (Hess, 1986).

\subsubsection{Vertebrate hosts:}

The warthogs are reservoir host for ASFV (Thomson, 1985; Hess, 1986)

\subsubsection{Human disease:}

Not reported (Loh et al., 2009).

\subsubsection{Animal disease}

Hog cholera (classical swine fever) in swine and wild boar (Schlafer and Mebus, 1984).

\subsubsection{Epidemiology:}

Worldwide (Costard, S.2009).

\subsubsection{Treatment:}

No treatment for ASF (Zaberezhnyı̌ et al., 2012)

\subsubsection{Vaccine}


There is no effective vaccine available for African swine fever (Penrith et al., 2013).

\subsubsection{Genome of Roboviruses and Arboviruses}

All these viral families have a RNA genome except of the family Asfarviridae that contains DNA (Table 21). Therefore, RNA viruses replication include high mutation and short replication times in compare to DNA viruses. RNA viruses are able to jump from its original host into a new host species and adapt to changing new environmental conditions.

Table 21. Genome of roboviruses and arboviruses

\begin{tabular}{|l|l|l|l|l|}
\hline Viral Family & Enveloped & Sence & Segments & Reference \\
\hline Arenaviridae & Yes & ssRNA (-) & Bisegmented (S and L) & (Buchmeier Mj, 2007) \\
\hline Asfarviridae & Yes & dsDNA & Non-segemnted & (Dixon et al., 2013) \\
\hline Bunyaviridae & Yes & ssRNA (-) & Tripartile (S, M and L) & (Nichol St, 2005) \\
\hline Flaviviridae & Yes & ssRNA (+) & Non-segmented & (Mukhopadhyay et al., 2005) \\
\hline Orthomixoviridae & Yes & ssRNA (-) & Six to Eight segmented & (Kawaoka Y., 2005) \\
\hline Reoviridae & No & dsRNA & Ten - twelve (size S,M and L) & (Verwoerd et al., 1972) \\
\hline Togaviridae & Yes & ssRNA (+) & Non-segmented & (Lee et al., 2014) \\
\hline
\end{tabular}

\subsubsection{Diagnosis of viral infections:}

Historically, the diagnosis of viral infections includes virus isolation in cell culture, the direct immunofluorescence and enzyme immunoassays methods. Recently, the polymerase chain reaction (PCR) has revolutionized the diagnosis of viral infections by increasing the detection sensitivity and enabling the detection of several viruses in parallel. However, the multiple steps necessary for performing conventional PCR make 
it too laborious and prone of contamination with the amplification product, generating false positives results. This problem was solved with the development of the real-time PCR. This method is based on DNA amplification in addition to a fluorescent agent that is detected in the same thermal cycler that the amplification occurs. This method requires no manipulation after amplification and is therefore called a closed system. The main advantages of this homogeneous system are: reducing the time required for the test the possibility of viral load and low risk of contamination with the amplified product (Böhland, 1992). However, the technology currently available for real-time PCR allows detection of only a few viruses in a single test. To solve this limitation, DNA microarray platform are been develop for the detection of several viral agents (Palacios et al., 2007). This method consists of detecting the viral genome by means of DNA probes, which are fixed on silica plates. The microarray platform has the potential to detect multiple viral agents. The number of viral agents that can be detected with the microarray platform far exceeds any other method currently available hundreds of thousands of probes can be printed on a sheet of $70 \times 20 \mathrm{~mm}$ to detect a large number of viral agents. 


\section{JUSTIFICATION}

Several viruses transmitted by rodents and arthropods cause permanent threat to human health; in addition, others new viruses could become emergent viruses. Therefore, there is a great interest in the development of method for early diagnosis of infection with these viruses. Traditional diagnostic methods can detect only one or few viruses in a single assay, turning the final diagnosis very slow and expensive when several assays are needed. The DNA microarray platform has emerged recently as a high-throughput method that can be use to screen up to thousand of pathogens in a single assay, providing a early and cheaper final diagnosis. 


\section{OBJECTIVES}

\subsection{GENERAL:}

To develop a DNA microarray platform for the detection of viruses transmitted by rodents and arthropods

\subsection{SPECIFIC:}

1) To develop a DNA microarray slide (RoboArboVirusChip) to target viruses from the Arenaviridae, Asfarviridae, Bunyaviridae, Flaviviridae, Reoviridae, Rhabdoviridae and Togaviridae families.

2) To prepare a control DNA microarray slide by using published probes.

3) To evaluate the RoboArboVirusChip and control slides by using laboratory reference viruses.

4) To determine the lower limit of detection of the RoboArboVirusChip.

5) To evaluate the applicability of the RoboArboVirusChip for detecting viruses in serum samples. 


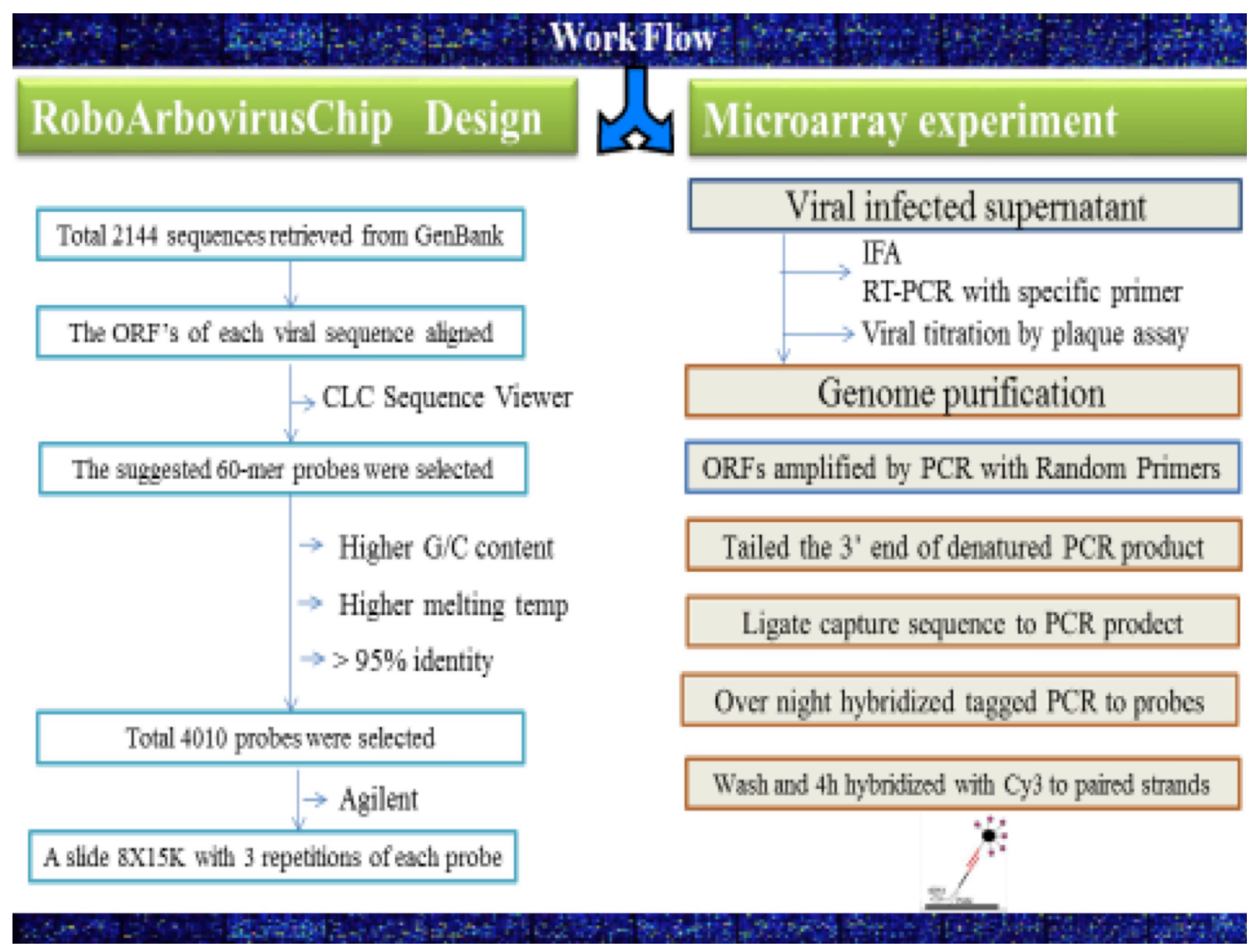

Figure 1. WORK PLAN. 


\section{MATERIAL AND METHODS}

\subsection{Viral reference Strains:}

The viral reference strains were available in a repository at the Center for Research in Virology (CPV), Faculty of Medicine of Ribeirao Preto (FMRP), Universityof Sao Paulo. A total 21 known viruses were used in this study (Table 22).

Table 22. Reference viruses used in this study.

\begin{tabular}{|c|c|c|c|c|c|c|}
\hline Family & Genus & Virus & Abbreviation & Strain & Cell & BSL \\
\hline \multirow[t]{3}{*}{ Bunyaviridae } & \multirow[t]{2}{*}{ Orthobunyavirus } & $\begin{array}{l}\text { Guaroa } \\
\text { virus }\end{array}$ & GROV & BeAn 277 & $\mathrm{C} 6 / 36$ & 2 \\
\hline & & $\begin{array}{l}\text { Oropouche } \\
\text { virus }\end{array}$ & OROV & BeAn19991 & C6/36 & 3 \\
\hline & Hantavirus & $\begin{array}{l}\text { Rio Mamore } \\
\text { virus }\end{array}$ & RIOMV & OM 556 & $\begin{array}{l}\text { VERO } \\
\text { E6 }\end{array}$ & 3 \\
\hline \multirow{11}{*}{ Flaviviridae } & \multirow{11}{*}{ Flavivirus } & $\begin{array}{l}\text { Bussuquara } \\
\text { virus }\end{array}$ & BSQV & BeAn 4073 & $\mathrm{C} 6 / 36$ & 2 \\
\hline & & $\begin{array}{l}\text { Dengue } \\
\text { virus type -1 }\end{array}$ & DENV-1 & Mochizuki & C6/36 & 2 \\
\hline & & $\begin{array}{l}\text { Dengue } \\
\text { virus type -2 }\end{array}$ & DENV-2 & $\begin{array}{l}\text { New } \\
\text { Guinea C }\end{array}$ & $\mathrm{C} 6 / 36$ & 2 \\
\hline & & $\begin{array}{l}\text { Dengue } \\
\text { virus type }-3\end{array}$ & DENV-3 & H87 & C6/36 & 2 \\
\hline & & $\begin{array}{l}\text { Dengue } \\
\text { virus type }-4\end{array}$ & DENV-4 & H 241 & C6/36 & 2 \\
\hline & & Iguape virus & IGUV & $\begin{array}{ll}\text { Span } & 71 \\
686 & \end{array}$ & $\mathrm{C} 6 / 36$ & 2 \\
\hline & & Ilheus virus & ILHV & $\mathrm{BeH} 7445$ & $\mathrm{C} 6 / 36$ & 2 \\
\hline & & Rocio virus & ROCV & SPH 34675 & $\mathrm{C} 6 / 36$ & 3 \\
\hline & & $\begin{array}{l}\text { St.Louis } \\
\text { encephalitis } \\
\text { virus }\end{array}$ & SLEV & $\begin{array}{l}\mathrm{BeH} \\
356964\end{array}$ & C6/36 & 3 \\
\hline & & $\begin{array}{ll}\text { West } & \text { Nile } \\
\text { virus } & \end{array}$ & WNV & NY99-4132 & C6/36 & 3 \\
\hline & & $\begin{array}{l}\text { Yellow fever } \\
\text { virus }\end{array}$ & YFV & $\begin{array}{l}\text { 17D } \\
\text { (vaccine) }\end{array}$ & $\mathrm{C} 6 / 36$ & 3 \\
\hline Rhabdoviridae & Vesiculovirus & Piry virus & PIRYV & BeAn24232 & $\mathrm{C} 6 / 36$ & 3 \\
\hline Togaviridae & Alphavirus & Mayaro & MAYV & BeAn243 & $\mathrm{C} 6 / 36$ & 2 \\
\hline
\end{tabular}




\begin{tabular}{|l|l|l|l|l|l|l|}
\hline & virus & & & & \\
\hline
\end{tabular}

4.2. Design of the DNA microarray slide for viruses transmitted by rodents and arthropods (RoboArboVirusChip)

\subsection{Database}

Roboviruses and arboviruses were selected from the virus taxonomy list of the International Committee on the taxonomy of viruses (ICTV 2011 Master Species List (MSL) released in February 2012 (E.J. San Diego, 2012) and from the Arbovirus Catalog-Virus section (Arbocat) (Https://Wwwn.Cdc.Gov/Arbocat/Virusbrowser.Aspx). All sequences of roboviruses and arboviruses available in the GenBank were retrieved for probes design. The obtained sequences belong to viruses within seven families and 13 genera: Family Bunyaviridae: Orthobunyavirus, Nairovirus, Phlebovirus and Hantavirus genera; family Flaviviridae: Flavivirus genus; family Reoviridae: Orbivirus, Coltivirus and Seadornavirus genera; family Rhabdoviridae: Vesiculovirus, Ephemerovirus genera; Togaviridae: Alphavirus genus; family: Asfarviridae, Asfarvirus genus; and family: Arenaviridae, Arenavirus genus. We have found 412 viral species, tentative or strains with sequences available in GenBank and we obtained total 2144 viral sequences from viruses mentioned above (Table 23). 
Table 23. Summary of viruses and sequences retrieved from GenBank.

\begin{tabular}{|c|c|c|c|c|c|c|}
\hline Family & Genus & $\begin{array}{l}\text { Vector } \\
\text { Arthropods/ } \\
\text { Rodents }\end{array}$ & $\begin{array}{l}\text { Number } \\
\text { of } \\
\text { viruses }\end{array}$ & $\begin{array}{l}\text { Number of } \\
\text { Sequences }\end{array}$ & $\begin{array}{l}\text { Number } \\
\text { of specific } \\
\text { probes }\end{array}$ & $\begin{array}{l}\text { Number } \\
\text { of generic } \\
\text { probes }\end{array}$ \\
\hline \multirow{4}{*}{ Bunyaviridae } & Orthobunyavirus & $\begin{array}{l}\text { Mosquitoes, } \\
\text { ticks and flies } \\
\text { Culicoides }\end{array}$ & 86 & 272 & 690 & 5 \\
\hline & Nairovirus & $\begin{array}{l}\text { Ticks, flies, } \\
\text { mosquitoes } \\
\text { culicidae }\end{array}$ & 14 & 41 & 100 & 6 \\
\hline & Phlebovirus & $\begin{array}{l}\text { Sandflies, } \\
\text { mosquitoes and } \\
\text { ticks }\end{array}$ & 56 & 262 & 627 & ND \\
\hline & Hantavirus & Rodents & 73 & 299 & 638 & 18 \\
\hline Flaviviridae & Flavivirus & $\begin{array}{l}\text { Mosquitoes and } \\
\text { ticks }\end{array}$ & 74 & 165 & 418 & 13 \\
\hline \multirow{3}{*}{ Reoviridae } & Orbivirus & $\begin{array}{l}\text { Sand flies, } \\
\text { mosquitoes and } \\
\text { ticks }\end{array}$ & 18 & 434 & 783 & 6 \\
\hline & Coltivirus & Ticks & 2 & 12 & 41 & ND \\
\hline & Seadornavirus & Mosquitos & 2 & 20 & 83 & ND \\
\hline \multirow{2}{*}{ Rhabdoviridae } & Vesiculovirus & $\begin{array}{l}\text { Sandflies and } \\
\text { mosquitoes }\end{array}$ & 18 & 20 & 122 & 11 \\
\hline & Ephemerovirus & Sandflies & 5 & 7 & 57 & ND \\
\hline Togaviridae & Alphavirus & Mosquitos & 29 & 386 & 130 & 8 \\
\hline Orthomixoviridae & Thogotovirus & Ticks & ND & ND & ND & ND \\
\hline Asfarviridae & Asfivirus & Culicoides & 1 & 100 & 17 & ND \\
\hline
\end{tabular}




\begin{tabular}{c|l|l|l|l|l|l}
\hline Arenaviridae & Arenavirus & Rodents & 41 & 126 & 503 & 20 \\
\hline Total & 14 & --- & $\mathbf{4 1 9}$ & $\mathbf{2 1 4 4}$ & $\mathbf{4 2 0 9}$ & $\mathbf{8 7}$ \\
\hline
\end{tabular}

ND: Not done

\subsection{Oligonucleotide Probe design}

For selection of specific probes, the relevant open reading frame of viral sequences from multiple genes including a highly conserved region corresponding to each viral species were aligned using the program CLC Main Workbench (CLCbio, USA). Alignment was analyzed using the CLC Main Workbench or SCPrimer (www.scprimer.cpmc.columbia.edu) programs. The suggested 60-mer probes were selected based on those having melting temperature $60-77^{\circ} \mathrm{C}$, higher $\mathrm{G} / \mathrm{C}$ pair content 40 to $60 \%$. For viruses with a single genome segment, up to 10 probes were selected; for those with more than one genome segment, up to three probes per segment were selected. For family Reoviridae, Orbivirus genus contains 10 segments; Coltivirus and Seadornavirus contain 12 segments. For these viruses, the probes were designed for VP2 (S-2), VP5 (S-6) and NS3 (S-10) segments. The sequences of the probes obtained were analyzed with the BLAST program (http://www.ncbi.nlm.nih.gov/) and those with $>95 \%$ identity with the virus in question was selected.

For selection of generic probes, sequences of representative viruses within each genus were aligned. These alignments were used to select generic 20-35-mer probes from conserved genomic regions as mentioned above.

\subsection{Preparation of RoboArboVirusChip}

The slide was drawn using the Agilent eArray program (Https://Earray.Chem.Agilent.Com/Earray/). The slide was designed in such a manner that Agilent added the necessary repetitions of each probe together with the positive and negative controls sequences by default to reach 15,000 probes per array. A slide containing eight arrays with 15,000 probes were designed. 


\subsection{Control slide (GreeneChipVr):}

The control slides were used for compare reference viruses with RoboArboVirusChip. The GreeneChipVr design for all viruses causes problem in vertebrates by Dr. W. Ian Lipkin group at the Mailman School of Public Health at Columbia University, New York-USA. The probes of the GreeneChipVr are available on the Gene Expression Omnibus (GEO) database with GEO number GPL10319 were used. The virus species corresponding to each probe is not indicated. For the identification of viral species, each probe was checked by BLAST. To prepare this slide in the same format of eight arrays with 15,000 probes/array, probes corresponding to various controls were removed. Remaining mostly, those corresponding to the virus.

\subsection{Preparation of viral stocks}

All viral infections were performed by using C6/36 or Vero E6 cell line, which were cultured in $5 \mathrm{ml}$ of medium Leibowitz L15. The C6/36 cells were grown 24 hours before infection in $25 \mathrm{~cm}^{2}$ flask and Vero E6 cells were in $25 \mathrm{~cm}^{2}$ tissue culture flask (vented cap) with 10\% inactivated fetal calf serum (FCS), 10\% tryptose phosphate broth (Oxid, England), $100 \mathrm{U} / \mathrm{ml}$ penicillin and $100 \mu \mathrm{g} / \mathrm{ml}$ streptomycin. The plate kept at $28^{\circ} \mathrm{C}$ for $\mathrm{C} 6 / 36$ cells and for Vero E6 kept in a humidified incubator at $30^{\circ} \mathrm{C}$ with $5 \%$ $\mathrm{CO}_{2}$. The culture medium was aspirated from a bottle and the cell monolayer was 3 times washed with 1x phosphate buffer solution (1X PBS), in order to remove dead cells and traces of fetal calf serum, After the cells became confluent, a monolayer was infected with $10 \mu \mathrm{l}$ of viral suspension then, the bottle was shaken every 15 minutes and incubated for 1 hour at $37^{\circ} \mathrm{C}$ so that the virus was absorbed. Then L-15 medium with $2 \%$ FCS was added and the cells were incubated at $37^{\circ} \mathrm{C}$. Viral infection allowed proceeding until the onset of cytopathic effect (CPE). The supernatant was collected for further use such as RNA extraction, RT-PCR, Real- time PCR, Viral titration and microarray experiments. The cells were harvested, viral infection was confirmed by RT-PCR and indirect immunofluorescence, the supernatants were centrifuged at 3,000 rpm for 5 minutes, supplemented with $20 \%$ FCS aliquot in to sterile tubes $(200 \mu 1)$ and stored at$80^{\circ} \mathrm{C}$ until use. 


\subsection{Confirmation of viral infection by indirect immunofluorescence}

The viral infected and normal cells (C6/36 or Vero E6) were harvested and cells washed 3 times with 1 XPBS by centrifugation at $1000 \mathrm{rpm}$ for 10 minutes at $4^{\circ} \mathrm{C}$, then cells were re-suspend in 1 XPBS and $20 \mu 1$ was dispensed onto immunofluorescent glass slides and allowed to air-dry at room temperature. Cells were fixed onto a slide and place in a coplin jar for 10 minutes containing 100\% cold acetone, then the cells were permeabilized to rapture cell wall in $0.2 \%$ Triton X-100 and 1\% FCS for 5 minutes in ice, then the cells were washed three times with $1 \mathrm{X}$ PBS containing $1 \%$ FCS for 10 minutes. Fixed cells were incubated with $20 \mu 1$ of a 1:100 dilution of primary antibody Mouse immune ascetic fluids (MIAF diluted in 3xPBS containing 3\% FCS) at $37^{\circ} \mathrm{C}$ in a humidified chamber for 1 hour to specifically binds the target molecule and then the cells were washed 3 times with 1X PBS containing 1\% FCS for 10 minutes. Thereafter, added $20 \mu 1$ of a 1/256 dilution of the secondary antibody which carries the fluorophore (antimouse IgG raised in rabbit were added, in conjunction with FITC), containing Evans blue dye $\left(1 / 20.000\right.$, diluted in blocking buffer) and the slide was incubated at $37^{\circ} \mathrm{C}$ in humidified chamber for 1 hour and again cells washed four times with 1XPBS for 10 minutes. Finally, mounted slides were visualized under a fluorescence microscope.

\subsection{Confirmation of viral infection by RT-PCR}

\subsubsection{Viral RNA extraction}

RNA from virally infected and uninfected cell cultures was purified by using AxyPrep viral RNA/DNA Miniprep Kit (Axigen, USA), following the protocol recommended by the manufacturer. The viral RNA was suspended in $60 \mu 1$ of elution buffer.

\subsubsection{The cDNA synthesis}

The reaction mixture for cDNA synthesis had a total volume $20 \mu 1$, contained $10 \mu 1$ of RNA, $15 \mathrm{ng} / \mu 1$ random primer (Invitrogen USA), $0.5 \mathrm{mM}$ dNTPs (Invitirogen USA) and added 1 drop of oil. The mixture was incubated at $95^{\circ} \mathrm{C}$ for 1 minute and 20 seconds and quickly cooled in ice for 5 minutes. Into this mixture, was added $4 \mathrm{mM}$ DTT, 4U RNase inhibitors (RNAseOUT, Invitrogen USA), 200U Reverse Transcriptase MMLV (Invitrogen, USA) and $4 \mu \mathrm{l}$ of $5 \mathrm{X}$ buffer $(250 \mathrm{mM}$ Tris-HCL [pH 8,3], 375mM 
$\mathrm{KCl}, 15 \mathrm{mM} \mathrm{MgCl} \neg 2)$. Mixture was incubated at $25^{\circ} \mathrm{C}$ for 10 minutes; second incubation cycle was performed at $37^{\circ} \mathrm{C}$ for 1 hour and $85^{\circ} \mathrm{C}$ for 5 minutes in a Thermo cycler (BIO-RAD, USA). The cDNA was treated with $1 \mathrm{U}$ RNase $\mathrm{H}$ at $37^{\circ} \mathrm{C}$ for 30 minutes and stored at $-20^{\circ} \mathrm{C}$ until use.

\subsection{The reverse-transcription PCR amplification}

The final volume of the PCR reaction mixture was $50 \mu 1$, contained: $4 \mu 1 \mathrm{cDNA}$, $0.2 \mathrm{mM}$ dNTPs, $0.3 \mu \mathrm{M}$ primer sense and complementary for (Bronzoni et al., 2005), (Ref of Piry, Oropauche and Iguape) 1.5 U enzyme Platinum Taq DNA Polymerase High Fidelity (Invitrogen, USA), 10X buffer (600mm Tris-SO4 [pH 8.9], 180mM NH4 SO4) suitable for each enzyme and $2 \mathrm{mM} \mathrm{Mg} 2 \mathrm{SO}$. Amplification was performed using thermo cycler MyCycler (BIO-RAD, USA). The reaction mixture was heated at $94^{\circ} \mathrm{C}$ for 2 minutes and the temperature profile for PCR was as follow:

$94^{\circ} \mathrm{C}$ for 30 seconds $\quad$ Initial denaturation

$56^{\circ} \mathrm{C}$ for 01 minute $\quad$ Denaturation $\quad 45$ cycles

$68^{\circ} \mathrm{C}$ for 05 minutes Annealing \& Extension

the reaction ending with a final extension at $68^{\circ} \mathrm{C}$ for 7 minutes.

\subsection{Visualization of DNA:}

An aliquot of $10 \mu 1$ of the amplification products were evaluated by electrophoresis, loaded on $1.8 \%$ agarose gel (Pronadisa,Spain) in $40 \mathrm{mM}$ Tris-Acetate$1 \mathrm{mM}$ EDTA (TAE) buffer. The bands of DNA were achieved through gel stained with GelRed and visualized with UV light.

\subsection{Determination of the viral infectivity titer by plaque assay}

A total 15 viruses were titrated by Plaque assay (Burleson, 1992). VERO E6 cells were washed 3 times with sterile 1X PBS and trypsinized, seeded cells were grown in 24-well plate $\left(2 \times 10^{5}\right.$ cells/wells) in L-15 medium supplemented with $10 \%$ FBS and plates were incubated at $28^{\circ} \mathrm{C}$ with $5 \% \mathrm{CO}_{2}$ in an incubator. For each dilution, $2 \mathrm{ml}$ sterile tubes were used with decade dilutions from $1^{-1}$ to $10^{-10}$ and added to $900 \mu \mathrm{l}$ of L15 medium without FCS. One hundred $\mu 1$ of the viral supernatant were added to the first 
vortex tube. Plates were checked under a light microscope to confirm $>70 \%$ confluence and homogenous cell distribution, medium was aspirated from the cells with a sterile Pasteur pipette without disturbing the cells by vacuum. The cells were infected with $400 \mu 1 /$ well of 10 -fold serially diluted virus in duplicate, $400 \mu 1$ of L-15 medium was added without FCS as a negative control and $100 \mu$ l of viral supernatant was used as positive control and incubated 1 hour at $28^{\circ} \mathrm{C}$ with $5 \% \mathrm{CO}_{2}$ in an incubator. After anincubation period, supernatant was carefully aspirated out from the cells with a sterile Pasteur pipette; the monolayers were covered with a nutrient medium containing agar. It One thousand $\mu \mathrm{l}$ of carboxymethyl-cellulose (CMC) was added to each well. This solution was prepared with $1.8 \%$ of CMC in $2 \mathrm{X} \mathrm{L-15}$ medium containing $2 \%$ of FCS and $1 \%$ of antibiotic $(\mathrm{Ab})$ and the cells were incubated as per virus plaque forming character 3 to 10 days post infection at $28^{\circ} \mathrm{C}$ with $5 \% \mathrm{CO}_{2}$ in an incubator. The medium was removed and the cells were fixed and stained by addition of $200 \mu$ of black naphthalene dye that remained in contact with the cells for 40 minutes at room temperature in a mixer. The dye was aspirated and the cells were dried at room temperature. The lysed plates were quantified by viewing under a stereoscopic microscope and the light areas of cell foci were counted to calculate the viral titer expressed as plaque forming units per $\mathrm{ml}(\mathrm{PFU} / \mathrm{ml})$.

\subsection{Dengue virus RNA detection and quantification: Quantitative real-time RT-}

\section{PCR (qRT-PCR)}

Viral RNA detection was carried out by real-time RT-PCR using the SuperScript III Platinum SYBR Green One-Step qRT-PCR kit (Invitrogen, USA), as previously described (Dos Santos et al., 2008). Briefly, the $25-\mu \mathrm{L}$ reaction mixture contained $0.5 \mu \mathrm{L}$ of SuperScript III RT Platinum Taq Mix, $0.2 \mathrm{mM}$ of each primer, 12.5 $\mu \mathrm{L}$ of $2 \mathrm{X}$ SYBR Green, and $5 \mu \mathrm{L}$ of purified RNA. The amplification program was as follows: $50^{\circ} \mathrm{C}$ for $20 \mathrm{~min}$ for reverse transcription, $95^{\circ} \mathrm{C}$ for $5 \mathrm{~min}$ for reverse transcriptase inhibition and Taq DNA polymerase activation, followed by 45 cycles of PCR amplification with denaturation at $95^{\circ} \mathrm{C}$ for $15 \mathrm{sec}$, annealing at $60^{\circ} \mathrm{C}$ for $40 \mathrm{sec}$, and extension at $72^{\circ} \mathrm{C}$ for 30 sec. Finally, to verify the specificity of the PCR products, a melting curve was 
constructed by incubating the amplification products from $60^{\circ} \mathrm{C}$ to $90^{\circ} \mathrm{C}$ with an increase of $0.2^{\circ} \mathrm{C} / \mathrm{sec}$. The melting temperature (Tm) values of the specific amplicons were in the range of $80.57^{\circ} \mathrm{C}-81.73^{\circ} \mathrm{C}$. For viral load determination, a standard curve was constructed using RNA transcribed in vitro from a plasmidial clone containing a fragment of 2500 base pairs (bp) corresponding to the 5' end of DENV-3 strain D3BR/RP1/2003 (Aquino et al., 2006). This plasmid was prepared as follows: the 2500bp fragment was amplified by RT-PCR and inserted into the plasmid pXL (Invitrogen, USA), which was used to transform Escherichia coli. An aliquot of $250 \mu \mathrm{L}$ of the bacteria was inoculated into $10 \mathrm{~mL}$ of $\mathrm{LB}+$ ampicillin medium, followed by incubation at $37^{\circ} \mathrm{C}$ for $14 \mathrm{~h}$ with shaking. The plasmid was purified using the QIAGEN Plasmid Mini Kit (Qiagen, Germany) following the manufacturer's recommendations. The plasmid was linearized by digestion with Bam HI, subjected to electrophoresis through a $1 \%$ agarose gel, and purified from the gel using the QIAquick Gel Extraction Kit (Qiagen, Germany) following the manufacturer's specifications. For RNA preparation, $1 \mu \mathrm{g}$ of the linearized plasmid was transcribed using RNAMaxx High Yield Transcription Kit (Stratagene, USA) following the manufacturer's specifications. The cDNA was digested using RQ DNase (Promega, USA) at $37^{\circ} \mathrm{C}$ for $20 \mathrm{~min}$. After this, the RNA was purified using the QIAamp Viral RNA Kit (QIAGEN, Germany), and the concentration was determined by spectrophotometry at $260 \mathrm{~nm}$. Based on the concentration and size of the RNA product $(2500 \mathrm{bp}$ ), the copy number equivalent to the genomic RNA was calculated. Serial decimal dilutions of this RNA were prepared to construct the standard curve by real-time RT-PCR for determination of the virus titer, which was expressed in copy numbers per milliliters. 


\subsection{Serum samples}

The human serum samples were used for the determination of Dengue virus in this study from serum bank at our virology laboratory called "Arbovirus". All these samples were collected during year 2006-2014 from deferent primary health care centers at Ribierao Preto.

\subsection{Microarray experiment}

\subsubsection{Positive RNA Spike controls}

The Agilent RNA spike positive controls are optimized to anneal to complementary probes on the microarray with minimal self-hybridization or crosshybridization. The Spike-In probe sets were designed not to have complementary sequences to the biological samples used on most microarrays, even to the viruses included in our array. The RNA spike control was diluted 1:5000 for use in the experiment.

\subsection{6. cDNA synthesis (Reverse Transcription):-}

The synthesis of cDNA was performed using a random primer eight nucleotides linked to an artificial specific sequence (SIA, 5 'TAG GTC CAG TCC GTT TCN NNN NNN N3') (Bohlander et al., 1992). The reaction mixture for synthesis of cDNA ( total volume of $25 \mu \mathrm{l}$ ) contained: $12 \mu \mathrm{l}$ of viral RNA, $1.2 \mathrm{mM}$ CIA random primers (Invitrogen, USA), $2 \mu 1$ of 1:5000 dilution of Spike (Agilent, USA), $0.4 \mathrm{mM}$ dNTPs (Invitrogen, USA), 40 U RNAse inhibitor (RNAseOUT, Invitrogen, U.S.), 4 mM DTT, $200 \mathrm{U}$ of M-MLV reverse transcriptase (Invitrogen,USA) and $5 \mu 1$ of $5 \mathrm{X}$ buffer $(250 \mathrm{mM}$ Tris- $\mathrm{HCl}$ [pH 8.3], 375mM KCl, $15 \mathrm{mM} \mathrm{MgCl} 2$ ). The mixture was incubated at $25^{\circ} \mathrm{C}$ for 10 minutes followed by incubation at $37^{\circ} \mathrm{C}$ for 2 hours and finally at $85^{\circ} \mathrm{C}$ for 5 minutes.

\subsection{The polymerase chain reaction (PCR) amplification}

The PCR mixture contained in a ratio of 1:9 primers SIAN (5 'GTA GCA CGT TTC CCA GGT CTC 3'), the latter recognizes a specific region of primer SIA. The PCR reaction mix had a final volume of $50 \mu 1$, containing $4 \mu \mathrm{l}$ of cDNA, $2 \mathrm{mM} \mathrm{MgCl} 2,0.2$ mM dNTP, 5U enzyme Platinum Taq DNA Polymerase (Invitrogen, USA), $5 \mu 1$ of 10X 
buffer (SO4 600mm Tris [pH 8.9], NH4 SO4 180mM) suitable for each enzyme. Amplification was performed using Thermo Cycler MyCycler (BIO-RAD, USA). The reaction mixture was submitted to 8 cycles of $94^{\circ} \mathrm{C}$ for 30 seconds, $25^{\circ} \mathrm{C}$ for 1 min and $72^{\circ} \mathrm{C}$ for 1 minute, followed by 35 cycles at $94^{\circ} \mathrm{C}$ for 30 seconds, $55^{\circ} \mathrm{C}$ for 1 minute, and $72^{\circ} \mathrm{C}$ extension for 1 minute.

\subsection{Purification of PCR product}

PCR products were purified with Wizard SV Gel and PCR Clean-Up System (Progmega, USA) following the manufacturer's recommendations. The PCR product was eluted with $15 \mu \mathrm{l}$ of RNase /DNase free water, before proceeding with the labeling reaction.

\subsection{Addition of the poly - T tail:}

The PCR products were attached to a poly-T tail. To this new product, $10 \mu 1$ of the modified PCR product was added to $6.5 \mu \mathrm{R}$ Rase/DNase free water and incubated at $95^{\circ} \mathrm{C}$ for 2 minutes for opening the double-stranded DNA, the product was then transferred in ice for 2 minutes. Then, $8.5 \mu \mathrm{l}$ of a mixture containing $2.5 \mu \mathrm{l}$ of $10 \mathrm{X}$ Tailing buffer, $0.8 \mathrm{mM}$ dTTP, (Genisphere, USA) and $2 \mu \mathrm{l}$ of the enzyme terminal deoxynucleotidyl transferase (Genisphere, USA) were added. The reaction mixture was incubated at $37^{\circ} \mathrm{C}$ for 30 minutes and subjected immediately to a connection process.

\subsection{Ligation of 3 DNA capture sequence}

The DNA with the poly-T tail $(25 \mu \mathrm{l})$ was heated at $95^{\circ} \mathrm{C}$ for 10 minutes and immediately transferred in ice for 2 minutes. Subsequently the mixture was added to $5 \mu 1$ link (Cy3) and $2 \mathrm{U}$ of T4 DNA ligase in each sample, which was then incubated at $25^{\circ} \mathrm{C}$ for 30 minutes. In order to stop the reaction, EDTA was added to obtain a final concentration of $300 \mathrm{mM}$. The mixture was then homogenized and the volume was adjusted with $1 \mathrm{X}$ TE buffer to a final volume of $50 \mu$. 


\subsection{Purification of Tagged DNA}

The tagged DNA was purified with Wizard SV Gel and PCR Clean-Up System (Progmega, USA) following the manufacturer's recommendations. The PCR product was eluted with $15 \mu \mathrm{l}$ of RNase/DNase free water.

\subsection{DNA Hybridization}

The hybridization buffers (Genisphere, USA) were thawed, heated at $65^{\circ} \mathrm{C}$ for 10 minutes, homogenized by vortexing and subjected to a brief centrifugation before use. A mix containing $10 \mu \mathrm{l}$ of nuclease free water (Genisphere, USA) and $20 \mu \mathrm{l}$ of $2 \mathrm{X}$ hybridization buffer (Genisphere, USA) were added to $10 \mu 1$ of the PCR product. This mixture was heated at $80^{\circ} \mathrm{C}$ for 10 minutes and then added onto the gasket (Agilent, USA) and subsequently the microarray slide (RoboArboVirusChip) was mounted on the gasket hybridization chamber and incubated overnight at $65^{\circ} \mathrm{C}$ in a hybridization oven with a rotation of $15 \mathrm{rpm}$.

\subsection{First Wash Post cDNA Hybridization}

After hybridization, slides were washed three times to remove non-hybridized PCR products. The wash solution ( $2 \mathrm{X} \mathrm{SSC}, 0.2 \% \mathrm{SDS}$,) was first heated to $65^{\circ} \mathrm{C}$. The gasket and the RoboArboChip were removed and washed for 15 minutes in a pre-heated buffer ( $2 \mathrm{X} \mathrm{SSC}, 0.2 \% \mathrm{SDS}$ ). Subsequently, the slide was washed for 15 minutes at room temperature in $2 \mathrm{X} \mathrm{SSC}$ and finally for 15 minutes with $0.2 \mathrm{X} \mathrm{SSC}$. The slide was then transferred to a $50 \mathrm{ml}$ tube and centrifuged at $1000 \mathrm{rpm}$ for 2 minutes for drying.

\subsection{Hybridization of 3DNA dendrimers}

For this second hybridization, $2,5 \mu$ of capture reagent of 3DNA dendrimer were mixed with $20 \mu \mathrm{l}$ of $2 \mathrm{X}$ hybridization buffer (Genisphere, USA) and $17.5 \mu \mathrm{l}$ RNase/DNase free water to a final volume of $40 \mu$. The mixture was incubated at $80^{\circ} \mathrm{C}$ for 10 minutes and then applied to the array. The RoboArboChip was again mounted on the hybridization chamber and incubated at $65^{\circ} \mathrm{C}$ in a hybridization oven with a rotation of $15 \mathrm{rpm}$ for 4 hours. This was followed by washing the slide in the dark as mentioned above. 


\subsection{Slide scan and data analysis}

The slide was scanned at $532 \mathrm{~nm}$ using the Axon GenePix 4000B scanner (Molecular Devices, USA) with $10 \mu$ pixel resolution. The obtained image was analyzed with software GenePix Pro 7 to obtain data of fluorescence intensity of each point. Briefly, the GenePix Array List "gal file", containing the list of probes, was open generating the feature grid, which was positioned on the microarray image and then the fluorescence intensity of spots were obtained. The obtained data were analyzed with the program DetectiV (Watson et al., 2007). Two kinds of files were used, one containing the probes ID and intensities and the other containing the probes annotation file, which has information about species, genus and family of each probes. Probe intensity values were $\log 2$ transformed. The mean intensity of the negative control was calculated and used to divide the intensity of the probes for normalization. In case a virus is not present in the sample, it is expected the probes value for this virus to be equal to zero. To analyze if the probes intensity was significantly different from zero, a t-test was carried out. Results were first filtered such that groups had a normalized $\log 2$ ratio greater than or equal to 1 (a ratio of two to the control) and then sorted by $p$-value.

\subsubsection{Estimated the sensitivity of RoboArboVirusChip and comparison with control slide and qReal-time PCR}

The sensitivity of RoboArboVirusChip was compare with control slide. A control slide was designed using sequences available on the slide GreeneChip database Gene Expression Omnibus (GEO) database. The platform selected was GPL10319, which have 45,000 probes. However, the virus species corresponding to each probe is not indicated. For the identification of viral species, each probe was checked by BLAST. To prepare this slide in the same format of eight arrays with 15,000 probes / array, probes corresponding to various controls were removed. Remaining mostly, those corresponding to the virus. In this experiment, we were selected DENV-4 titrated stocks. AxyPrep viral RNA/DNA Miniprep Kit (Axigen, USA) purified total RNA. The RNA were diluted in 10 folds serial dilutions and dilutions $10^{-3}$ to $10^{-8}\left(4.2 \times 10^{8}\right.$ to $4.2 \times 10^{1} \mathrm{PFU} / \mathrm{mL}$ ) were used for both slides. All steps same as mention above follow for microarray experiment. 


\subsection{Detection of mixture of viruses}

We used viral RNA of twelve viruses divided in to three pools to evaluate the ability of the RoboArboVirusChip to detect mixture of viruses in a single sample. First pool was mix of viruses represented from three families; BSQV and SLEV (Flaviviridae), PIRYV (Rhabdoviridae) and MAYV (Togaviridae). Second pool was purely belong to flaviviruses: ROCV, SLEV, YFV and DENV-2 and third pool included was the four DENV serotypes: DENV-1, DENV-2, DENV-3 and DENV-4. All viral RNAs derived from cell culture were purified separately and $2.5 \mu$ from each virus were mixed and used for cDNA synthesis. The PCR amplification and microarray experiment were performed as mention above.

\subsection{Clinical serum samples}

Dengue positive $(n=4)$ and negaive $(n=40)$ serum samples from dengue suspected cases confirmed by RT-PCR were included in the study. All these samples were collected during 2006 - 2012 from deferent primary health care centers at Ribierao Preto and stored in the serum repository of the Virologoy Laboratory at the FCFRP-USP. This study was approved by the Ethical Committee of the FCFRP-USP (CEP/FCFRP $\mathrm{n}^{\circ} 313$ ). 


\section{RESULTS}

\subsection{Preparation of viral stocks}

A total 15 viruses were propagated in C6/36 mosquito cell line for the preparation of viral stocks, which were used for the validation, Lower limits of detection and pools of the RoboArboVirusChip.

\subsection{Confirmation of viral infection by indirect immunofluorescence}

The infected mosquito $\mathrm{C6} / 36$ cells with all viruses were confirmed by indirect immunofluorescence and RT-PCR as illustrated in Figures 2 and 3, respectively.
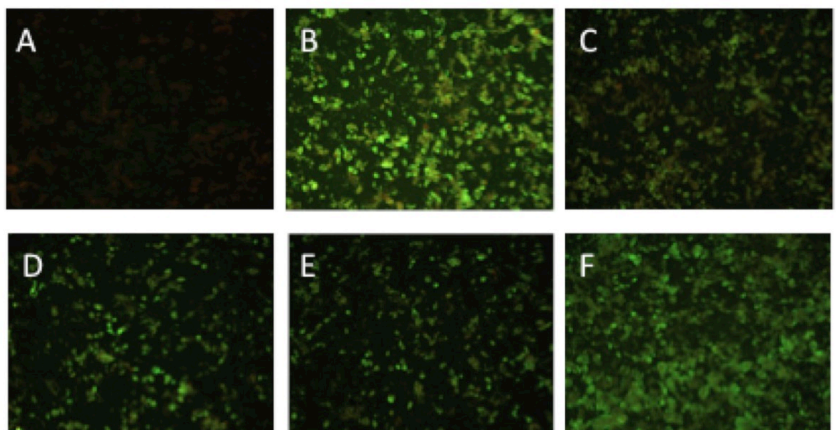

Figure 2. Indirect immunofluorescence demonstrating infection in C6/36 cells with DENV-2 (B), (C) SLEV, (D) YFV,(E) OROV, and (F) PIRY. (A) Negative control.

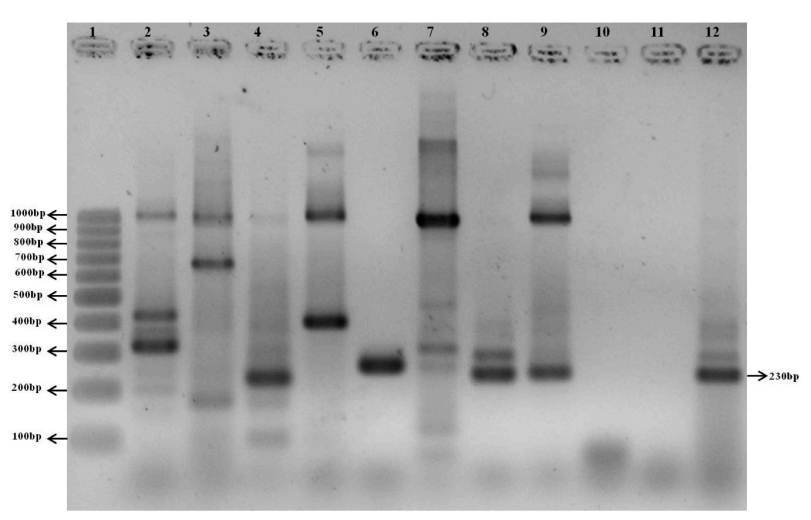

Figure 3. Electrophoresis on $1.8 \%$ agarose gel showing the DNA bands with the molecular-weight marker as well as negative, positive controls and viruses lane1Marker, lane-2 DENV-2 (band size 316bp), lane-3 DENV-3 (659bp), lane 4 DENV4(222bp), lane-5 Busuquara (388bp), lane-6 YFV(253bp),lane -7 Ilheus (474bp). Lane-8 Rocio (230bp), lane -9 SLEV (232bp), lane-10 Negative control-1(during RNA extraction), lane-11 Negative control and lane- 2 Positive control (Rocio virus). 


\subsection{Determination of viral titer by plaque assay}

Viral titer of stocks supernatant was determined by the plaque assay and this supernatant was used for the lower limit of detection of the RoboAboVirusChip (Table 24).

Table 24. Reference virus titers.

\begin{tabular}{|c|c|c|c|c|c|}
\hline Family & Genus & Virus & $\begin{array}{l}\text { CPE/ } \\
\text { Days }\end{array}$ & $\begin{array}{l}\text { Number } \\
\text { of } \\
\text { plaques }\end{array}$ & $\begin{array}{l}\text { Viral } \\
\text { titer in } \\
\text { PFU/ml }\end{array}$ \\
\hline \multirow[t]{3}{*}{ Bunyaviridae } & Orthobunyavirus & Oropouche virus & 8 & $5 / 2=2.5$ & $6.25 \times 10^{7}$ \\
\hline & & Guaroa virus & 7 & $13 / 2=6.5$ & $1.6 \times 10^{7}$ \\
\hline & Hantavirus & Rio Mamore virus & & & $3.0 \times 10^{5}$ \\
\hline \multirow[t]{10}{*}{ Flaviviridae } & Flavivirus & Dengue virus type 1 & 5 & $4 / 2=2$ & $5.0 \times 10^{4}$ \\
\hline & & Dengue virus type 2 & 10 & $2 / 2=1$ & $2.5 \times 10^{8}$ \\
\hline & & Dengue virus type 3 & 10 & $4 / 2=2$ & $5 . \times 10^{6}$ \\
\hline & & Dengue virus type 4 & 10 & 27 & $6.75 \times 10^{11}$ \\
\hline & & Yellow fever virus & 7 & $20 / 2=10$ & $2.5 \times 10^{11}$ \\
\hline & & Bussuquara virus & 8 & $16 / 2=8$ & $2.0 \times 10^{4}$ \\
\hline & & Iguape virus & & & $3.4 \times 10^{6}$ \\
\hline & & Ilheus virus & 6 & $18 / 2=9$ & $2.5 \times 10^{11}$ \\
\hline & & Rocio virus & 7 & 3 & $7.5 \times 10^{10}$ \\
\hline & & $\begin{array}{l}\text { St.Louis encephalitis } \\
\text { virus }\end{array}$ & 7 & $8 / 2=4$ & $1.0 \times 10^{9}$ \\
\hline Rhabdoviridae & Vesiculovirus & Piry virus & 7 & $15 / 2=7.5$ & $1.875 \times 10^{4}$ \\
\hline Togaviridae & Alphavirus & Mayaro virus & 6 & 1 & $2.5 \times 10^{5}$ \\
\hline
\end{tabular}

\subsection{Design of probes for RoboArboVirusChip V1 (version 1) and control slides}

In first version of RoboArboVirusChip V1 we selected viruses from five families and eight genera: Arenaviridae, Arenavirus genus; Bunyaviridae, Orthobunyavirus, Nairovirus, Phlebovirus and Hantavirus genera; Flaviviridae, Flavivirus genus, Rhabdoviridae, Vesiculovirus genus and Togaviridae, Alphavirus genus. A total 1718 specific viral oligonucleotide probes targeting 239 viruses were designed. In addition, we designed a control slide based on the GreeneChipVr probes list deposited in the GEO 
data base (GPL10319). Both RoboArboVirusChip and GreeneChipVr were prepared in a format of eight arrays per slide.

\subsection{Implementation of microarray method: Control slide}

In the first microarray experiment, we evaluated the performance of the control slide with cDNA and PCR products of four viruses: DENV-2, DENV-3, YFV and BUSV. The cDNA and PCR products were hybridized against the probes contained in the slide arryas. The PCR known products were obtained with primers that amplify a specific a genomic region. The slide was scanned to obtain fluorescence intensity image (Figure 4).

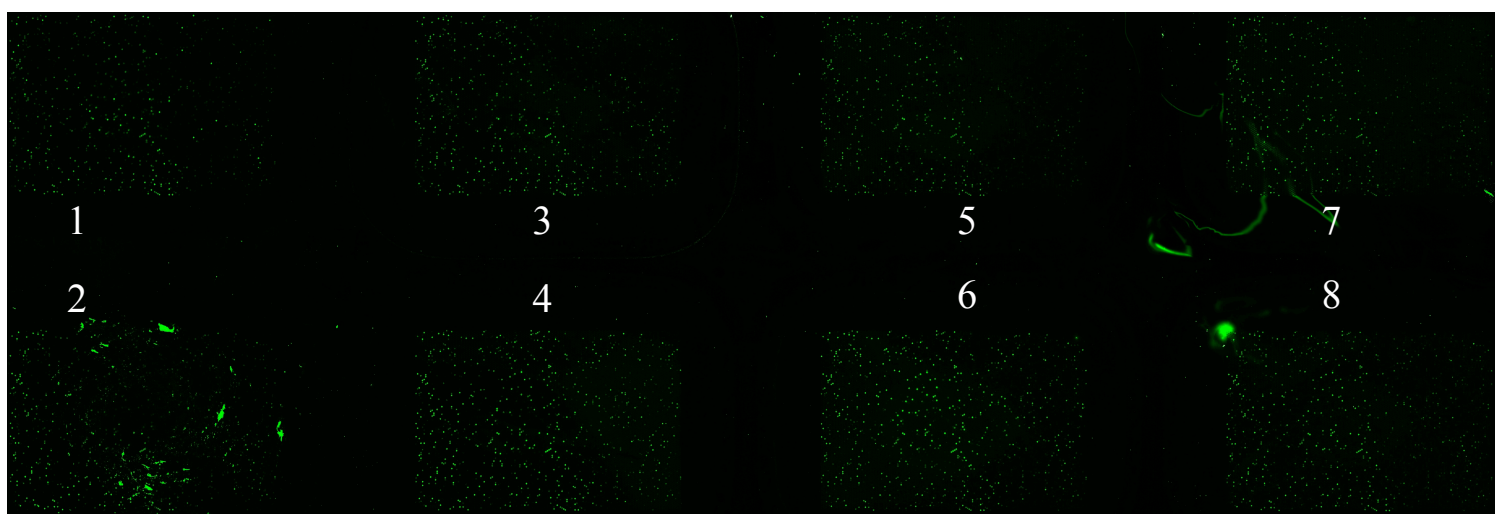

Figure 4. Microarray control slide with 8 arrays scanned at $532 \mathrm{~nm}$. 1. DENV-3 (PCR); 2. DENV-3 (PCR); 3. DENV-2 (cDNA); 4. DENV-3 (cDNA); 5. YFV (cDNA); 6. BUSV (cDNA); DENV-2 (cDNA); and 7. YFV (cDNA).

Figure 5 shows the presence of fluorescence in several spots within the arrays, but also the presence of artifact, which might be due to problem during the washing steps. The feature data from the scanned image was extracted and analyzed with the program GenePix Pro7. Spots with artifacts were excluded from the analysis. The visualization of fluorescence intensity and significant analysis was carried out with the DetectiV program. Figures 6-13 show the visualization of spots fluorescence intensity grouped by family, genus and species levels. While Table 22-29 show the significant analysis of probes for each virus target sorted by $p$-values. 


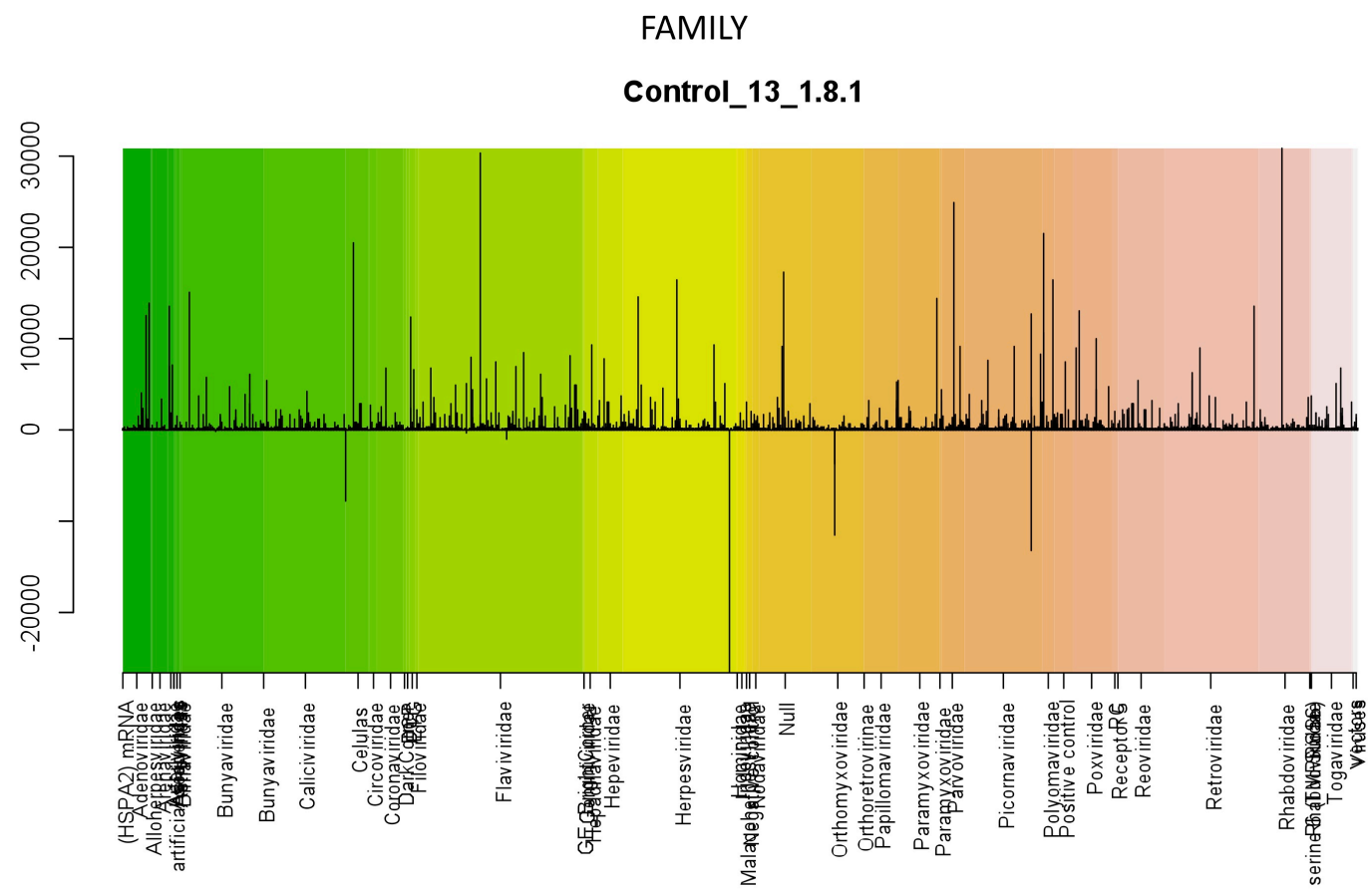

GENUS

Control_13_1.8.1

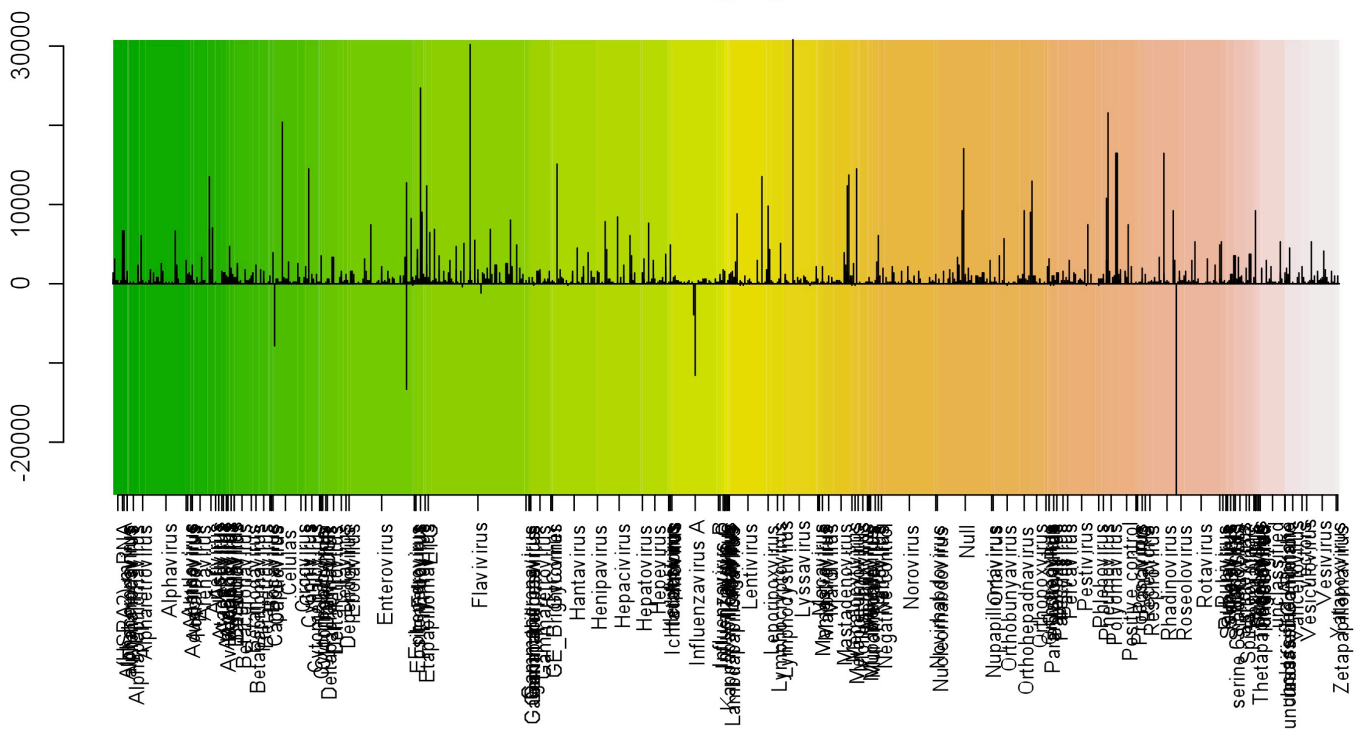


SPECIES

Control_13_1.8.1

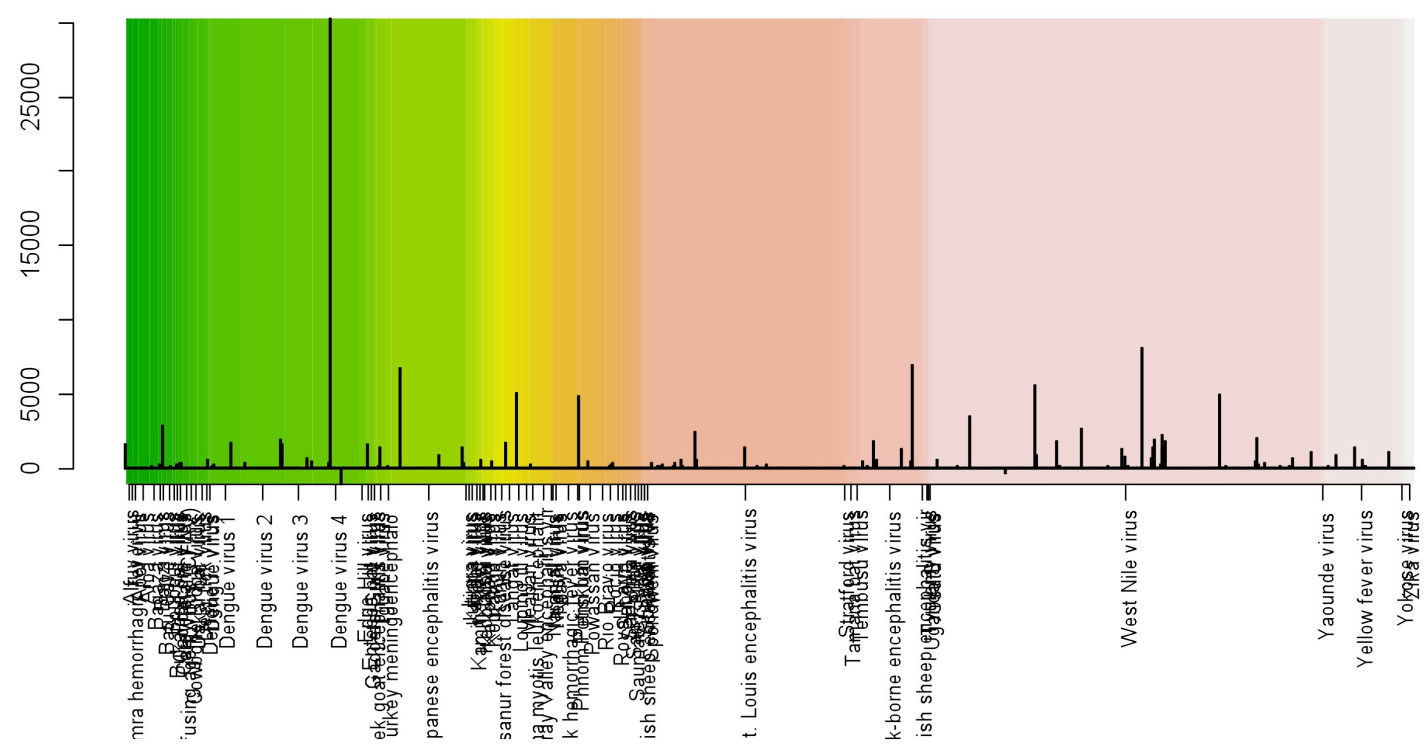

Figure 5. Visualization of probes fluorescence intensity of control slide hybridized with DENV-3 (genomic region: 1-950 bp). Data were sorted by family, genus and species levels.

Table 25. Significant analysis of array hybridized with DENV-3. The top 10 viruses with lowest $p$-values.

\begin{tabular}{cccc}
\hline Virus & No. of probes & p-value & Average \\
\hline Lambdapapillomavirus 1 & 5 & 0,0148112 & 2,29 \\
Foot-and-mouth disease virus & 6 & 0,017701354 & 2,22 \\
Striped bass reovirus & 7 & 0,02206254 & 1,65 \\
Avian carcinoma virus & 5 & 0,028607965 & 1,45 \\
Carey Island virus & 3 & 0,030997797 & 2,07 \\
Cebus albifrons lymphocryptovirus 1 & 4 & 0,035129362 & 2,08 \\
Atractoscion nobilis nervous necrosis virus & 5 & 0,039452058 & 1,51 \\
Porcine rubulavirus & 5 & 0,039655445 & 1,18 \\
Murine rotavirus EMcN & 3 & 0,040393312 & 1,86 \\
Vaccinia virus Tian Tan & 3 & 0,042275962 & 2,56 \\
\hline
\end{tabular}


FAMILY

Control_13_2.8.1

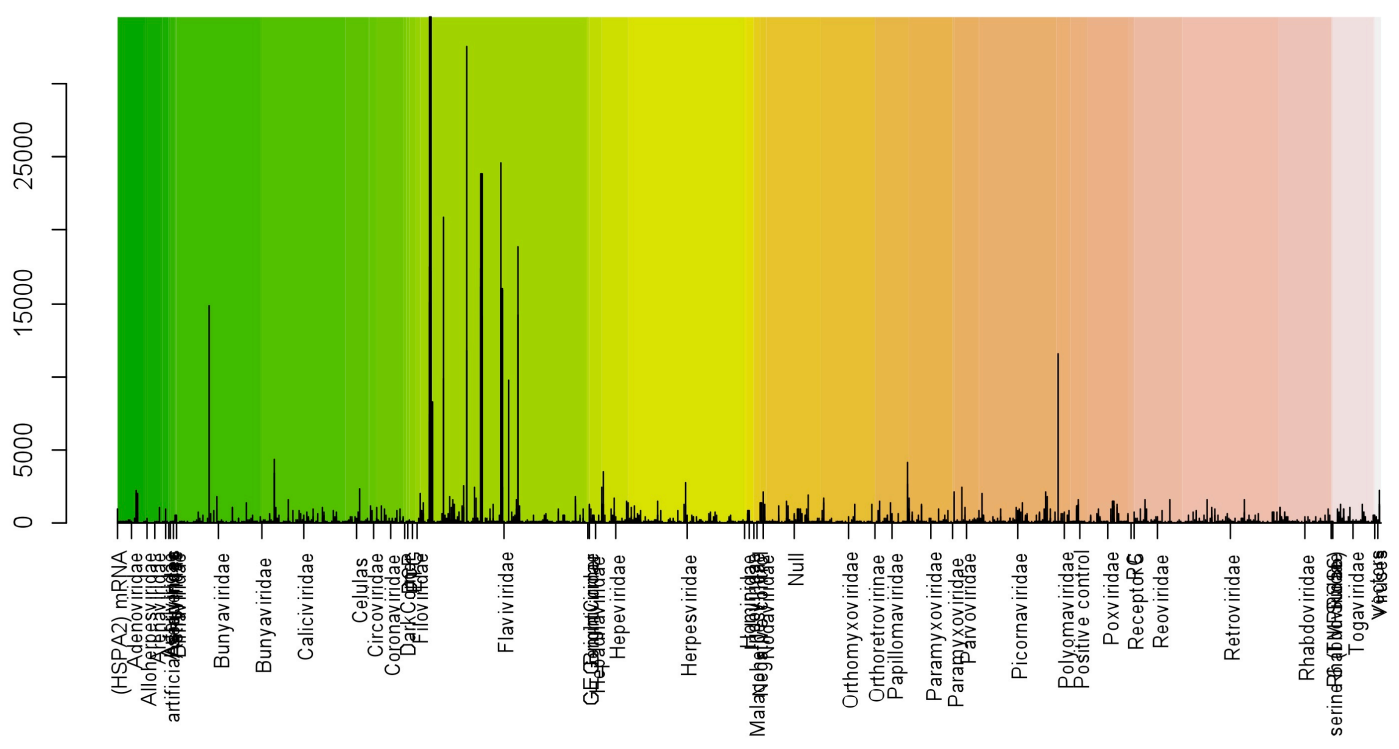

GENUS

Control_13_2.8.1

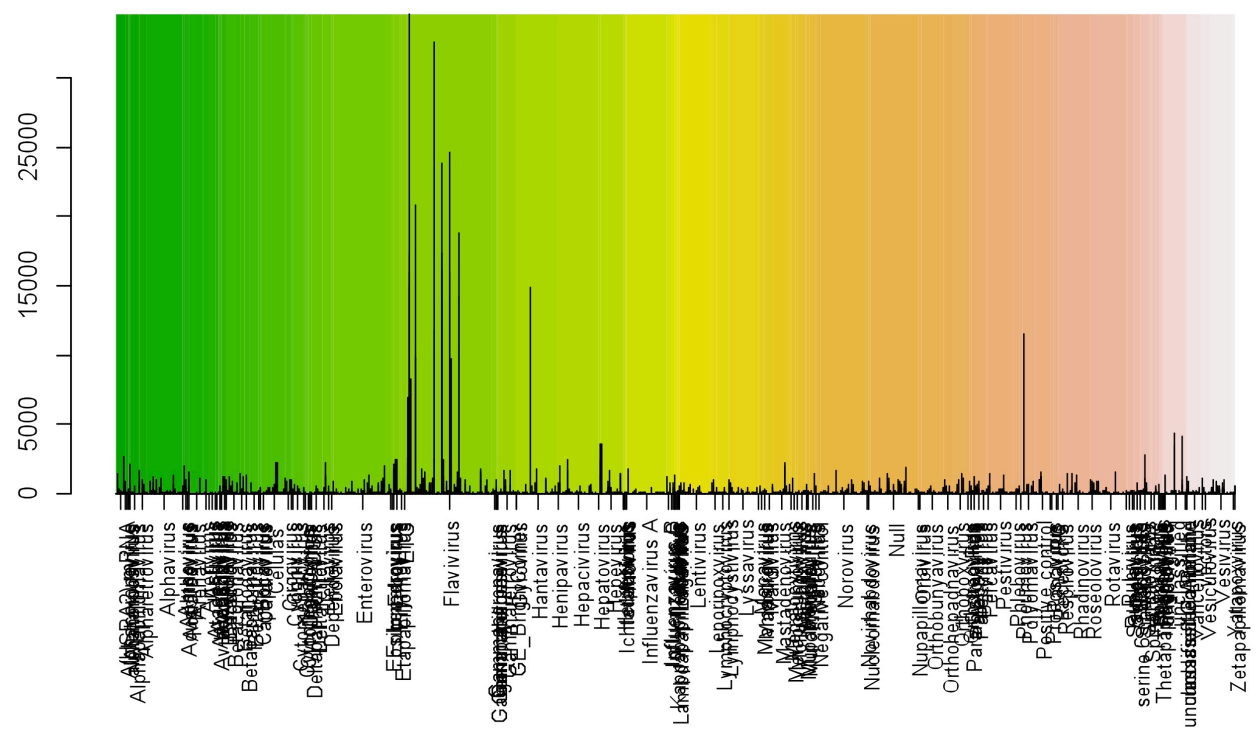


SPECIES

Control_13_2.8.1

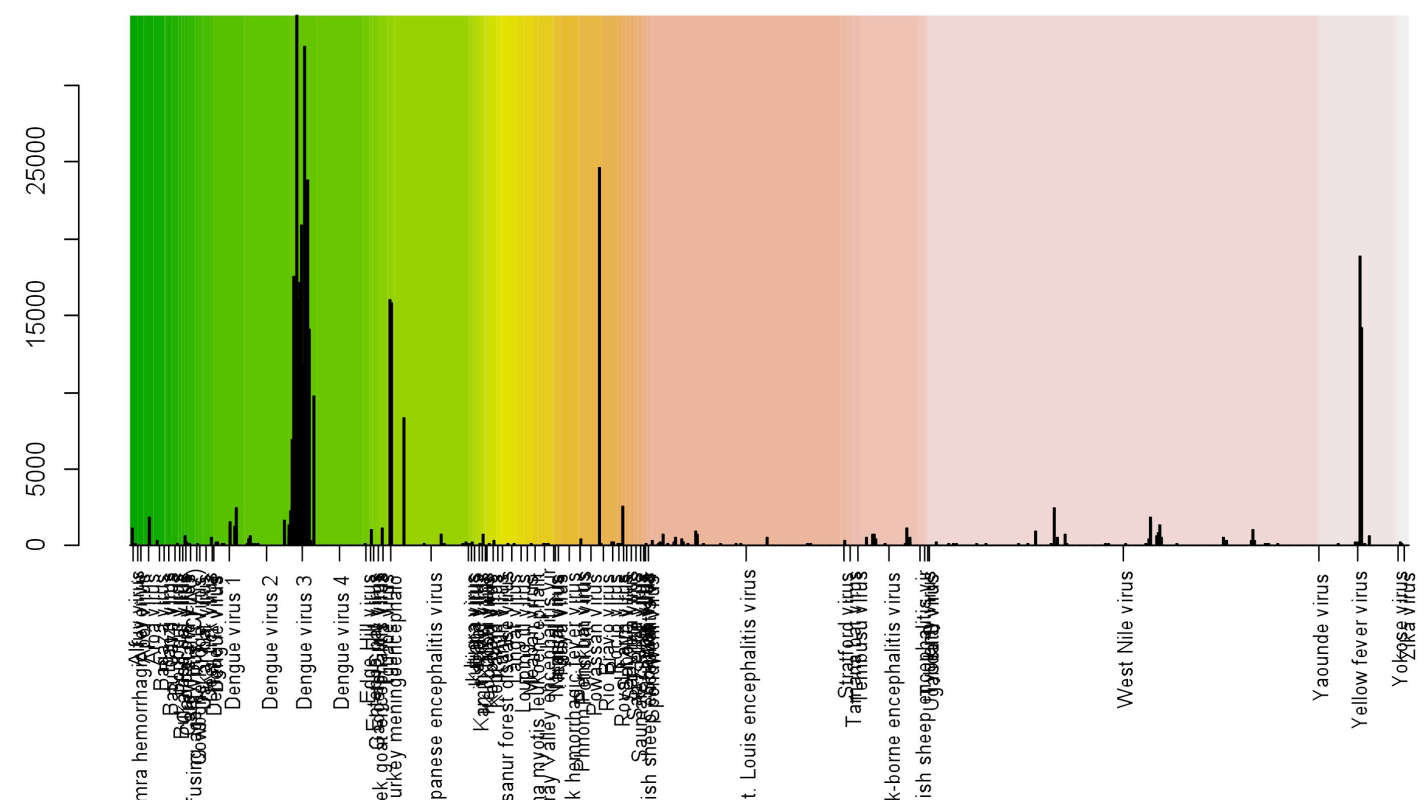

Figure 6. Visualization of probes fluorescence intensity of control slide hybridized with DENV-3 (genomic region 8800-10707 bp). Data were sorted by family, genus and species levels.

Table 26. Significant analysis of array hybridized with DENV-3. The top 10 viruses with lowest $p$-values.

\begin{tabular}{cccc}
\hline Virus & No. of probes & $\boldsymbol{p}$-values & average \\
\hline Dengue virus 3 & 26 & $9,49 \mathrm{E}-10$ & 5,92 \\
Foot-and-mouth disease virus & 6 & 0,00483233 & 2,29 \\
Carey Island virus & 3 & 0,018282742 & 2,57 \\
Lambdapapillomavirus 1 & 5 & 0,031740476 & 1,78 \\
Human parechovirus 1 & 8 & 0,033104426 & 1,21 \\
Moloney murine leukemia virus & 11 & 0,034032917 & 1,12 \\
Striped bass reovirus & 7 & 0,036758429 & 1,42 \\
Cebus albifrons lymphocryptovirus 1 & 4 & 0,039069131 & 1,68 \\
Atractoscion nobilis nervous necrosis virus & 5 & 0,03914734 & 1,07 \\
Avian carcinoma virus & 5 & 0,042591587 & 1,63 \\
\hline
\end{tabular}


FAMILY

Control_13_3.8.1

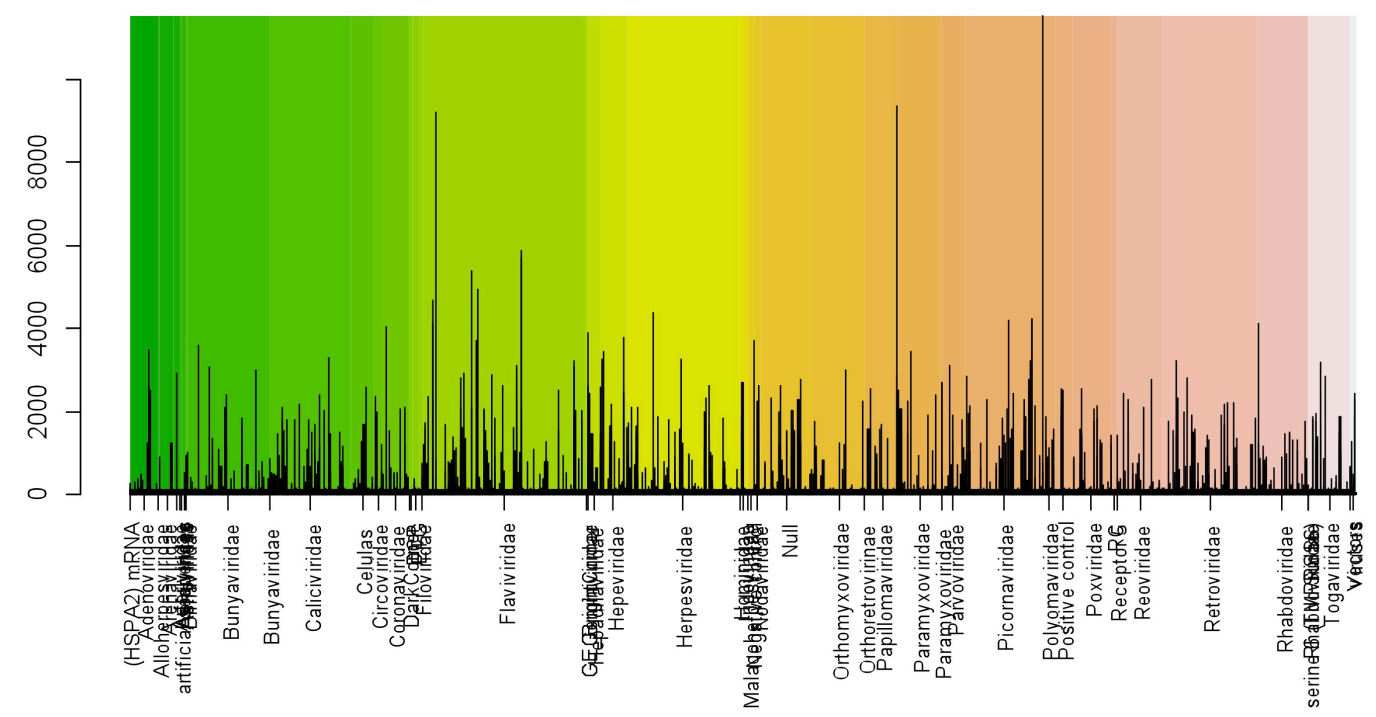

GENUS

Control_13_3.8.1

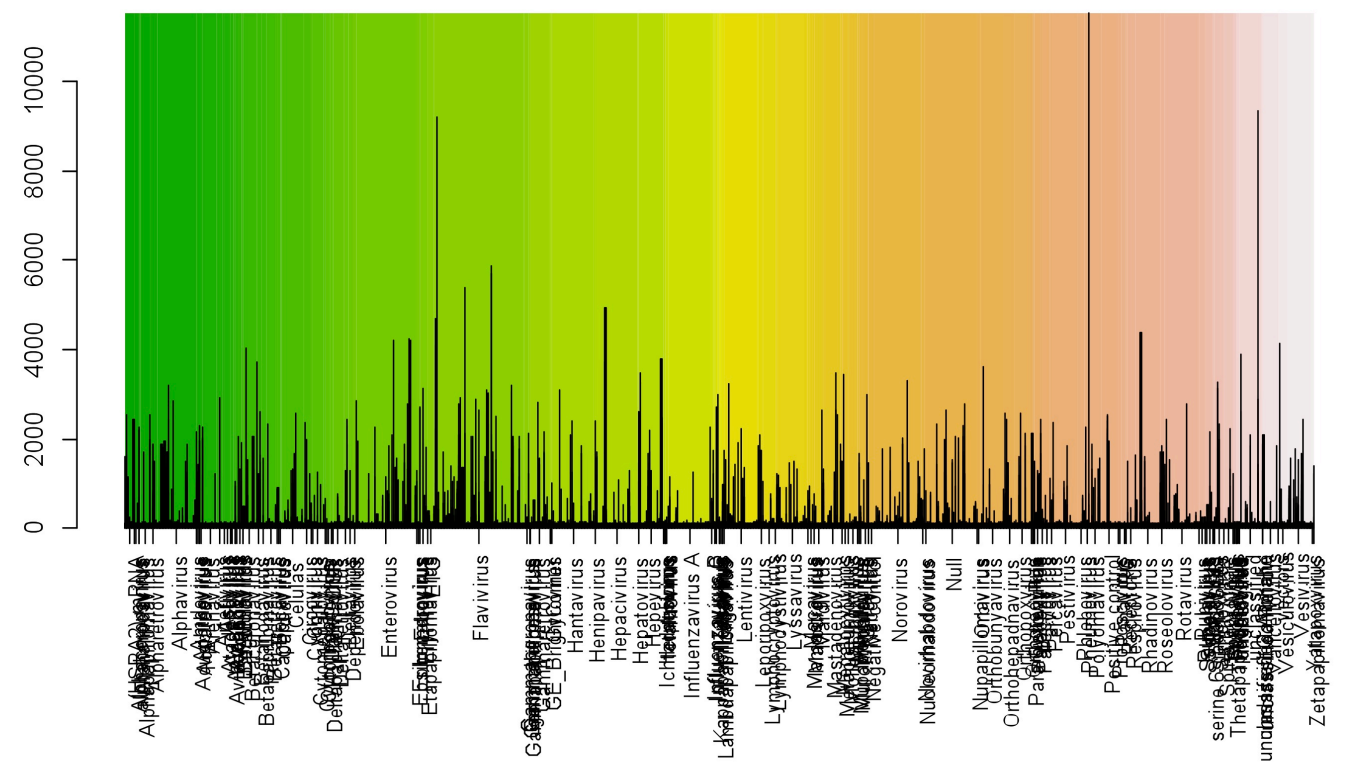




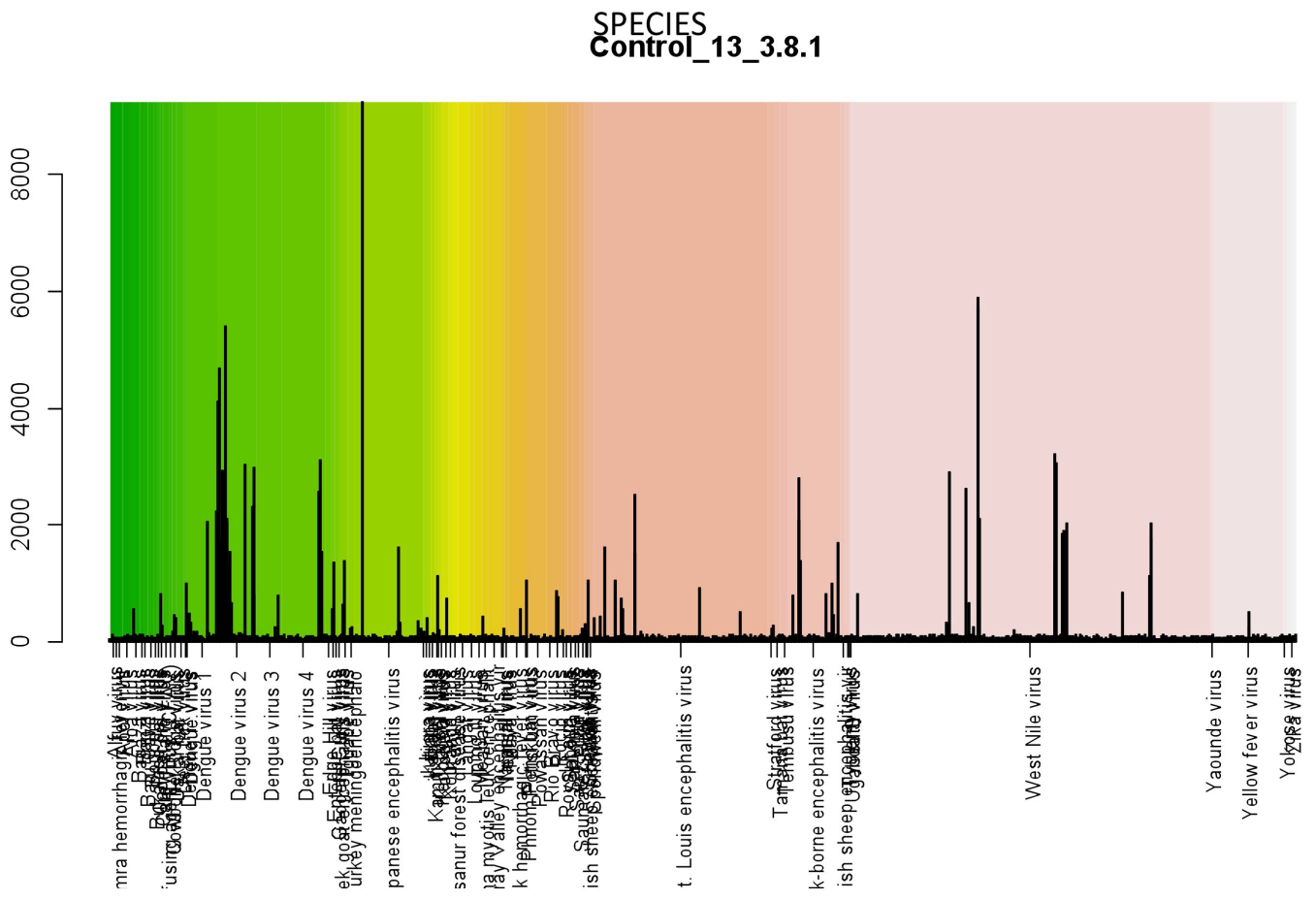

Figure 7. Visualization of probes fluorescence intensity of control slide hybridized with DENV-2 (5 $\mu \mathrm{L}$ cDNA). Data were sorted by family, genus and species levels.

Table 27. Significant analysis of array hybridized with DENV-2. The top 10 viruses with lowest $p$-values.

\begin{tabular}{cccc}
\hline Virus & No. of probes & $\boldsymbol{p}$-values & average \\
\hline Dengue virus 2 & 40 & $1,22 \mathrm{E}-07$ & 2,20 \\
Sepik virus & 4 & 0,002754051 & 1,13 \\
Dicentrarchus labrax encephalitis virus & 15 & 0,00617462 & 1,53 \\
Dakar bat virus & 4 & 0,006267702 & 1,82 \\
Foot-and-mouth disease virus - type SAT 2 (FMDV-SAT2) & 6 & 0,011241274 & 2,32 \\
Carey Island virus & 3 & 0,01622768 & 2,70 \\
Lambdapapillomavirus 1 & 5 & 0,019340717 & 2,09 \\
Atractoscion nobilis nervous necrosis virus & 5 & 0,022621486 & 1,49 \\
Avian carcinoma virus & 5 & 0,027913564 & 2,21 \\
Moloney murine leukemia virus & 5 & 0,02883574 & 1,30
\end{tabular}


FAMILY

Control_13_4.8.1

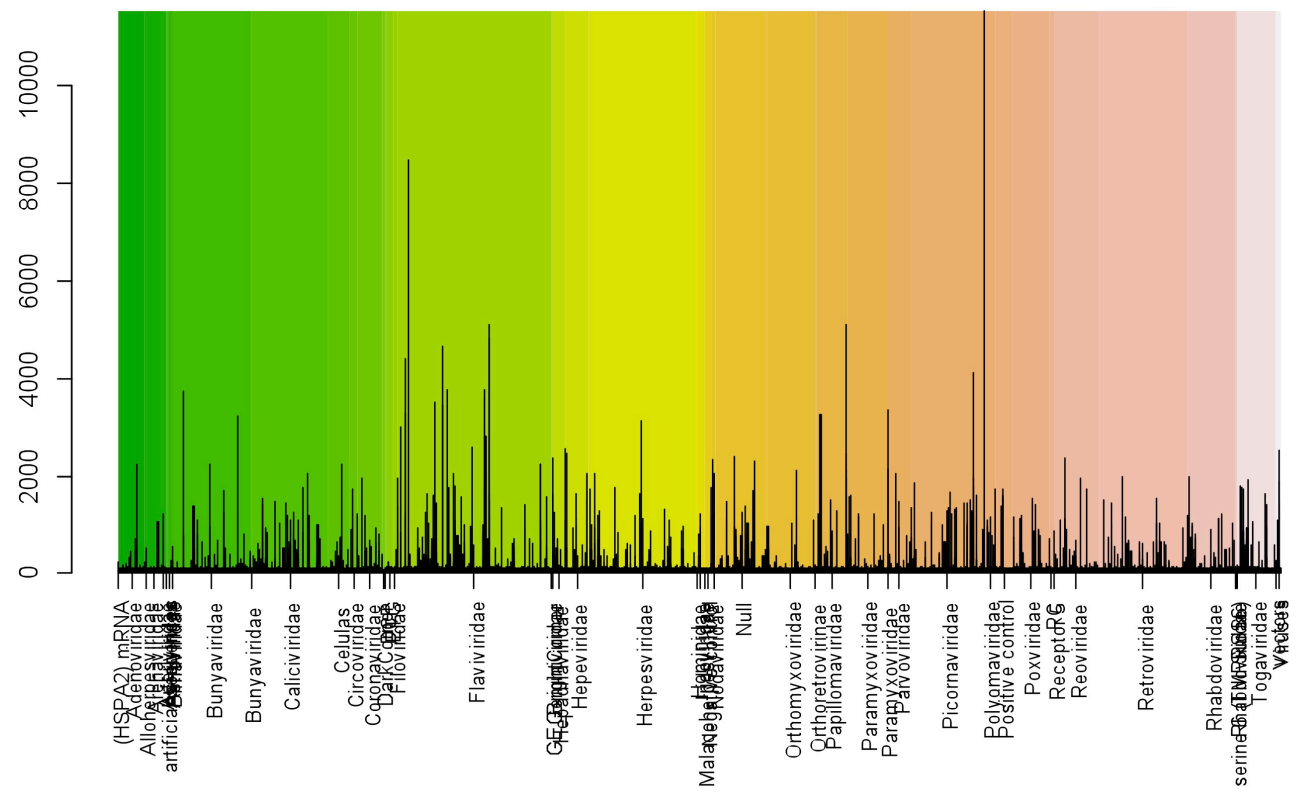

GENUS

Control_13_4.8.1

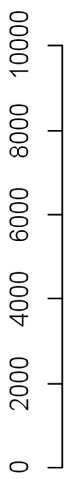

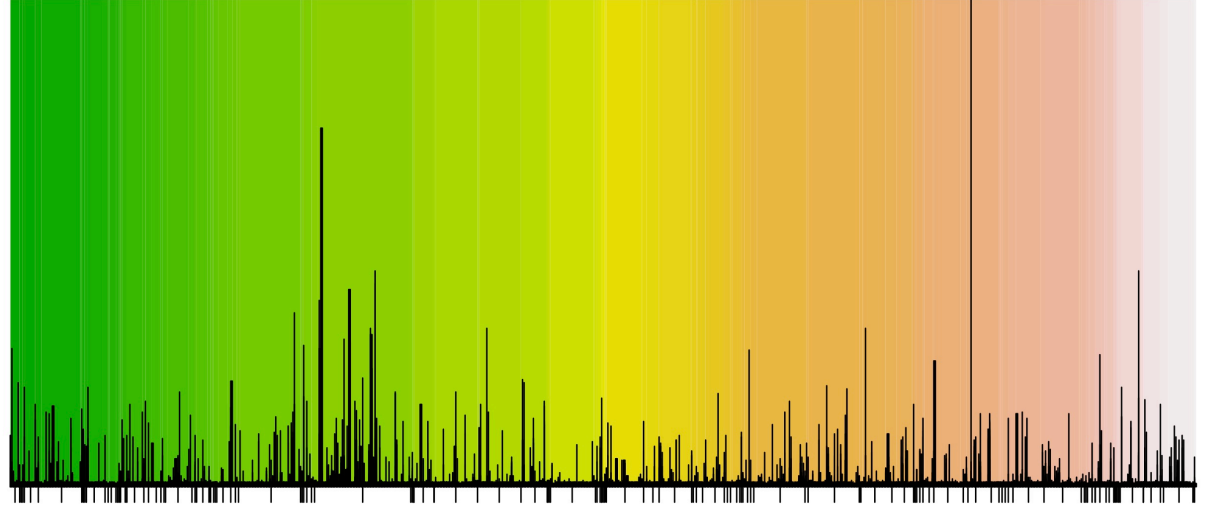

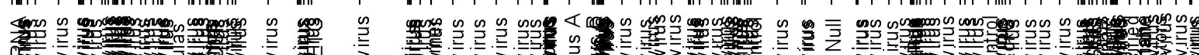

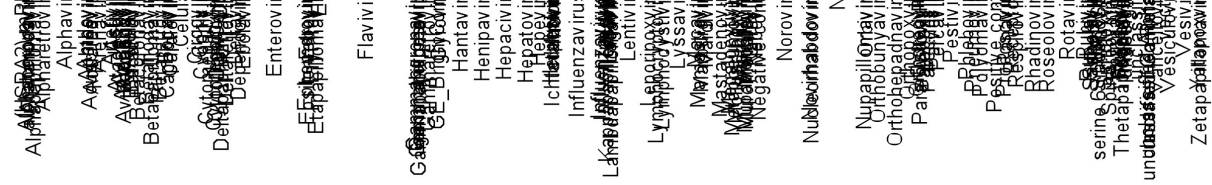




\section{SPECIES}

Control_13_4.8.1

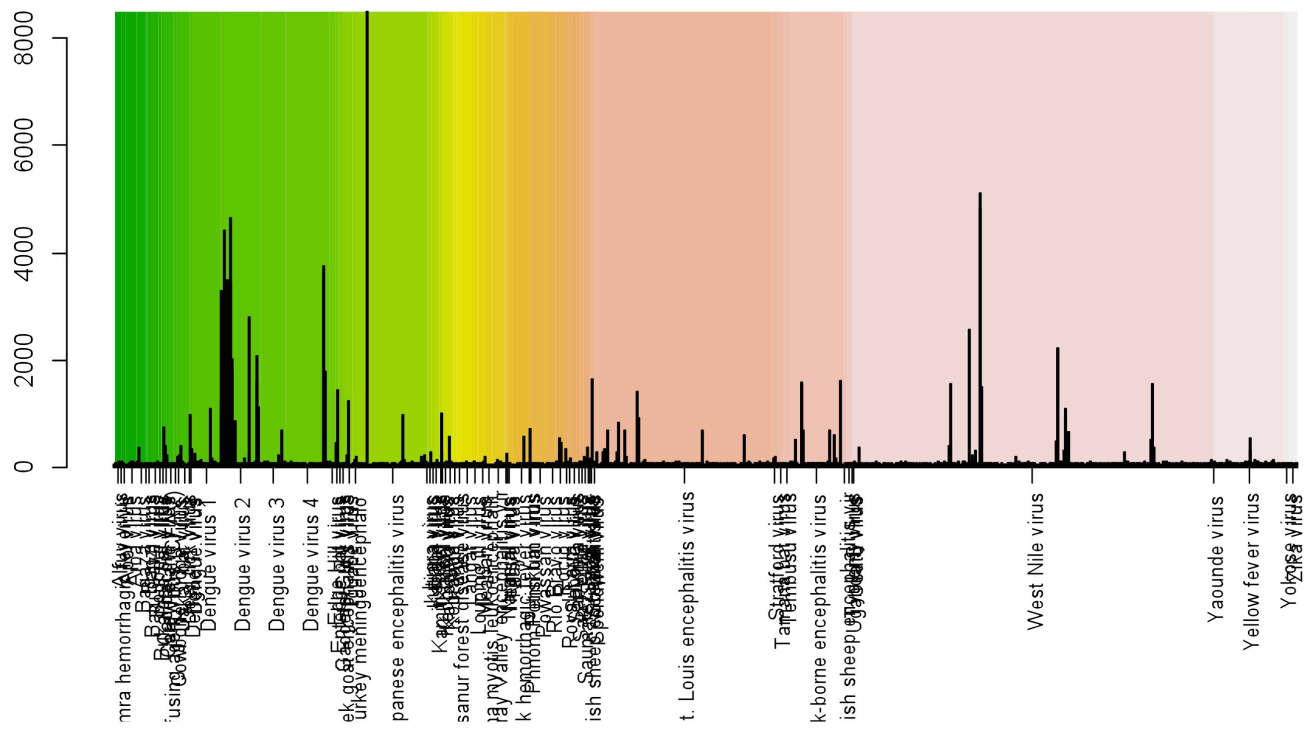

Figure 8. Visualization of probes fluorescence intensity of control slide hybridized with DENV-2 (10 $\mu$ L cDNA). Data were sorted by family, genus and species levels.

Table 28. Significant analysis of array hybridized with DENV-2. The top 10 viruses with highest $p$-values.

\begin{tabular}{cccc}
\hline Virus & No. of probes & $\boldsymbol{p}$-vavlues & Average \\
\hline Dengue virus 2 & 40 & $1,18 \mathrm{E}-07$ & 2,14 \\
Dakar bat virus & 4 & 0,002389779 & 1,65 \\
Sepik virus & 4 & 0,004997352 & 1,03 \\
Foot-and-mouth disease virus & 6 & 0,010961059 & 2,24 \\
Dicentrarchus labrax encephalitis virus & 15 & 0,01362258 & 1,20 \\
Atractoscion nobilis nervous necrosis virus & 5 & 0,014797867 & 1,05 \\
$\quad$ Carey Island virus & 3 & 0,019887576 & 2,33 \\
Lambdapapillomavirus 1 & 5 & 0,030582442 & 1,39 \\
Cebus albifrons lymphocryptovirus 1 & 4 & 0,031386664 & 2,15 \\
Avian carcinoma virus & 5 & 0,038736648 & 1,54 \\
\end{tabular}


FAMILY

Control_13_5.8.1

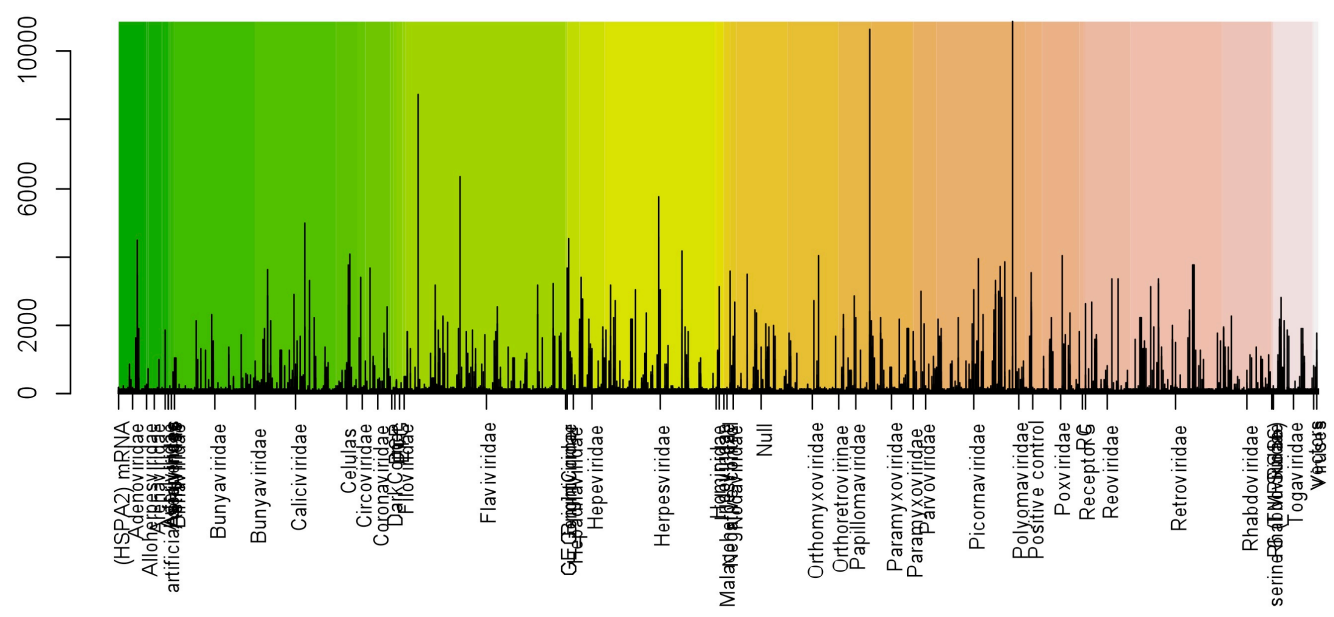

GENUS

Control_13_5.8.1

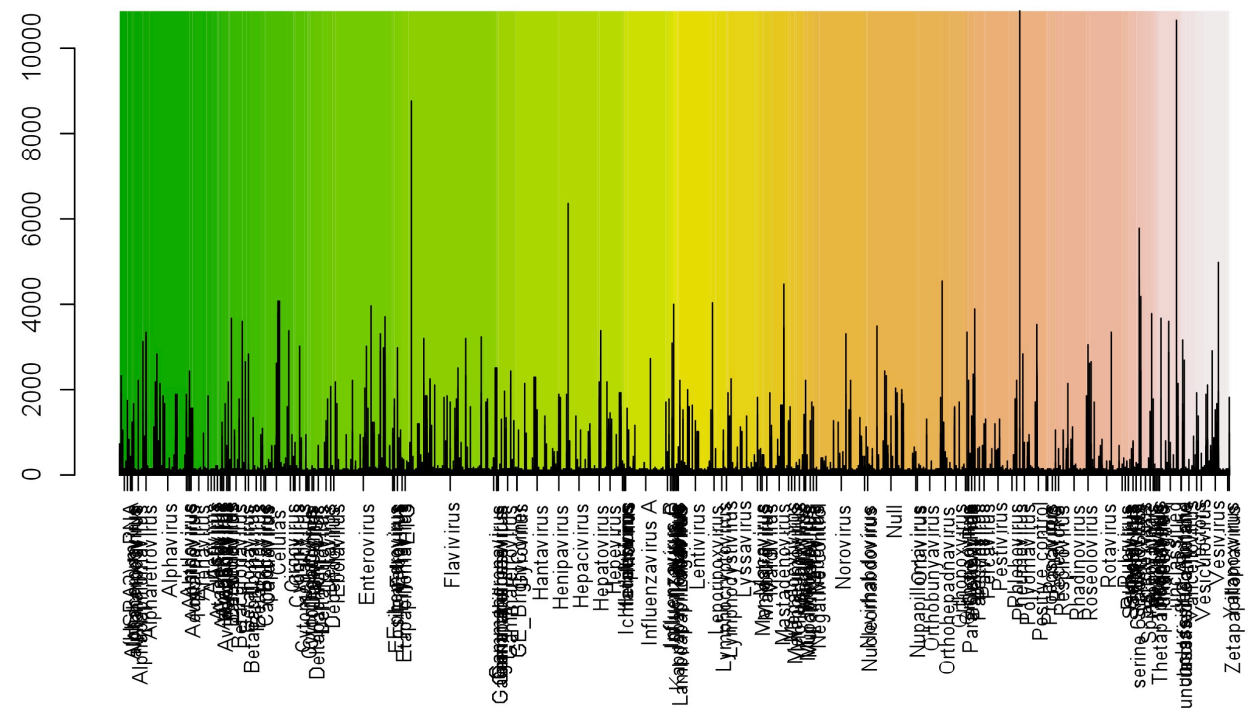


Control_13_5.8.1

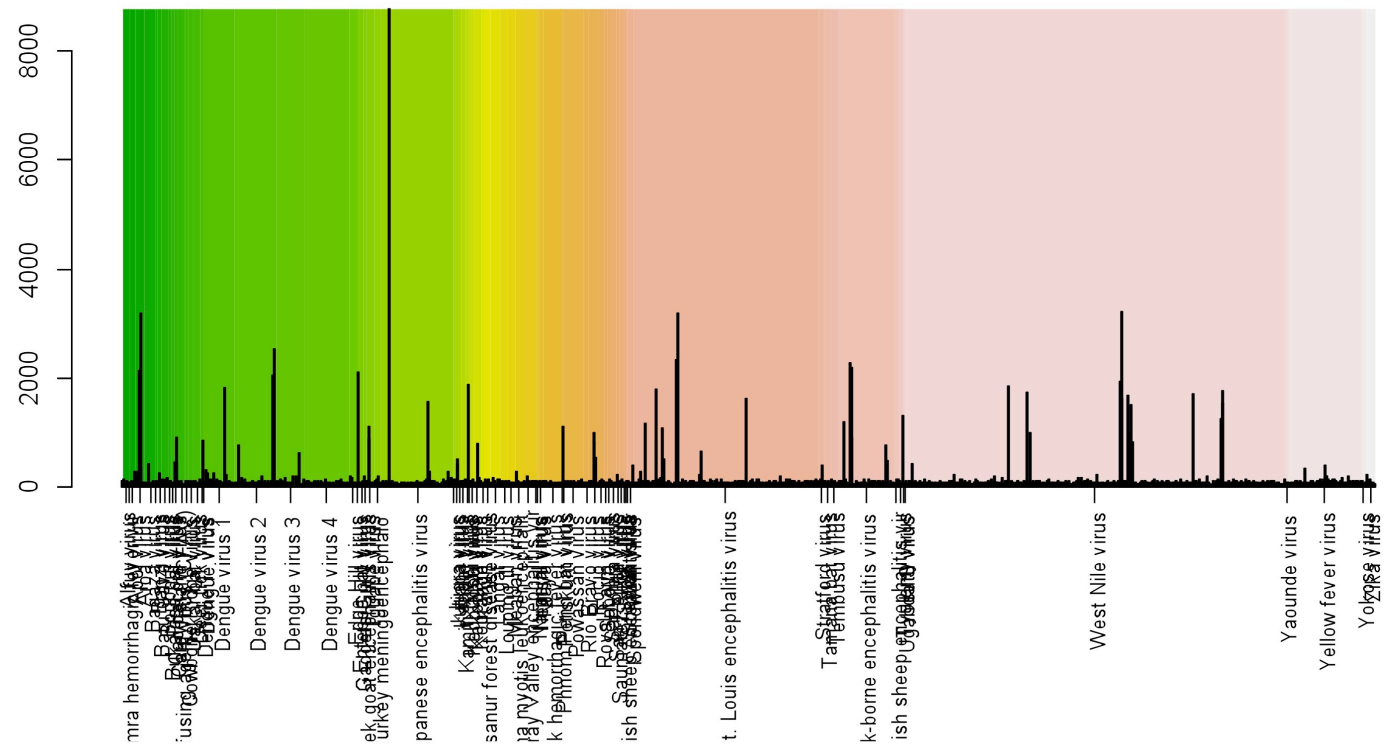

Figure 9. Visualization of probes fluorescence intensity of control slide hybridized with BUSQV. Data were sorted by family, genus and species levels.

Table 29. Significant analysis of array hybridized with BUSQV. The top 10 viruses with lowest $p$-values.

\begin{tabular}{cccc}
\hline Virus & No. of probes & $\boldsymbol{p}$-value & Average \\
\hline Foot-and-mouth disease virus & 6 & 0,002642923 & 2,17 \\
Carey Island virus & 3 & 0,008005324 & 2,55 \\
Dicentrarchus labrax encephalitis virus & 15 & 0,012449416 & 1,30 \\
Aroa virus & 10 & 0,01648986 & 1,50 \\
Cebus albifrons lymphocryptovirus 1 & 4 & 0,029382763 & 2,14 \\
Striped bass reovirus & 7 & 0,032645494 & 1,55 \\
Lambdapapillomavirus 1 & 5 & 0,049746858 & 1,56 \\
Macacine herpesvirus 1 (B virus) & 3 & 0,056500526 & 1,49 \\
Human papillomavirus type 55 & 3 & 0,057039384 & 1,56 \\
Avian carcinoma virus & 5 & 0,057581968 & 2,13 \\
\hline
\end{tabular}


FAMILY

Control_13_6.8.1

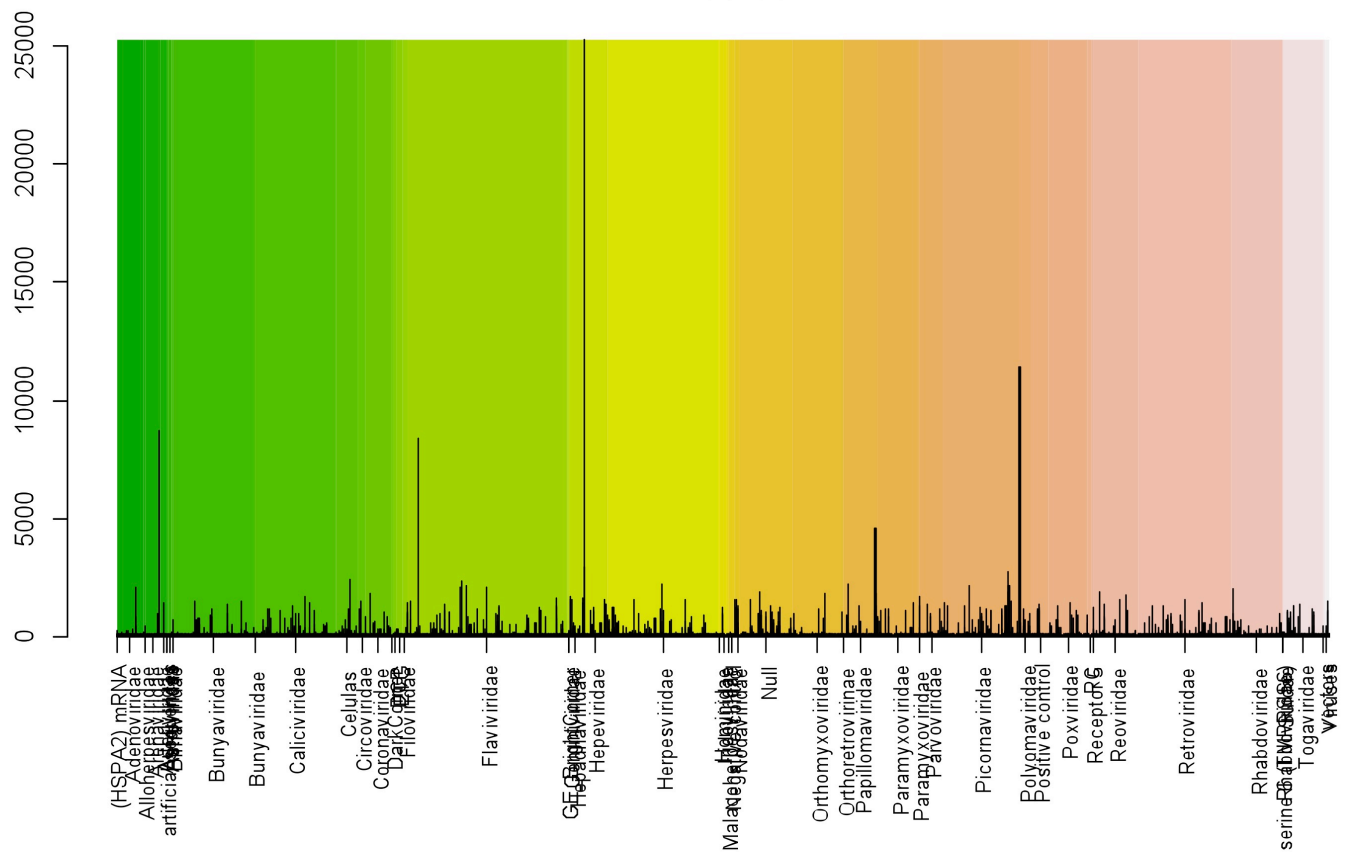

Genttof_13_6.8.1

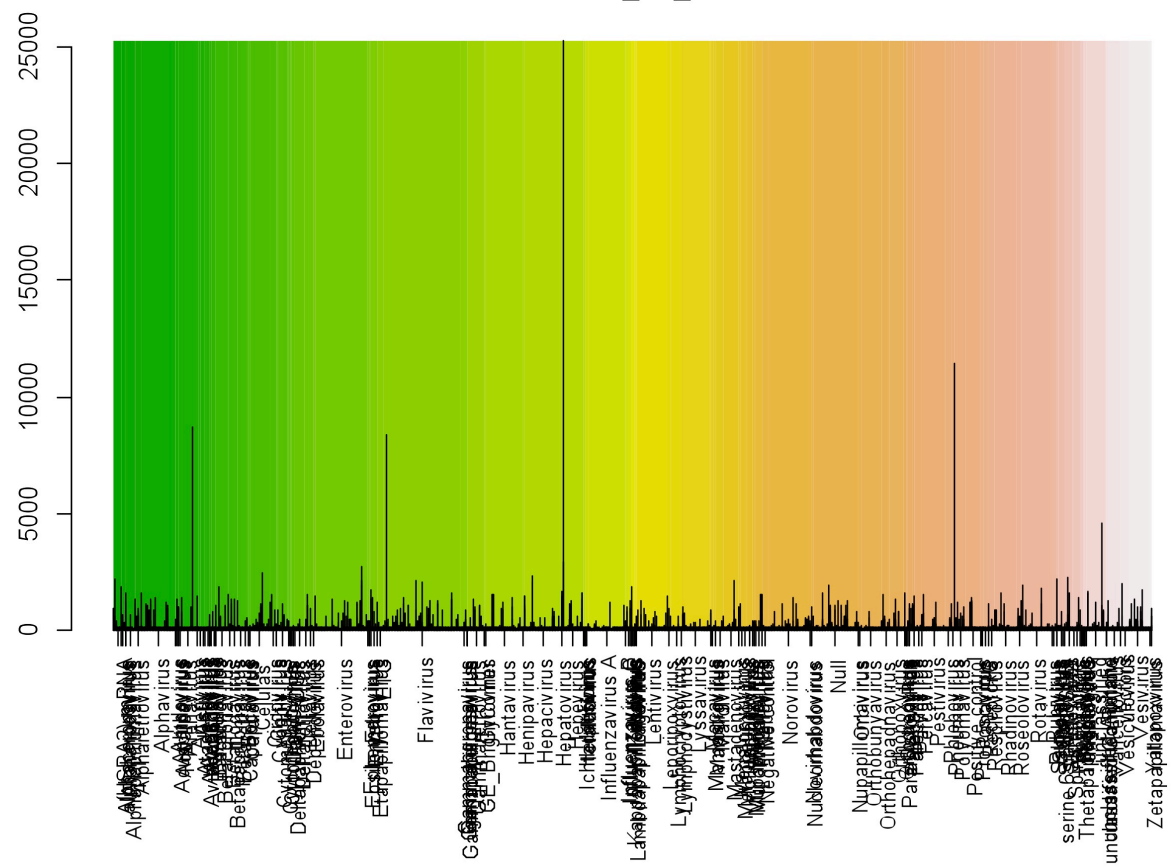


SPECIES

Control_13_6.8.1

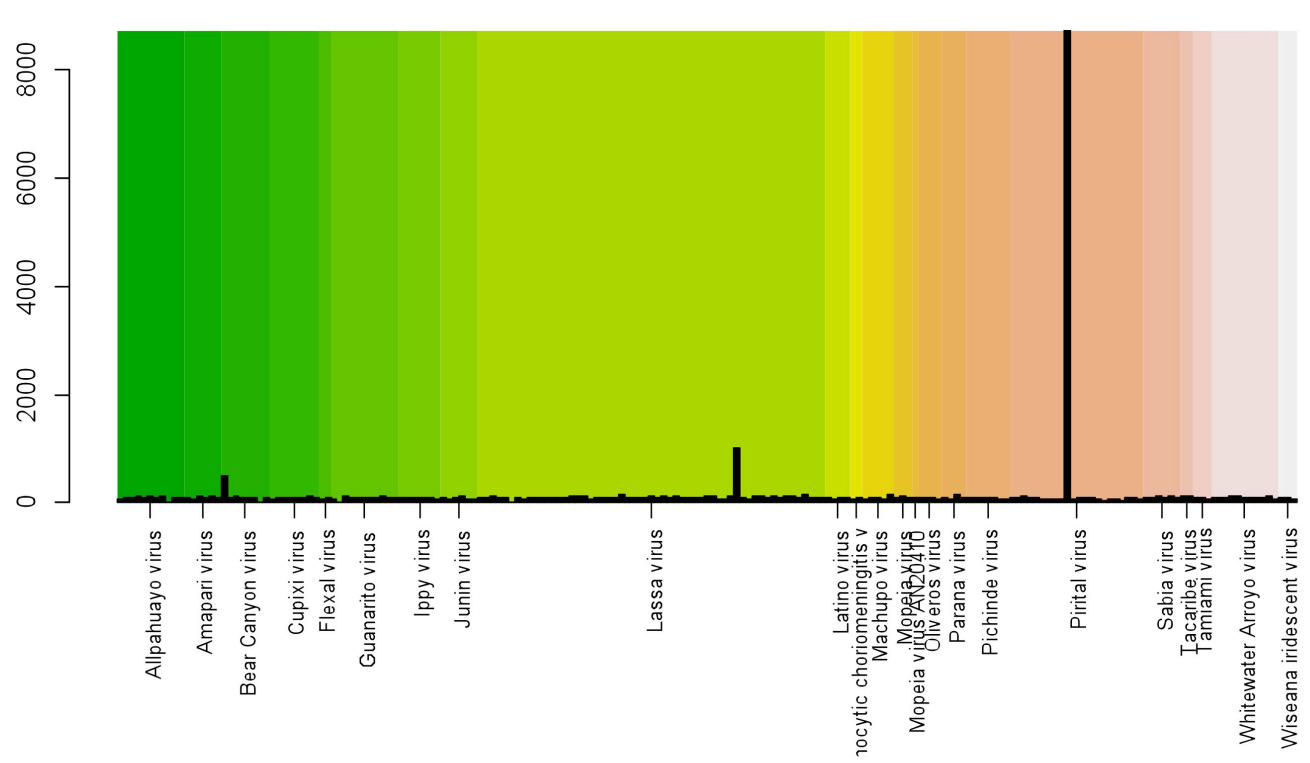

Figure 10. Visualization of probes fluorescence intensity of control slide hybridized with YFV ( $5 \mu \mathrm{L}$ cDNA). Data were sorted by family, genus and species levels.

Table 30. Significant analysis of array hybridized with YFV. The top 10 viruses with lowest $p$-values.

\begin{tabular}{cccc}
\hline Virus & No. of probes & $\boldsymbol{p}$-value & Average \\
\hline Foot-and-mouth disease virus - & 6 & 0,003351185 & 2,01 \\
Carey Island virus & 3 & 0,00539798 & 2,23 \\
Striped bass reovirus & 7 & 0,030127191 & 1,20 \\
Avian hepatitis E virus & 14 & 0,047470809 & 1,10 \\
Lambdapapillomavirus 1 & 5 & 0,050015069 & 1,31 \\
Cebus albifrons lymphocryptovirus 1 & 4 & 0,051171923 & 1,34 \\
Avian carcinoma virus & 5 & 0,058107026 & 1,32 \\
Human papillomavirus type 91 (candHPV91) & 7 & 0,062493027 & 1,17 \\
Rous-associated virus type 1 & 3 & 0,085542893 & 1,67 \\
Tensaw virus & 3 & 0,088415069 & 1,87 \\
\hline
\end{tabular}




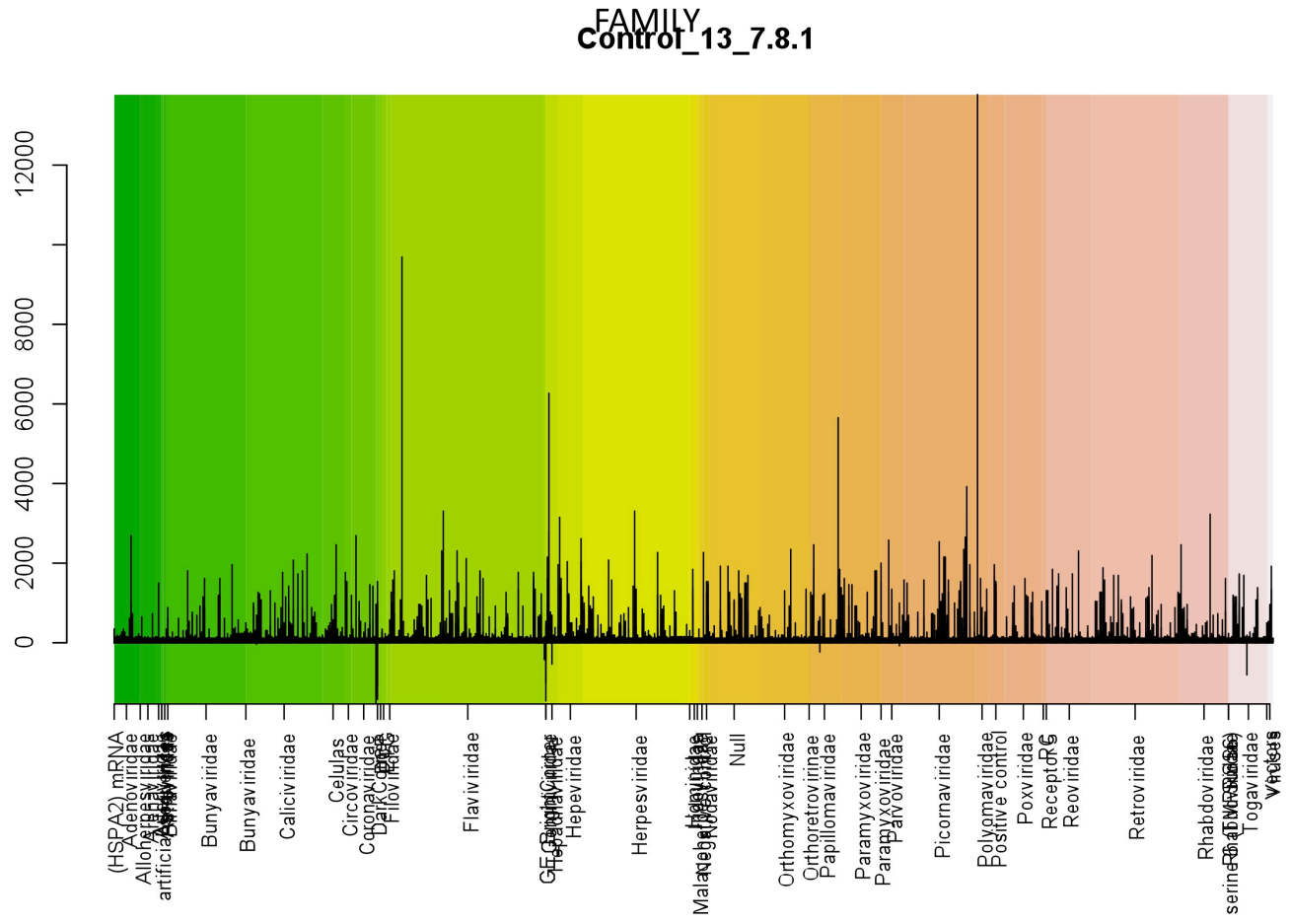

GENUS

Control_13_7.8.1

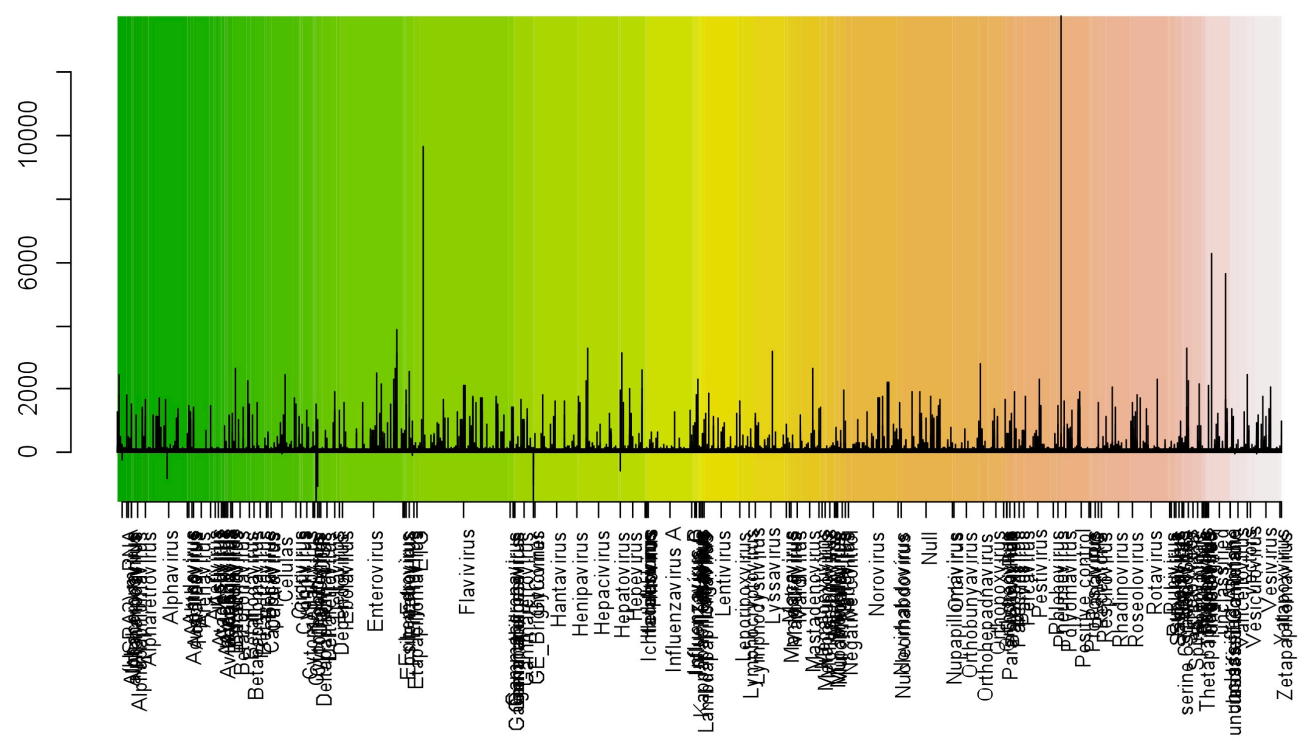




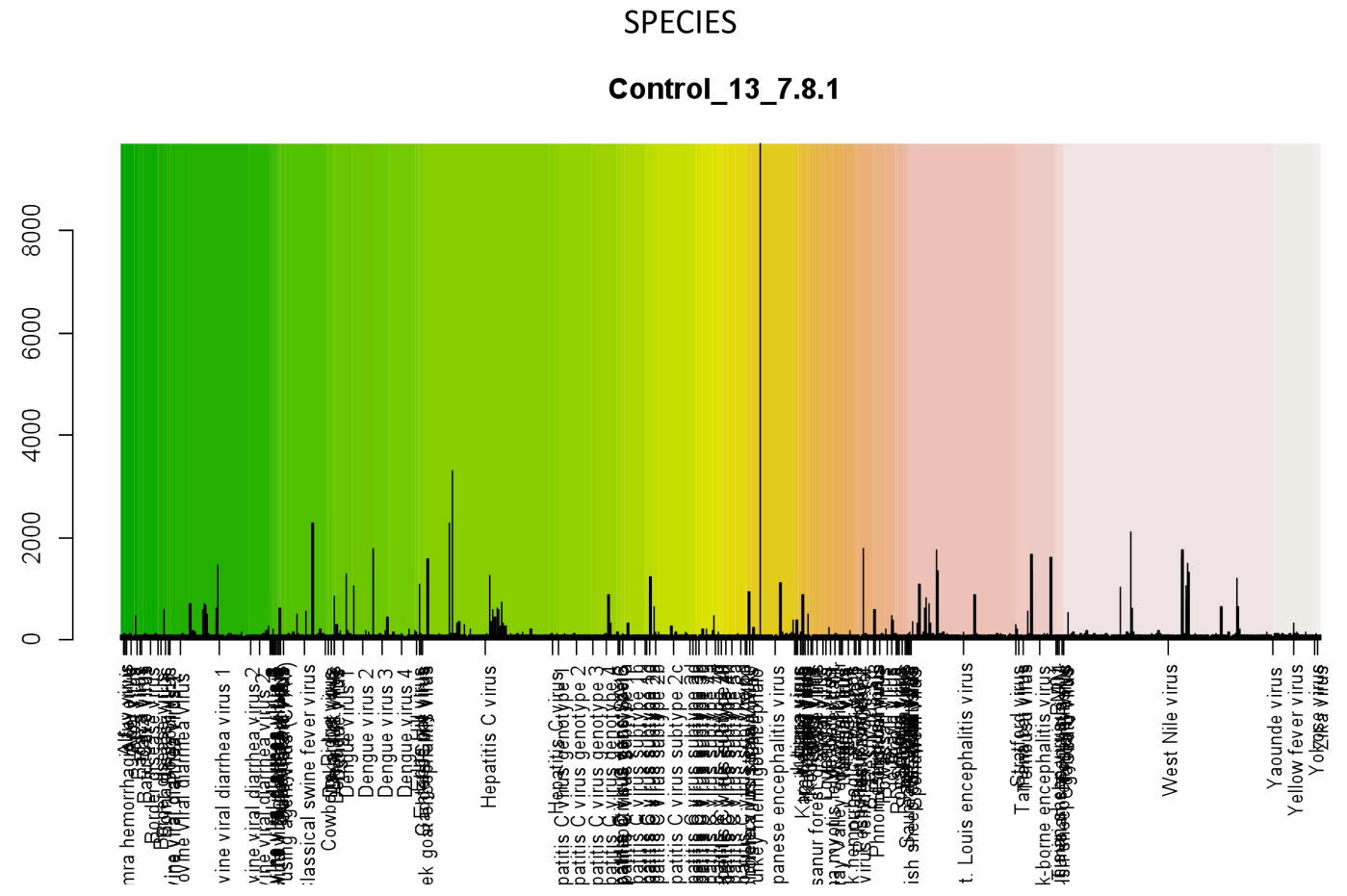

Figure 11. Visualization of probes fluorescence intensity of control slide hybridized with DENV-2 (5 $\mu \mathrm{L}$ cDNA). Data were sorted by family, genus and species levels.

Table 31. Significant analysis of array hybridized with DENV-2 . The top 10 viruses with lowest $p$-values.

\begin{tabular}{cccc}
\hline Virus & No. of probes & $p$-value & Average \\
\hline Carey Island virus & 3 & 0,001506437 & 2,66 \\
Foot-and-mouth disease virus - type SAT 2 (FMDV-SAT2) & 6 & 0,003821819 & 2,25 \\
Dicentrarchus labrax encephalitis virus & 15 & 0,015104683 & 1,13 \\
Atractoscion nobilis nervous necrosis virus & 5 & 0,029818769 & 1,06 \\
Avian carcinoma virus & 5 & 0,030631464 & 1,95 \\
Cebus albifrons lymphocryptovirus 1 & 4 & 0,030682021 & 1,80 \\
Striped bass reovirus & 7 & 0,034686301 & 1,46 \\
Lambdapapillomavirus 1 & 5 & 0,038762179 & 1,68 \\
Moloney murine leukemia virus & 11 & 0,040688916 & 1,03 \\
Human parechovirus 1 & 8 & 0,061227608 & 1,06
\end{tabular}


FAMILY

Control_13_8.8.1

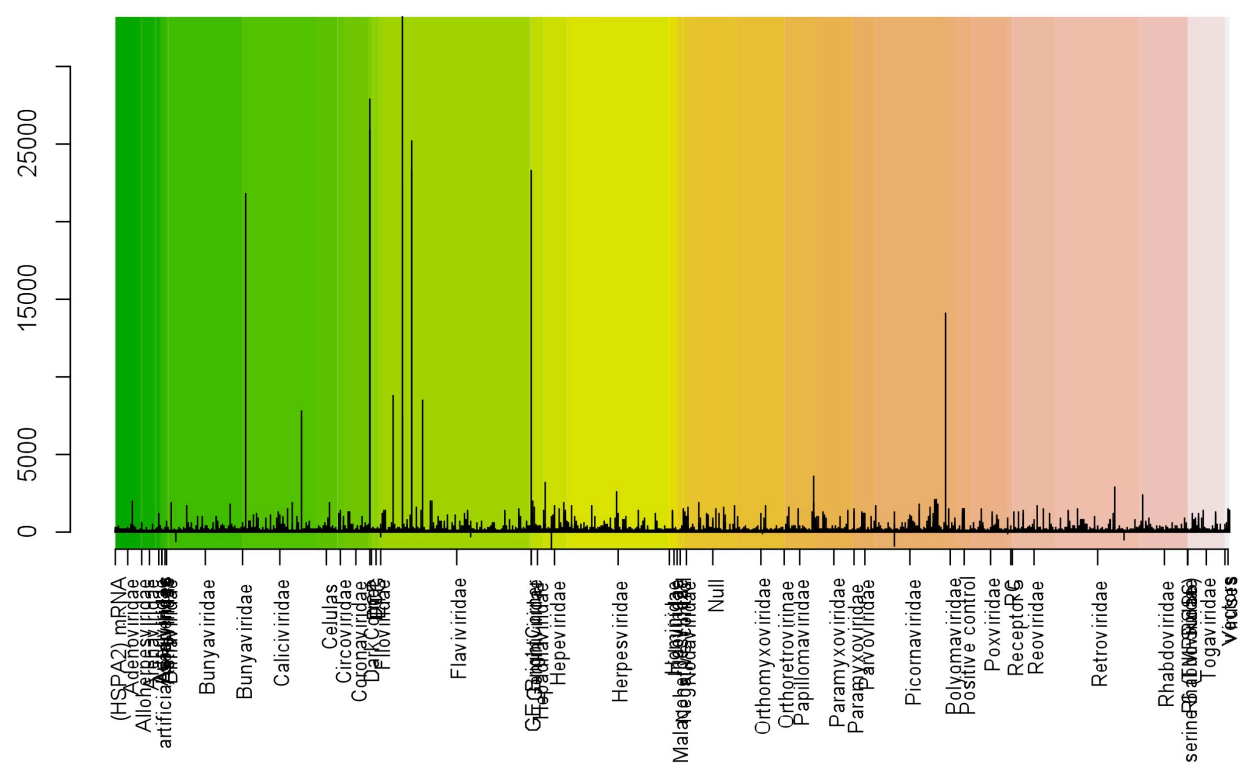

GENUS

Control_13_8.8.1

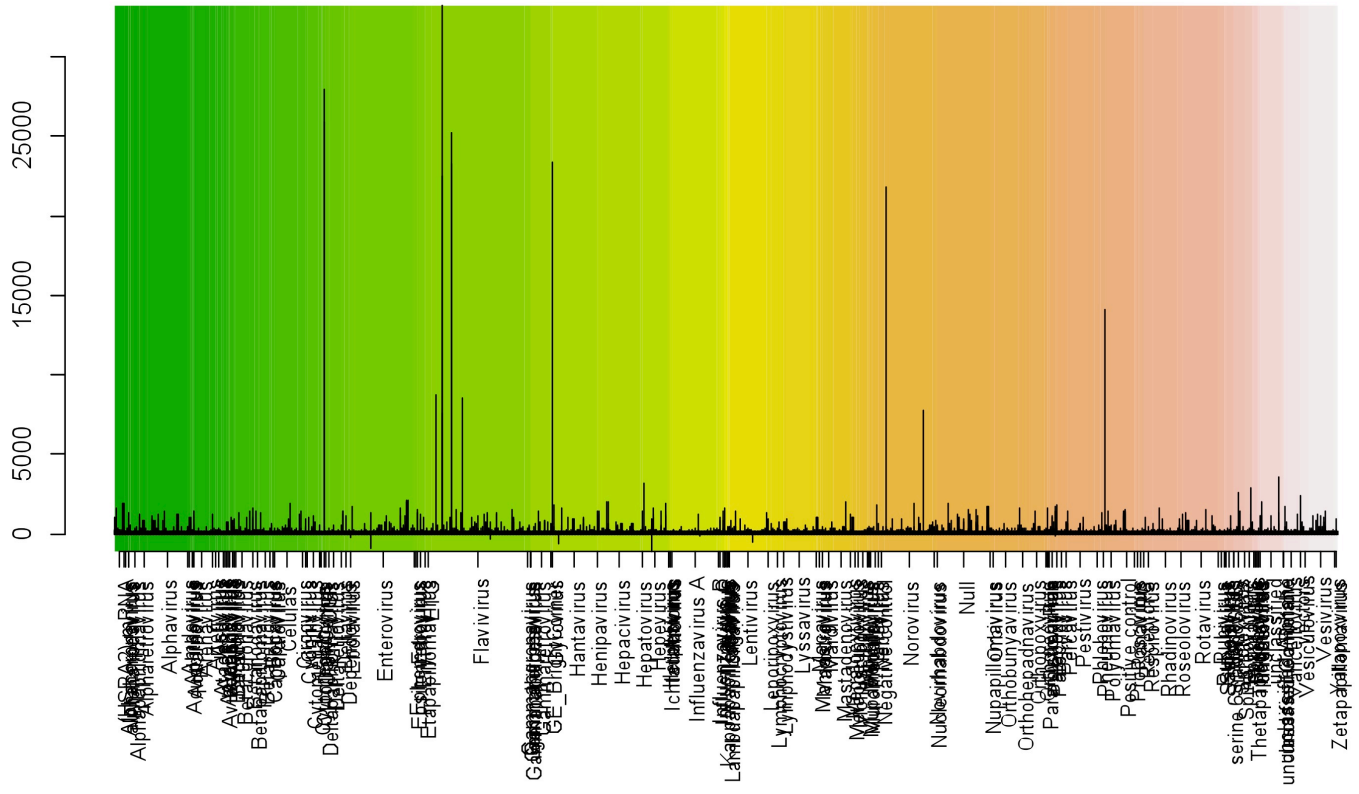


SPECIES

Control_13_8.8.1

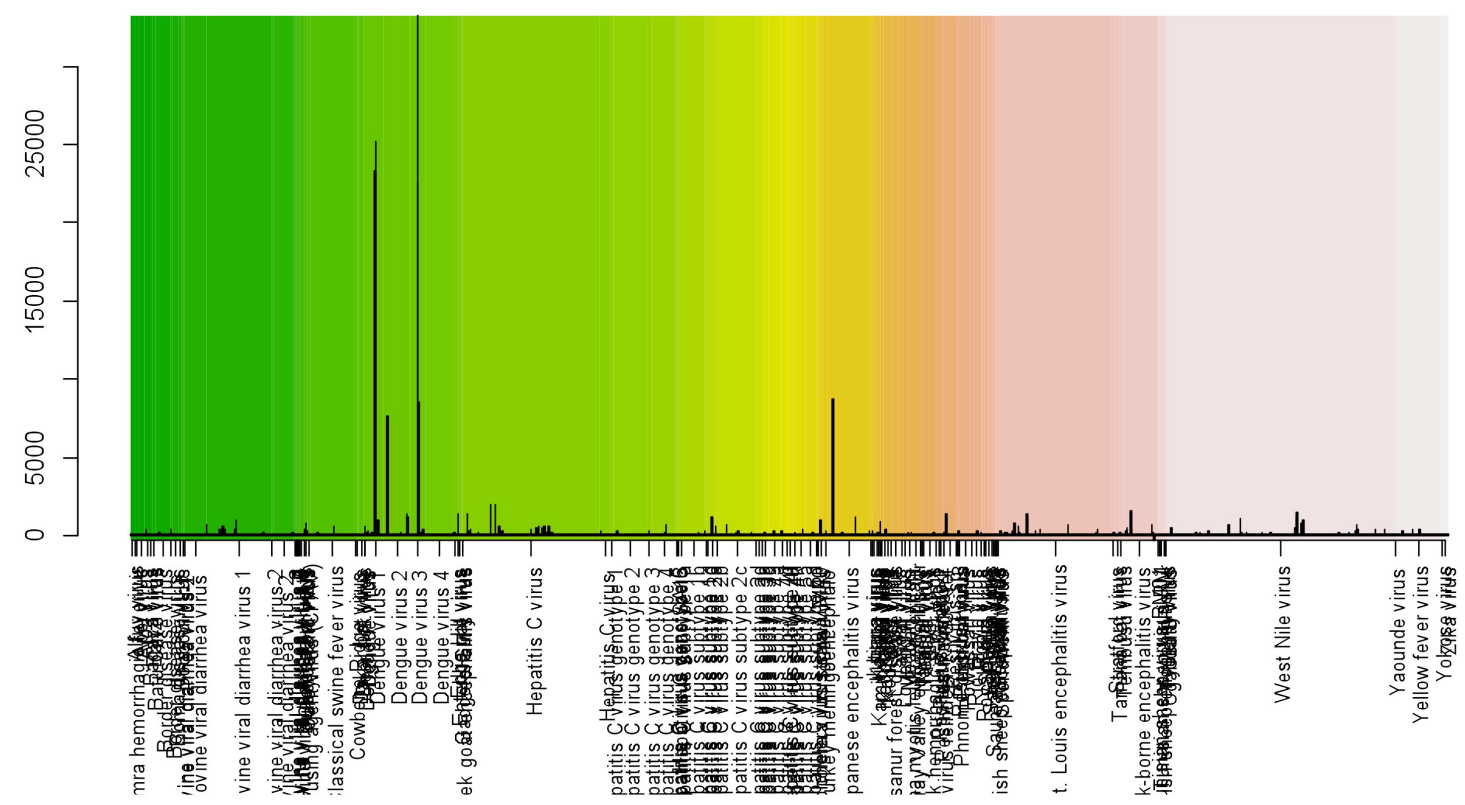

Figure 12. Visualization of probes fluorescence intensity of control slide hybridized with YFV ( $5 \mu \mathrm{L}$ cDNA). Data were sorted by family, genus and species levels.

Table 32. Significant analysis of array hybridized with YFV. The top 10 viruses with lowest $p$-values.

\begin{tabular}{cccc}
\hline Virus & No. of probes & $\boldsymbol{p}$-value & Average \\
\hline Foot-and-mouth disease virus & 6 & 0,008474099 & 1,68 \\
Carey Island virus & 3 & 0,015505887 & 2,12 \\
Lambdapapillomavirus 1 & 5 & 0,02127612 & 1,25 \\
Foot-and-mouth disease virus O/SKR/2000 & 3 & 0,02862171 & 1,63 \\
Cebus albifrons lymphocryptovirus 1 & 4 & 0,035972593 & 1,61 \\
Striped bass reovirus & 7 & 0,039311243 & 1,13 \\
Nodamura virus & 7 & 0,061602055 & 1,10 \\
Human papillomavirus type 91 (candHPV91) & 7 & 0,062985925 & 1,09 \\
Avian carcinoma virus & 5 & 0,067795501 & 1,10 \\
Human parechovirus & 5 & 0,083180856 & 1,59 \\
\hline
\end{tabular}


The control slide was able to detect DENV-2 and DENV-3, but not YFV neither BUSV. In addition, several cross-hybridization were observed. We did not found any difference between cDNA or PCR products.

\subsection{Microarray experiments with control and RoboArboVirusChip v1 slides}

A second experiment was performed with the control and RoboArboVirusChip slides, including agitation during the washing steps to reduce the production of artifacts. The following viruses were analyzed with both control and RoboArboVirusChip slides: DENV-2, DENV-3, YFV, BUSV, DENV-4, ILHEV, SLEV and OROV. For the two slides, only cDNA was used. Figures 14 and 15 show the scanned images of control and RoboArboVirusChip slides, respectively, without any artifacts.

Figure 13. Microarray control slide with 8 arrays scanned at $532 \mathrm{~nm}$. DENV-2, DENV3, YFV, BUSV, DENV-4, ILHEV, SLEV and OROV.

Figure 14. Microarray RoboArboVirusChip slide with 8 arrays scanned at $532 \mathrm{~nm}$. 1DENV-2, DENV-3, YFV, BUSV, DENV-4, ILHEV, SLEV and OROV. 
Figures 16-31 show the visualization of spots fluorescence intensity grouped by family, genus and species levels for control and RoboArboVirusChip. While Table 25-40 show the significant analysis of probes for each virus target sorted by $p$-values for control and RoboArboVirusChip.

FAMILY

Control_1.8.1

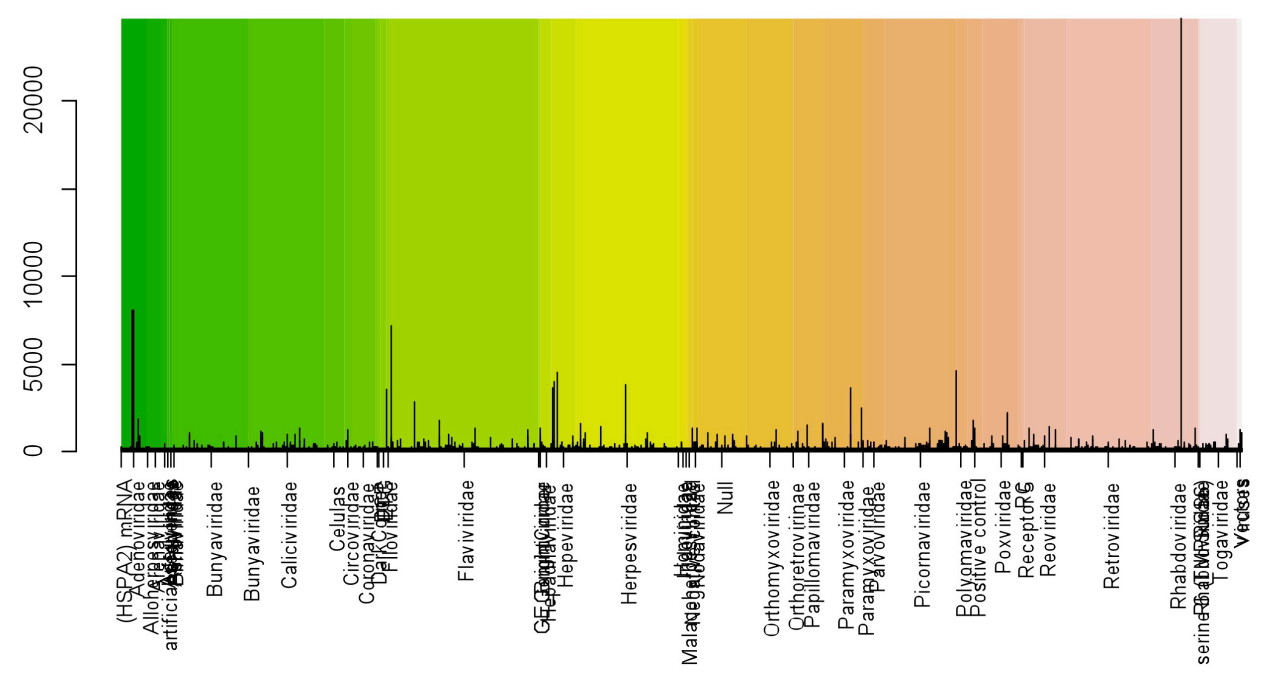


GENUS

Control_1.8.1

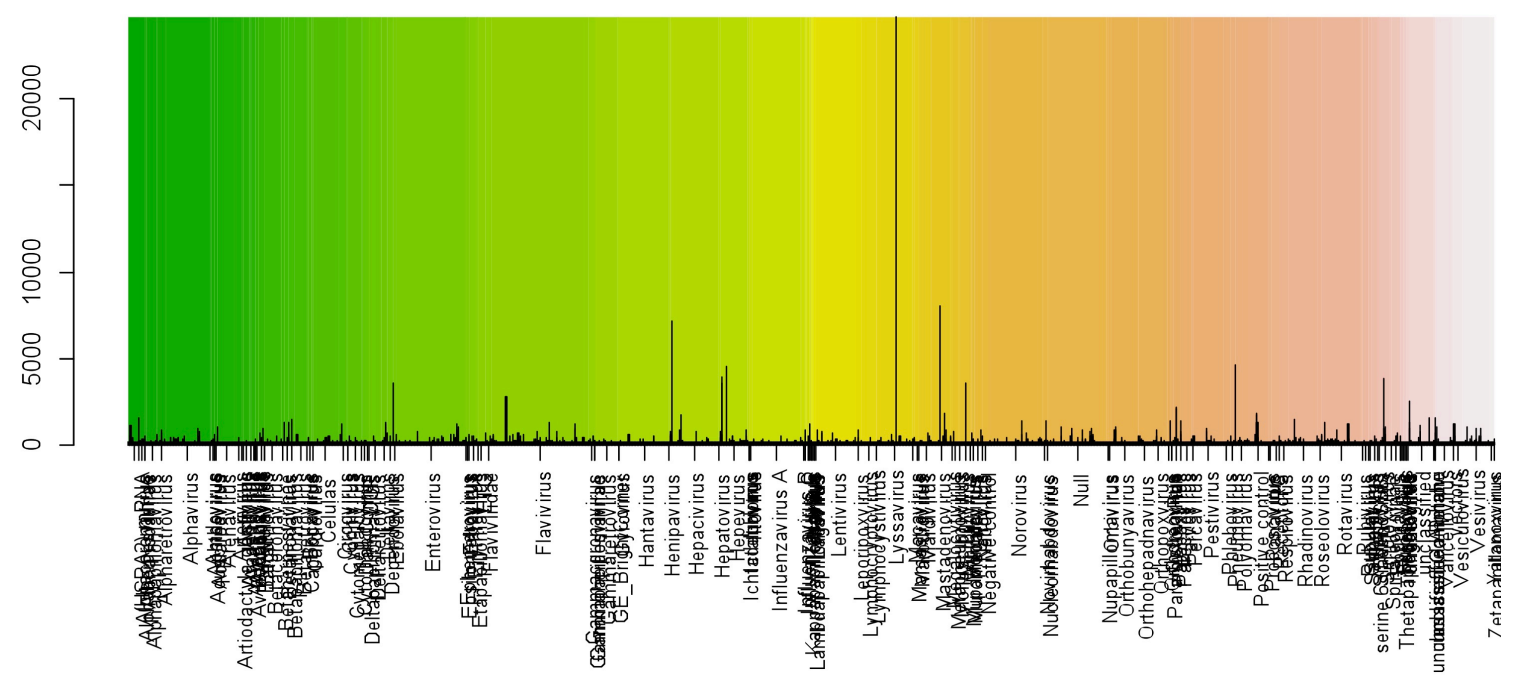

SPECIES

Control_1.8.1

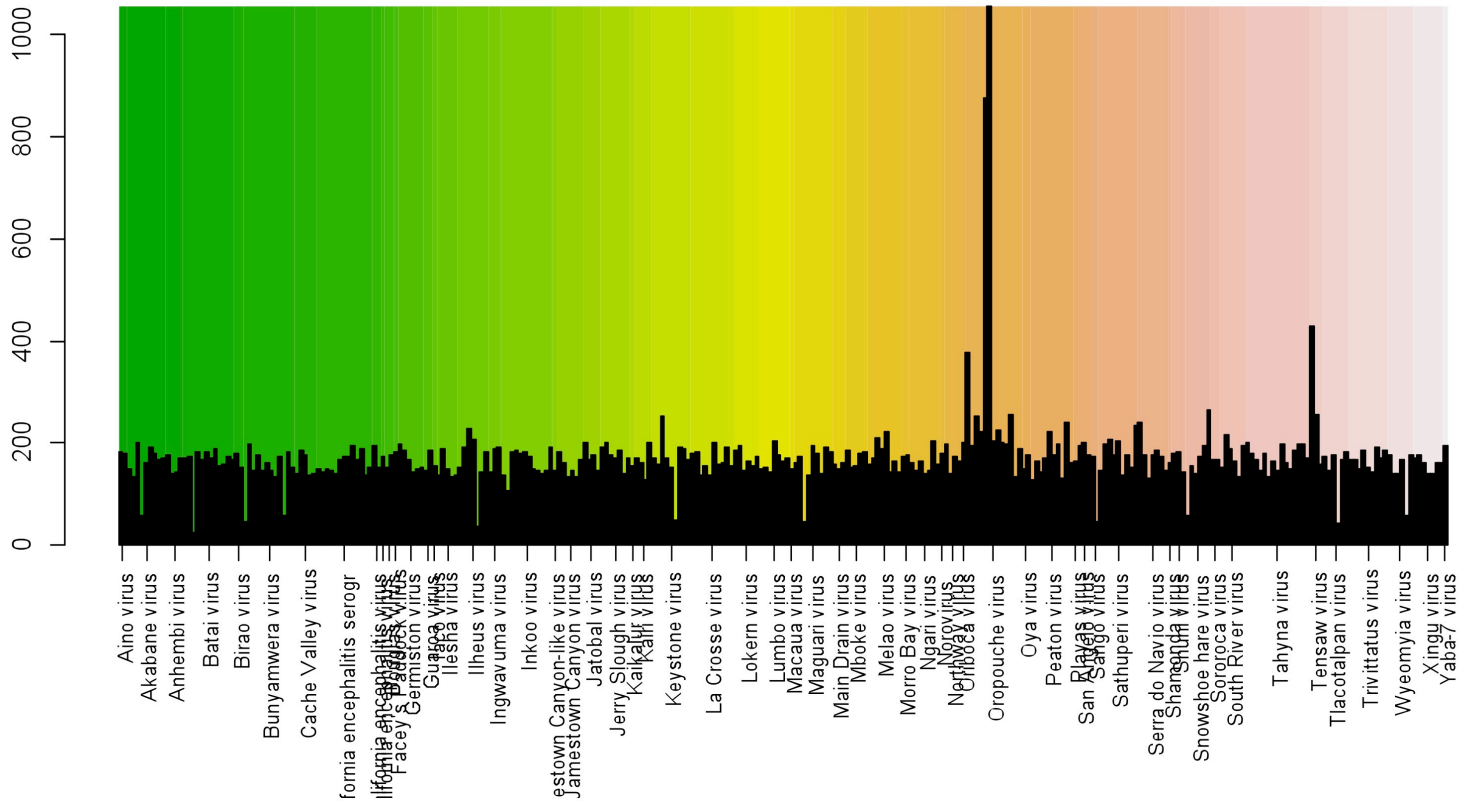

Figure 15. Visualization of probes fluorescence intensity of control slide hybridized with OROV. Data were sorted by family, genus and species levels. 
Table 33. Significant analysis of array hybridized with OROV. The top 10 viruses with lowest $p$-values.

\begin{tabular}{cccc}
\hline Virus & No. of probes & $\boldsymbol{p}$-value & Average \\
\hline Foot-and-mouth disease virus & 6 & 0,008474099 & 1,68 \\
Carey Island virus & 3 & 0,015505887 & 2,12 \\
Lambdapapillomavirus 1 & 5 & 0,02127612 & 1,25 \\
Foot-and-mouth disease virus O/SKR/2000 & 3 & 0,02862171 & 1,63 \\
Cebus albifrons lymphocryptovirus 1 & 4 & 0,035972593 & 1,61 \\
Striped bass reovirus & 7 & 0,039311243 & 1,13 \\
Nodamura virus & 7 & 0,061602055 & 1,10 \\
Human papillomavirus type 91 (candHPV91) & 7 & 0,062985925 & 1,09 \\
Avian carcinoma virus & 5 & 0,067795501 & 1,10 \\
Human parechovirus & 5 & 0,083180856 & 1,59 \\
\hline
\end{tabular}

FAMILY

Control_2.8.1

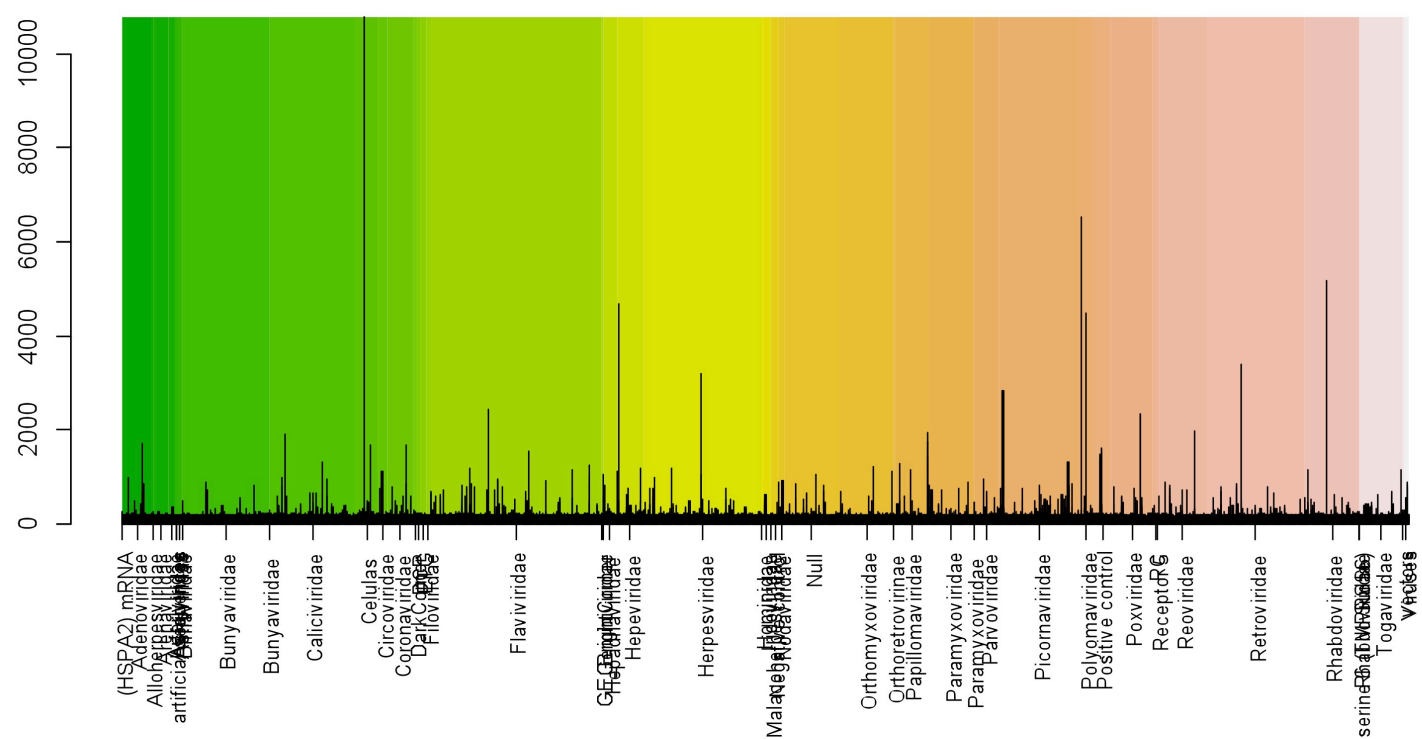


GENUS

Control_2.8.1

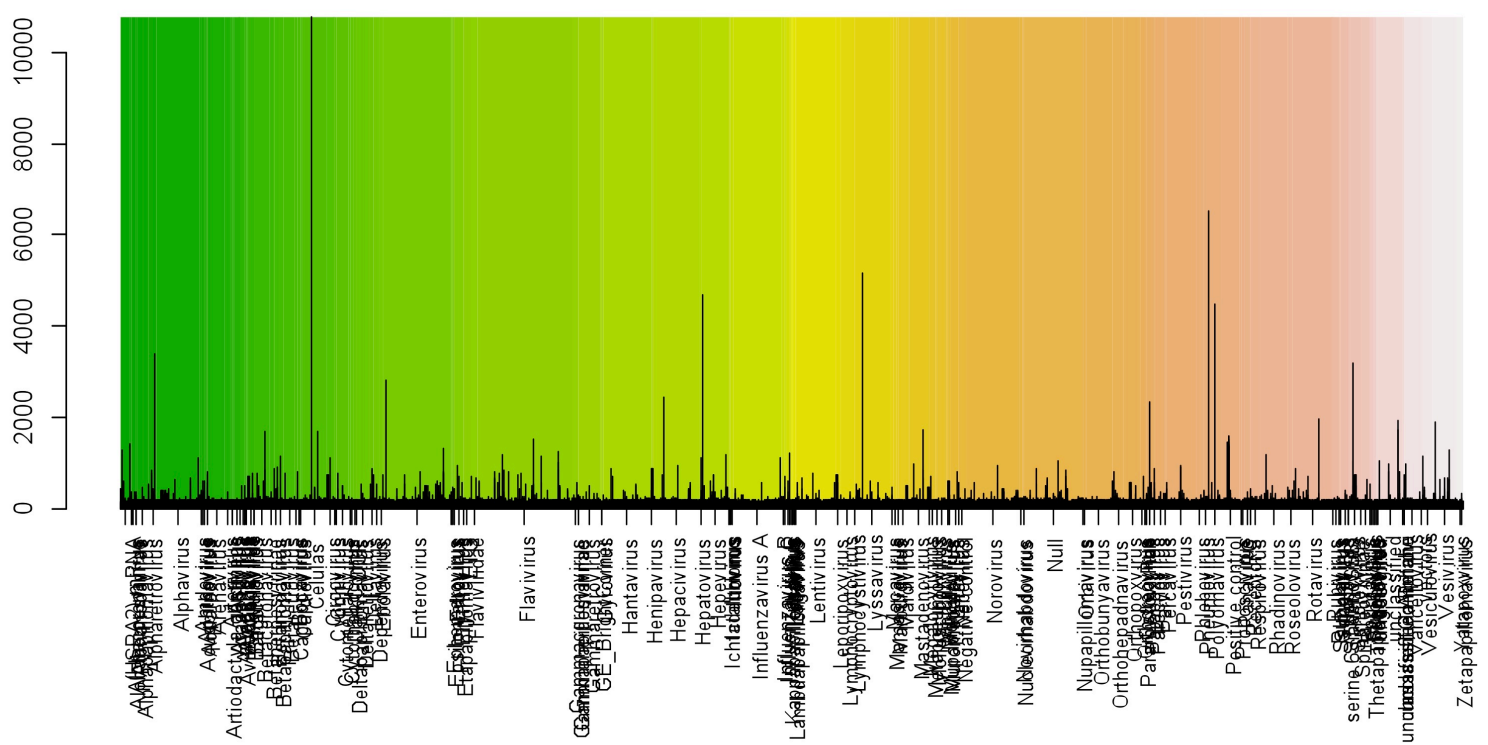

SPECIES

Control_2.8.1

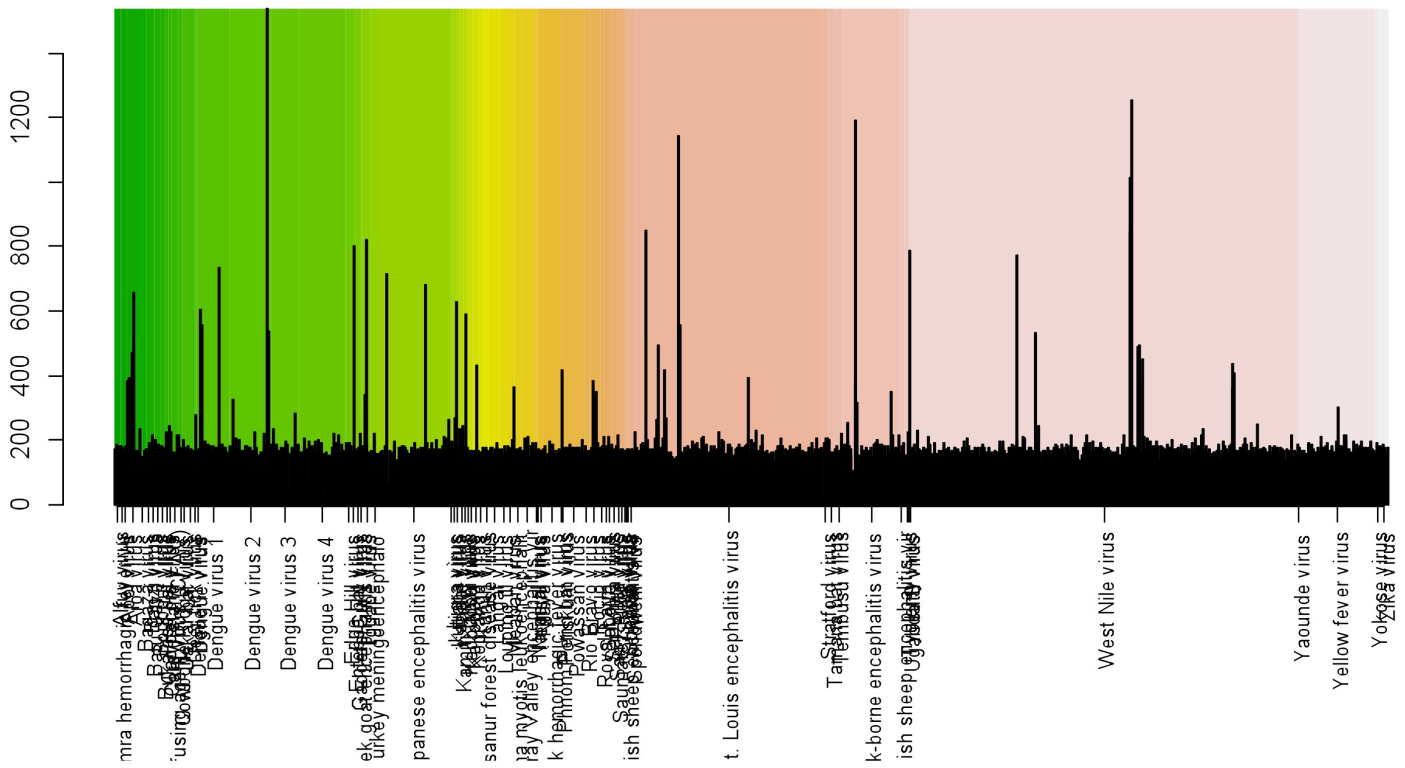

Figure 16. Visualization of probes fluorescence intensity of control slide hybridized with BUSQV. Data were sorted by family, genus and species levels. 
Table 34. Significant analysis of array hybridized with BUSQV. The top 10 viruses with lowest $p$-values.

\begin{tabular}{cccc}
\hline Virus & No. of probes & $\boldsymbol{p}$-value & Average \\
\hline Ross's goose hepatitis B virus & 4 & 0,088137166 & 1,13 \\
Simian adenovirus 3 & 5 & 0,106228303 & 1,05 \\
Enterovirus T75 & 4 & 0,154424677 & 1,19 \\
Budgerigar fledgling disease polyomavirus (BFPyV) & 5 & 0,176025292 & 1,10 \\
Human parvovirus B19 & 2 & NA & 1,42 \\
Duck circovirus & 2 & NA & 1,30 \\
Uganda S virus & 1 & NA & 2,25 \\
Potiskum virus & 1 & NA & 1,33 \\
Entebbe bat virus & 2 & NA & 1,12 \\
Human papillomavirus type 62 & 2 & NA & 2,26 \\
\hline
\end{tabular}

FAMILY

Control_3.8.1

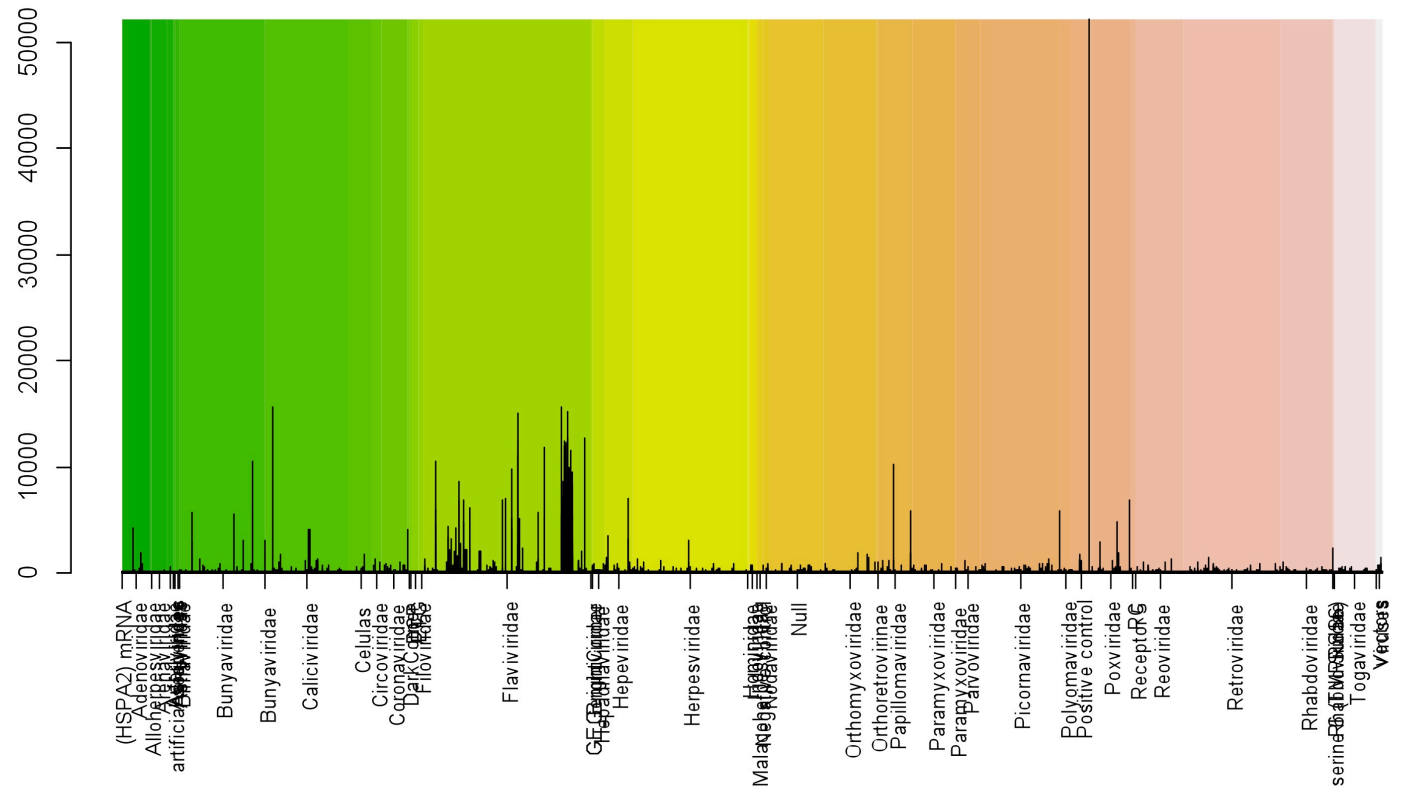




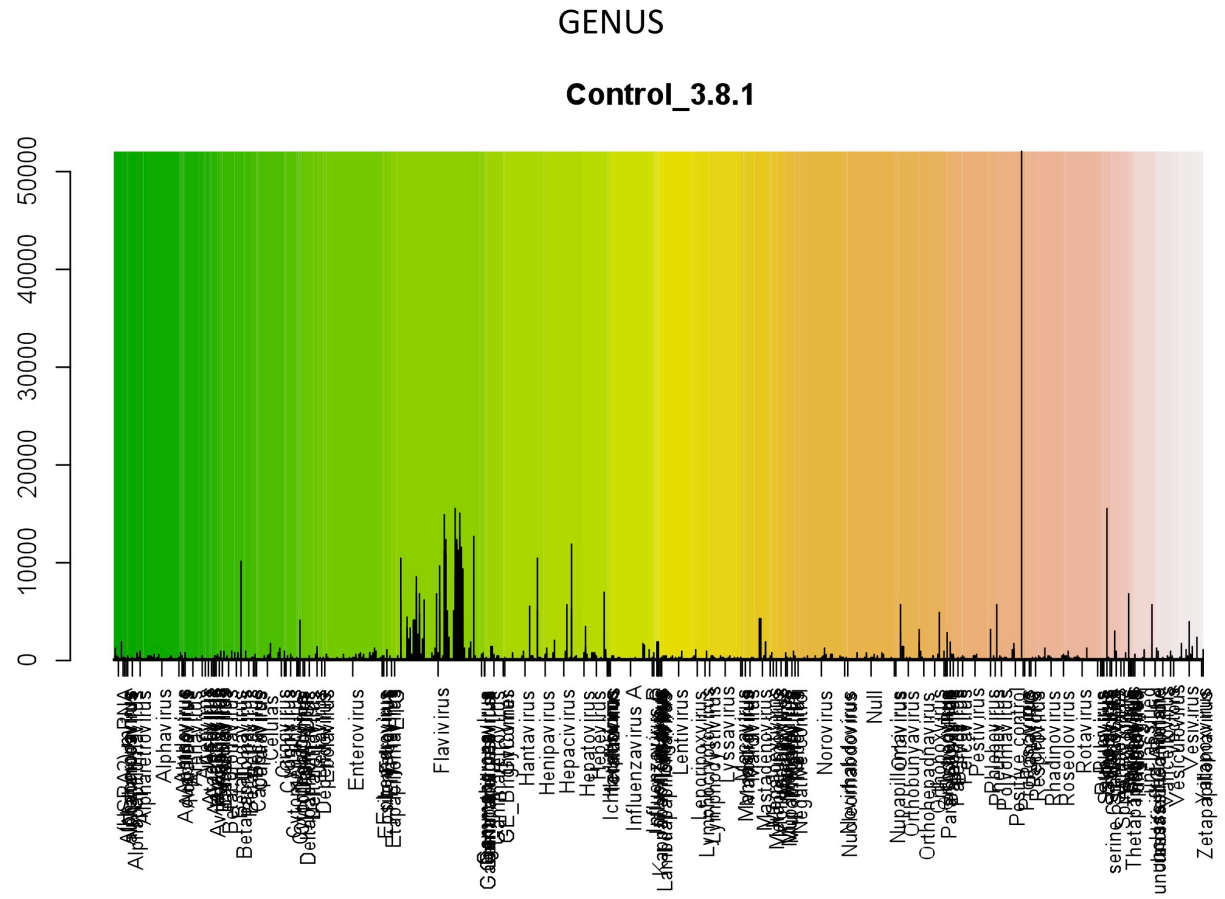

SPECIES

Control_3.8.1

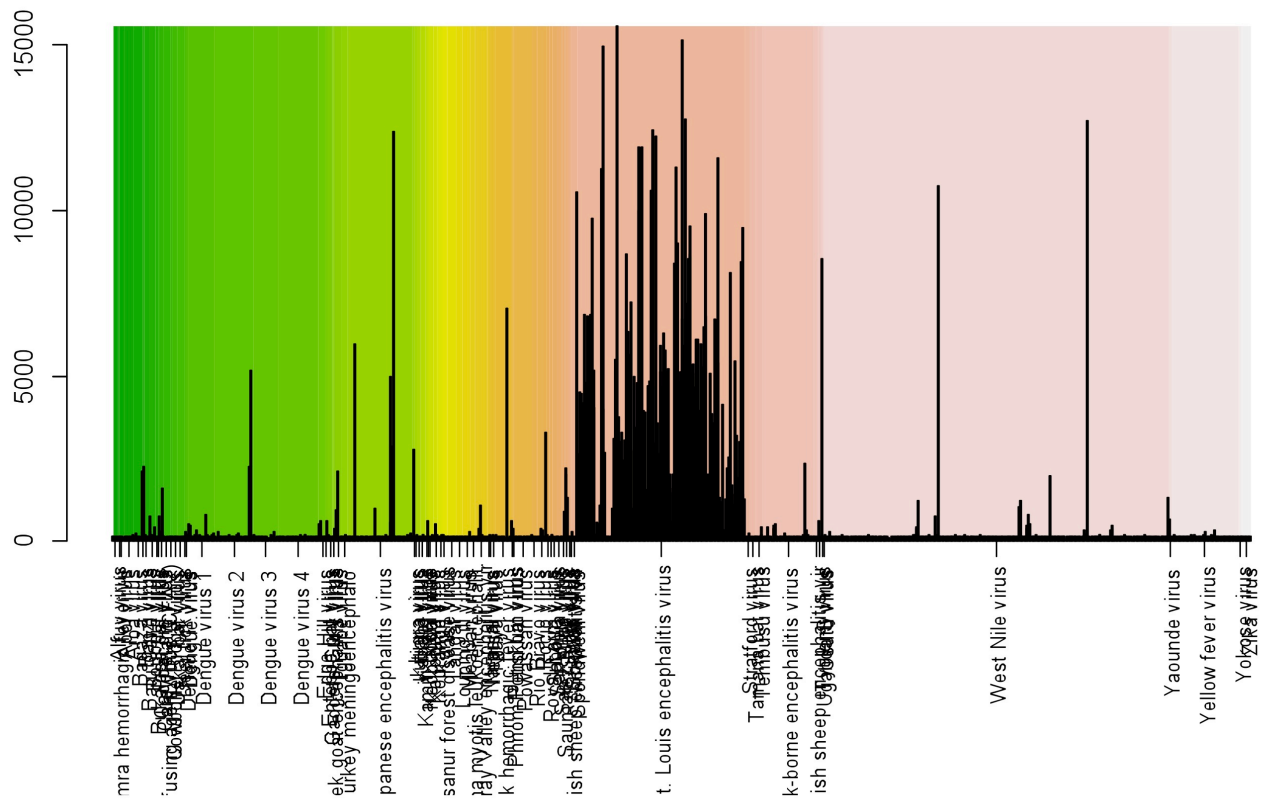

Figure 17. Visualization of probes fluorescence intensity of control slide hybridized with SLEV. Data were sorted by family, genus and species levels. 
Table 35. Significant analysis of array hybridized with SLEV. The top 10 viruses with lowest $p$-values.

\begin{tabular}{cccc}
\hline Virus & No. of probes & $\boldsymbol{p}$-value & Average \\
\hline St. Louis encephalitis virus & 176 & $4,87 \mathrm{E}-79$ & 4,20 \\
Sepik virus & 4 & 0,000677613 & 3,41 \\
Bouboui virus & 6 & 0,014903764 & 1,04 \\
Iguape virus & 8 & 0,037594137 & 1,11 \\
Aquareovirus A & 4 & 0,083036614 & 1,27 \\
Vaccinia virus Tian Tan & 3 & 0,089755356 & 1,01 \\
Ilheus virus & 7 & 0,097969637 & 1,33 \\
Yaounde virus & 3 & 0,103427328 & 1,79 \\
Carey Island virus & 3 & 0,107897284 & 1,66 \\
Ross's goose hepatitis B virus & 4 & 0,109009823 & 1,06 \\
\hline
\end{tabular}

FAMILY

Control_4.8.1

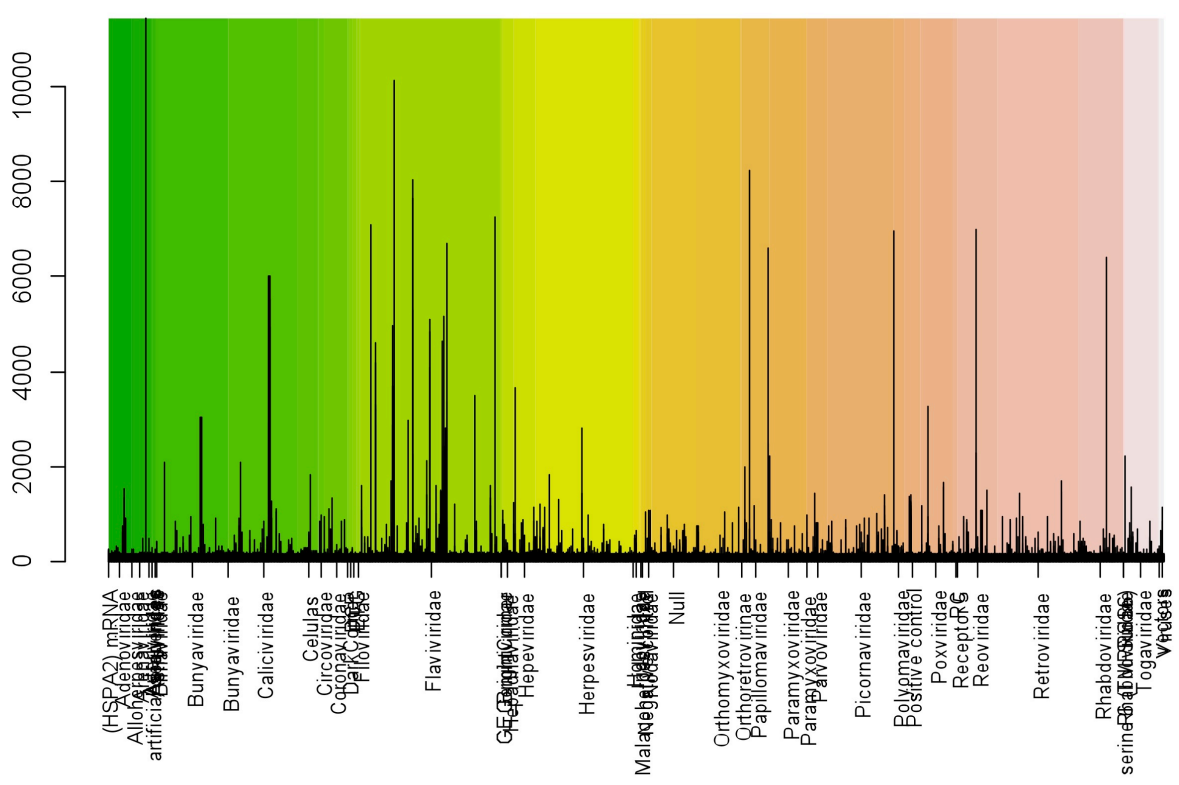



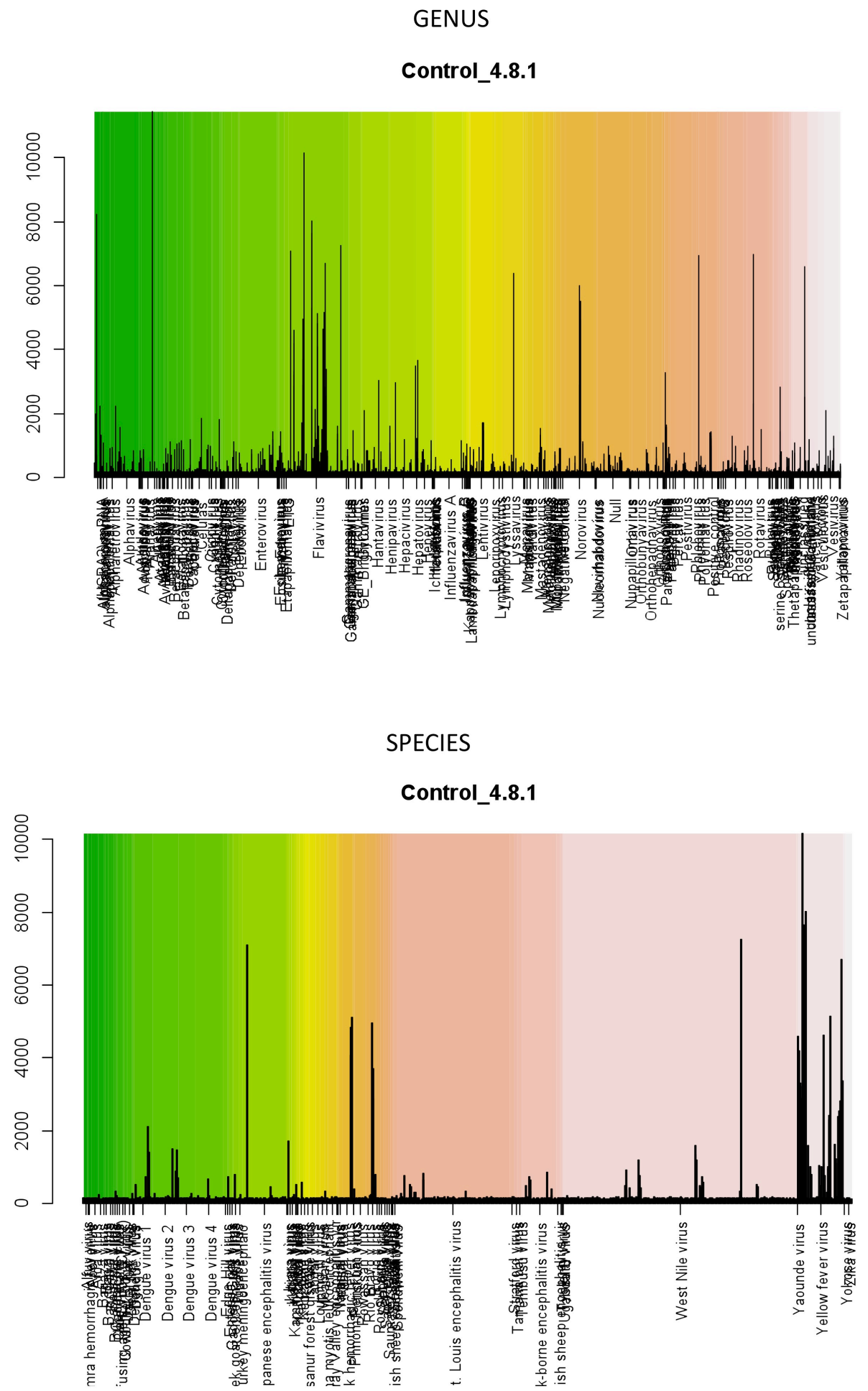

Figure 18. Visualization of probes fluorescence intensity of control slide hybridized with YFV. Data were sorted by family, genus and species levels. 
Table 36. Significant analysis of array hybridized with YFV. The top 10 viruses with lowest $p$-values.

\begin{tabular}{cccc}
\hline Virus & No. of probes & $\boldsymbol{p}$-value & Average \\
\hline Yellow fever virus & 70 & $1,57 \mathrm{E}-11$ & 1,97 \\
Rocio virus & 10 & 0,004416565 & 2,08 \\
Ross's goose hepatitis B virus & 4 & 0,088646201 & 1,35 \\
Aquareovirus A & 4 & 0,120164631 & 1,09 \\
Budgerigar fledgling disease polyomavirus (BFPyV) & 5 & 0,205378295 & 1,05 \\
TGEV Miller M60 (TGEV) & 3 & 0,214080666 & 1,07 \\
Human papillomavirus type 77 & 3 & 0,216642785 & 1,92 \\
Jutiapa virus & 3 & 0,232050769 & 1,11 \\
Human parvovirus B19 & 2 & NA & 2,47 \\
Amur virus & 2 & NA & 1,90 \\
\hline
\end{tabular}

FAMILY

Control_5.8.1

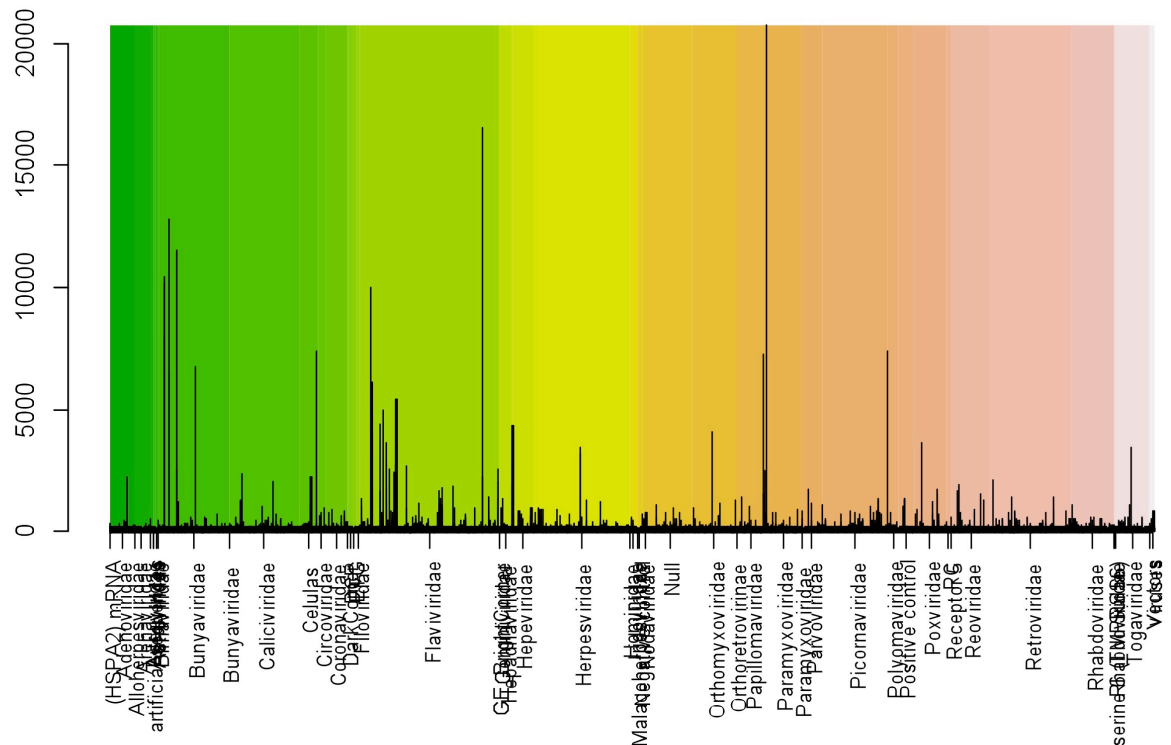




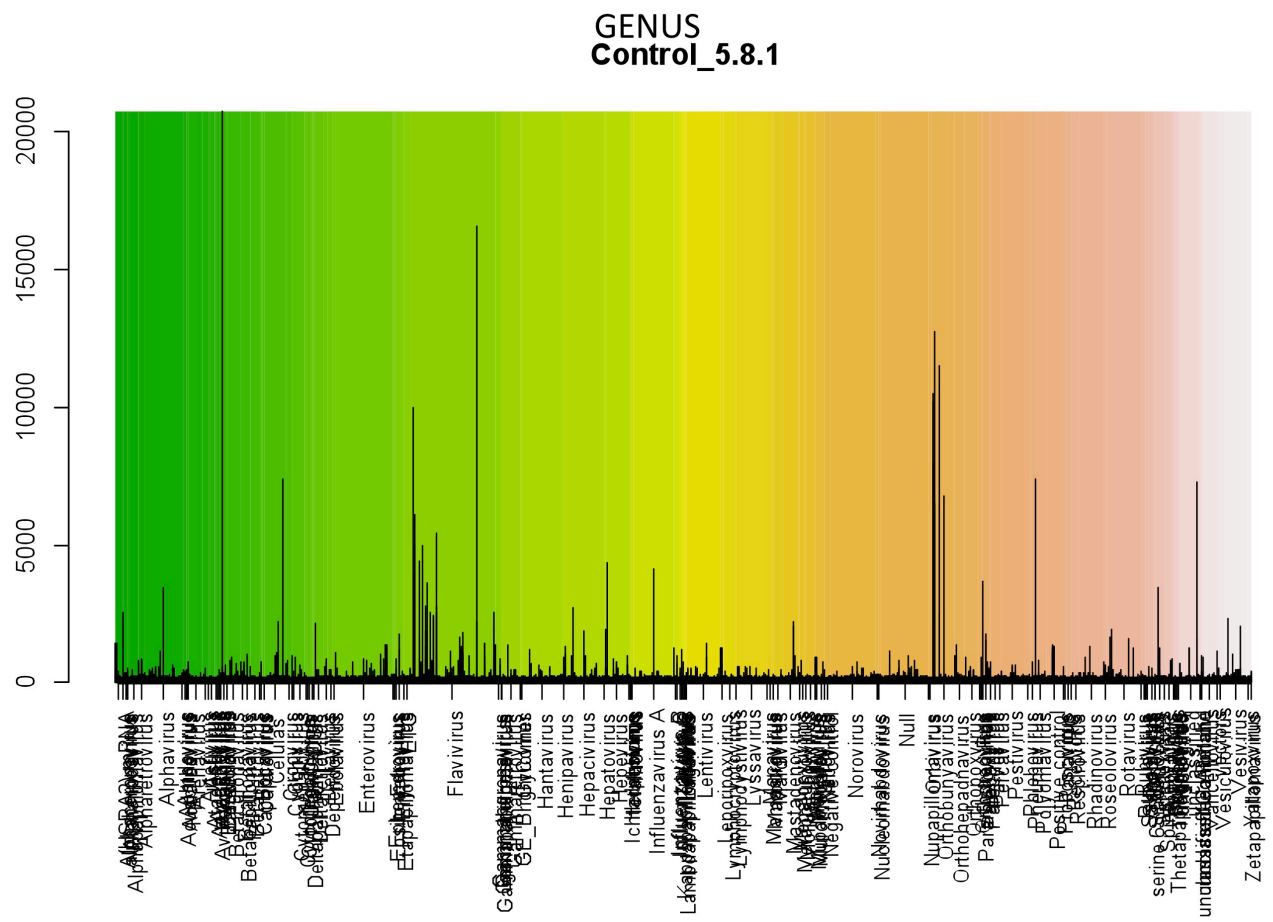

SPECIES

Control_5.8.1

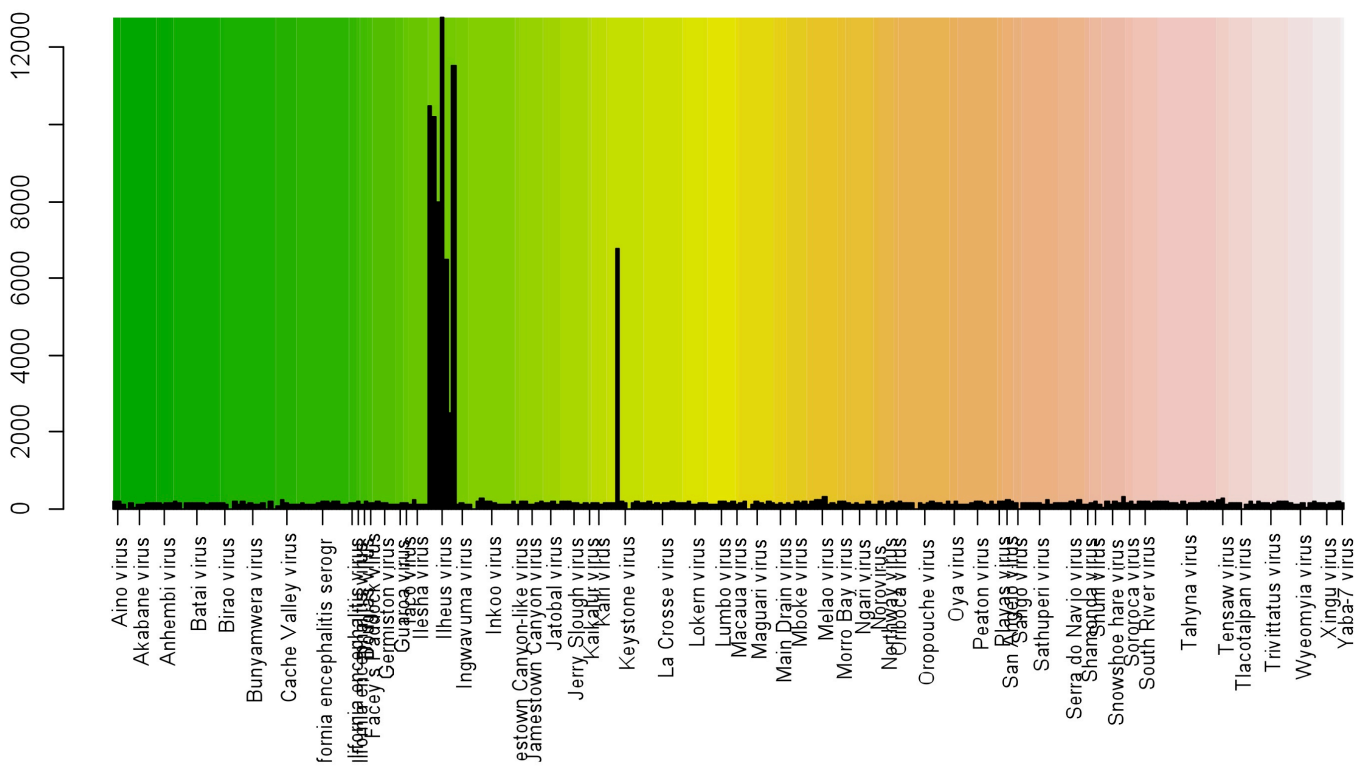

Figure 19. Visualization of probes fluorescence intensity of control slide hybridized with ILHV. Data were sorted by family, genus and species levels. 
Table 37. Significant analysis of array hybridized with ILHV. The top 10 viruses with lowest $p$-values.

\begin{tabular}{cccc}
\hline Virus & No. of probes & $\boldsymbol{p}$-value & Average \\
\hline Ilheus virus & 7 & $8,36 \mathrm{E}-07$ & 5,62 \\
Sepik virus & 4 & 0,000504498 & 3,70 \\
Aquareovirus A & 4 & 0,080335801 & 1,12 \\
Human papillomavirus type JEB2 & 4 & 0,088757631 & 1,03 \\
Dakar bat virus & 4 & 0,095624451 & 2,47 \\
Infectious salmon anemia virus & 3 & 0,163918924 & 1,13 \\
Kadam virus & 3 & 0,199990503 & 1,42 \\
Budgerigar fledgling disease polyomavirus (BFPyV) & 5 & 0,208990471 & 1,02 \\
Human parvovirus B19 & 2 & NA & 2,06 \\
Duck circovirus & 2 & NA & 1,12 \\
\hline
\end{tabular}

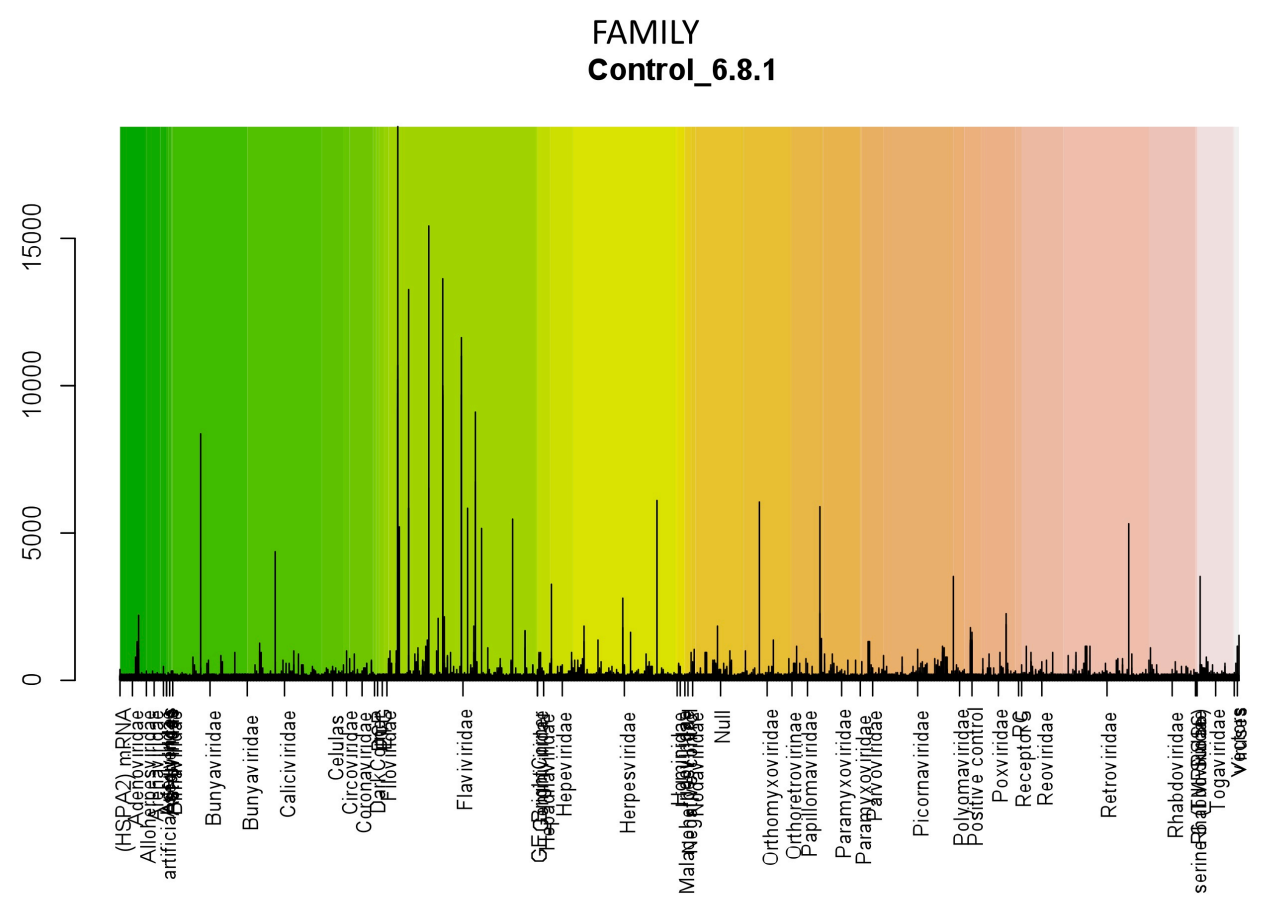




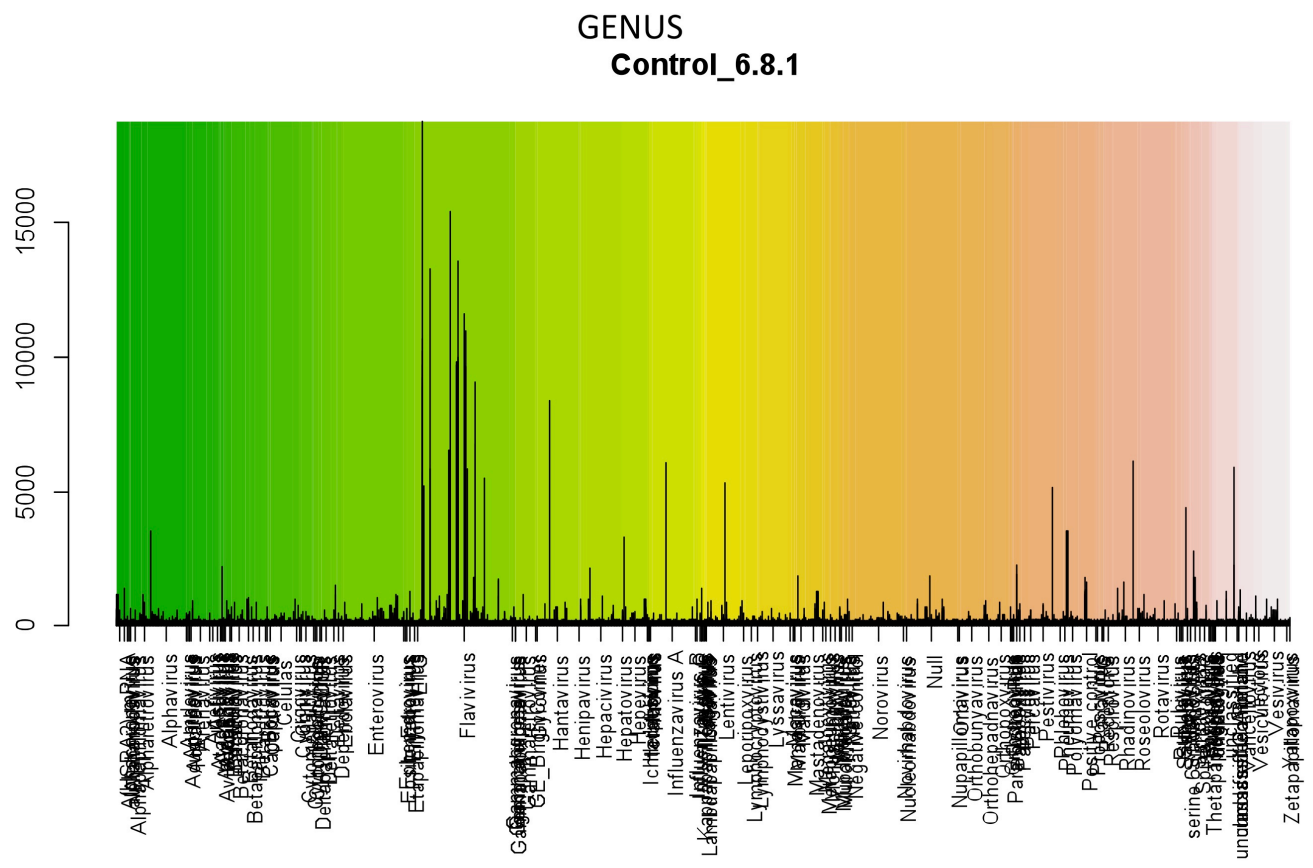

SPECIES

Control_6.8.1

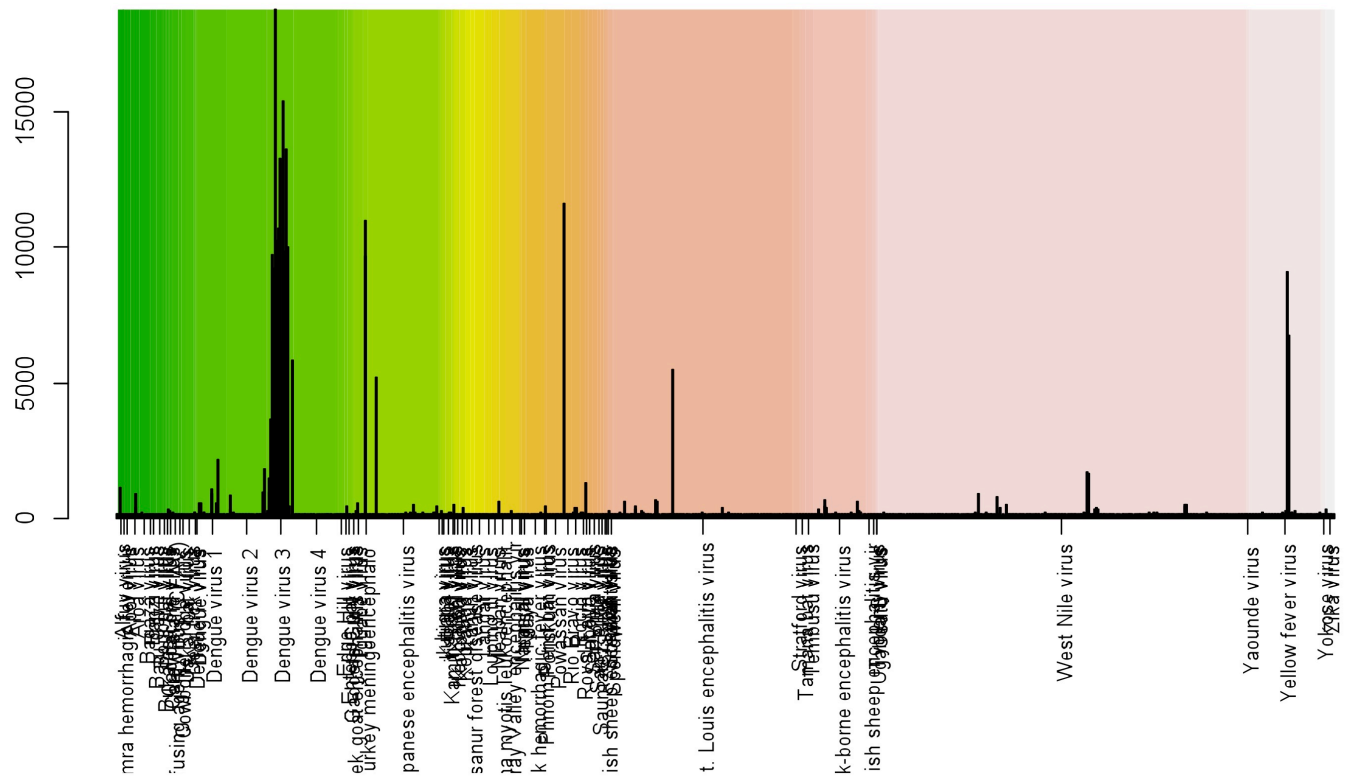

Figure 20. Visualization of probes fluorescence intensity of control slide hybridized with DENV-3. Data were sorted by family, genus and species levels. 
Table 38. Significant analysis of array hybridized with DENV-3. The top 10 viruses with lowest $p$-values.

\begin{tabular}{cccc}
\hline Virus & No. of probes & $p$-value & Average \\
\hline Dengue virus 3 & 26 & $3,49 \mathrm{E}-09$ & 4,10 \\
Ross's goose hepatitis B virus & 4 & 0,091616271 & 1,18 \\
Israel turkey meningoencephalomyelitis virus & 6 & 0,092116512 & 1,92 \\
Aquareovirus A & 4 & 0,093947029 & 1,08 \\
Infectious salmon anemia virus & 3 & 0,176806457 & 1,11 \\
Human parvovirus B19 & 2 & NA & 1,87 \\
Duck circovirus & 2 & NA & 1,18 \\
Potiskum virus & 1 & NA & 1,33 \\
Human papillomavirus type 62 & 2 & NA & 2,32 \\
Human papillomavirus type 15 & 2 & NA & 1,14 \\
\hline
\end{tabular}

FAMILY

Control_7.8.1

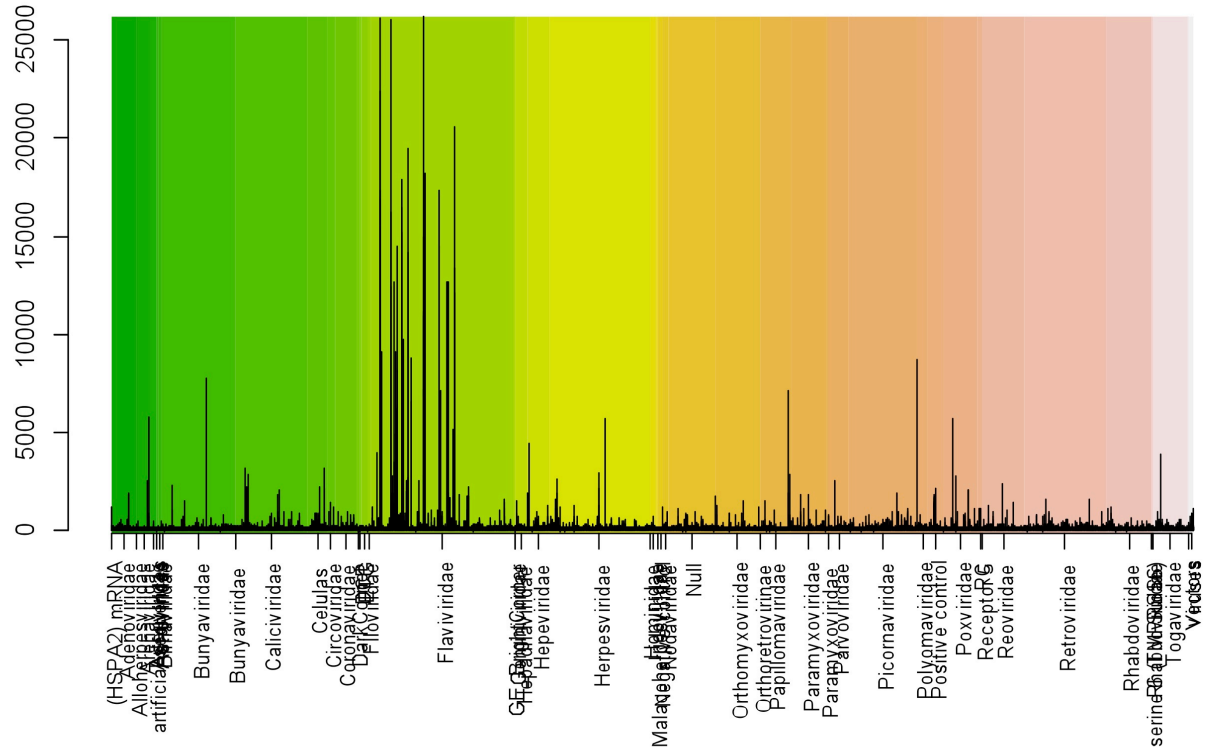




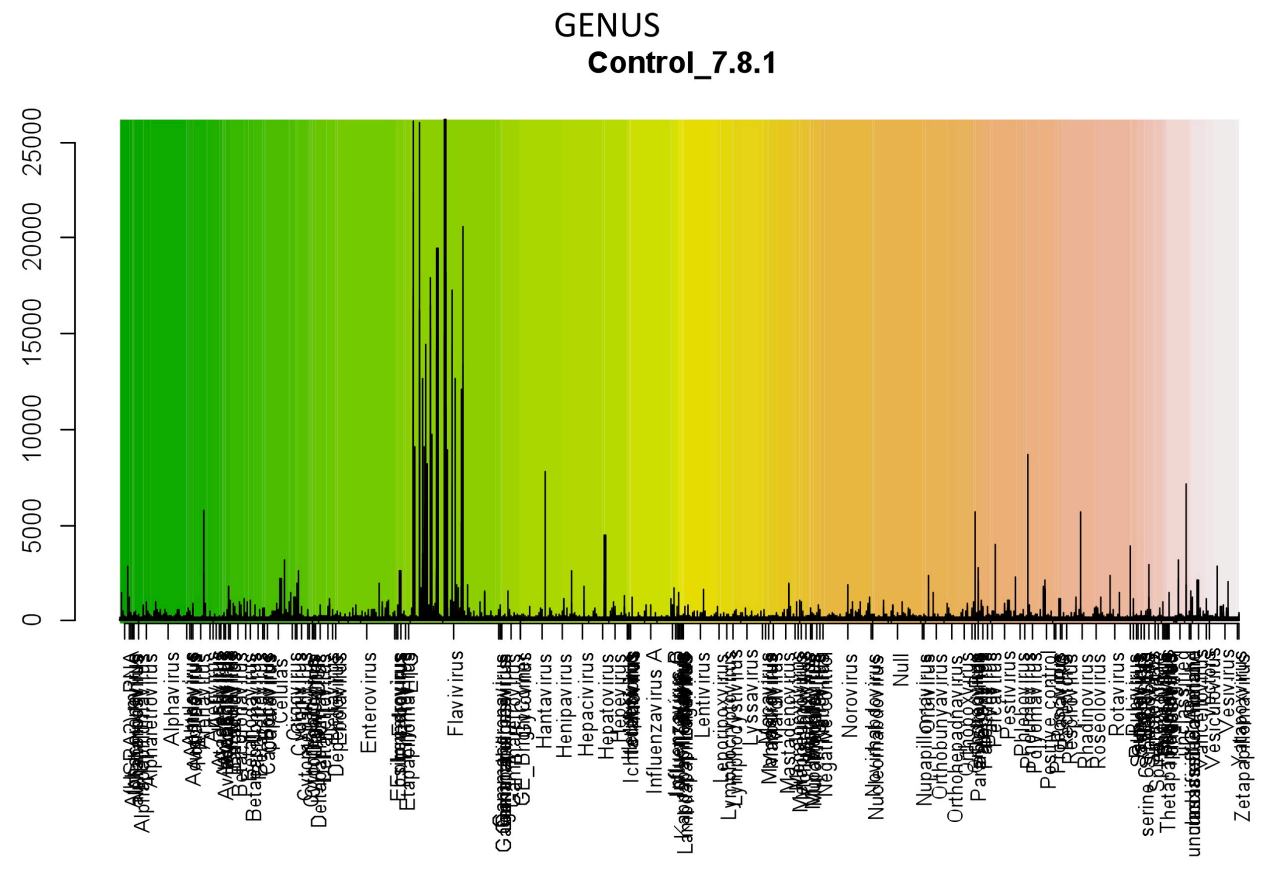

SPECIES

Control_7.8.1

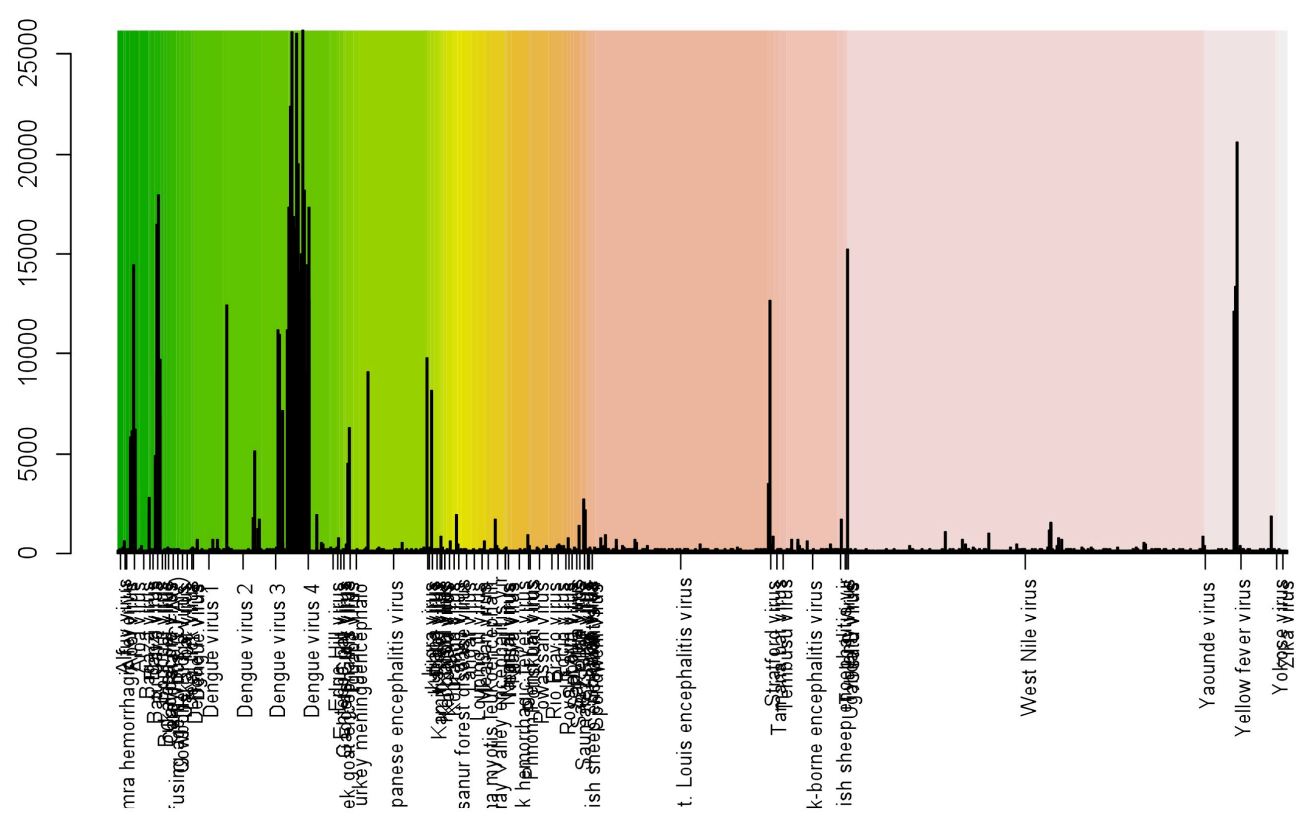

Figure 21. Visualization of probes fluorescence intensity of control slide hybridized with DENV-4. Data were sorted by family, genus and species levels. 
Table 39. Significant analysis of array hybridized with DENV-4. The top 10 viruses with lowest $p$-values.

\begin{tabular}{cccc}
\hline Virus & No. opf probes & $p$-value & Average \\
\hline Dengue virus 4 & 43 & $3,32 \mathrm{E}-09$ & 3,56 \\
Bouboui virus & 6 & $2,85 \mathrm{E}-06$ & 5,87 \\
Aroa virus & 10 & 0,000994282 & 3,56 \\
Sepik virus & 4 & 0,024625891 & 2,96 \\
Iguape virus & 8 & 0,045791538 & 1,53 \\
Aquareovirus A & 4 & 0,047480907 & 1,28 \\
Kyasanur forest disease virus & 5 & 0,10878446 & 1,01 \\
Stratford virus & 6 & 0,121011845 & 1,90 \\
Ross's goose hepatitis B virus & 4 & 0,123320852 & 1,26 \\
Sagiyama virus & 3 & 0,124897547 & 1,30 \\
\hline
\end{tabular}

\section{FAMILY}

Control_8.8.1

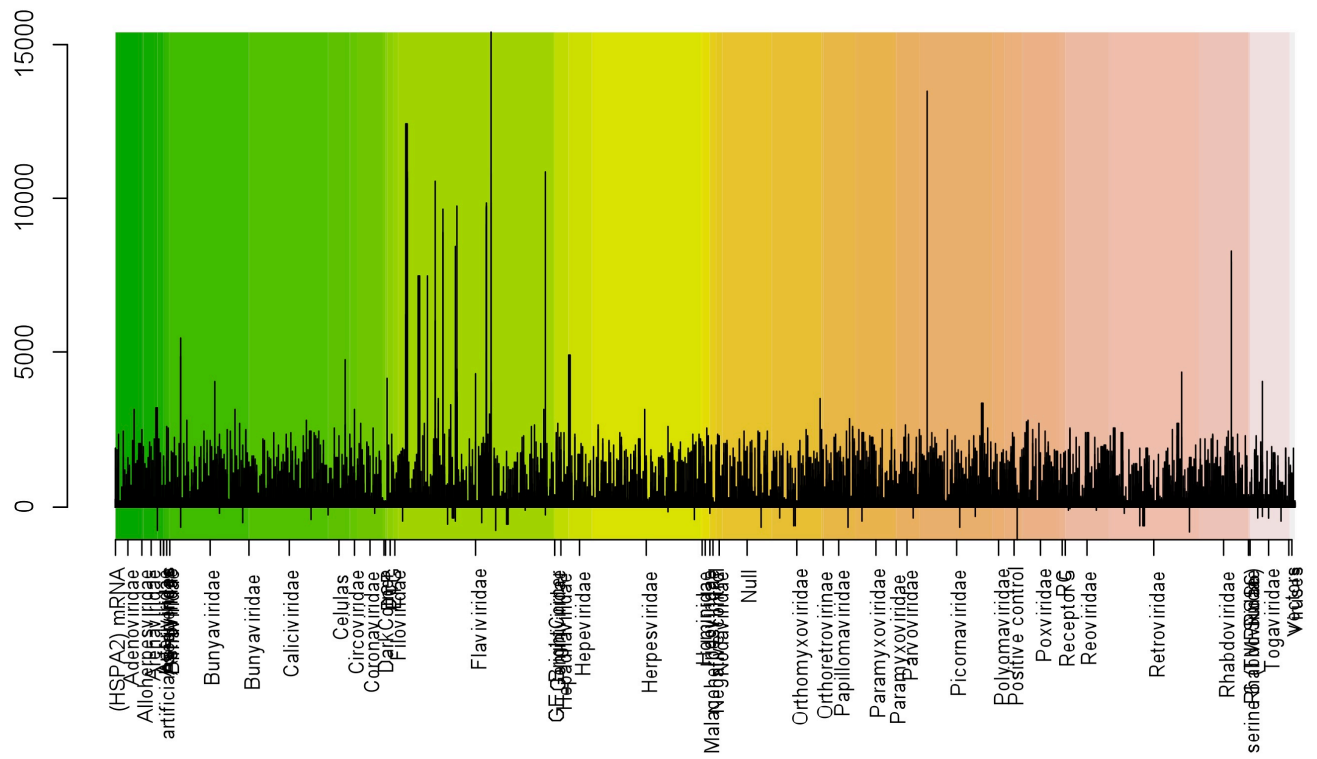




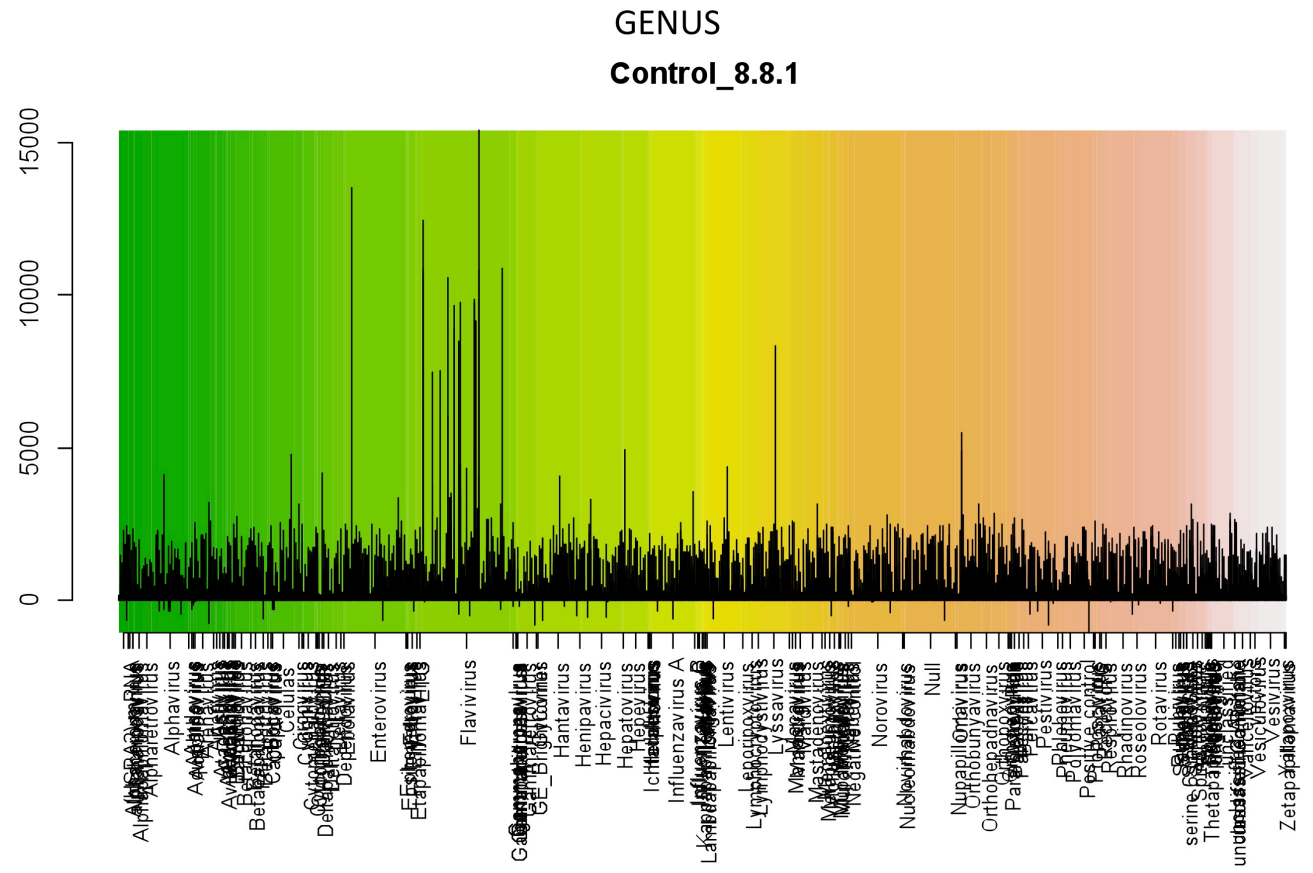

SPECIES

Control_8.8.1

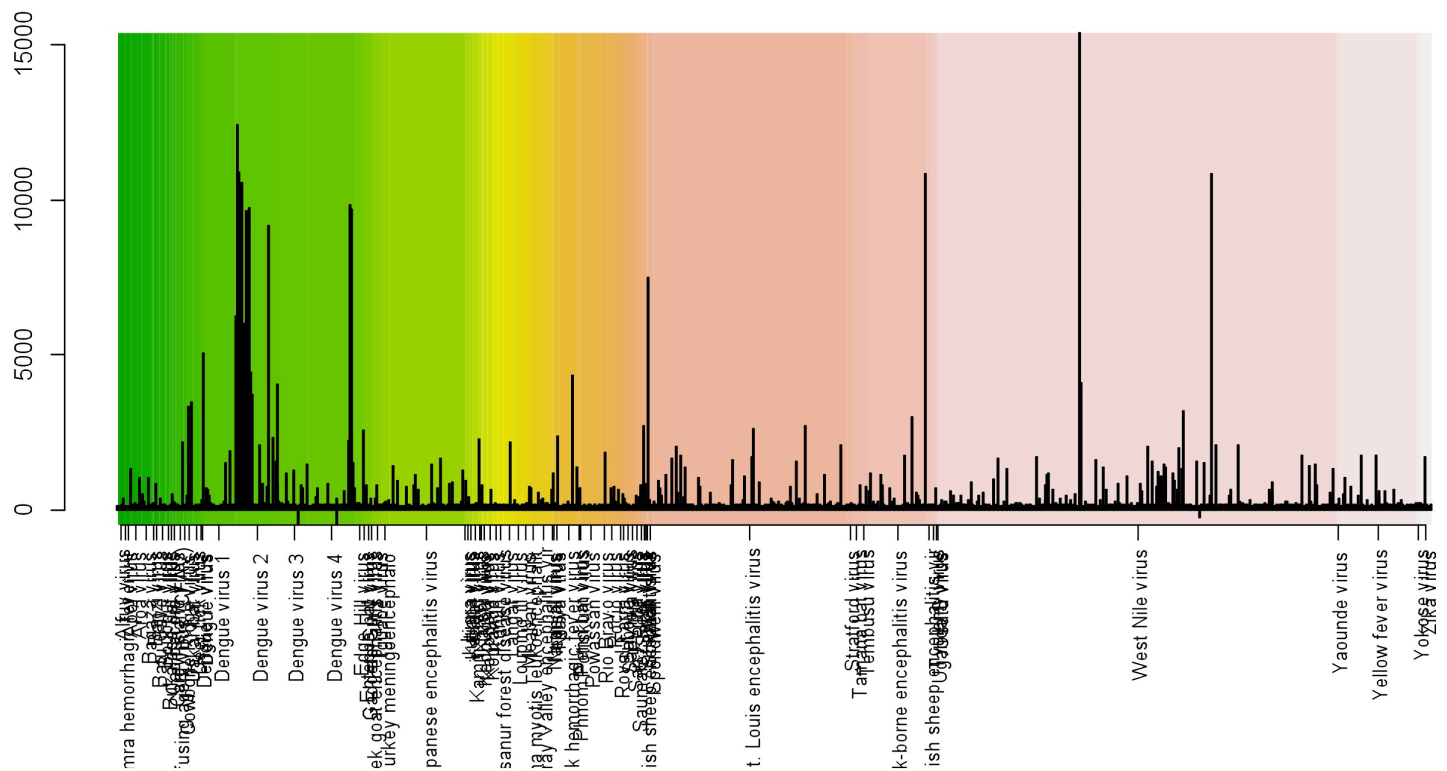

Figure 22. Visualization of probes fluorescence intensity of control slide hybridized with DENV-2. Data were sorted by family, genus and species levels. 
Table 40. Significant analysis of array hybridized with DENV-2. The top 10 viruses with lowest $p$-values.

\begin{tabular}{cccc}
\hline Virus & No. of probes & $p$-value & Average \\
\hline Dengue virus 2 & 40 & $3,27 \mathrm{E}-09$ & 2,99 \\
Sepik virus & 4 & 0,001131728 & 2,19 \\
Simian cytomegalovirus & 13 & 0,00185129 & 1,51 \\
Avian carcinoma virus & 5 & 0,002049661 & 1,90 \\
Sapporo virus & 17 & 0,002101187 & 1,12 \\
Chipmunk parvovirus (ChPV) & 10 & 0,00524159 & 1,66 \\
Dakar bat virus & 4 & 0,007803725 & 3,49 \\
Cercopithecine herpesvirus 2 (Simian agent 8) & 10 & 0,008182422 & 1,36 \\
Atractoscion nobilis nervous necrosis virus & 5 & 0,008779628 & 1,91 \\
Dicentrarchus labrax encephalitis virus & 15 & 0,00943468 & 1,21 \\
\hline
\end{tabular}

The control slide was able to detect SLEV, YFV, ILHV, DENV-4, DENV-3, and DENV-2, but not OROV neither BUSV. After analysis of the probes included in the control slide, we found that no probes were included for BUSQV. In addition, several probes with cross-hybridization were found in both experiments using this slide. We concluded that this slide is not matching the standard as a control slide; that is why we decided not to use farther in this study. 
FAMILY

RoboArbochip_results_1.8.1

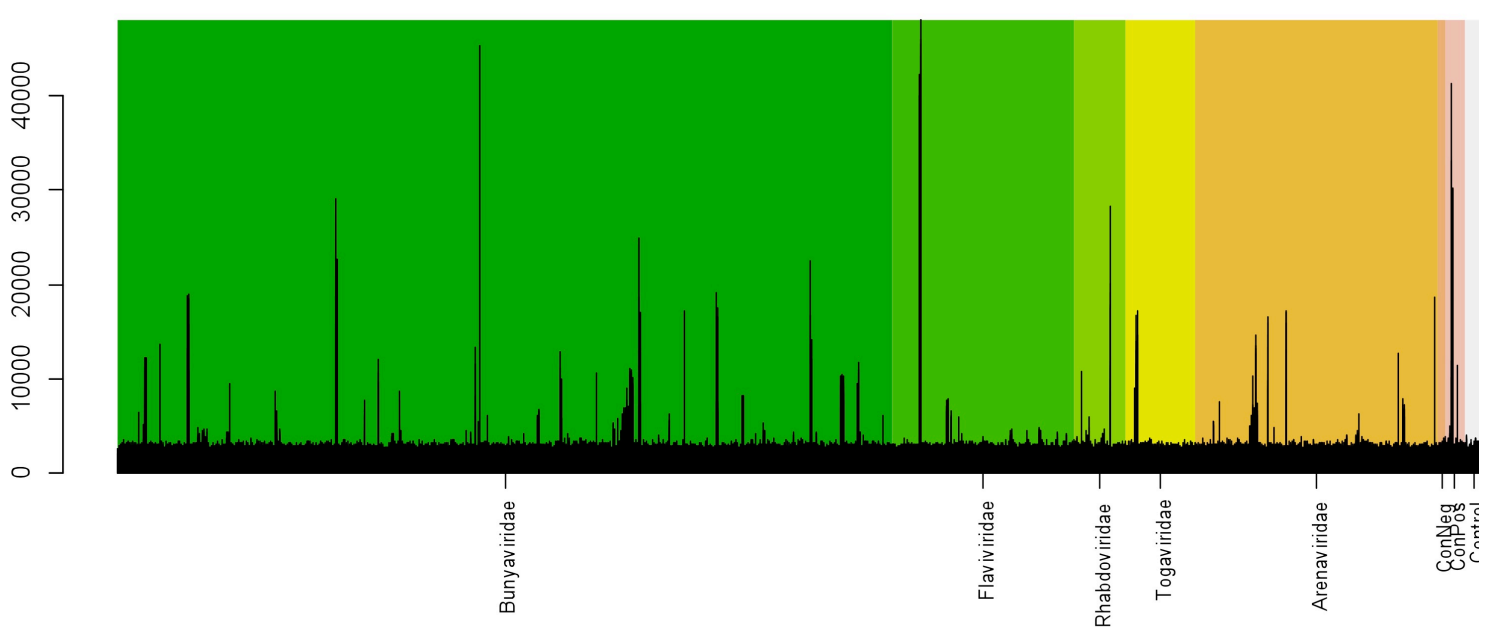

RoboArbochip_results_1.8.1

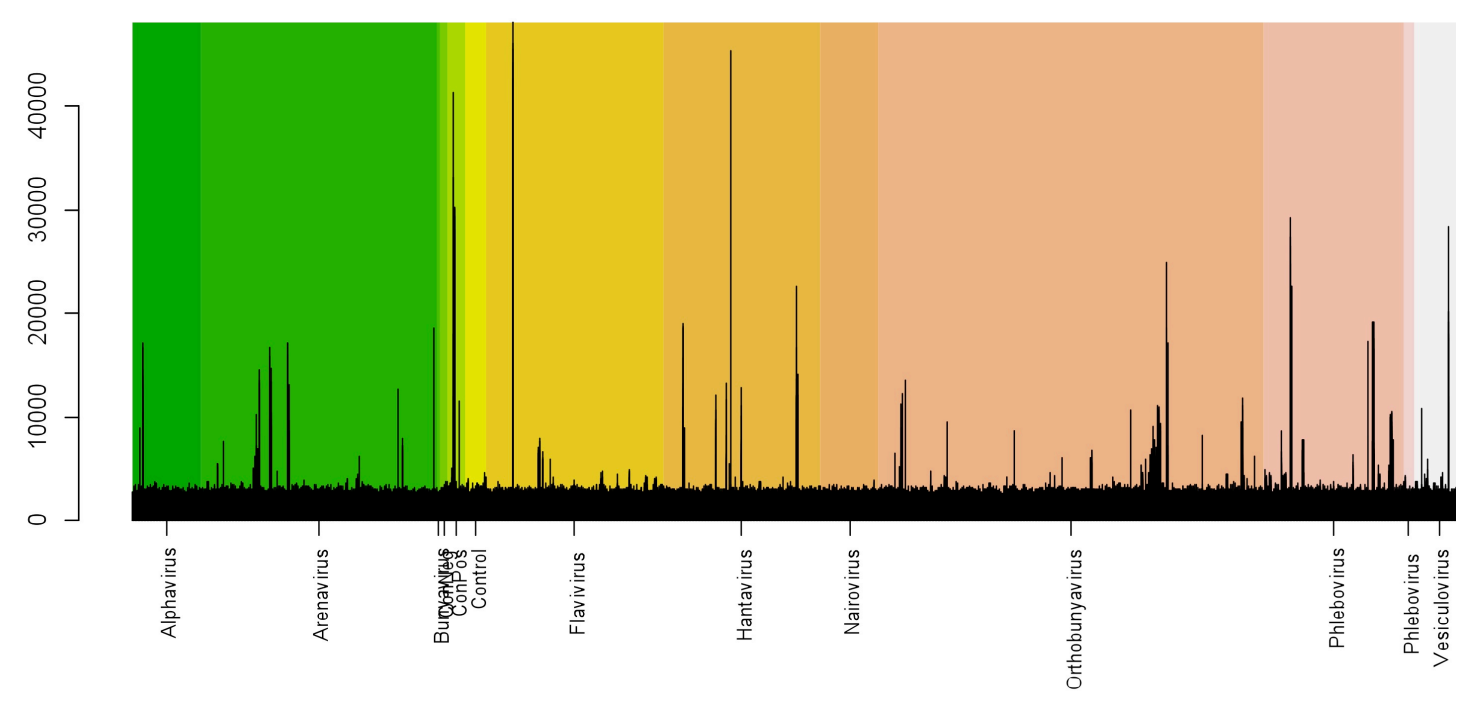


SPECIES - Orthobunyavirus

RoboArbochip_results_1.8.1

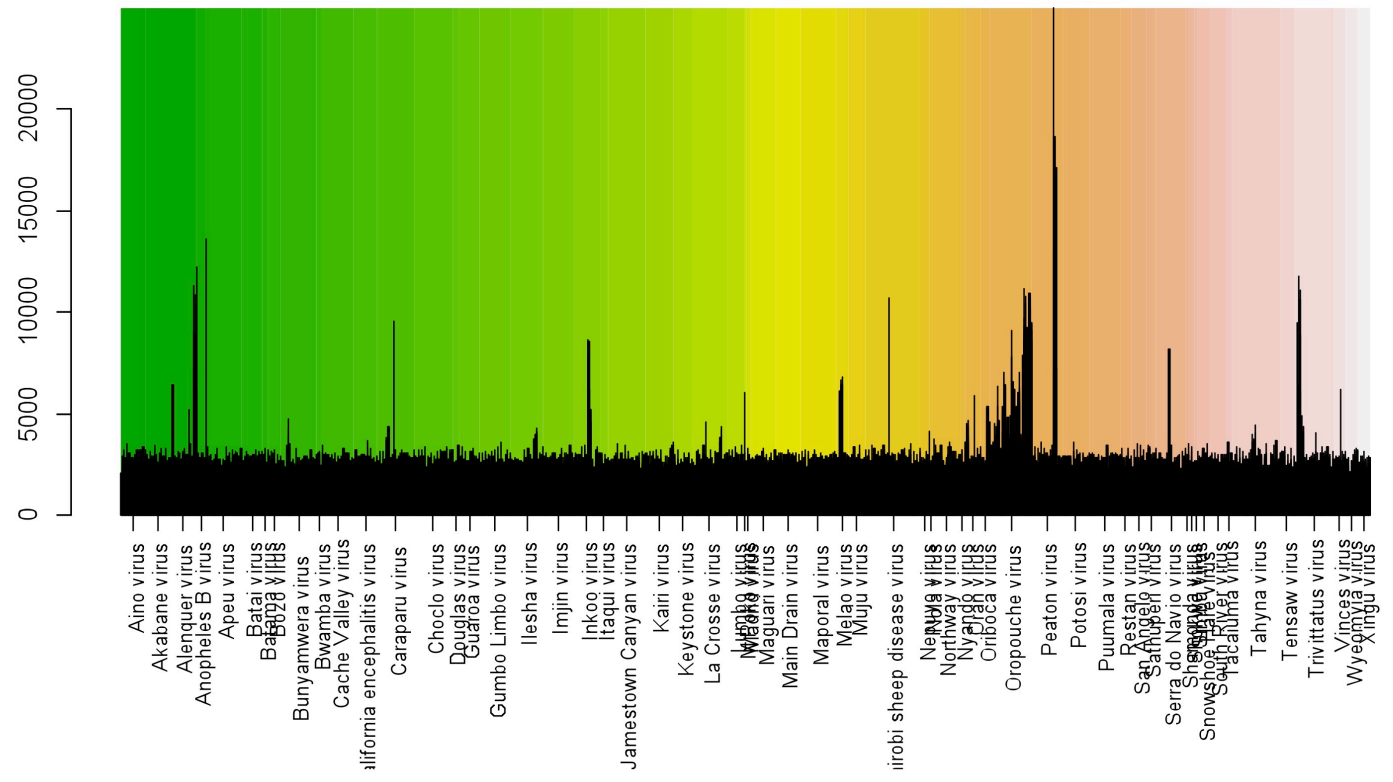

Figure 23. Visualization of probes fluorescence intensity of control slide hybridized with OROV. Data were sorted by family, genus and species levels.

Table 41. Significant analysis of array hybridized with OROV. The top 10 viruses with lowest $p$-values.

\begin{tabular}{cccc}
\hline Virus & No. of probes & $\boldsymbol{p}$-value & Average \\
\hline Edge Hill virus & 11 & $1,15 \mathrm{E}-12$ & 1,40 \\
Muleshoe virus & 11 & $6,40 \mathrm{E}-08$ & 1,58 \\
Cy1014 virus & 22 & $4,95 \mathrm{E}-05$ & 2,07 \\
\hline
\end{tabular}


FAMILY

RoboArbochip_results_2.8.1

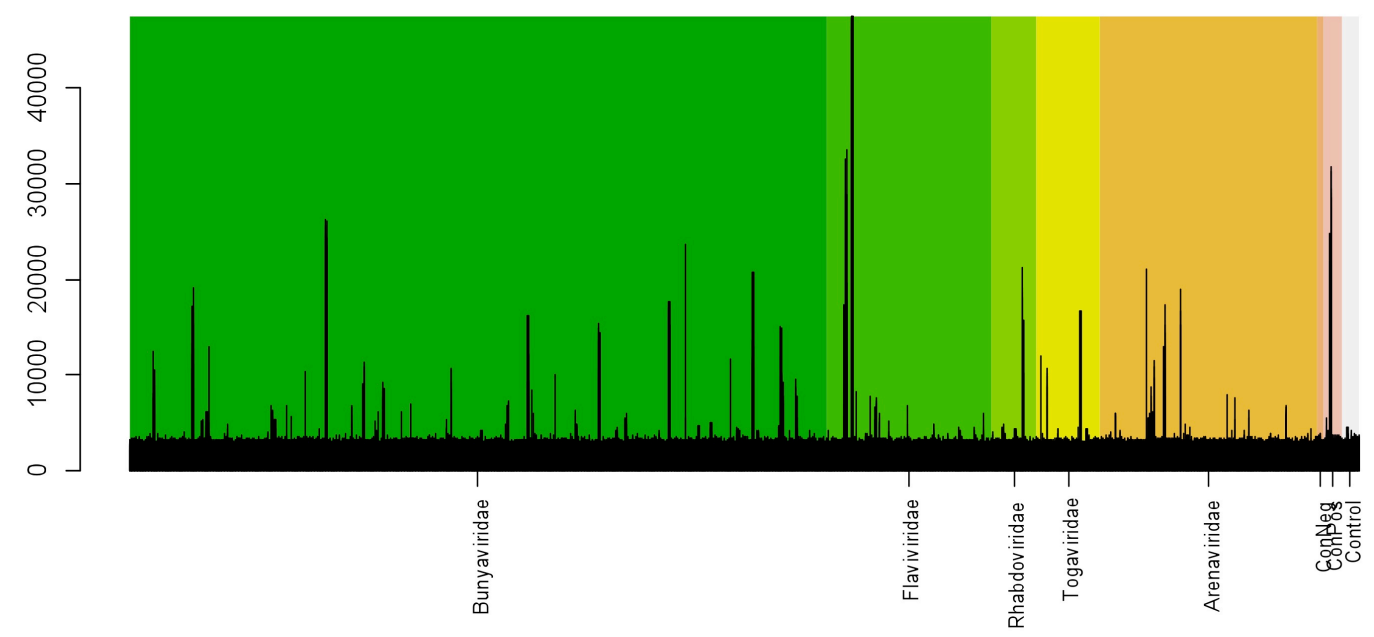

GENUS

RoboArbochip_results_2.8.1

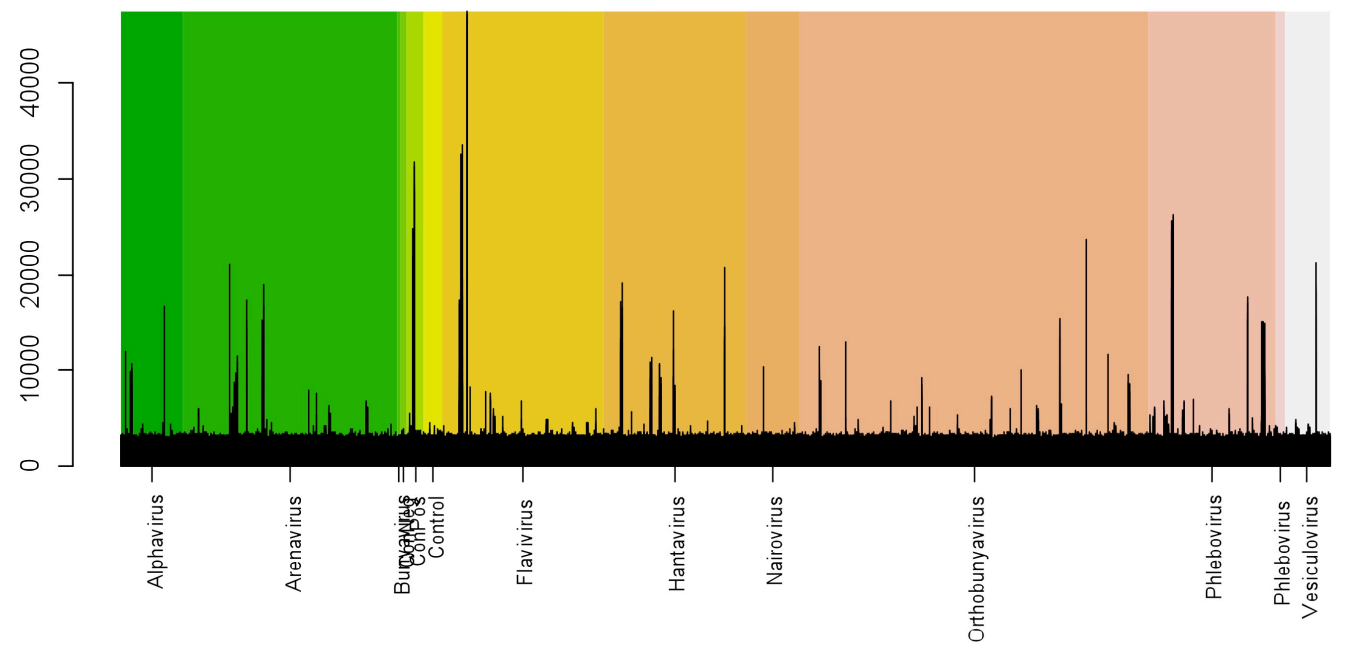




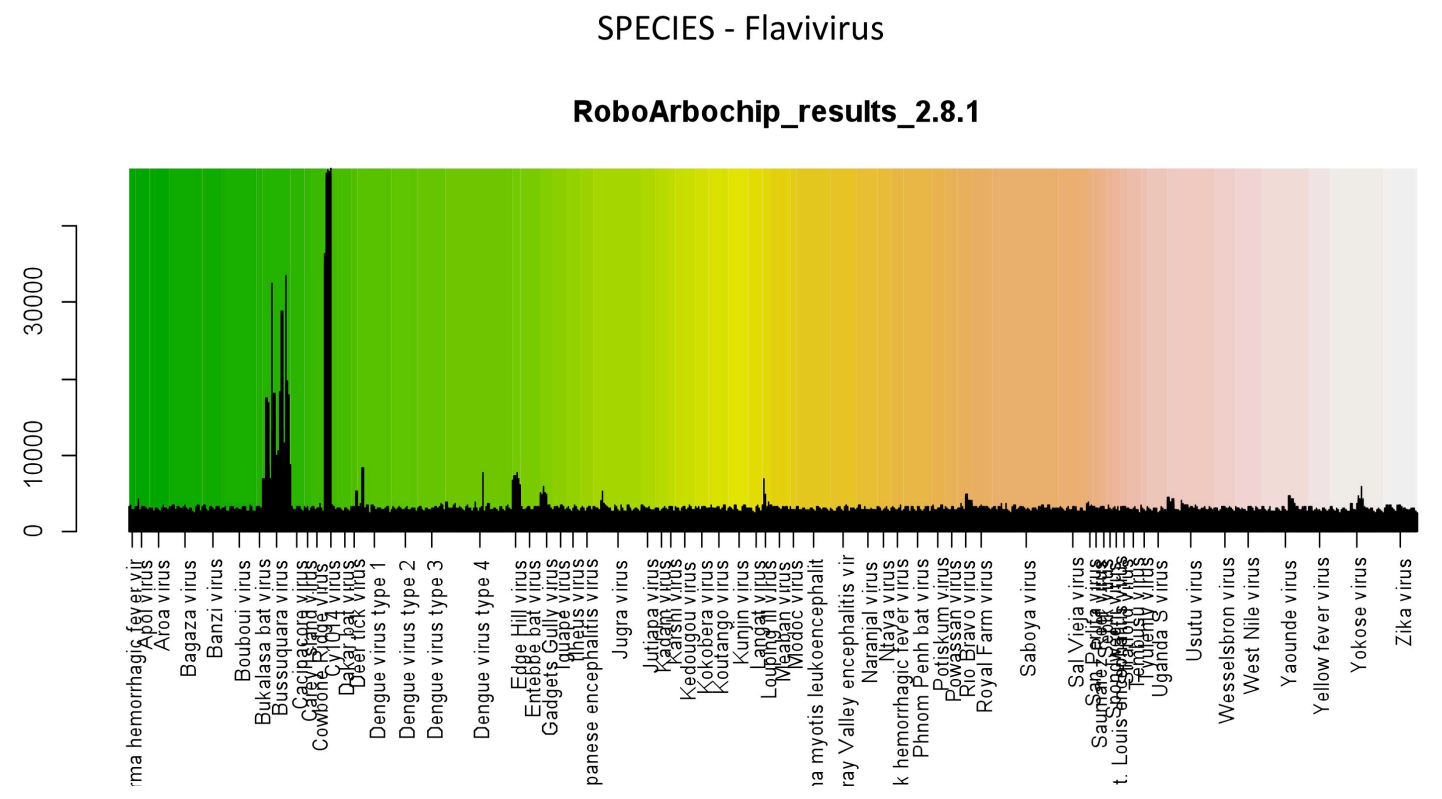

Figure 24. Visualization of probes fluorescence intensity of control slide hybridized with BUSQV. Data were sorted by family, genus and species levels.

Table 42. Significant analysis of array hybridized with BUSQV. The top 10 viruses with lowest $p$-values.

\begin{tabular}{cccc}
\hline Virus & No. of probes & $\boldsymbol{p}$-value & Average \\
\hline Bussuquara virus & 44 & $6,16 \mathrm{E}-22$ & 1,84 \\
Edge Hill virus & 11 & $1,16 \mathrm{E}-11$ & 1,22 \\
Muleshoe virus & 11 & $3,46 \mathrm{E}-08$ & 1,63 \\
Cy1014 virus & 22 & $5,19 \mathrm{E}-05$ & 1,98 \\
\hline
\end{tabular}


FAMILY

RoboArbochip_results_3.8.1

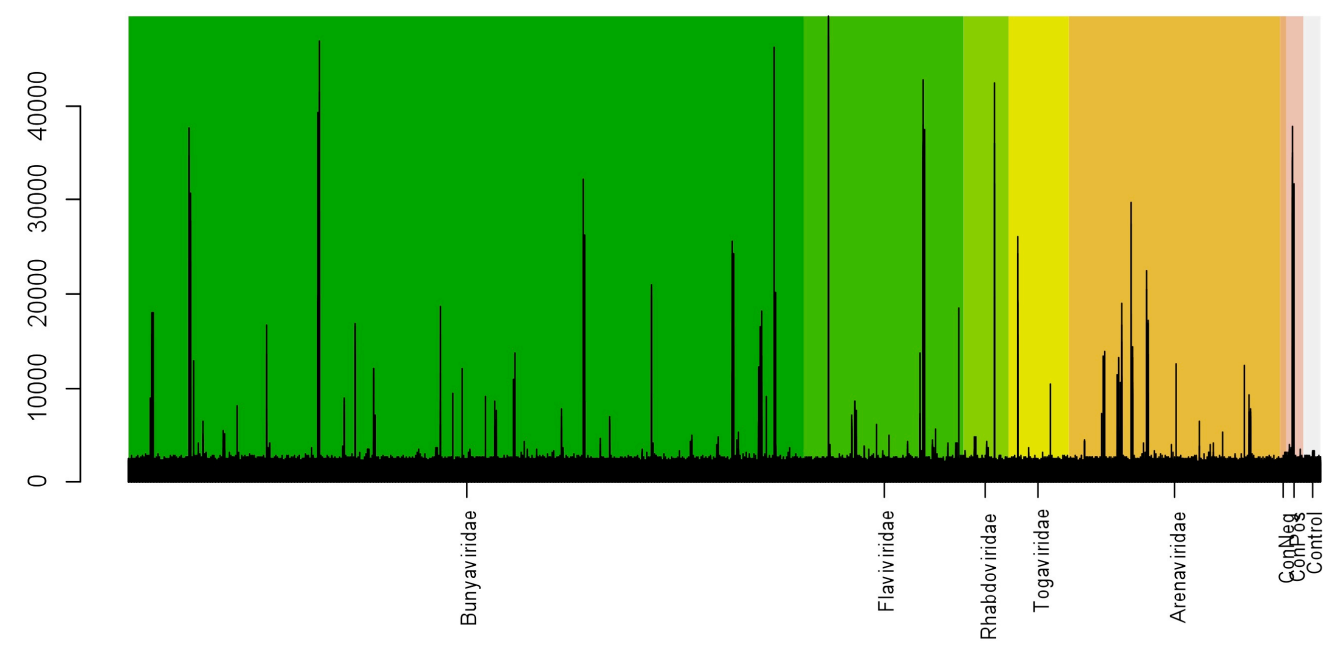

GENUS

RoboArbochip_results_3.8.1

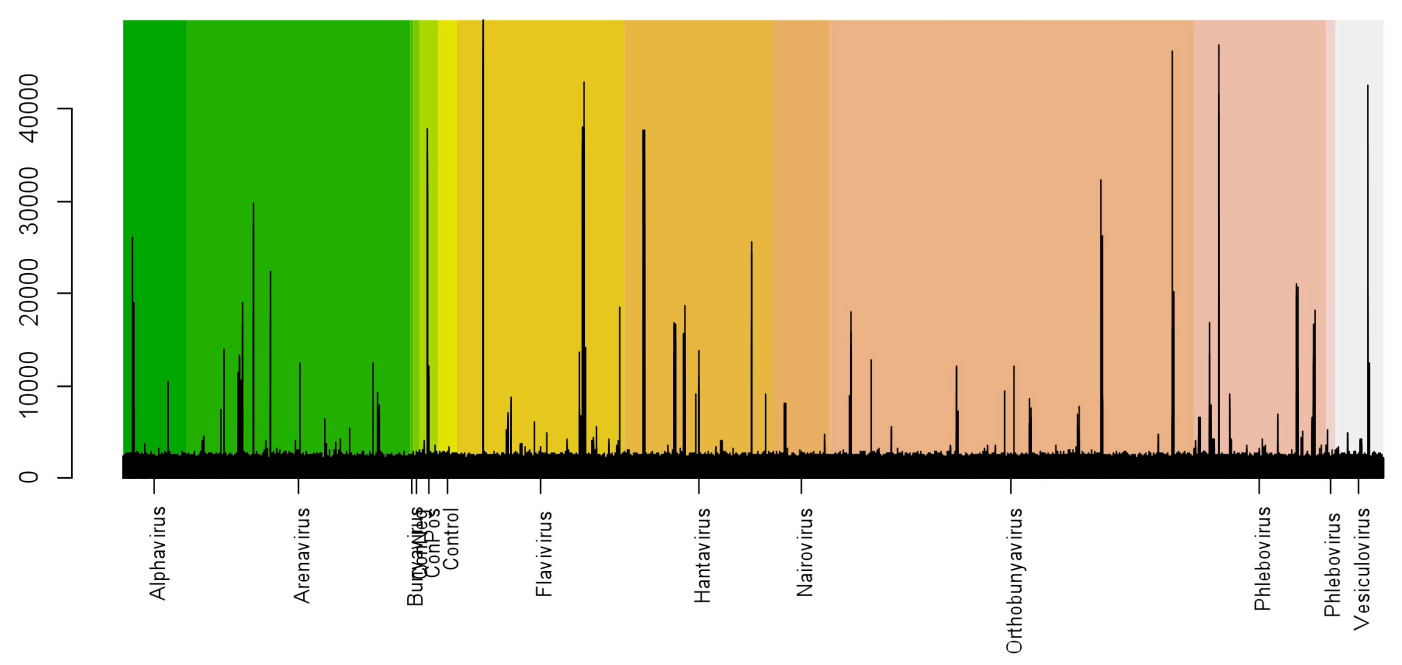




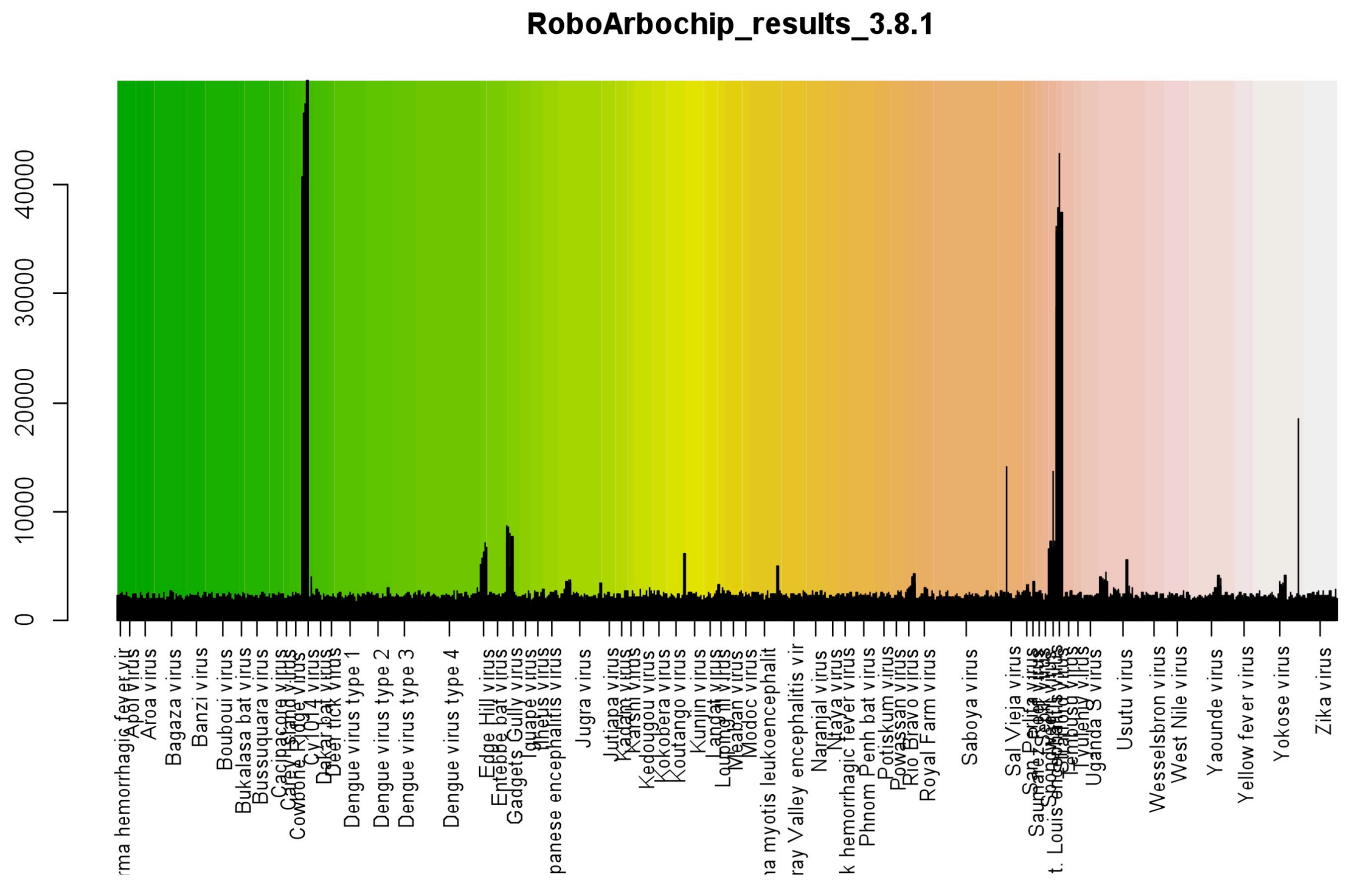

Figure 25. Visualization of probes fluorescence intensity of control slide hybridized with SLEV. Data were sorted by family, genus and species levels.

Table 43. Significant analysis of array hybridized with SLEV. The top 10 viruses with lowest $p$-values.

\begin{tabular}{cccc}
\hline Virus & No. of probes & $\boldsymbol{p}$-value & Average \\
\hline Stratford virus & 11 & $1,53 \mathrm{E}-16$ & 4,06 \\
Edge Hill virus & 11 & $1,36 \mathrm{E}-11$ & 1,45 \\
Muleshoe virus & 11 & $9,95 \mathrm{E}-09$ & 1,92 \\
St. Louis encephalitis virus & 11 & $6,74 \mathrm{E}-08$ & 1,65 \\
Cy1014 virus & 22 & $3,91 \mathrm{E}-05$ & 2,27 \\
\hline
\end{tabular}


FAMILY

RoboArbochip_results_4.8.1

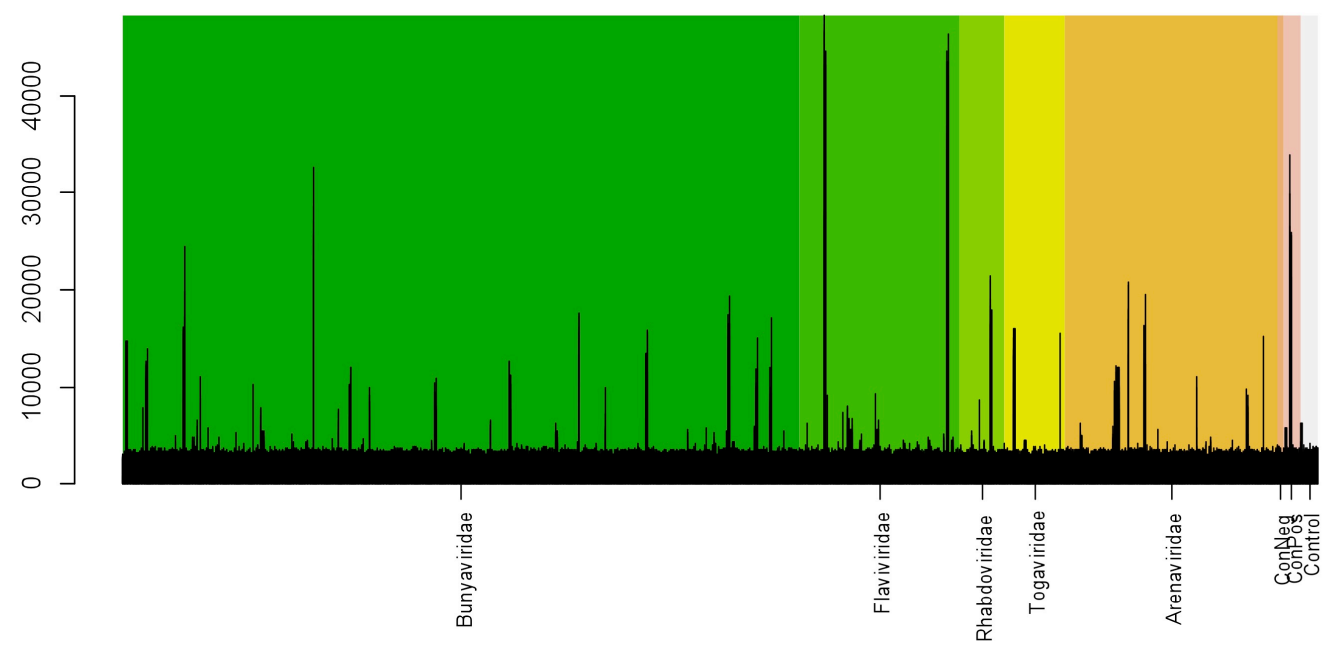

GENUS

RoboArbochip_results_4.8.1

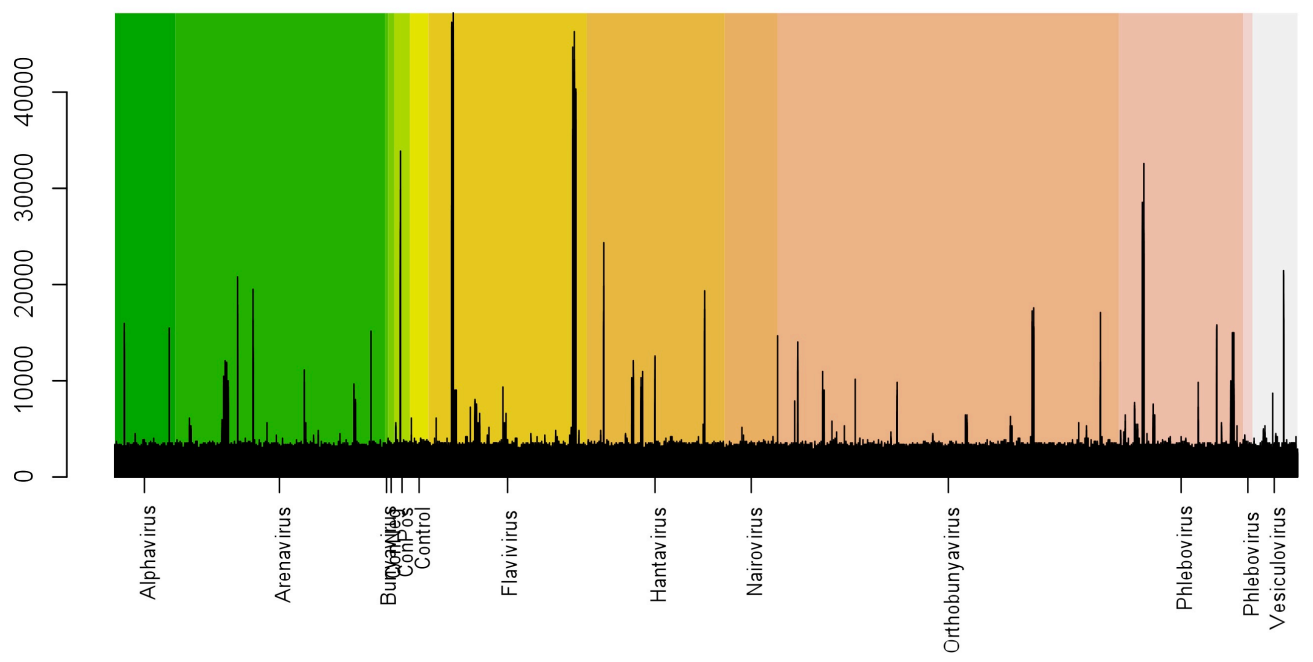




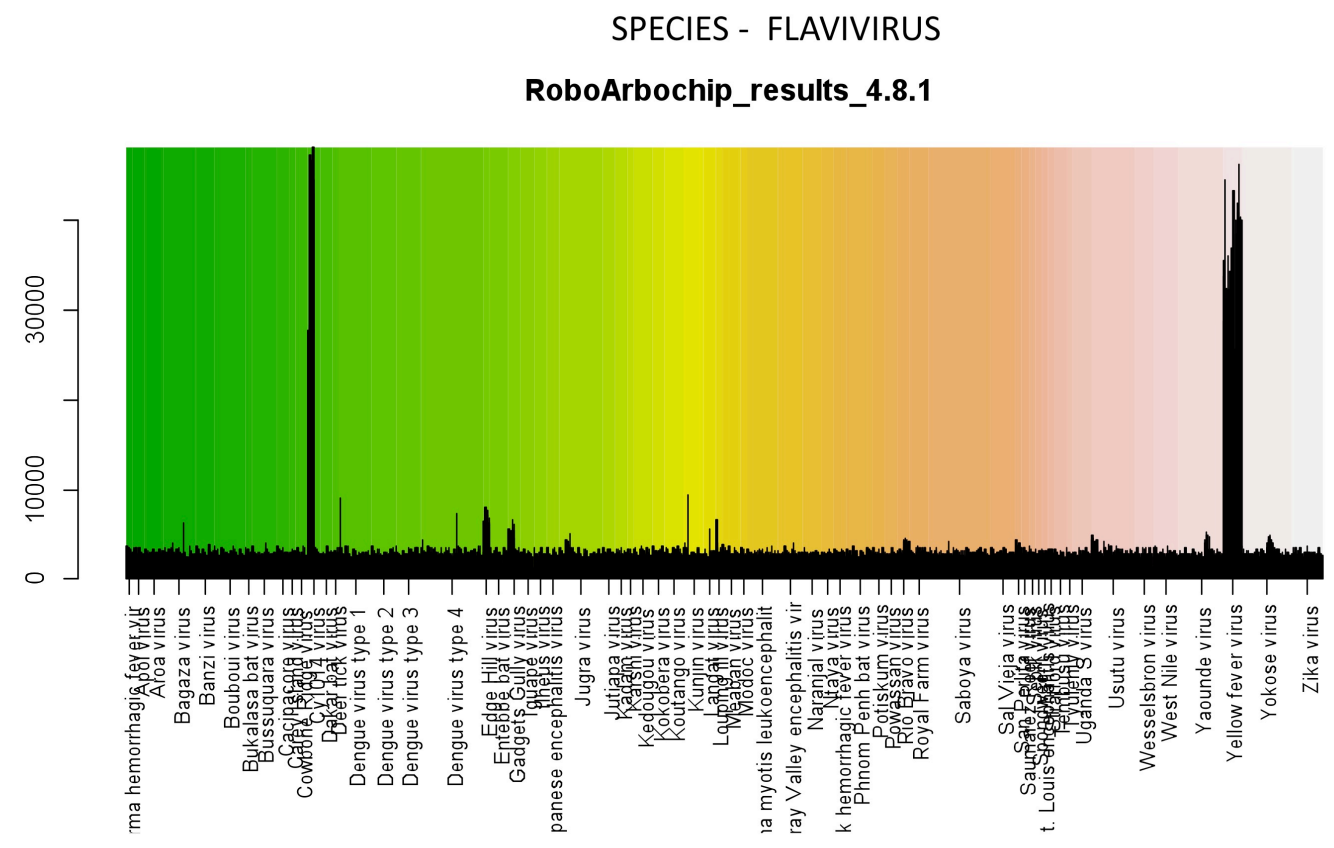

Figure 26. Visualization of probes fluorescence intensity of control slide hybridized with YFV. Data were sorted by family, genus and species levels.

Table 44. Significant analysis of array hybridized with YFV. The top 10 viruses with lowest $p$-values.

\begin{tabular}{cccc}
\hline Virus & No. of probes & $\boldsymbol{p}$-value & Average \\
\hline Yellow fever virus & 33 & $3,68 \mathrm{E}-37$ & 3,57 \\
Edge Hill virus & 11 & $4,32 \mathrm{E}-11$ & 1,27 \\
Muleshoe virus & 11 & $6,44 \mathrm{E}-08$ & 1,57 \\
Cy1014 virus & 22 & $5,62 \mathrm{E}-05$ & 1,94 \\
\hline
\end{tabular}


FAMILY

RoboArbochip_results_5.8.1

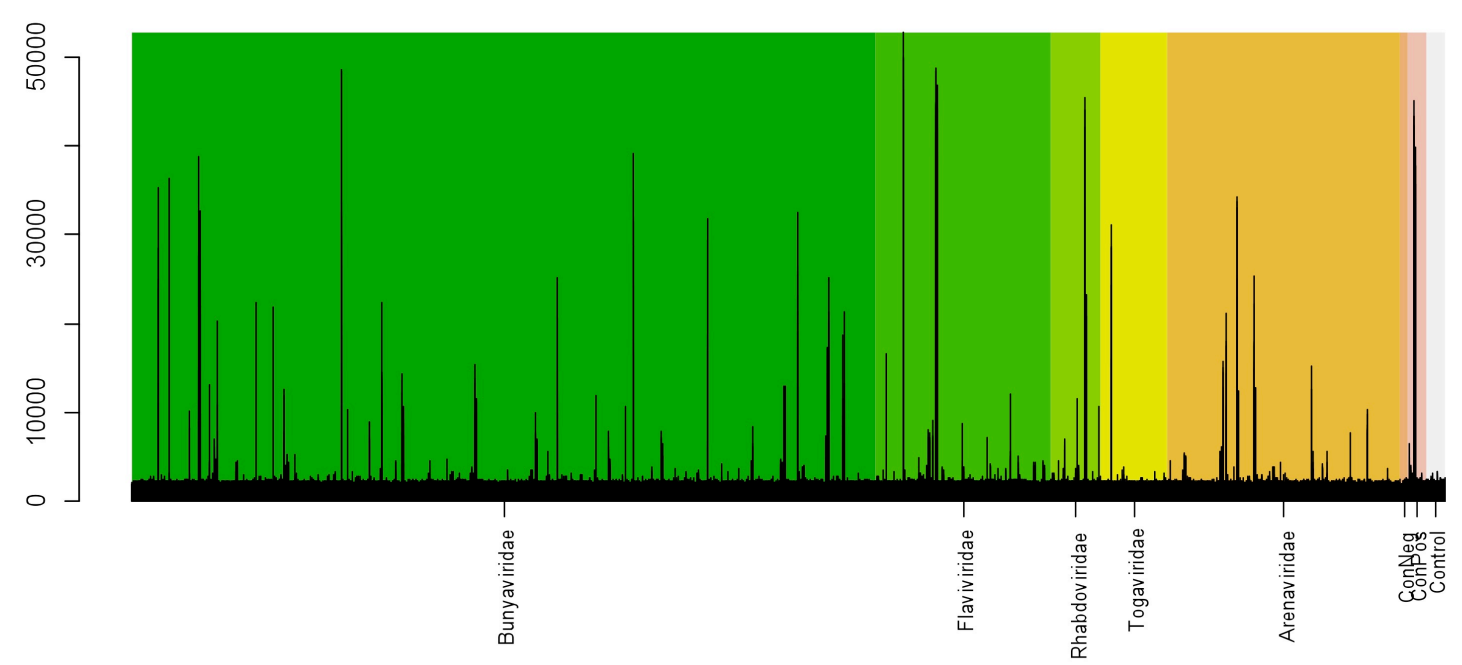

GENUS

RoboArbochip_results_5.8.1

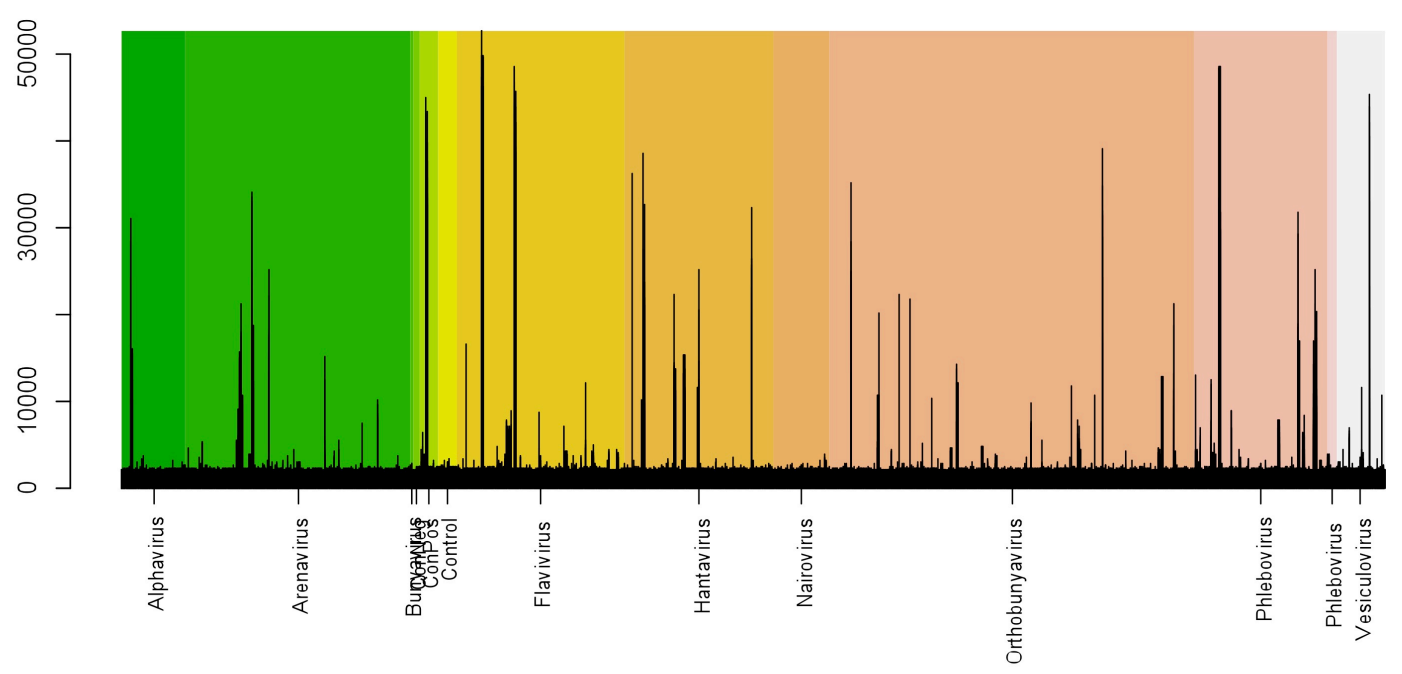


SPECIES - FLAVIVIRUS

RoboArbochip_results_5.8.1

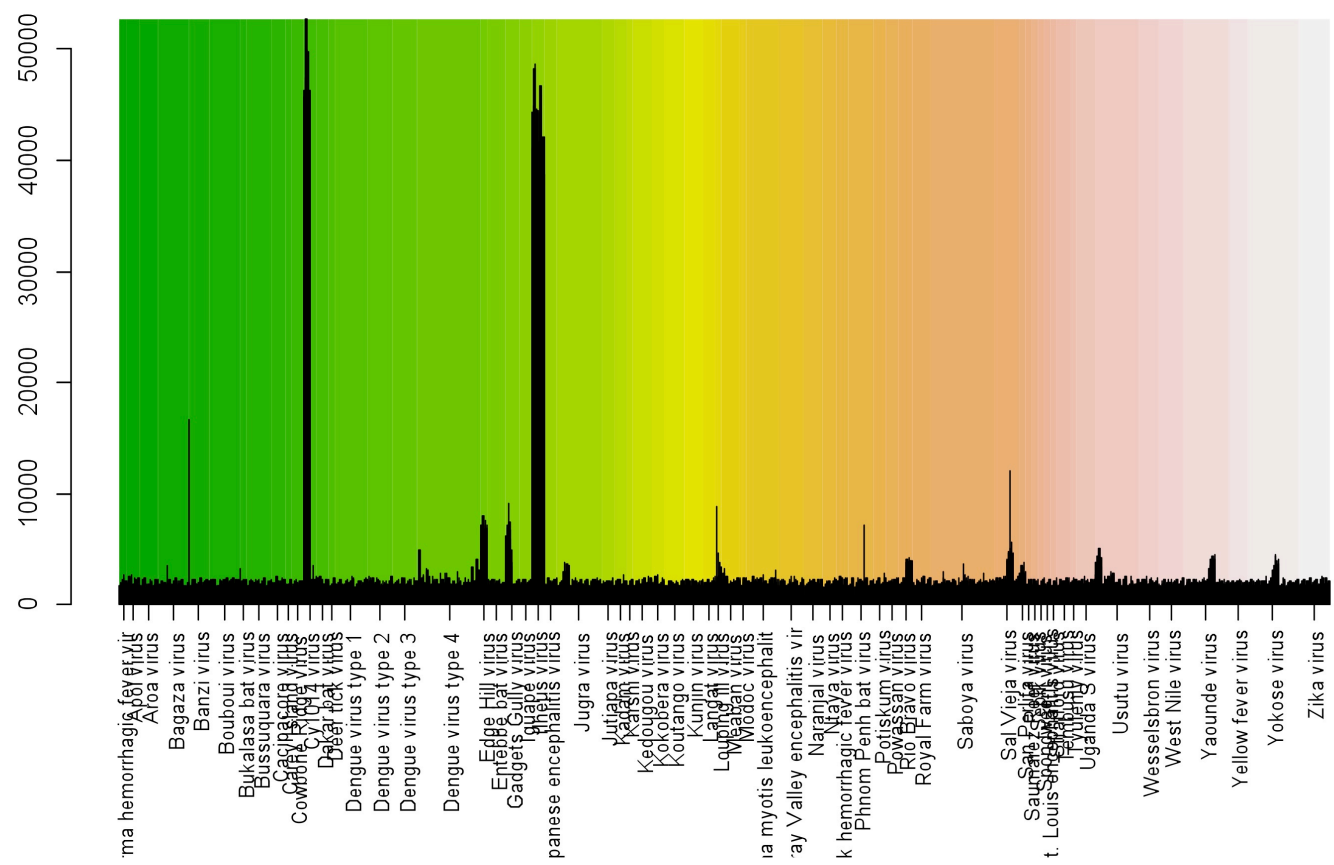

Figure 27. Visualization of probes fluorescence intensity of control slide hybridized with ILHV. Data were sorted by family, genus and species levels.

Table 45. Significant analysis of array hybridized with ILHV. The top 10 viruses with lowest $p$-values.

\begin{tabular}{cccc}
\hline Virus & No. of probes & $\boldsymbol{p}$-value & Average \\
\hline Ilheus virus & 22 & $5,85 \mathrm{E}-37$ & 4,446324797 \\
Edge Hill virus & 11 & $5,34 \mathrm{E}-12$ & 1,773708468 \\
Guanarito virus & 55 & $7,07 \mathrm{E}-09$ & 1,079062403 \\
Bujaru virus & 11 & $1,26 \mathrm{E}-08$ & 1,362636889 \\
Muleshoe virus & 11 & $7,39 \mathrm{E}-08$ & 2,476204129 \\
Cy1014 virus & 22 & $5,16 \mathrm{E}-05$ & 2,317890492 \\
\hline
\end{tabular}


FAMILY

RoboArbochip_results_6.8.1

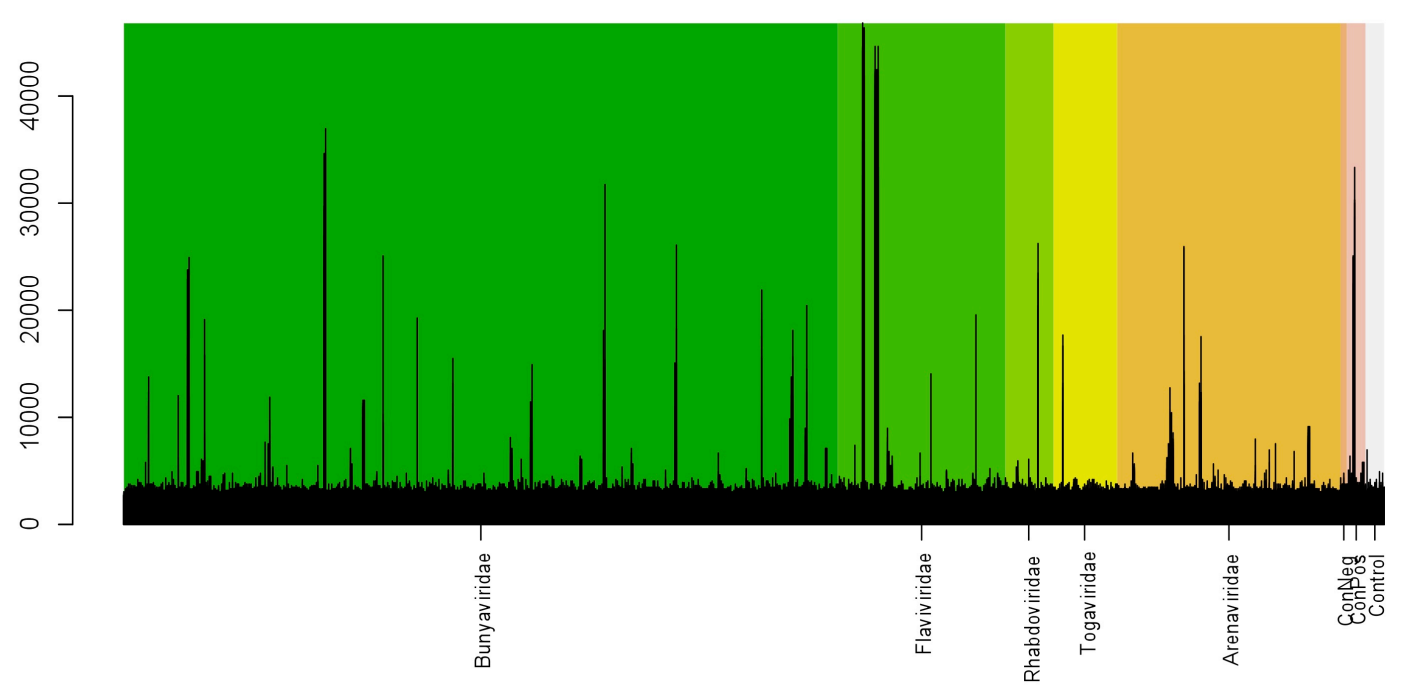

GENUS

RoboArbochip_results_6.8.1

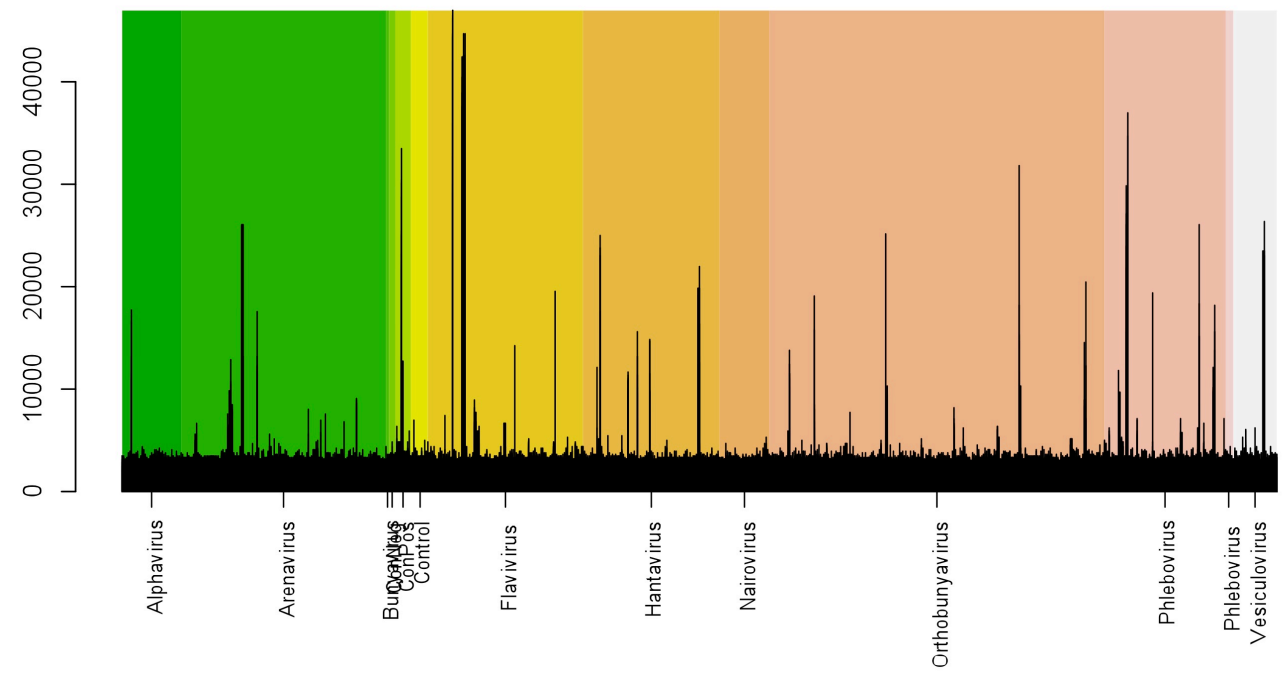


SPECIES - FLAVIVIRUS

RoboArbochip_results_6.8.1

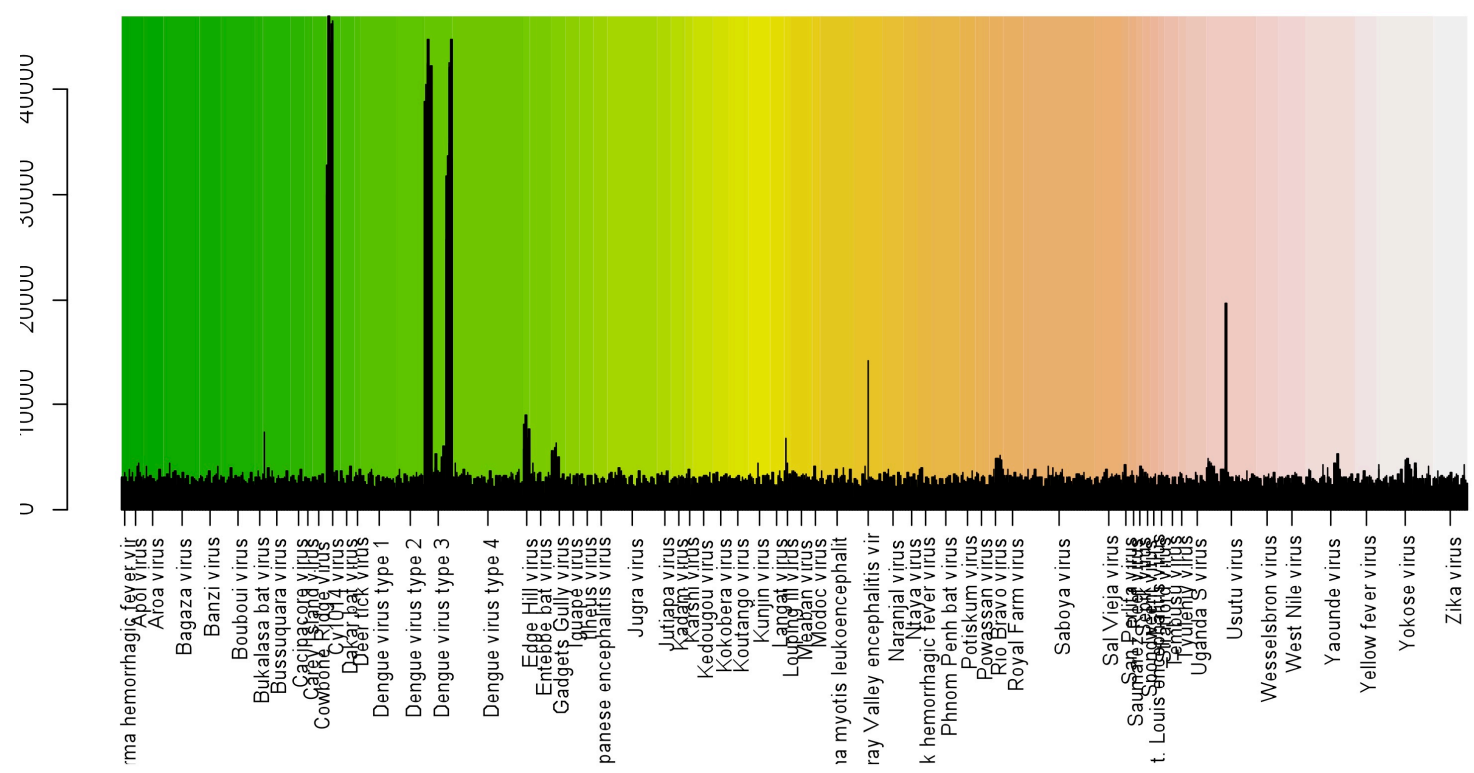

Figure 28. Visualization of probes fluorescence intensity of control slide hybridized with DENV-3. Data were sorted by family, genus and species levels.

Table 46. Significant analysis of array hybridized with DENV-3. The top 10 viruses with lowest $p$-values.

\begin{tabular}{cccc}
\hline Virus & No. of probes & $\boldsymbol{p}$-value & Average \\
\hline Dengue virus type 3 & 44 & $4,35 \mathrm{E}-10$ & 2,01 \\
Edge Hill virus & 11 & $7,43 \mathrm{E}-10$ & 1,22 \\
Muleshoe virus & 11 & $1,14 \mathrm{E}-08$ & 1,72 \\
Cy1014 virus & 22 & $8,59 \mathrm{E}-05$ & 1,88 \\
\hline
\end{tabular}


FAMILY

RoboArbochip_results_7.8.1

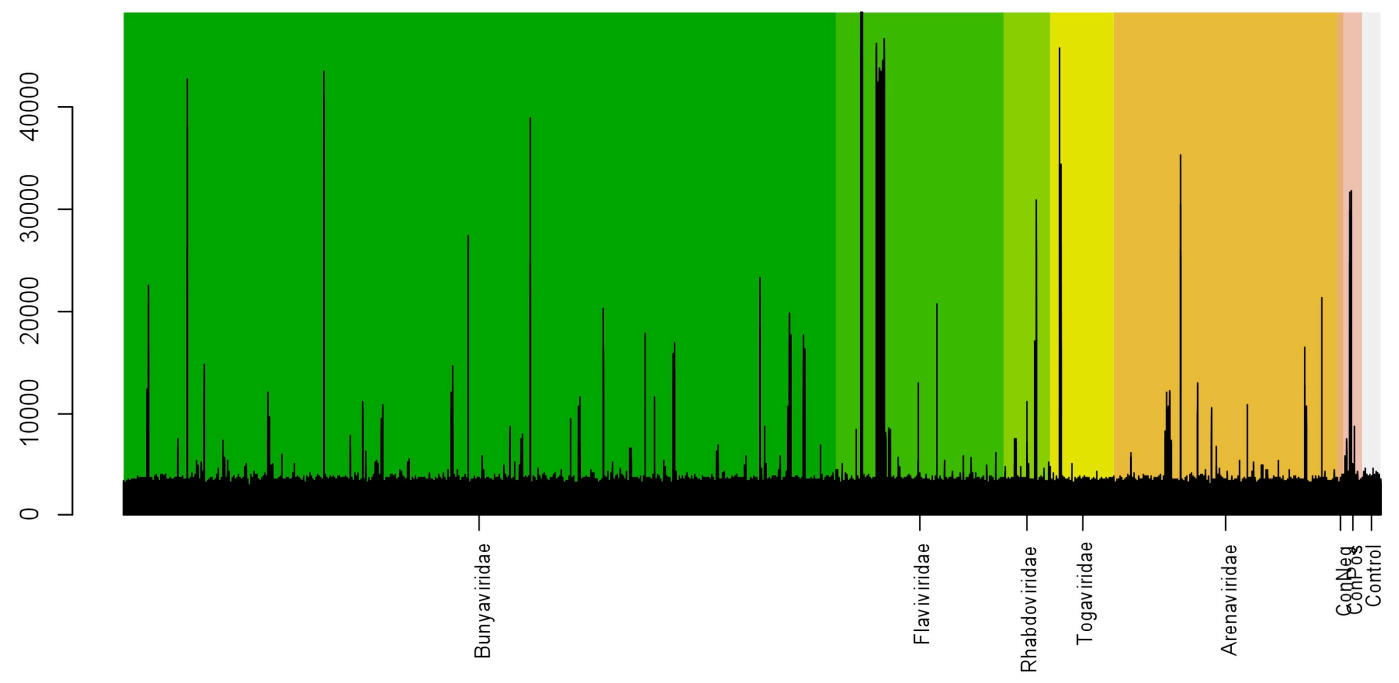

GENUS

RoboArbochip_results_7.8.1

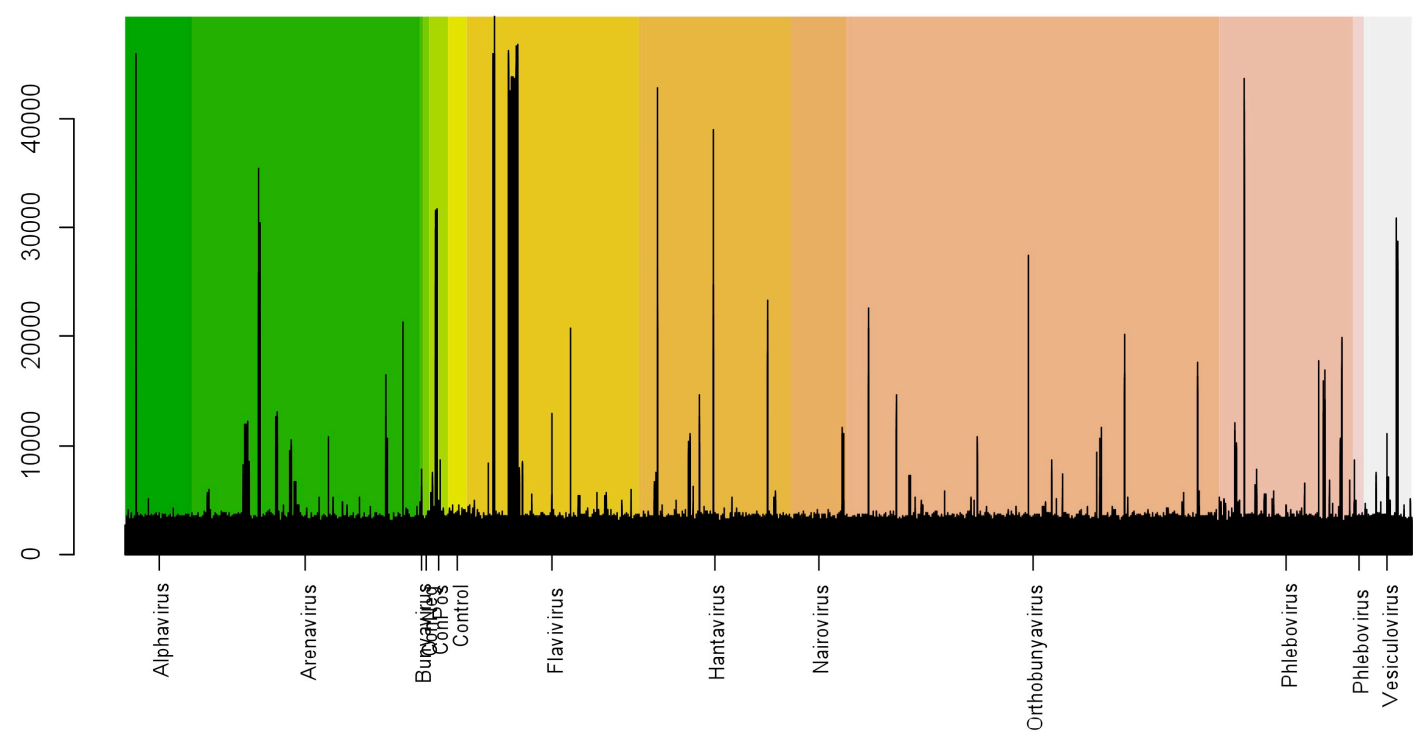


SPECIES - FLAVIVIRUS

RoboArbochip_results_7.8.1

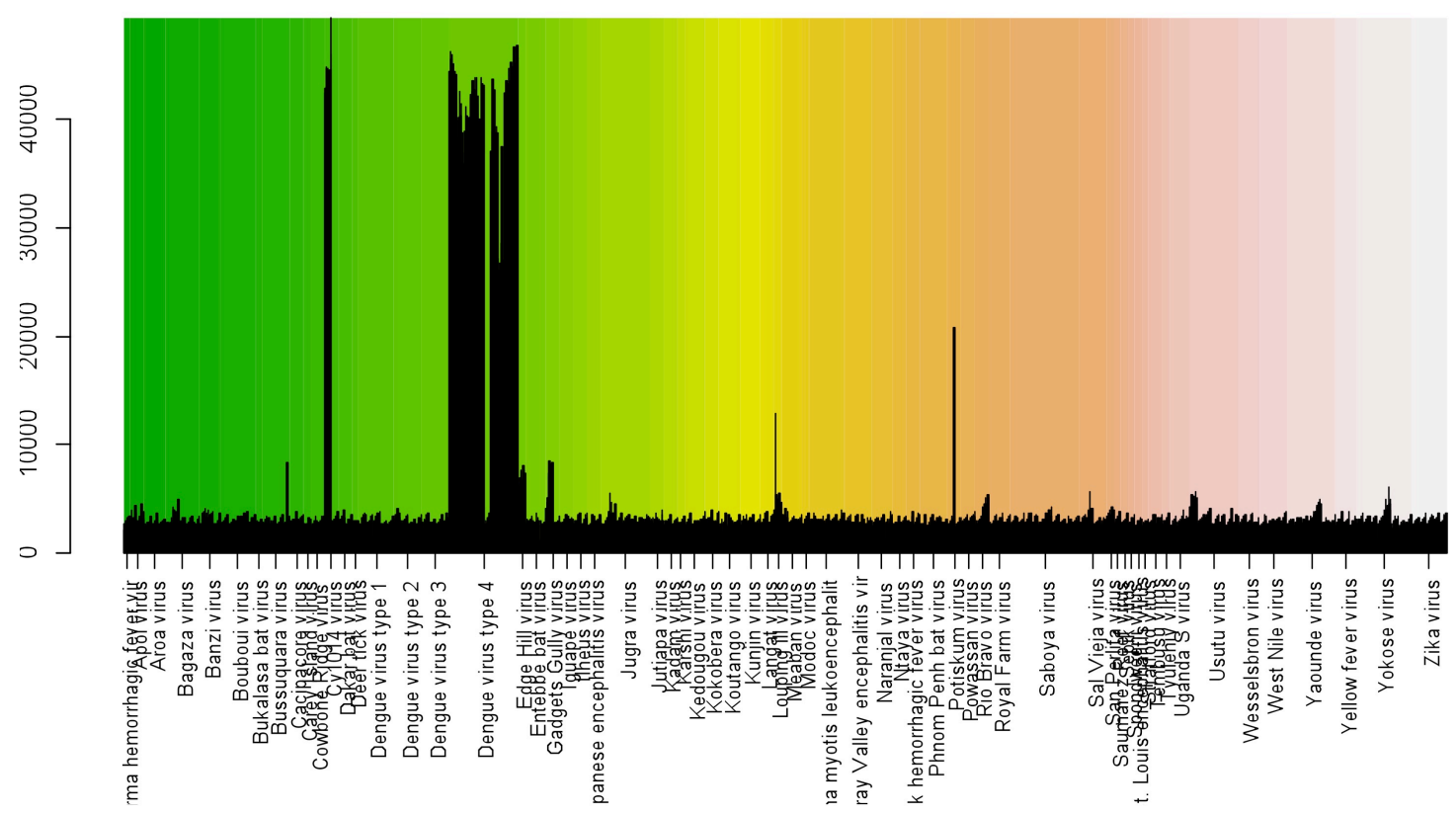

Figure 29. Visualization of probes fluorescence intensity of control slide hybridized with DENV-4. Data were sorted by family, genus and species levels.

Table 47. Significant analysis of array hybridized with DENV-4. The top 10 viruses with lowest $p$-values.

\begin{tabular}{cccc}
\hline Virus & No. of probes & $\boldsymbol{p}$-value & Average \\
\hline Dengue virus type 4 & 110 & $1,60 \mathrm{E}-54$ & 3,35 \\
Edge Hill virus & 11 & $1,03 \mathrm{E}-10$ & 1,24 \\
Muleshoe virus & 11 & $4,06 \mathrm{E}-10$ & 2,71 \\
Cy1014 virus & 22 & $4,32 \mathrm{E}-05$ & 2,00 \\
\hline
\end{tabular}


FAMILY

RoboArbochip_results_8.8.1

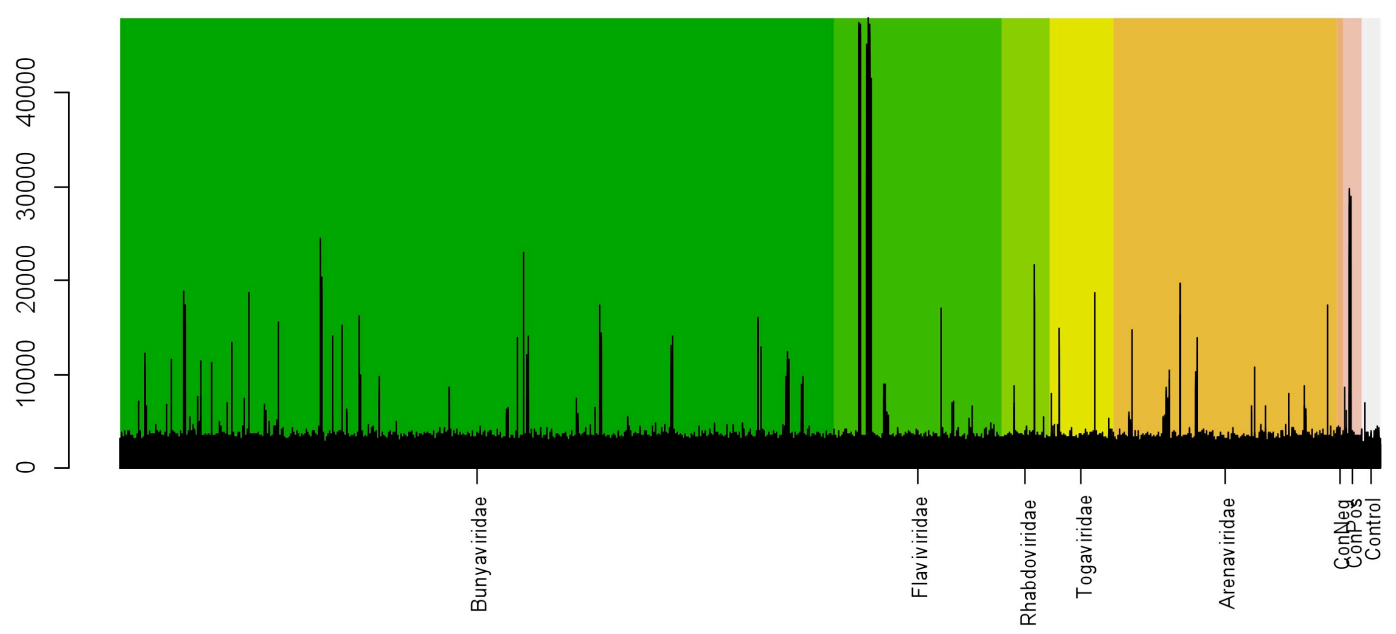

GENUS

RoboArbochip_results_8.8.1

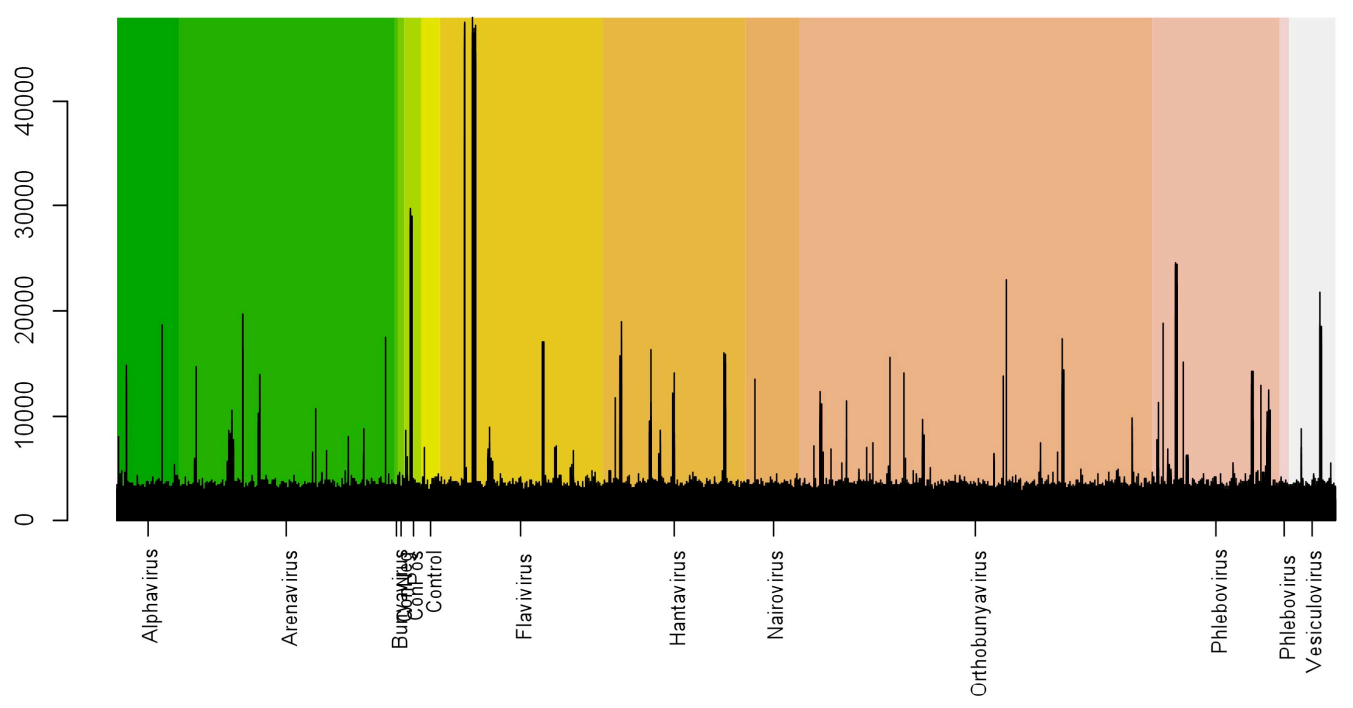




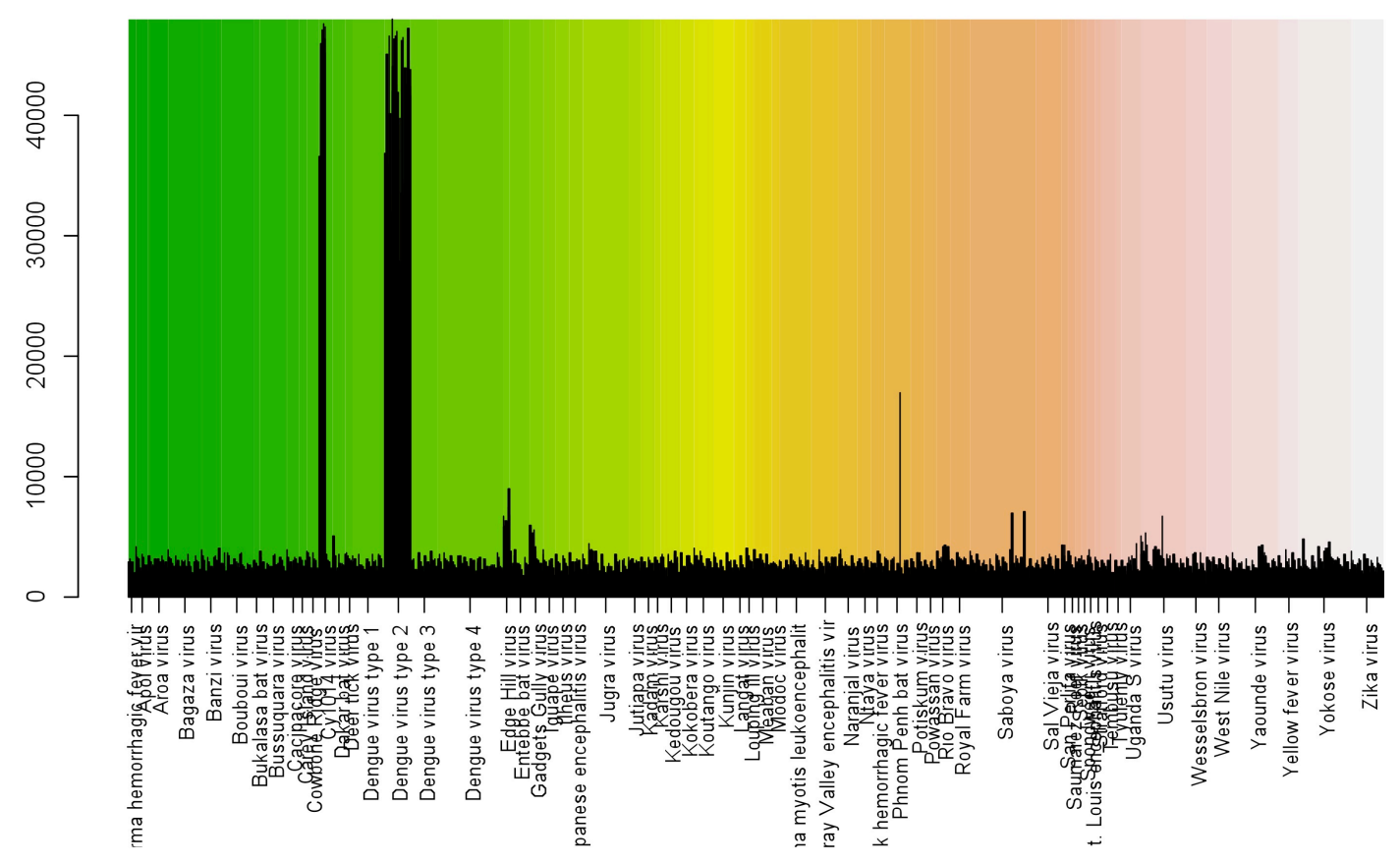

Figure 30. Visualization of probes fluorescence intensity of control slide hybridized with DENV-2. Data were sorted by family, genus and species levels.

Table 48. Significant analysis of array hybridized with DENV-2. The top 10 viruses with highest $p$-values.

\begin{tabular}{cccc}
\hline Virus & No. of probes & $p$-value & Average \\
\hline Dengue virus type 2 & 44 & $4,33 \mathrm{E}-53$ & 3,866424998 \\
Edge Hill virus & 11 & $3,67 \mathrm{E}-10$ & 1,296571693 \\
Muleshoe virus & 11 & $8,79 \mathrm{E}-07$ & 1,53532919 \\
Cy1014 virus & 22 & $7,36 \mathrm{E}-05$ & 2,003253838 \\
\hline
\end{tabular}

The RoboArboVirusChip v1 slide was able to detect SLEV, YFV, ILHV, DENV4, DENV-3, DENV-2, and BUSV but not OROV. However, cross-hybridization with the following viruses were also observed: Edge Hill virus, Muleshoe virus, Cy1014 virus, Edge Hill virus, Guanarito virus, Bujaru virus, Muleshoe virus, Cy1014 virus and Stratford virus. We have analyzed which probes were those showing cross-hybridization and removed and replaced with new probes for the next version. In addition, we included new probes for OROV. 


\subsection{RoboArboVirusChip second version (V2)}

To prepare RoboArboVirusChip V2, first we removed probes belonging to viruses mentioned above. In addition, we have included probes for other 16 viruses within the families mentioned in the first version and viruses of a new family Reoviridae, Orbivirus genus. This version contained total of 1743 specific oligonucleotide probes for targeting 255 viruses. Selection of probes and preparation of microarray slide was the same as RoboArboVirusChip v1. In the experiments with this slide, we started to use a positive RNA control (spike) provided by Agilent.

To analyze this new slide, we have used a cDNA of eight viruses: DENV-1, DENV-2, YFV, PIRYV, BUSQV, OROV, DENV-3 and DENV-4 (Tables 41-48). The hybridization experiments and data analysis were performed as mentioned above. Tables 25-32 showed the significant analysis of data of each array.

Table 49. Significant analysis of array hybridized with DENV-1. The top 10 viruses with lowest $p$-values.

\begin{tabular}{cccc}
\hline Virus & No. of probes & $\boldsymbol{p}$-value & Average \\
\hline Dengue virus type 1 & 44 & $6,08 \mathrm{E}-18$ & 5,04 \\
Spike & 20 & $1,49 \mathrm{E}-14$ & 1,09 \\
Turuna virus & 81 & $1,37 \mathrm{E}-10$ & 1,70 \\
Edge Hill virus & 9 & $6,22 \mathrm{E}-08$ & 3,00 \\
Muleshoe virus & 9 & $2,34 \mathrm{E}-06$ & 4,00 \\
Guanarito virus & 54 & $6,92 \mathrm{E}-06$ & 1,37 \\
Frijoles virus & 36 & $4,22 \mathrm{E}-05$ & 1,63 \\
\hline
\end{tabular}

Table 50. Significant analysis of array hybridized with DENV-2. The top 10 viruses with lowest $p$-values.

\begin{tabular}{lrrr}
\hline Virus & No. of probes & $\boldsymbol{p}$-value & Average \\
\hline Spike & 200 & $1,78 \mathrm{E}-31$ & 2,40 \\
Dengue virus type 2 & 36 & $4,99 \mathrm{E}-10$ & 2,03 \\
\hline
\end{tabular}


Table 51. Significant analysis of array hybridized with YFV. The top 10 viruses with lowest $p$-values.

\begin{tabular}{cccc}
\hline Virus & No. of probes & $\boldsymbol{p}$-value & Average \\
\hline Spike & 200 & $6,42 \mathrm{E}-36$ & 2,76 \\
Yellow fever virus & 63 & $4,57 \mathrm{E}-08$ & 1,00 \\
\hline
\end{tabular}

Table 52. Significant analysis of array hybridized with DENV-1. The top 10 viruses with lowest $p$-values.

\begin{tabular}{cccc}
\hline Virus & No. of probes & $\boldsymbol{p}$-value & Average \\
\hline Controle positivo 135 & 20 & $7,73 \mathrm{E}-16$ & 5,10 \\
Piry virus & 45 & $7,00 \mathrm{E}-11$ & 1,08 \\
Equine encephalosis virus & 135 & $2,86 \mathrm{E}-10$ & 1,14 \\
Candiru virus & 99 & $3,31 \mathrm{E}-10$ & 1,42 \\
Spike & 20 & $5,26 \mathrm{E}-10$ & 1,32 \\
Turuna virus & 81 & $3,26 \mathrm{E}-09$ & 1,79 \\
Muleshoe virus & 9 & $2,86 \mathrm{E}-08$ & 5,04 \\
Frijoles virus & 36 & $3,45 \mathrm{E}-08$ & 2,64 \\
Edge Hill virus & 9 & $1,94 \mathrm{E}-06$ & 4,00 \\
& & & \\
\hline
\end{tabular}

Table 53. Significant analysis of array hybridized with BUSQV. The top 10 viruses with lowest $p$-values.

\begin{tabular}{cccc}
\hline Virus & No. of probes & $\boldsymbol{p}$-value & Average \\
\hline Spike & 200 & $3,39 \mathrm{E}-28$ & 1,85 \\
Bussuquara virus & 36 & $1,70 \mathrm{E}-21$ & 5,23 \\
Muleshoe virus & 9 & $4,31 \mathrm{E}-05$ & 2,87 \\
Frijoles virus & 36 & 0,000126872 & 1,20 \\
\hline
\end{tabular}

Table 54. Significant analysis of array hybridized with OROV. The top 10 viruses with lowest $p$-values.

\begin{tabular}{cccc}
\hline Virus & No. of probes & $\boldsymbol{p}$-value & Average \\
\hline Oropouche virus & 126 & $3,18 \mathrm{E}-56$ & 4,55
\end{tabular}




\begin{tabular}{cccc} 
Spike & 200 & $4,92 \mathrm{E}-31$ & 2,19 \\
Muleshoe virus & 9 & $4,02 \mathrm{E}-08$ & 3,77 \\
Frijoles virus & 36 & 0,00010446 & 1,50 \\
\hline
\end{tabular}

Table 55. Significant analysis of array hybridized with DENV-3. The top 10 viruses with lowest $p$-values.

\begin{tabular}{cccc}
\hline Virus & No. of probes & $\boldsymbol{p}$-value & Average \\
\hline Muleshoe virus & 9 & $5,43 \mathrm{E}-07$ & 1,57 \\
Dengue virus type 3 & 36 & $3,06 \mathrm{E}-05$ & 2,14 \\
Spike & 200 & $2,11 \mathrm{E}-20$ & 1,09 \\
\hline
\end{tabular}

Table 56. Significant analysis of array hybridized with DENV-4. The top 10 viruses with lowest $p$-values.

\begin{tabular}{cccc}
\hline Virus & No. of probes & $p$-value & Average \\
\hline Dengue virus type 4 & 90 & $3,58 \mathrm{E}-43$ & 4,76 \\
Muleshoe virus & 9 & $1,34 \mathrm{E}-09$ & 1,46 \\
Spike & 200 & $8,14 \mathrm{E}-36$ & 2,75 \\
Broadhaven virus & 45 & $2,11 \mathrm{E}-10$ & 2,08 \\
Agilent_Bright corner control & 14 & $6,17 \mathrm{E}-09$ & 2,64 \\
Agilent_Internal control & 36 & $3,57 \mathrm{E}-08$ & 2,51 \\
Muleshoe virus & 9 & $1,39 \mathrm{E}-07$ & 1,92 \\
Frijoles virus & 36 & $8,46 \mathrm{E}-05$ & 1,07 \\
Edge Hill virus & 9 & 0,000163025 & 1,56 \\
\hline
\end{tabular}

The results showed that all analyzed viruses were specifically detected; although cross-hybridization was also observed in this version. 


\subsection{Comparison of cDNA and PCR products as target for the RoboArboVirusChip v2}

The virus load found in clinical samples, especially in serum samples are lower than the viral load found in the supernatant of cell cultures. Therefore, the inclusion of virus genomic amplification by PCR would improve the sensitivity of the RoboArboVirusChip v2 when using serum samples. To test this hypothesis, we have compared the sensitivity of RoboArboVirusChip v2 to detect cDNA and one step and two steps RT-PCR products of YFV $\left(2.5 \times 10^{11} \mathrm{PFU} / \mathrm{mL}\right)$ and DENV-2 $\left(2.5 \times 10^{8}\right.$ $\mathrm{PFU} / \mathrm{mL}$ ). In this experiment we have used cDNA and a one-step RT-PCR products obtained from virus RNAs diluted 1:10 and 1:1000 (Table 49). The RT-PCR was performed using random primers as described in Material and Methods.

Table 57. Significant analysis of RoboArboVirusChip v2 hybridized with cDNA and PCR products of YFV. The top 10 viruses with lowest $p$-values.

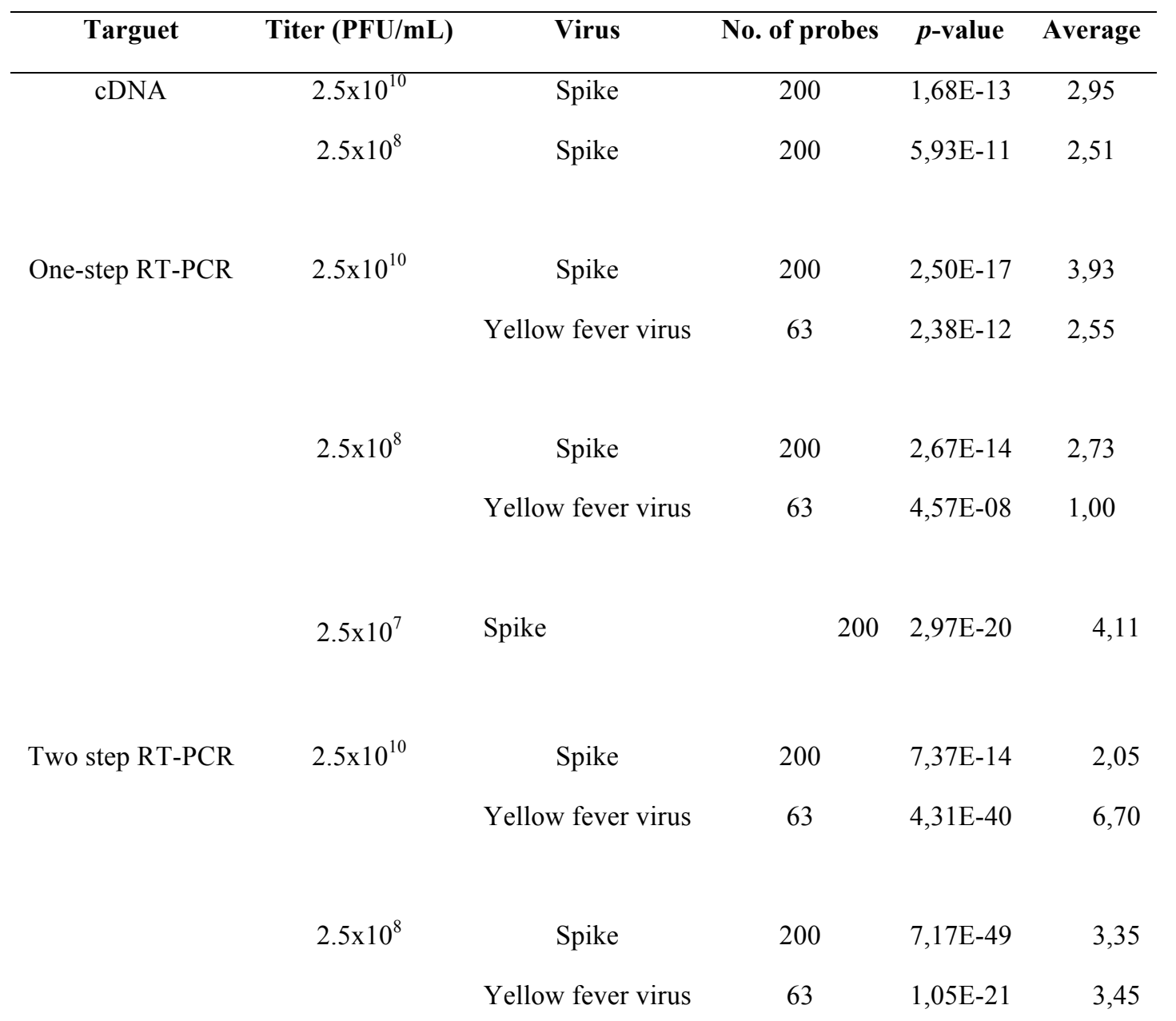




$\begin{array}{ccccc}2.5 \times 10^{7} & \text { Spike } & 200 & 3,41 \mathrm{E}-15 & 5,86 \\ & \text { Yellow fever virus } & 63 & 2,43 \mathrm{E}-11 & 1,55\end{array}$

The RoboArboVirusChip v2 was able to detect the viruses using PCR products, and the two steps RT-PCR was the better one. Therefore, we decided to use the two steps RT-PCR in the farther next all experiments.

\subsection{Detection of mixture of viruses by the RoboArboVirusChip v2}

Infection with more than one virus is a likely event that can be seen in human, especially for arboviruses. In this experiment, we have evaluated the ability of RoboArboVirusChip to detect mixture of viruses in a single sample, we used two pools of viral RNA of eight flaviviruses, each pool contained four viral RNAs: 1) ROCV, SLEV, YFV and DENV-2; and 2) DENV-1, DENV-2, DENV-3 and DENV-4. The microarray experiment and data analysis were performed as mention above (Table 55).

Table 58. Significant analysis of arrays hybridized with pool of viruses. The top 10 viruses with lowest $p$-values.

\begin{tabular}{lcccc}
\hline Pools & Virus & No. of probes & $\boldsymbol{p}$-value & Average \\
\hline 1 & Dengue virus type 4 & 90 & $9,46 \mathrm{E}-44$ & 5,28 \\
& Dengue virus type 2 & 36 & $7,48 \mathrm{E}-29$ & 4,47 \\
Dengue virus type 1 & 45 & $1,42 \mathrm{E}-16$ & 3,26 \\
Turuna virus & 81 & $1,24 \mathrm{E}-08$ & 1,20 \\
Edge Hill virus & 9 & $3,60 \mathrm{E}-08$ & 1,86 \\
& Muleshoe virus & 9 & $2,83 \mathrm{E}-06$ & 3,44 \\
& Dengue virus type 3 & 36 & $2,84 \mathrm{E}-06$ & 2,78 \\
& Guanarito virus & 54 & $8,22 \mathrm{E}-06$ & 1,08 \\
& Frijoles virus & 36 & $2,03 \mathrm{E}-05$ & 1,40 \\
& Snowshoe Hare virus & 18 & 0,000641864 & 1,21 \\
& & & & \\
& & 72 & $2,64 \mathrm{E}-72$ & 6,25
\end{tabular}




$\begin{array}{cccc}\text { Dengue virus type } 2 & 36 & 5,53 \mathrm{E}-34 & 5,29 \\ \text { Yellow fever virus } & 63 & 1,56 \mathrm{E}-27 & 5,28 \\ \text { Spike } & 200 & 2,14 \mathrm{E}-27 & 1,73 \\ \text { St. Louis encephalitis virus } & 72 & 2,85 \mathrm{E}-26 & 4,58 \\ \text { Aura virus } & 27 & 7,68 \mathrm{E}-18 & 3,38 \\ \text { Arbia virus } & 36 & 7,09 \mathrm{E}-11 & 2,66 \\ \text { Turuna virus } & 81 & 6,18 \mathrm{E}-08 & 1,05 \\ \text { Edge Hill virus } & 9 & 7,74 \mathrm{E}-07 & 1,68 \\ \text { Guanarito virus } & 54 & 3,13 \mathrm{E}-06 & 1,16 \\ \end{array}$

The RoboArboVirusChip v2 was able to specifically detect all viruses within the two pools. However, some probes cross-hybridized with non-target viruses.

\subsection{Determination of sensitivity of the RoboArboVirusChip v2}

The sensitivity of the RoboArboVirusChip was determined by using 10 foldserial dilutions of DENV-2 $\left(2.5 \times 10^{8}\right) / 2.5 \times 10^{9}$ and DENV-4 $\left(6.75 \times 10^{11}\right) / 2.1 \times 10^{9}$. Microarray experiment was performed as mention above (Table 56-57).

Table 59. Determination of sensitivity of the RoboArboChip v2 for DENV-2.

\begin{tabular}{ccccc}
\hline Titer (PFU/mL) & Virus & No. of probes & p-value & Average \\
\hline $2.5 \times 10^{6}$ & Spike & 200 & $5,15 \mathrm{E}-50$ & 3,80 \\
& Dengue virus type 2 & 36 & $7,23 \mathrm{E}-30$ & 5,40 \\
Turuna virus & 81 & $4,31 \mathrm{E}-09$ & 1,68 \\
Muleshoe virus & 9 & $2,24 \mathrm{E}-08$ & 4,99 \\
Guanarito virus & 54 & $5,10 \mathrm{E}-06$ & 1,55 \\
Frijoles virus & 36 & $5,18 \mathrm{E}-06$ & 2,20 \\
Edge Hill virus & 9 & $1,04 \mathrm{E}-05$ & 3,04 \\
& Snowshoe Hare virus & 18 & 0,000330158 & 1,87 \\
Rio Bravo virus & 18 & 0,000407347 & 1,83
\end{tabular}




\begin{tabular}{|c|c|c|c|c|}
\hline $2.5 \times 10^{5}$ & Spike & 200 & $2,17 \mathrm{E}-70$ & 5,27 \\
\hline & Dengue virus type 2 & 36 & $9,38 \mathrm{E}-22$ & 5,02 \\
\hline & Turuna virus & 81 & 2,72E-09 & 1,55 \\
\hline & Edge Hill virus & 9 & $6,15 \mathrm{E}-08$ & 2,71 \\
\hline & Muleshoe virus & 9 & $7,04 \mathrm{E}-07$ & 4,39 \\
\hline & Guanarito virus & 54 & $2,73 \mathrm{E}-06$ & 1,50 \\
\hline & Frijoles virus & 36 & $7,36 \mathrm{E}-06$ & 2,03 \\
\hline & Punta Salinas virus & 18 & 0,000218475 & 1,25 \\
\hline & Snowshoe Hare virus & 18 & 0,000266901 & 1,86 \\
\hline $2.5 \times 10^{4}$ & Spike & 200 & $3,65 \mathrm{E}-39$ & 2,57 \\
\hline & Edge Hill virus & 9 & $3,84 \mathrm{E}-07$ & 1,43 \\
\hline & Muleshoe virus & 9 & $3,45 \mathrm{E}-05$ & 2,11 \\
\hline $2.5 \times 10^{3}$ & Spike & 200 & $1,88 \mathrm{E}-42$ & 4,06 \\
\hline & Turuna virus & 81 & $9,45 \mathrm{E}-09$ & 1,17 \\
\hline & Guanarito virus & 54 & $3,73 \mathrm{E}-06$ & 1,19 \\
\hline & Edge Hill virus & 9 & $7,18 \mathrm{E}-06$ & 1,80 \\
\hline & Muleshoe virus & 9 & $2,28 \mathrm{E}-05$ & 3,28 \\
\hline & Frijoles virus & 36 & $3,05 \mathrm{E}-05$ & 1,38 \\
\hline & Snowshoe Hare virus & 18 & 0,001678851 & 1,17 \\
\hline $2.5 \times 10^{2}$ & Spike & 200 & $1,07 \mathrm{E}-45$ & 3,88 \\
\hline & Turuna virus & 81 & $6,06 \mathrm{E}-08$ & 1,30 \\
\hline & Edge Hill virus & 9 & $8,31 \mathrm{E}-06$ & 2,27 \\
\hline & Frijoles virus & 36 & $1,32 \mathrm{E}-05$ & 1,82 \\
\hline & Muleshoe virus & 9 & $1,56 \mathrm{E}-05$ & 4,17 \\
\hline & Guanarito virus & 54 & $2,24 \mathrm{E}-05$ & 1,28 \\
\hline & Snowshoe Hare virus & 18 & 0,000787344 & 1,42 \\
\hline & Thailand virus & 36 & 0,000960894 & 1,15 \\
\hline & Gadgets Gully virus & 18 & 0,001377639 & 1,08 \\
\hline
\end{tabular}


25

$\begin{array}{cccc}\text { Spike } & 200 & 1,07 \mathrm{E}-53 & 4,79 \\ \text { Turuna virus } & 81 & 1,02 \mathrm{E}-08 & 1,38 \\ \text { Edge Hill virus } & 9 & 6,05 \mathrm{E}-08 & 2,12 \\ \text { Muleshoe virus } & 9 & 5,12 \mathrm{E}-07 & 4,27 \\ \text { Guanarito virus } & 54 & 6,69 \mathrm{E}-06 & 1,35 \\ \text { Frijoles virus } & 36 & 1,92 \mathrm{E}-05 & 1,74 \\ \text { Rio Bravo virus } & 18 & 0,000681044 & 1,54 \\ \text { Snowshoe Hare virus } & 18 & 0,000837261 & 1,40 \\ \text { Oriboca virus } & 27 & 0,000987481 & 1,13\end{array}$

Table 60. Determination of sensitivity of the RoboArboChip for DENV-4.

\begin{tabular}{|c|c|c|c|c|}
\hline Dilution & Virus & No. of probes & p-value & Average \\
\hline \multirow[t]{4}{*}{$2.1 \times 10^{6}$} & Dengue virus type 4 & 90 & $3,40 \mathrm{E}-40$ & 5,81 \\
\hline & Spike & 200 & $1,26 \mathrm{E}-30$ & 8,04 \\
\hline & Muleshoe virus & 9 & $3,96 \mathrm{E}-10$ & 4,17 \\
\hline & Candiru virus & 99 & $4,90 \mathrm{E}-10$ & 1,02 \\
\hline \multirow[t]{4}{*}{$2.1 \times 10^{5}$} & Dengue virus type 4 & 90 & $1,33 \mathrm{E}-40$ & 6,34 \\
\hline & Spike & 200 & $3,23 \mathrm{E}-28$ & 8,82 \\
\hline & Turuna virus & 81 & $7,15 \mathrm{E}-09$ & 1,18 \\
\hline & Muleshoe virus & 9 & $7,80 \mathrm{E}-09$ & 1,95 \\
\hline \multirow[t]{4}{*}{$2.1 \times 10^{4}$} & Dengue virus type 4 & 90 & $9,00 \mathrm{E}-40$ & 5,67 \\
\hline & Spike & 200 & $1,46 \mathrm{E}-32$ & 8,69 \\
\hline & Turuna virus & 81 & 1,91E-08 & 1,43 \\
\hline & Muleshoe virus & 9 & $6,47 \mathrm{E}-08$ & 2,29 \\
\hline \multirow[t]{3}{*}{$2.1 \times 10^{3}$} & Dengue virus type 4 & 90 & $8,36 \mathrm{E}-30$ & 3,25 \\
\hline & Spike & 200 & $9,16 \mathrm{E}-27$ & 8,30 \\
\hline & Turuna virus & 81 & $9,25 \mathrm{E}-09$ & 1,19 \\
\hline
\end{tabular}


Muleshoe virus $\quad 9 \quad 1,93 \mathrm{E}-08 \quad 3,20$

$\begin{array}{rcccc}2.1 \times 10^{2} & \text { Spike } & 200 & 5,25 \mathrm{E}-17 & 6,11 \\ & \text { Turuna virus } & 81 & 2,59 \mathrm{E}-08 & 1,30 \\ & \text { Frijoles virus } & 36 & 9,49 \mathrm{E}-06 & 1,71\end{array}$

21

$\begin{array}{cccc}\text { Spike } & 200 & 6,94 \mathrm{E}-16 & 4,63 \\ \text { Guanarito virus } & 54 & 3,51 \mathrm{E}-05 & 1,02 \\ \text { Muleshoe virus } & 9 & 5,92 \mathrm{E}-05 & 2,35\end{array}$

The RoboArboVirusChip V2 was able to detect as few as $2.5 \times 10^{5} \mathrm{PFU} / \mathrm{mL}$ of DENV-2 and $2.1 \times 10^{3} \mathrm{PFU} / \mathrm{mL}$ of DENV-4.

\subsection{Design of the RoboArboVirusChip v3}

We found some probes from the following viruses with cross hybridization in the RoboArboVirusChip v2: Muleshoe virus, Edge Hill virus, Equine encephalosis virus, Frijoles virus, Broadhaven virus, Guanarito virus, Snowshoe Hare virus, Rio Bravo virus, Oriboca virus, Gadgets Gully virus, Punta Salinas virus, Thailand virus and Turuna virus. All probes showing cross-hybridization were removed and replaced by new ones to design the RoboArboVirusChip v3. In this version, we included the fallowing new families and their genera: Reoviridae; Coltivirus and Seadornavirus genera; Rhabdoviridae, Ephemerovirus genus; and Asfarviridae, Asfarvirus genus. In this version, we have also included generic probes to detect viruses at the genus level. These probes were designed from conserved RNA genomic regions of representative viruses within each genus. A total 4296 oligonucleotide probes were selected, including 4209 specific probes to target 412 virus species and 87 generic probes (Supplementary Table 1).

This new slide was tested with 17 viruses (BUSQV, CHIKV, DENV-1, DENV-2, DENV-3, DENV-4, GROV, IGUV, ILHV, MAYV, OROV, PIRYV, RIOMV, ROCV, 
SLEV, WNV and YFV) and RNA obtained from uninfected C6/36 cells as a negative control. Visualization of probes intensity sorted by families, genera and species for the array hybridized with DENV-3 are shown in Figure 32; while significance analysis is shown in Table 58.

RoboArboChip_27.01.2014_2_1.8.1

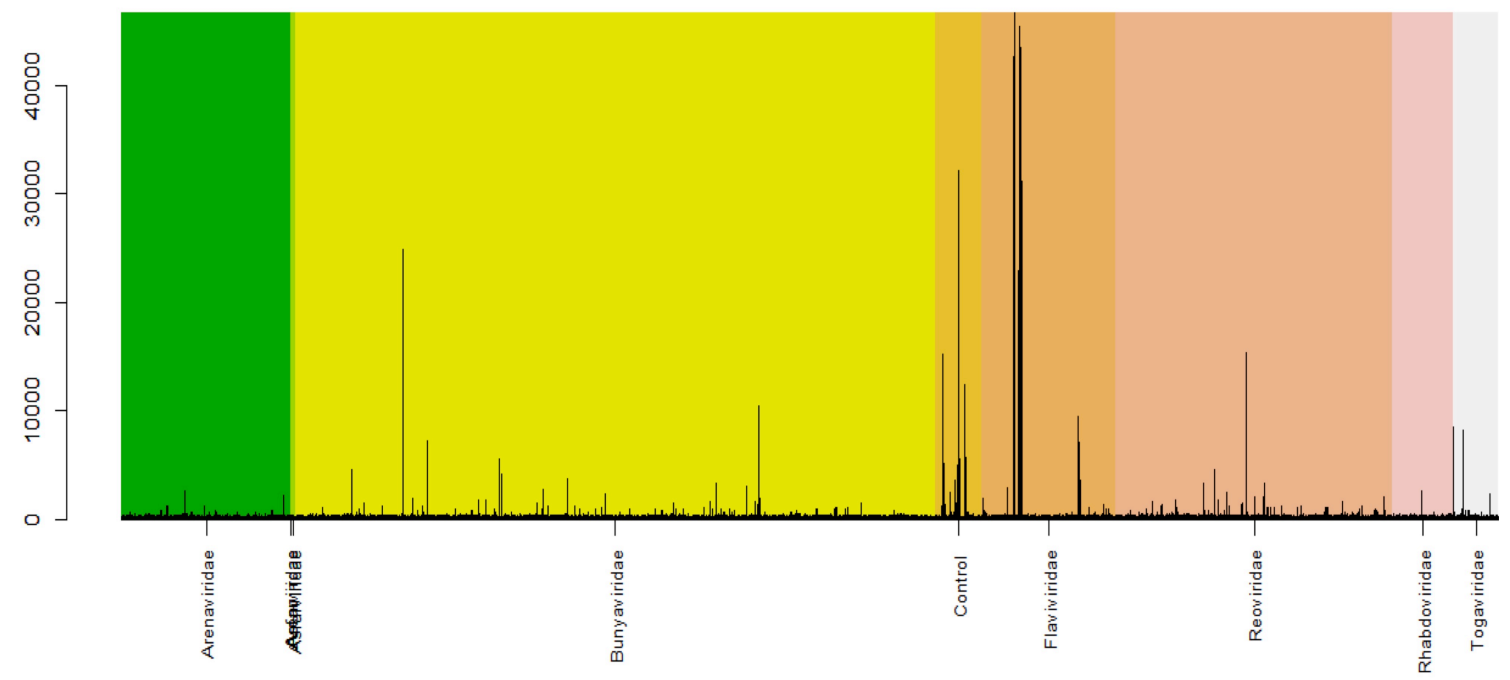

RoboArboChip_27.01.2014_2_1.8.1

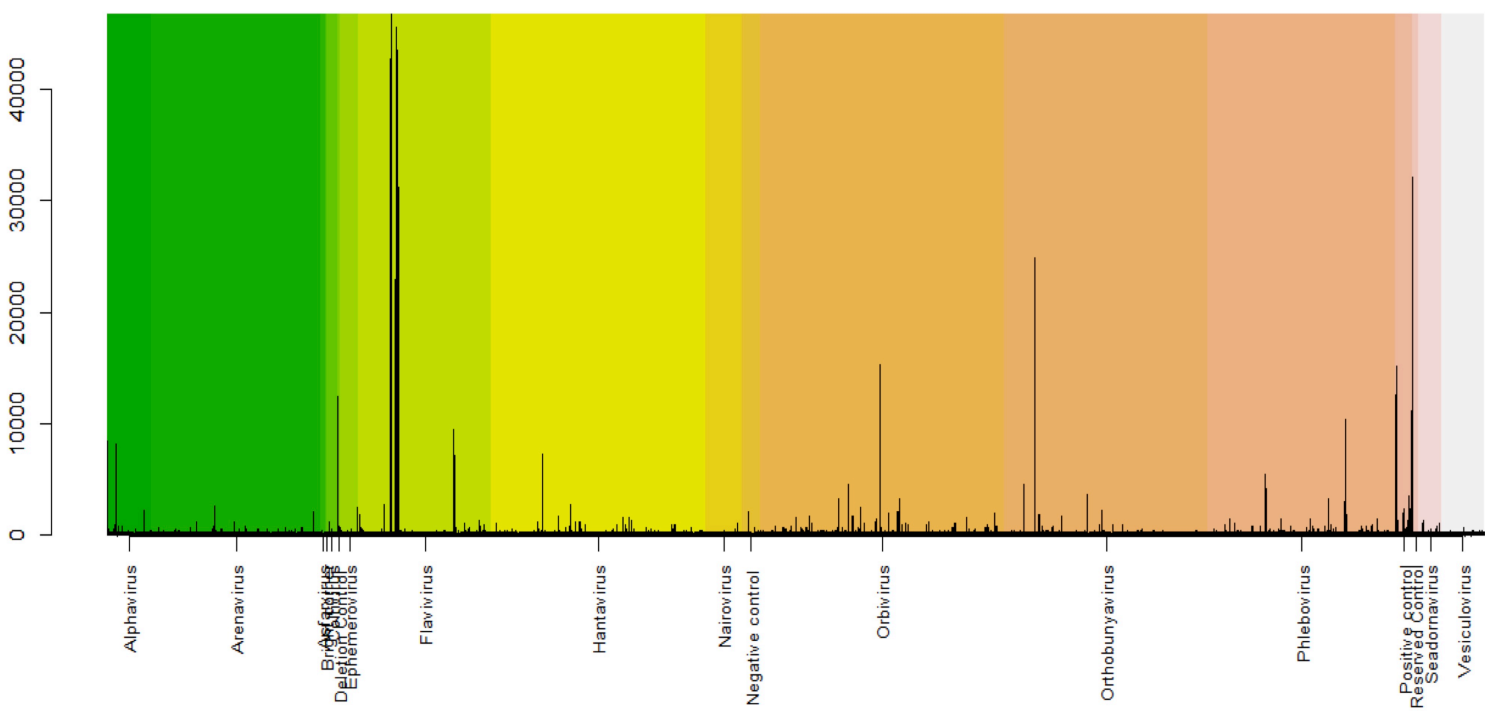




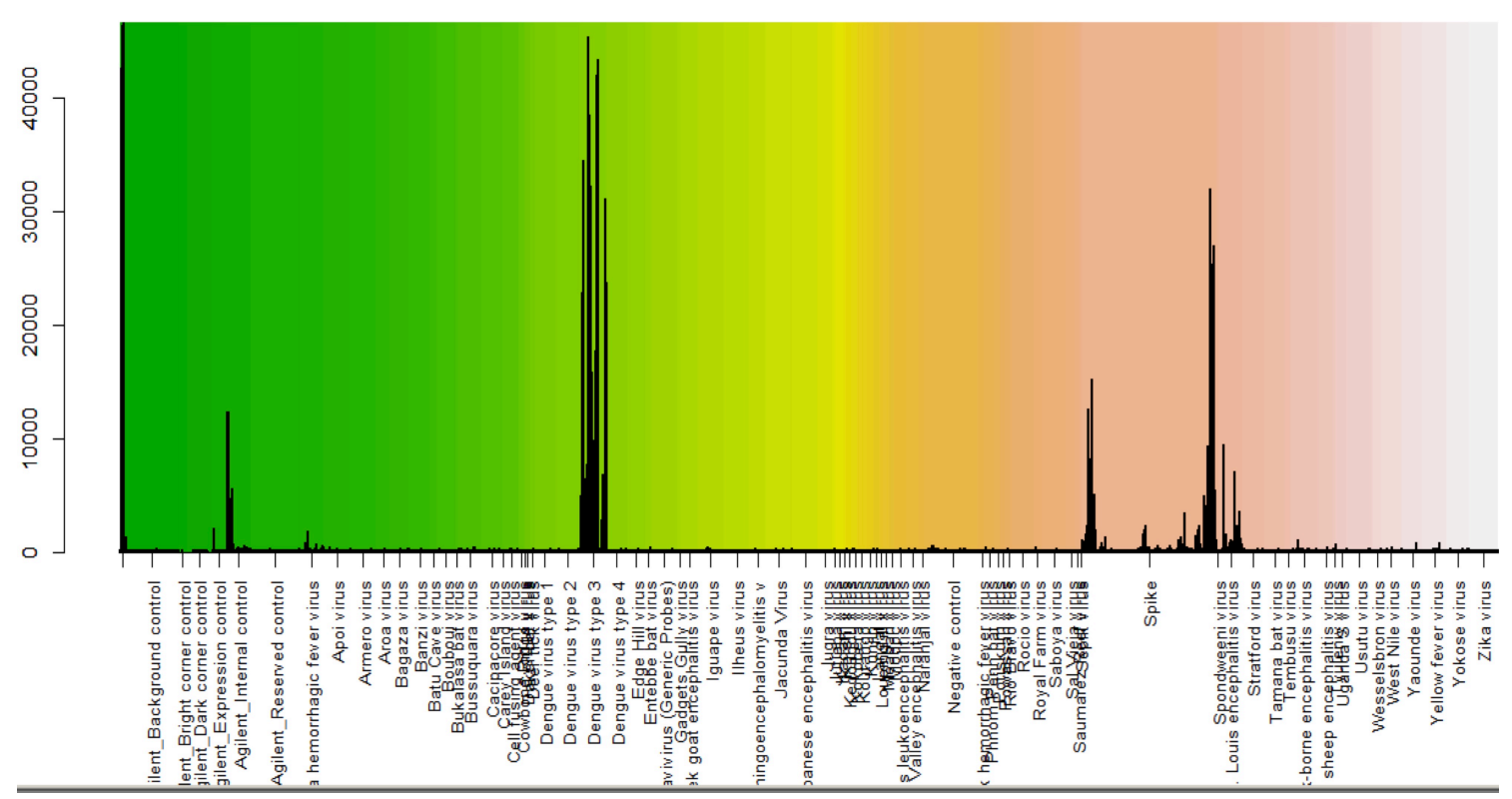

Figure 31. Visualization of probes fluorescence intensity of RoboArboVirusChi v3 slide hybridized with DENV-3. Data were sorted by family, genus and species levels.

Table 61. Significance analysis of arrays hybridized with DENV-3. The top 10 viruses with lowest $p$-values.

\begin{tabular}{cccc}
\hline Virus & No. of probes & $\boldsymbol{p}$-value & Average \\
\hline Spike & 200 & $1,82 \mathrm{E}-14$ & 1,02 \\
Dengue virus type 3 & 39 & $1,72 \mathrm{E}-12$ & 4,28 \\
Agilent_Internal control & 36 & $6,09 \mathrm{E}-05$ & 1,19 \\
NA & NA & NA & NA \\
\hline
\end{tabular}

In Figures 33-48, we are showing the visualization of probes intensity of arrays hybridized with BUSQV, CHIKV, DENV-1, DENV-2, DENV-4, GROV, IGUV, ILHV, MAYV, OROV, PIRYV, RIOMV, ROCV, SLEV, WNV, YFV and negative control. The significance analysis of data for these arrays are shown in Tables 59-75, 
RoboArboChip_27.01.2014_2_8.8.1

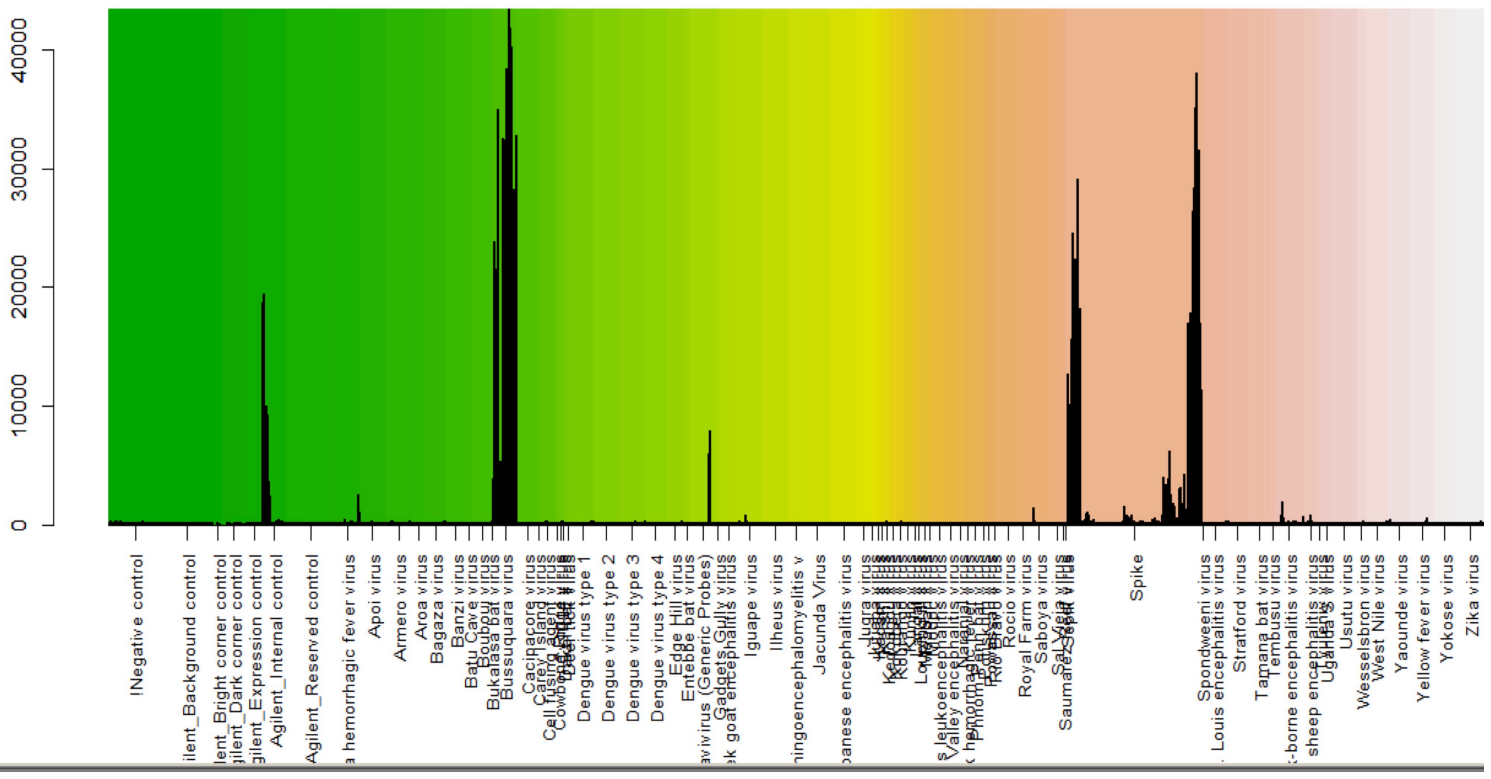

Figure 32. Visualization of probes fluorescence intensity of RoboArboVirusChi v3 slide hybridized with BUSQV. Data of virus species within the Flavivirus genus are shown.

Table 62. Significance analysis of arrays hybridized with BUSQV. The top 10 viruses with lowest $p$-values.

\begin{tabular}{cccr}
\hline Virus & No. of probes & $\boldsymbol{p}$-value & Average \\
\hline Spike & 200 & $3,01 \mathrm{E}-23$ & 1,80 \\
Bussuquara virus & 36 & $1,00 \mathrm{E}-17$ & 5,56 \\
Agilent_Internal control & 36 & 0,000113093 & 1,56 \\
NA & NA & NA & NA \\
\hline
\end{tabular}




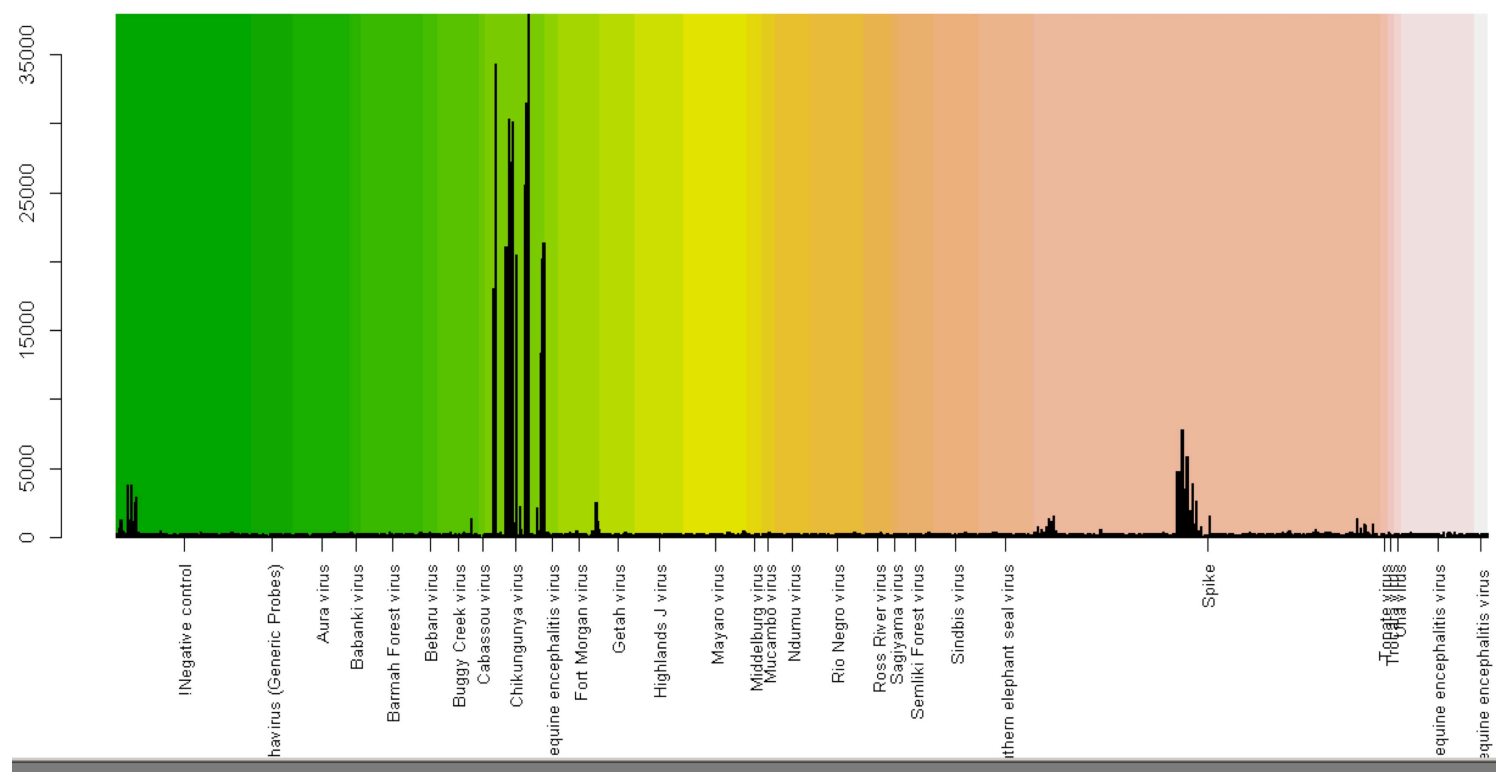

Figure 33. Visualization of probes fluorescence intensity of RoboArboVirusChi v3 slide hybridized with CHIKV. Data were sorted by species of the Alphavirus genus levels.

Table 63. Significance analysis of arrays hybridized with CHIKV. The top 10 viruses with lowest $p$-values.

\begin{tabular}{cccc}
\hline Virus & No. of probes & $\boldsymbol{p}$-value & Average \\
\hline Spike & 200 & $1,22 \mathrm{E}-06$ & 1,20 \\
Chikungunya virus & 34 & $4,59 \mathrm{E}-06$ & 2.81 \\
NA & NA & NA & NA \\
\hline
\end{tabular}




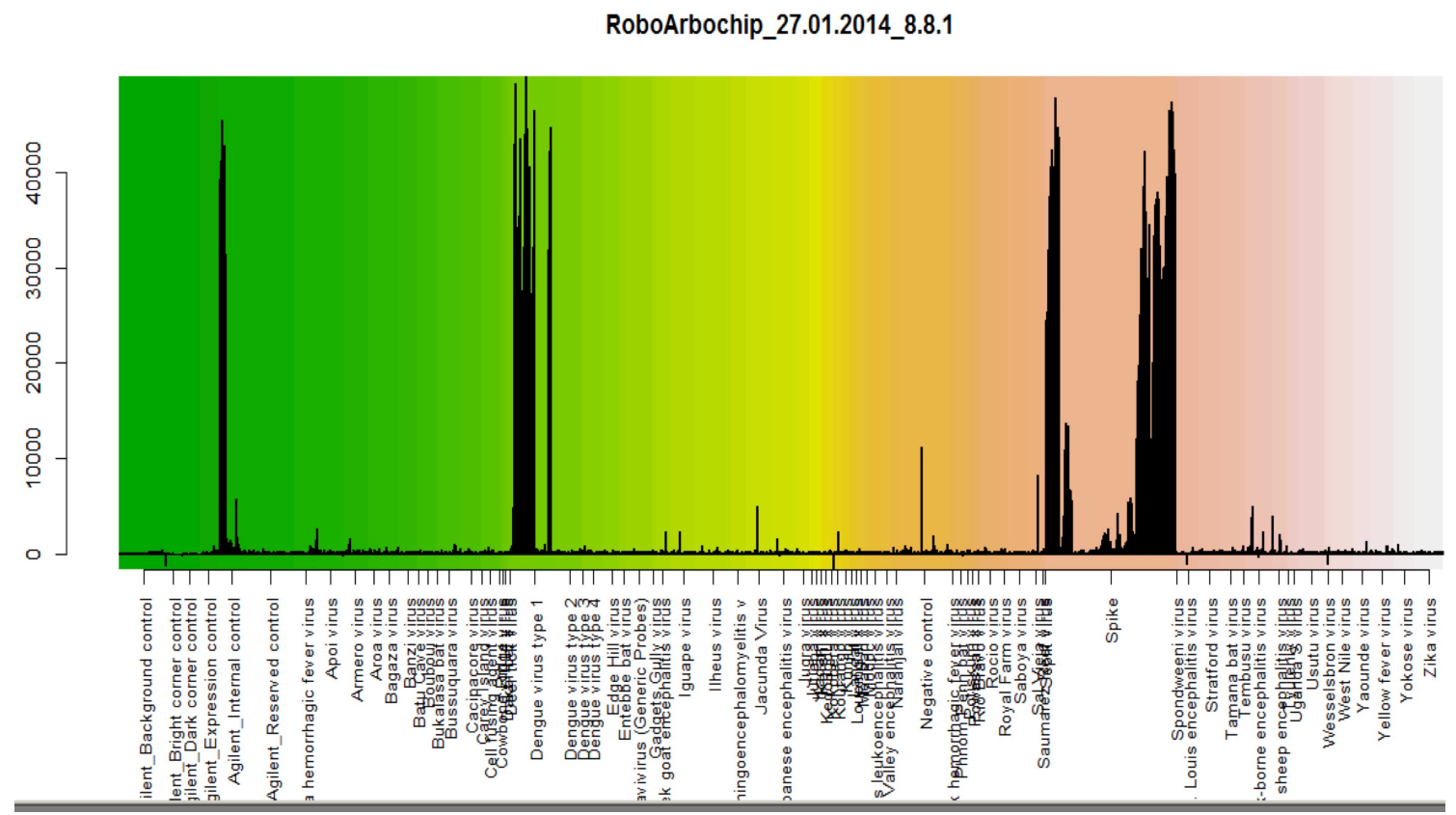

Figure 34. Visualization of probes fluorescence intensity of RoboArboVirusChi v3 slide hybridized with DENV-1. Data of virus species within the Flavivirus genus are shown.

Table 64. Significance analysis of arrays hybridized with DENV-1. The top 10 viruses with lowest $p$-values.

\begin{tabular}{cccc}
\hline Virus & No. of probes & $\boldsymbol{p}$-value & Average \\
\hline Spike & 200 & $7,69 \mathrm{E}-45$ & 3,71 \\
Dengue virus type 1 & 36 & $7,02 \mathrm{E}-21$ & 6,18 \\
Agilent_Internal control & 36 & $1,17 \mathrm{E}-07$ & 2,80 \\
NA & NA & NA & NA \\
\hline
\end{tabular}


RoboArbochip_27.01.2014_7.8.1

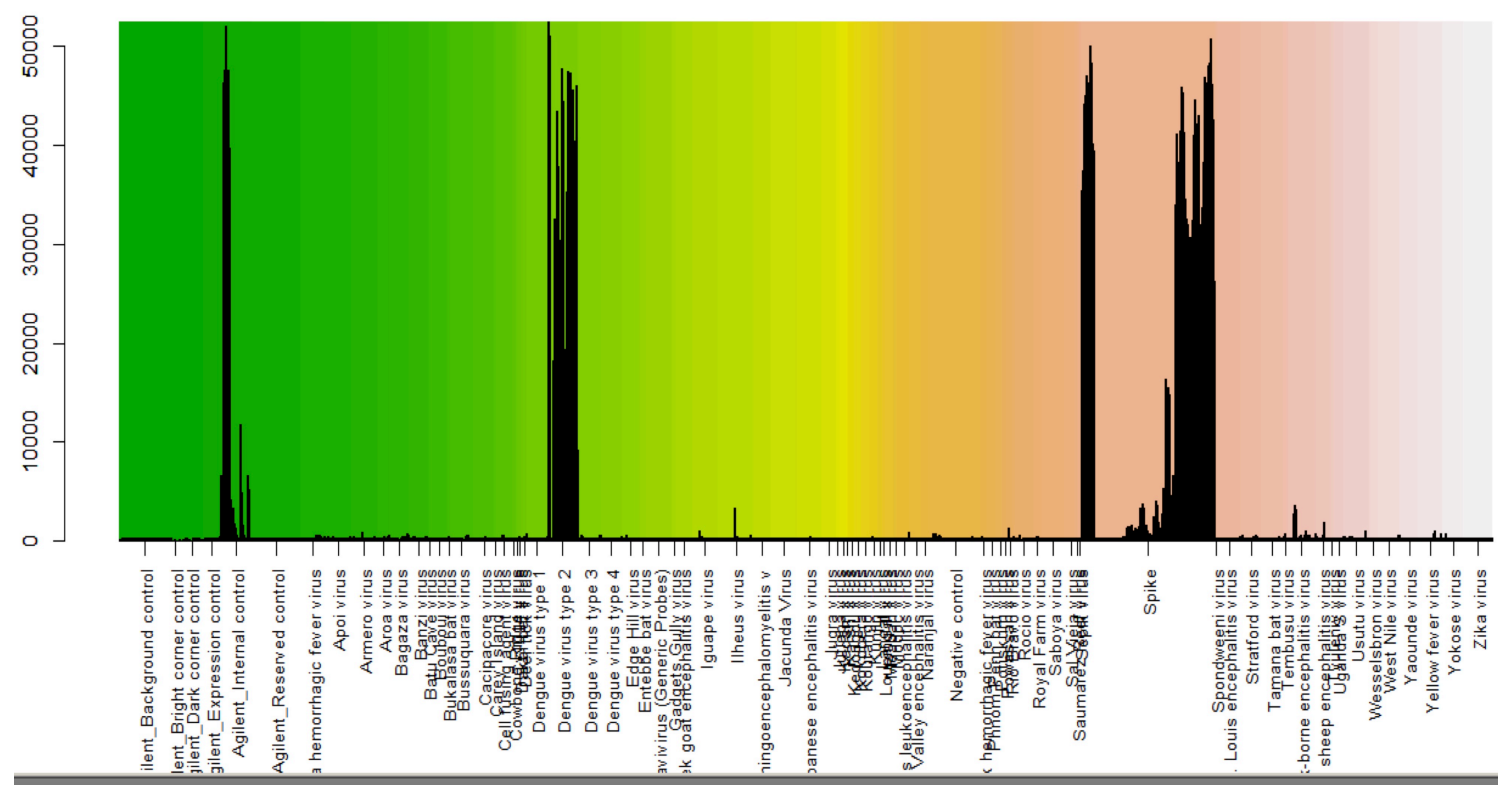

Figure 35. Visualization of probes fluorescence intensity of RoboArboVirusChi v3 slide hybridized with DENV-2. Data of virus species within the Flavivirus genus are shown.

Table 65. Significance analysis of arrays hybridized with DENV-2. The top 10 viruses with lowest $p$-values.

\begin{tabular}{cccc}
\hline Virus & No. of probes & $\boldsymbol{p}$-value & Average \\
\hline Spike & 200 & $4,15 \mathrm{E}-43$ & 3,76 \\
Dengue virus type 2 & 36 & $9,71 \mathrm{E}-16$ & 5,68 \\
Agilent_Internal control & 36 & $5,65 \mathrm{E}-08$ & 3,06 \\
NA & NA & NA & NA \\
\hline
\end{tabular}


RoboArboChip_27.01.2014_2_2.8.1

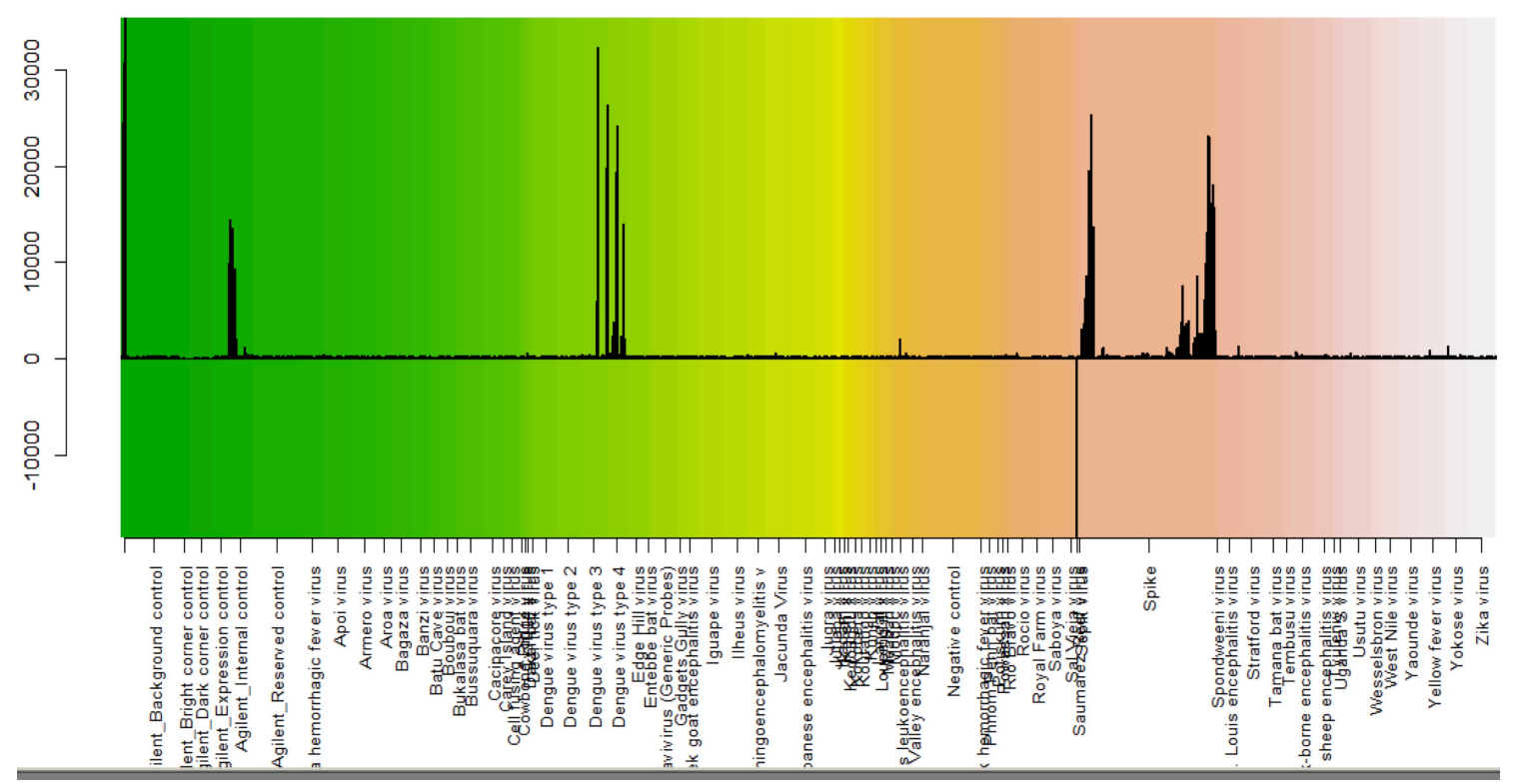

Figure 36. Visualization of probes fluorescence intensity of RoboArboVirusChi v3 slide hybridized with DENV-4. Data of virus species within the Flavivirus genus are shown.

Table 66. Significance analysis of arrays hybridized with DENV-4. The top 10 viruses with lowest $p$-values.

\begin{tabular}{cccr}
\hline Virus & No. of probes & $\boldsymbol{p}$-value & Average \\
\hline Spike & 200 & $4,76 \mathrm{E}-20$ & 1,48 \\
Dengue virus type 4 & 31 & $1,69 \mathrm{E}-05$ & 2,23 \\
Agilent_Internal control & 36 & $3,46 \mathrm{E}-05$ & 1,69 \\
NA & NA & NA & NA \\
\hline
\end{tabular}


RoboArbochip_27.01.2014_5.8.1

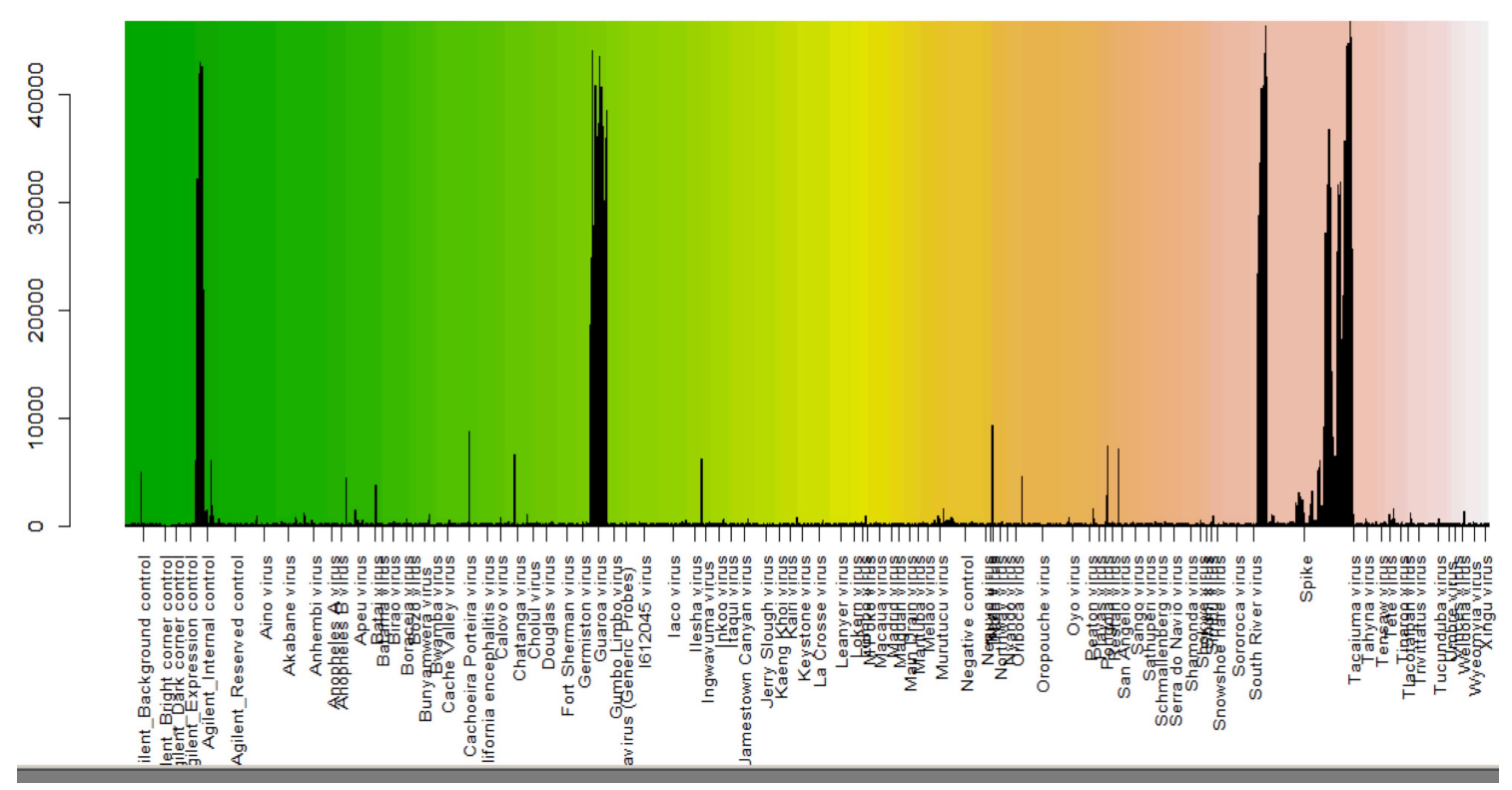

Figure 37. Visualization of probes fluorescence intensity of RoboArboVirusChi v3 slide hybridized with GROV. Data of virus species within the Orthobunyavirus genus are shown.

Table 67. Significance analysis of arrays hybridized with GROV. The top 10 viruses with lowest $p$-values.

\begin{tabular}{cccc}
\hline Virus & No. of probes & $\boldsymbol{p}$-value & Average \\
\hline Spike & 200 & $3,66 \mathrm{E}-38$ & 3,24 \\
Guaroa virus & 36 & $1,15 \mathrm{E}-32$ & 6,69 \\
Agilent_Internal control & 36 & $7,14 \mathrm{E}-07$ & 2,63 \\
NA & NA & NA & NA \\
\hline
\end{tabular}


RoboArbochip_27.01.2014_6.8.1

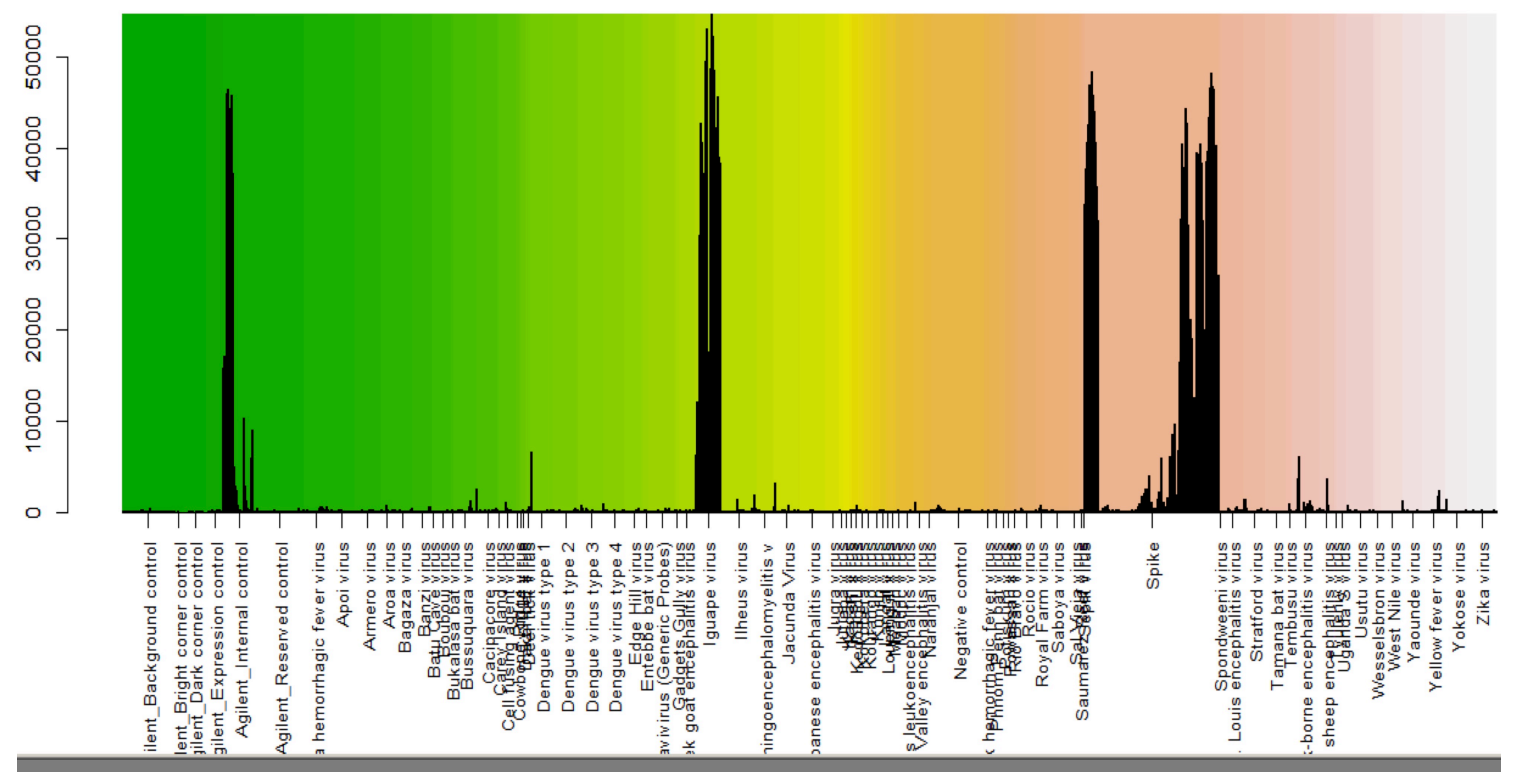

Figure 38. Visualization of probes fluorescence intensity of RoboArboVirusChi v3 slide hybridized with IGUV. Data of virus species within the Flavivirus genus are shown.

Table 68. Significance analysis of arrays hybridized with IGUV. The top 10 viruses with lowest $p$-values.

\begin{tabular}{cccc}
\hline Virus & No. of probes & $\boldsymbol{p}$-value & Average \\
\hline Spike & 200 & $4,88 \mathrm{E}-40$ & 3,67 \\
Iguape virus & 39 & $8,47 \mathrm{E}-27$ & 6,80 \\
Agilent_Internal control & 36 & $7,29 \mathrm{E}-08$ & 3,15 \\
NA & NA & NA & NA \\
\hline
\end{tabular}


RoboArbochip_27.01.2014_1.8.1

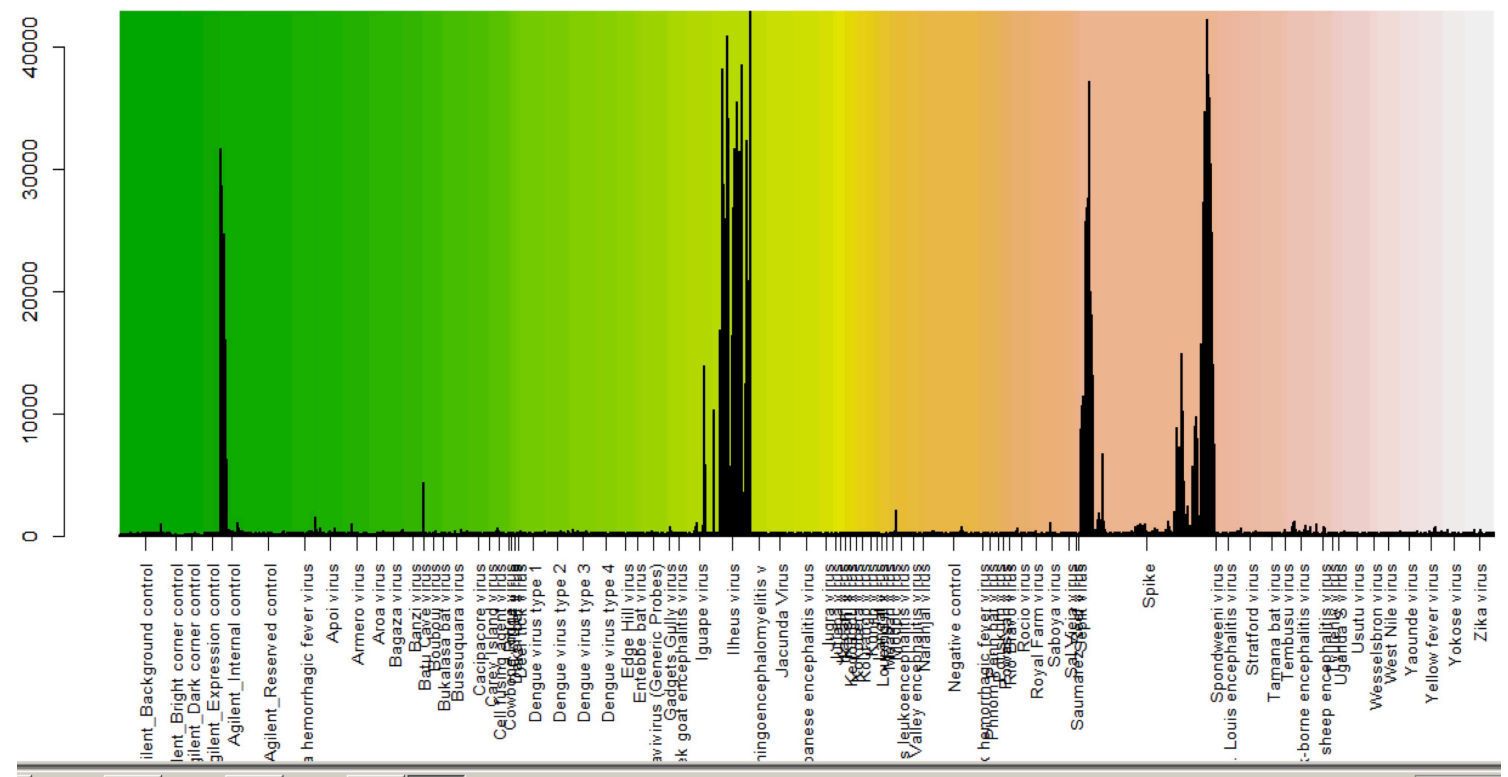

Figure 39. Visualization of probes fluorescence intensity of RoboArboVirusChi v3 slide hybridized with ILHV. Data of virus species within the Flavivirus genus are shown.

Table 69. Significance analysis of arrays hybridized with ILHV. The top 10 viruses with lowest $p$-values.

\begin{tabular}{cccc}
\hline Virus & No. of probes & $\boldsymbol{p}$-value & Average \\
\hline Spike & 200 & 12,50784687 & 2,08 \\
Ilheus virus & 38 & 18,59038861 & 5,42 \\
Agilent_Internal control & 36 & 4,708345624 & 1,82 \\
Spike & 200 & 12,50784687 & 2,08 \\
\hline
\end{tabular}


RoboArbochip_27.01.2014_2.8.1

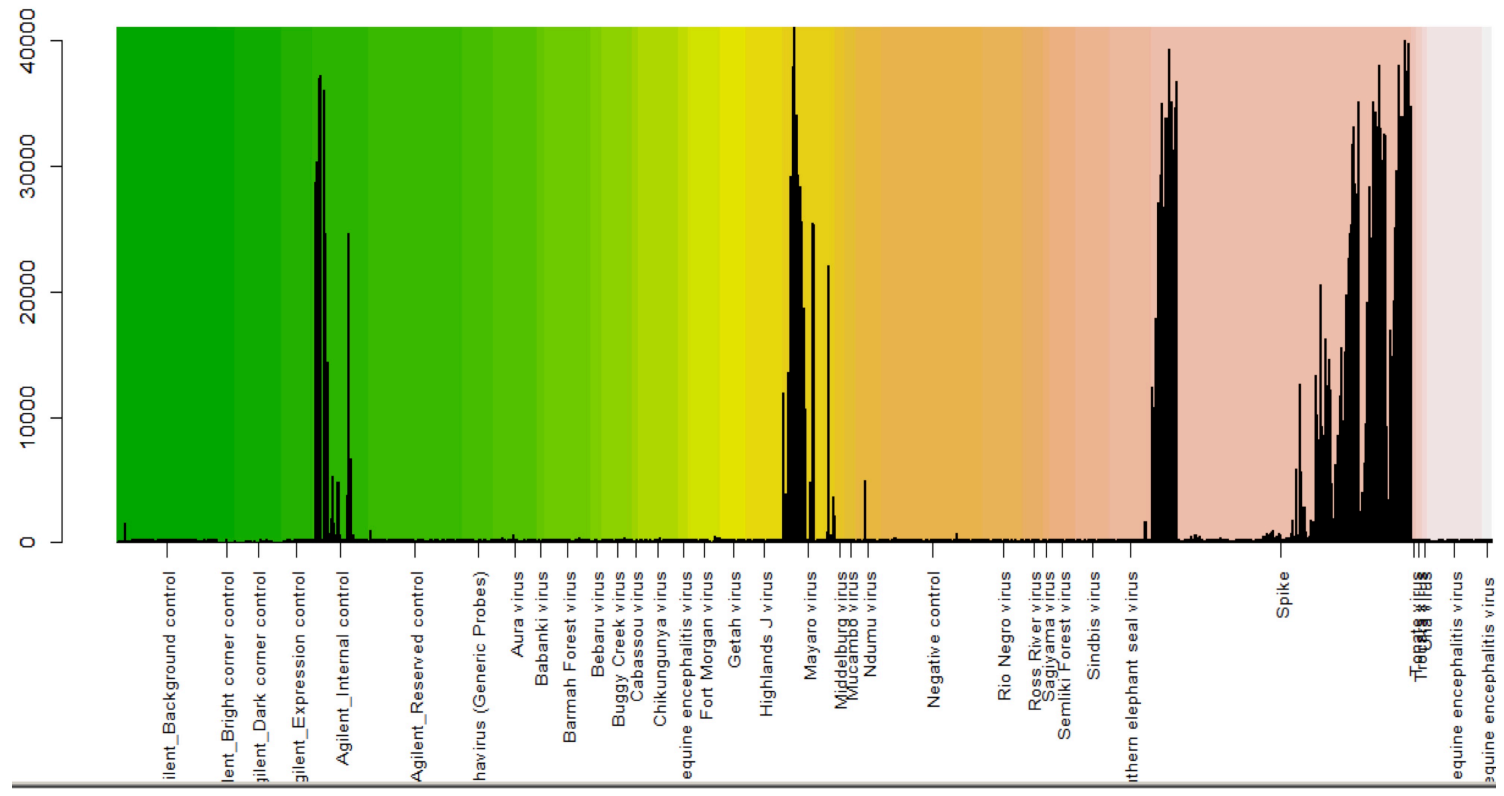

Figure 40. Visualization of probes fluorescence intensity of RoboArboVirusChi v3 slide hybridized with MAYV. Data of virus species within the Alphavirus genus are shown.

Table 70. Significance analysis of arrays hybridized with MAYV. The top 10 viruses with lowest $p$-values.

\begin{tabular}{cccc}
\hline Virus & No. of probes & $\boldsymbol{p}$-value & Average \\
\hline Spike & 200 & $2,11 \mathrm{E}-36$ & 3,28 \\
Mayaro virus & 37 & $1,42 \mathrm{E}-07$ & 3,24 \\
Agilent_Internal control & 36 & $2,57 \mathrm{E}-07$ & 2,83 \\
NA & NA & NA & NA \\
\hline
\end{tabular}


RoboArboChip_27.01.2014_2_5.8.1

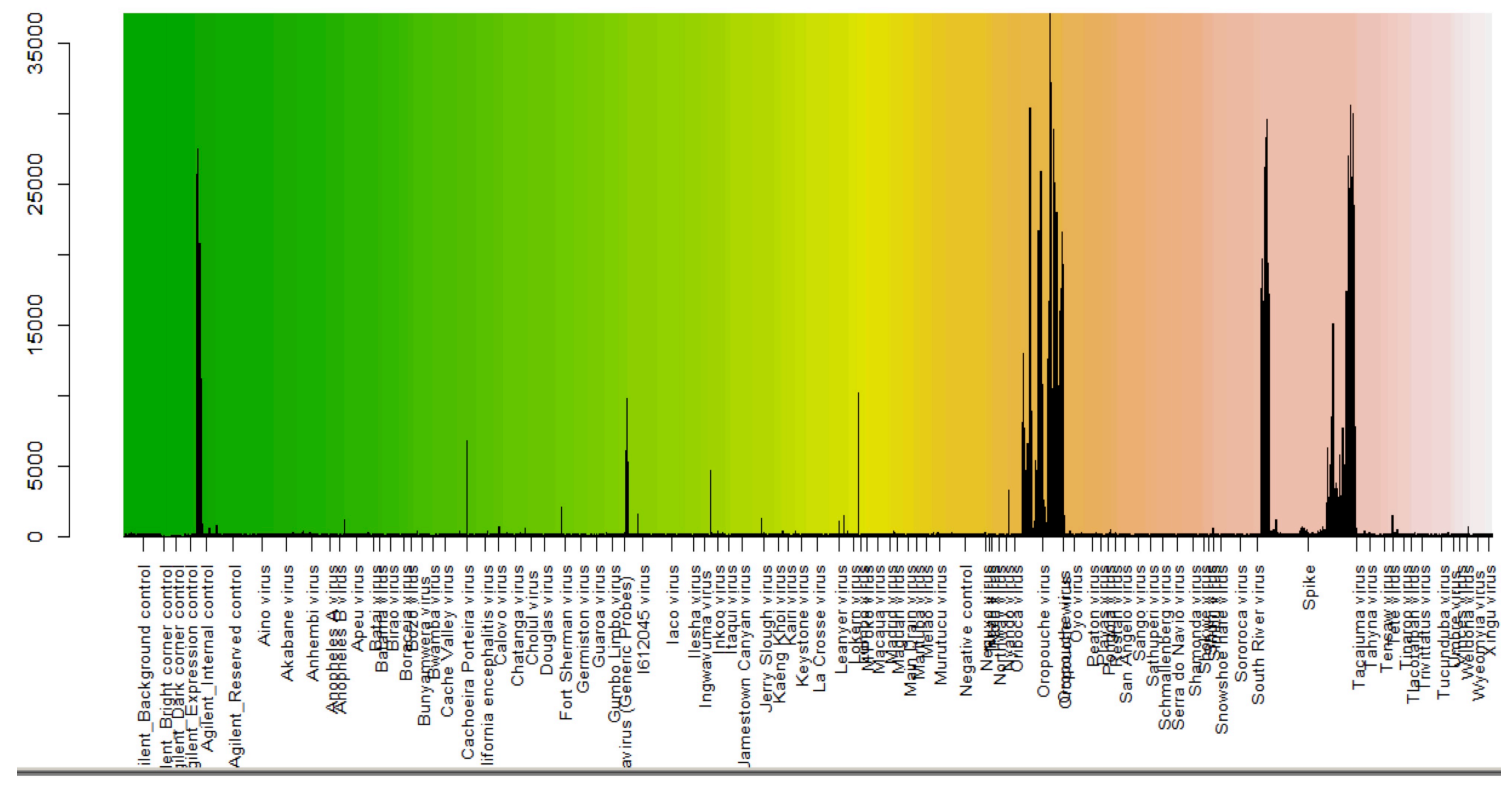

Figure 41. Visualization of probes fluorescence intensity of RoboArboVirusChi v3 slide hybridized with OROV. Data of virus species within the Orthobunyavirus genus are shown.

Table 71. Significance analysis of arrays hybridized with OROV. The top 10 viruses with lowest $p$-values.

\begin{tabular}{cccc}
\hline Virus & No. of probes & $\boldsymbol{p}$-value & Average \\
\hline Oropouche virus & 82 & $2,64 \mathrm{E}-34$ & 4,72 \\
Spike & 200 & $2,63 \mathrm{E}-27$ & 2,31 \\
Agilent_Internal control & 36 & $6,90 \mathrm{E}-05$ & 1,91 \\
NA & NA & NA & NA \\
\hline
\end{tabular}


RoboArbochip_27.01.2014_4.8.1

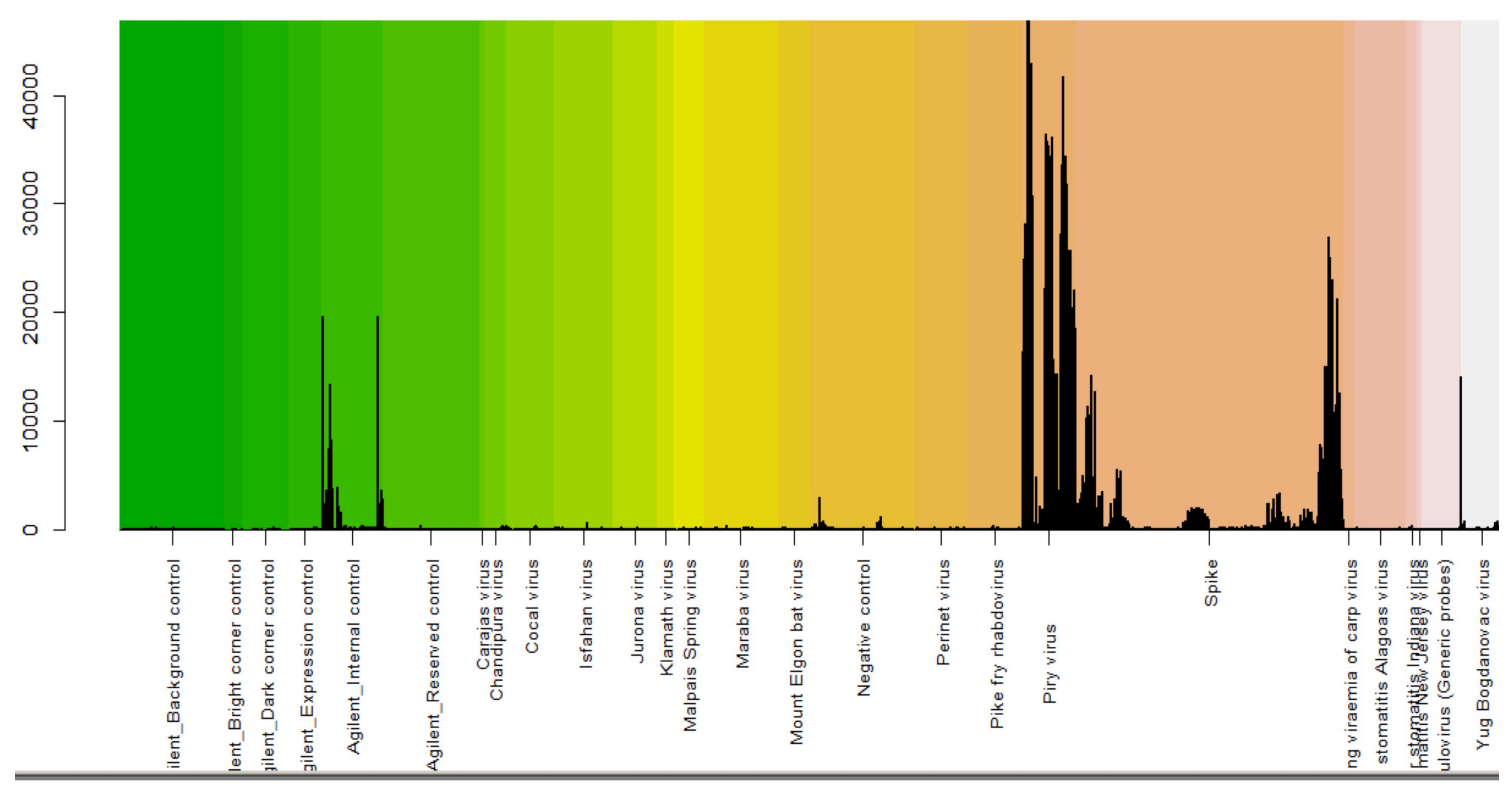

Figure 42. Visualization of probes fluorescence intensity of RoboArboVirusChi v3 slide hybridized with PIRYV. Data of virus species within the Vesiculovirus genus are shown.

Table 72. Significance analysis of arrays hybridized with PIRYV. The top 10 viruses with lowest $p$-values.

\begin{tabular}{cccc}
\hline Virus & No. of probes & $\boldsymbol{p}$-value & Average \\
\hline Spike & 200 & $4,04 \mathrm{E}-31$ & 1,90 \\
Piry virus & 40 & $1,50 \mathrm{E}-18$ & 5,73 \\
Agilent_Internal control & 36 & $4,08 \mathrm{E}-05$ & 1,29 \\
NA & NA & NA & NA \\
\hline
\end{tabular}


X11.04.2013_7.8.1

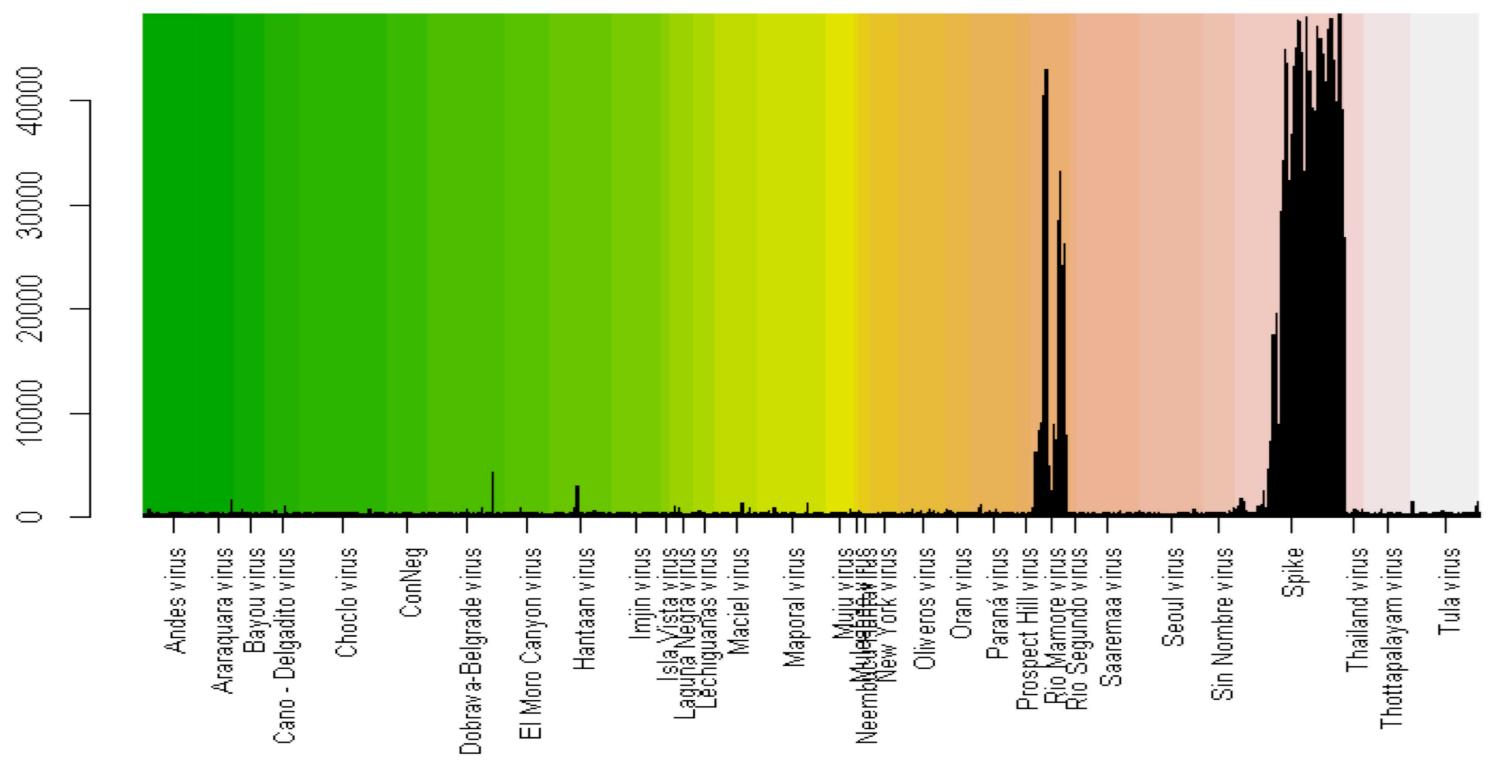

Figure 43. Visualization of probes fluorescence intensity of RoboArboVirusChi v3 slide hybridized with RIOMV. Data of virus species within the Hantavirus genus are shown.

Table 73. Significance analysis of arrays hybridized with RIOMV. The top 10 viruses with lowest $p$-values.

\begin{tabular}{cccc}
\hline Virus & No. of probes & $\boldsymbol{p}$-value & Average \\
\hline Spike & 200 & $1,22 \mathrm{E}-59$ & 4,49 \\
Rio Mamore virus & 72 & $7,14 \mathrm{E}-21$ & 3,35 \\
Agilent_Internal control & 36 & $1,12 \mathrm{E}-07$ & 2,96 \\
NA & NA & NA & NA \\
\hline
\end{tabular}




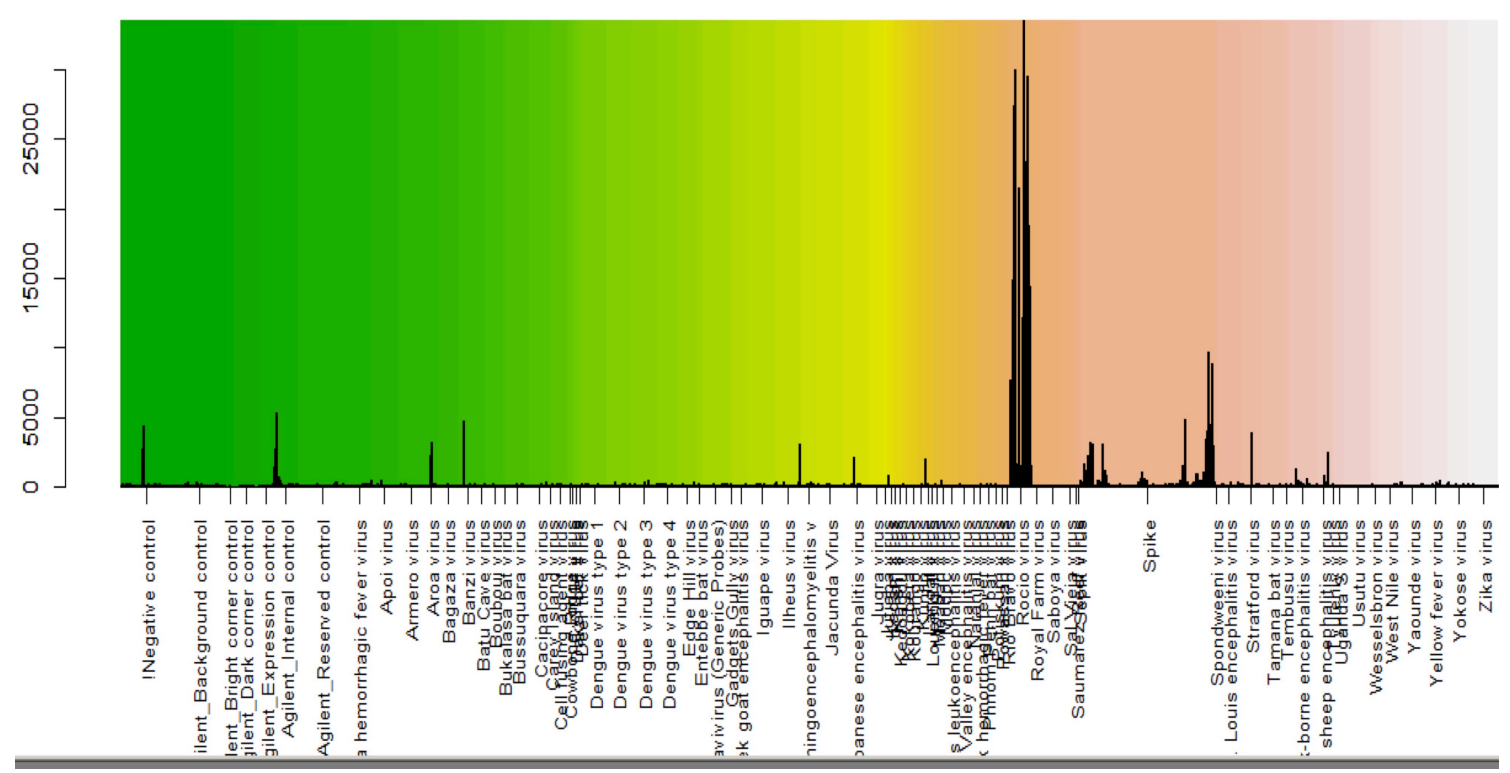

Figure 44. Visualization of probes fluorescence intensity of RoboArboVirusChi v3 slide hybridized with ROCV. Data of virus species within the Flavivirus genus are shown.

Table 74. Significance analysis of arrays hybridized with ROCV. The top 10 viruses with lowest $p$-values.

\begin{tabular}{cccc}
\hline Virus & No. of probes & $\boldsymbol{p}$-value & Average \\
\hline Spike & 200 & $3,64 \mathrm{E}-12$ & 3,61 \\
Rocio virus & 33 & $1,43 \mathrm{E}-10$ & 4,23 \\
NA & NA & NA & NA \\
\hline
\end{tabular}


RoboArboChip_27.01.2014_2_3.8.1

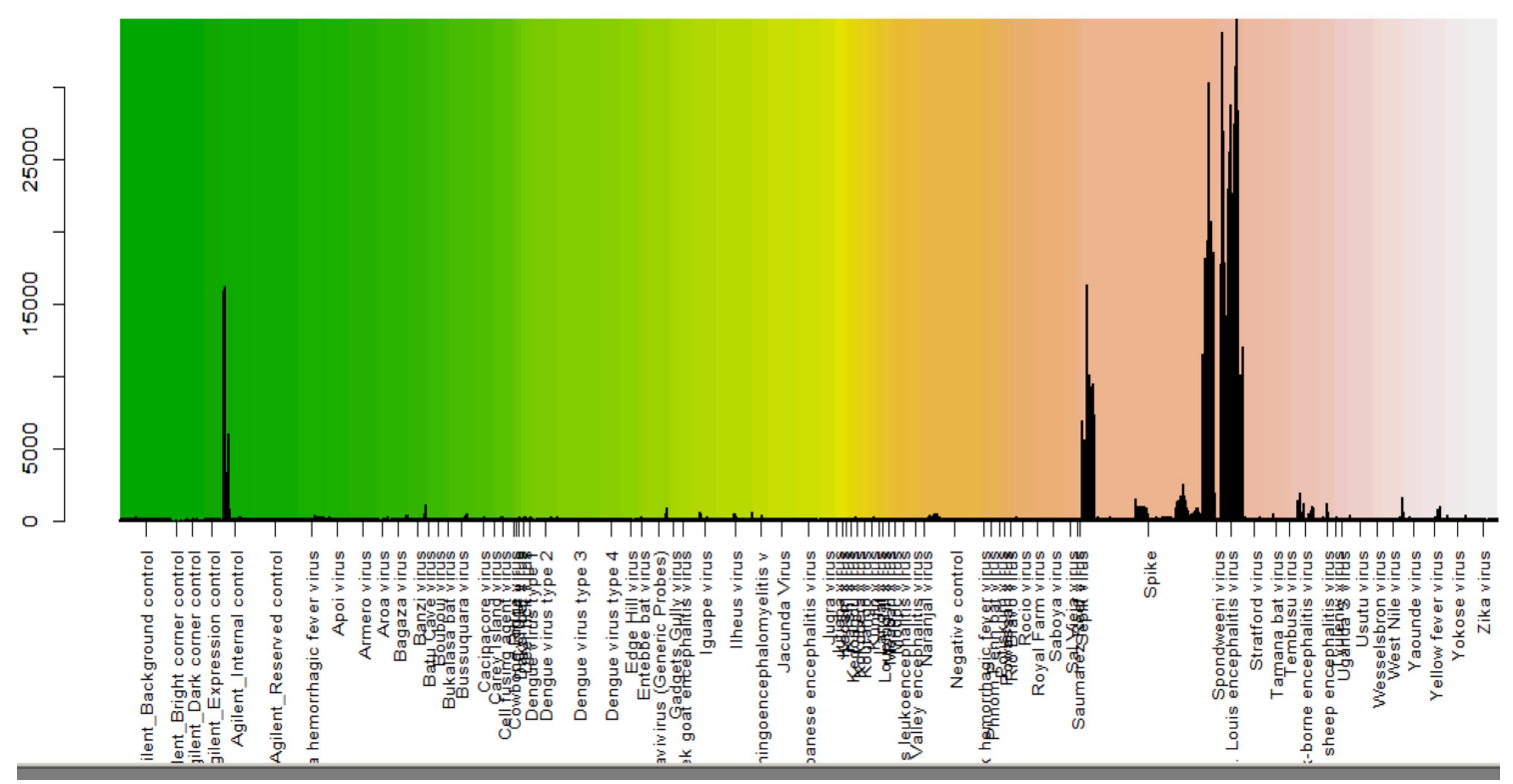

Figure 45. Visualization of probes fluorescence intensity of RoboArboVirusChi v3 slide hybridized with SLEV. Data of virus species within the Flavivirus genus are shown.

Table 75. Significance analysis of arrays hybridized with SLEV. The top 10 viruses with lowest $p$-values.

\begin{tabular}{cccc}
\hline Virus & No. of probes & $\boldsymbol{p}$-value & Average \\
\hline Spike & 200 & $2,37 \mathrm{E}-24$ & 1,71 \\
St. Louis encephalitis virus & 34 & $5,35 \mathrm{E}-14$ & 5,25 \\
Agilent_Internal control & 36 & 0,000296699 & 1,24 \\
NA & NA & NA & NA \\
\hline
\end{tabular}




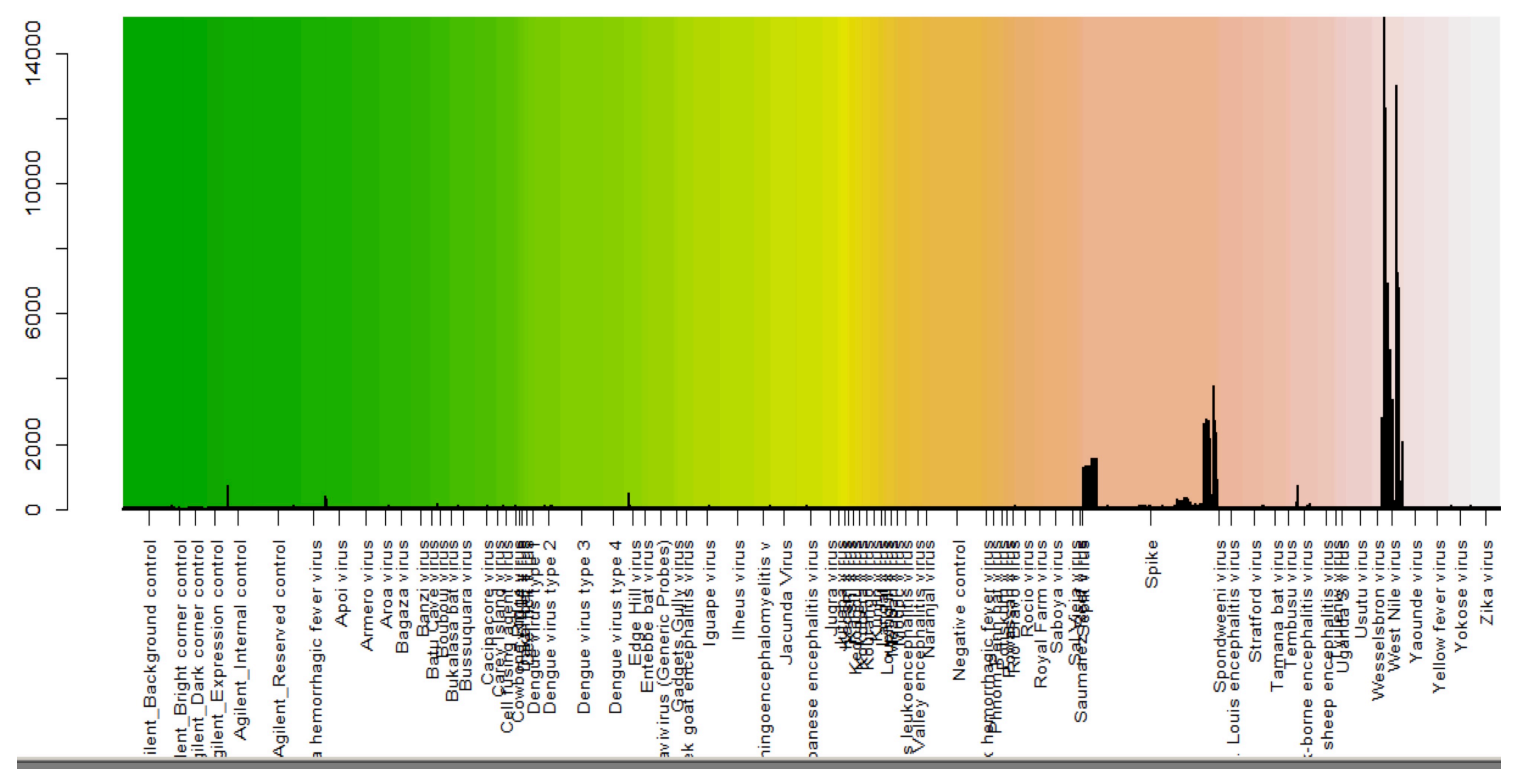

Figure 46. Visualization of probes fluorescence intensity of RoboArboVirusChi v3 slide hybridized with WNV. Data of virus species within the Flavivirus genus are shown.

Table 76. Significance analysis of arrays hybridized with WNV. The top 10 viruses with lowest $p$-values.

\begin{tabular}{cccc}
\hline Virus & No. of probes & $\boldsymbol{p}$-value & Average \\
\hline West Nile virus & 34 & 12,27891334 & 4,92 \\
Spike & 200 & 15,21410118 & 3,74 \\
NA & NA & NA & NA \\
\hline
\end{tabular}


RoboArboChip_27.01.2014_2_7.8.1

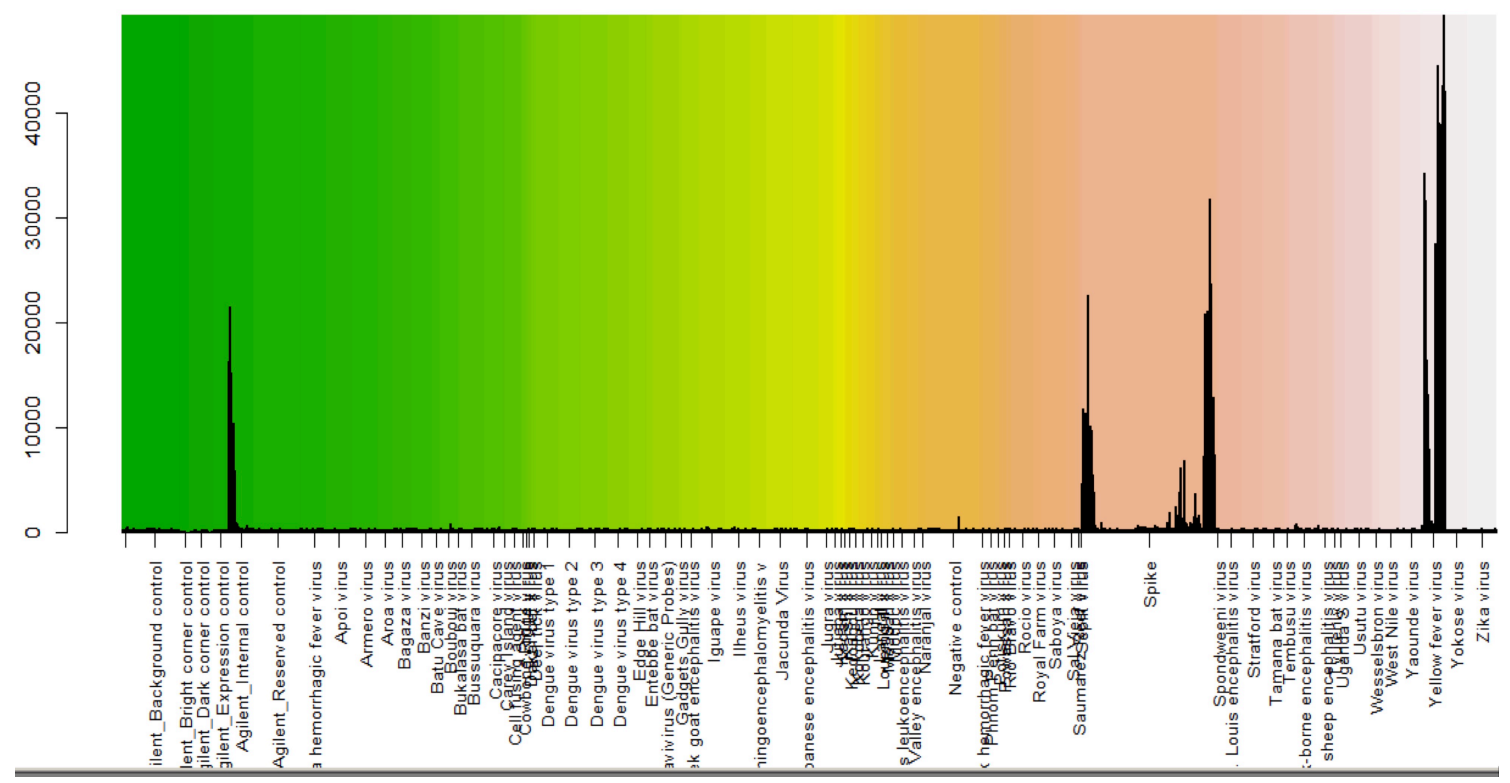

Figure 47. Visualization of probes fluorescence intensity of RoboArboVirusChi v3 slide hybridized with YFV. Data of virus species within the Flavivirus genus are shown.

Table 77. Significance analysis of array hybridized with YFV. The top 10 viruses with lowest $p$-values.

\begin{tabular}{cccc}
\hline Virus & No. of probes & $\boldsymbol{p}$-value & Average \\
\hline Spike & 200 & $9,80 \mathrm{E}-20$ & 1,43 \\
Yellow fever virus & 36 & $9,62 \mathrm{E}-11$ & 4,46 \\
Agilent_Internal control & 36 & $5,17 \mathrm{E}-05$ & 1,53 \\
NA & NA & NA & NA \\
\hline
\end{tabular}


RoboArbochip_27.01.2014_3.8.1

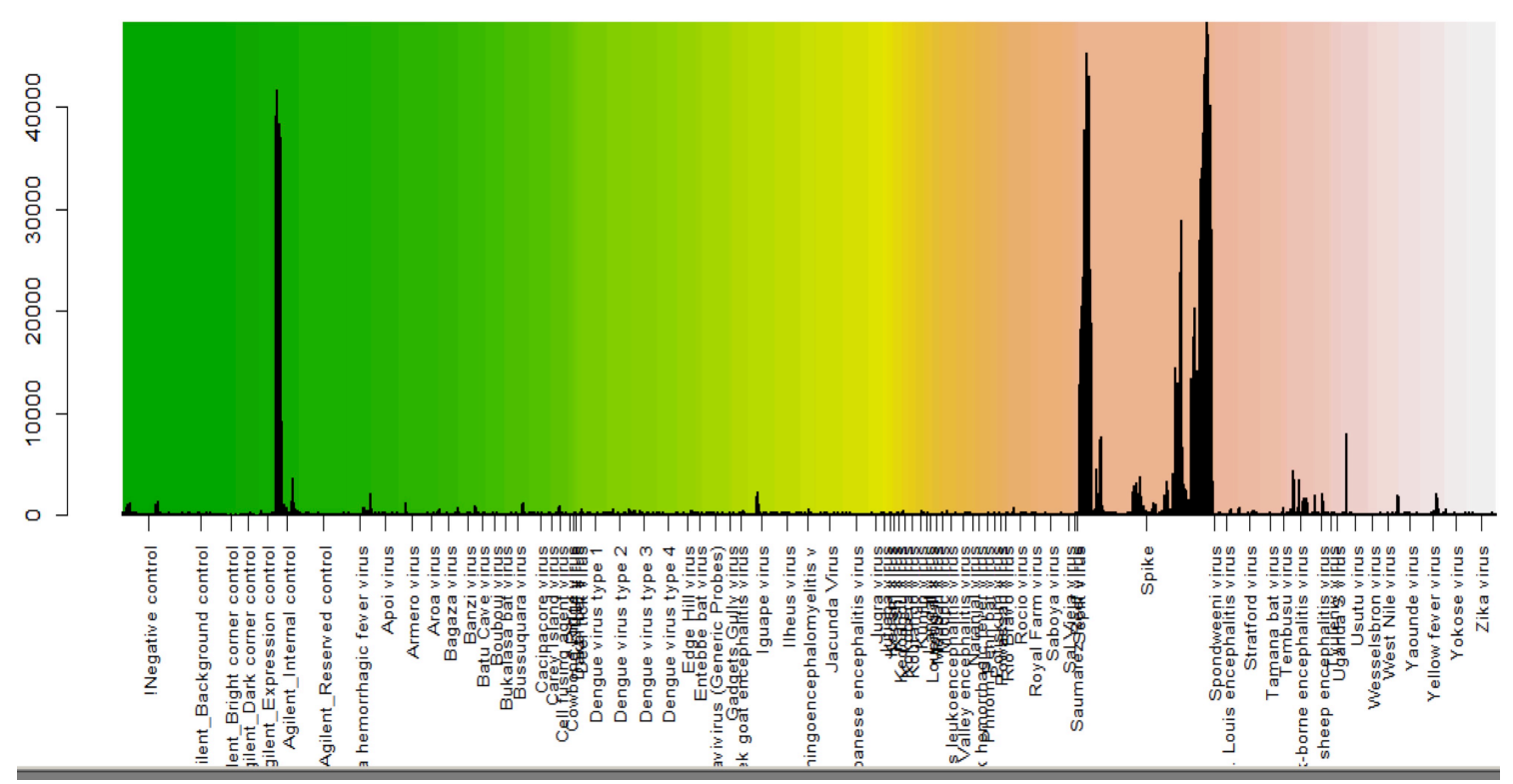

Figure 48. Visualization of probes fluorescence intensity of RoboArboVirusChi v3 slide hybridized with RNA of uninfected C6/36 cells. Data of virus species within the Flavivirus genus are shown.

Table 78. Significance analysis of array hybridized with RNA of uninfected C6/36 cells. The top 10 viruses with lowest $p$-values.

\begin{tabular}{cccc}
\hline Virus & No. of probes & $\boldsymbol{p}$-value & Average \\
\hline Spike & 200 & $6.53 \mathrm{E}-37$ & 2.91 \\
Agilent_Internal control & 36 & $1.11 \mathrm{E}-06$ & 2.42 \\
NA & NA & NA & NA \\
\hline
\end{tabular}

\subsection{Detection of mixture of viruses by the RoboArboVirusChip v3}

We tested the ability of this version to detect the mixture of viruses in a single sample. Two pools, one containing RNAs of viruses from three families, Togaviridae (MAYV), Flaviviridae (SLEV and BUSQV) and Rhabdoviridae (PIRYV), and the other containing RNAs of the four DENV serotypes were used. The visualizations of spots intensity are shown in Figures 50-53 and the significance analysis of the array hybridized with viruses from three different families is shown in Tables 76-77. 
PMT_400_RoboArboChip_20.09.2013_1_2.8.1

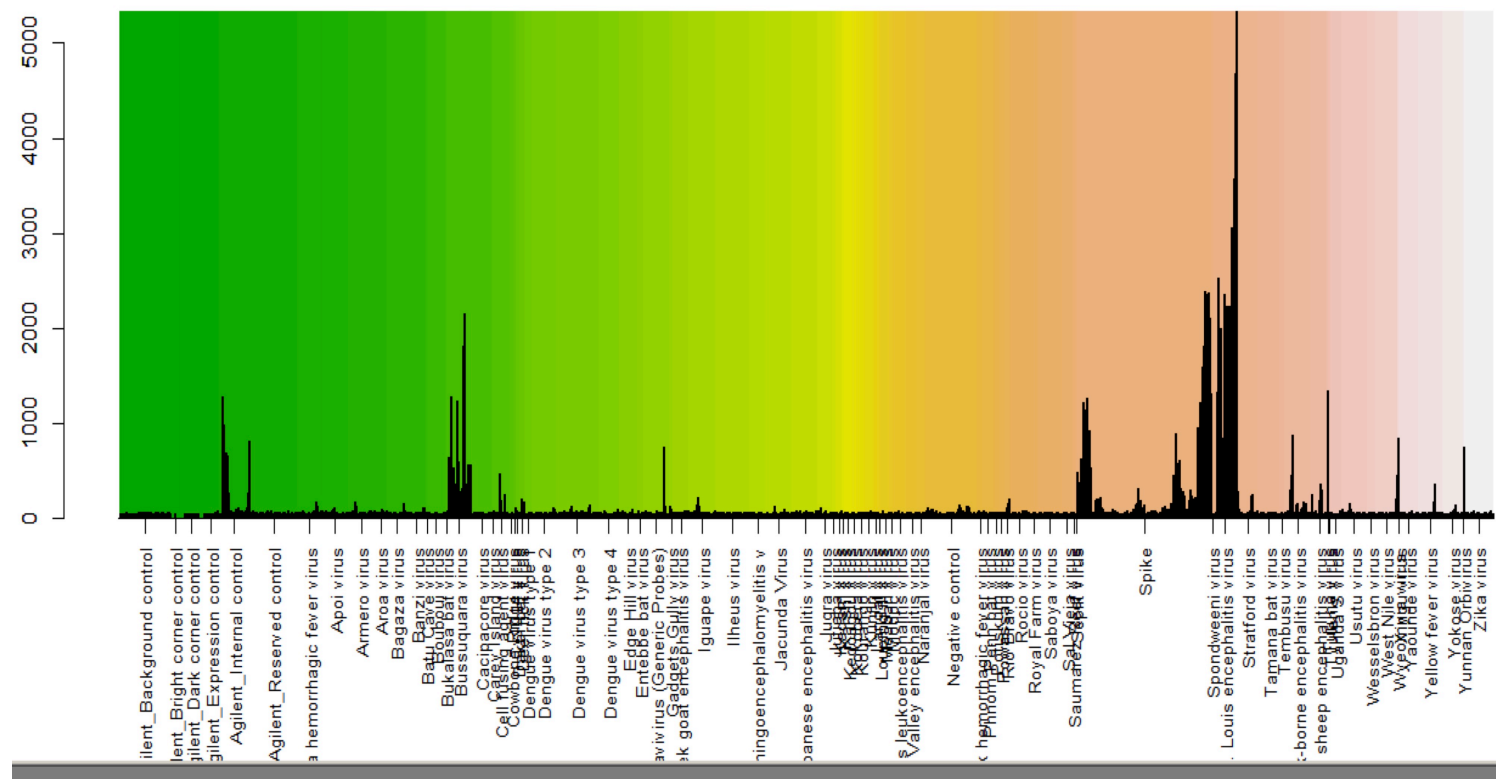

Figure 49. Visualization of probes fluorescence intensity of RoboArboVirusChi v3 slide hybridized with MAYV, SLEV, BUSQV and PIRYV. Data of virus species within the Flavivirus genus are shown.

PMT_400_RoboArboChip_20.09.2013_1_2.8.1

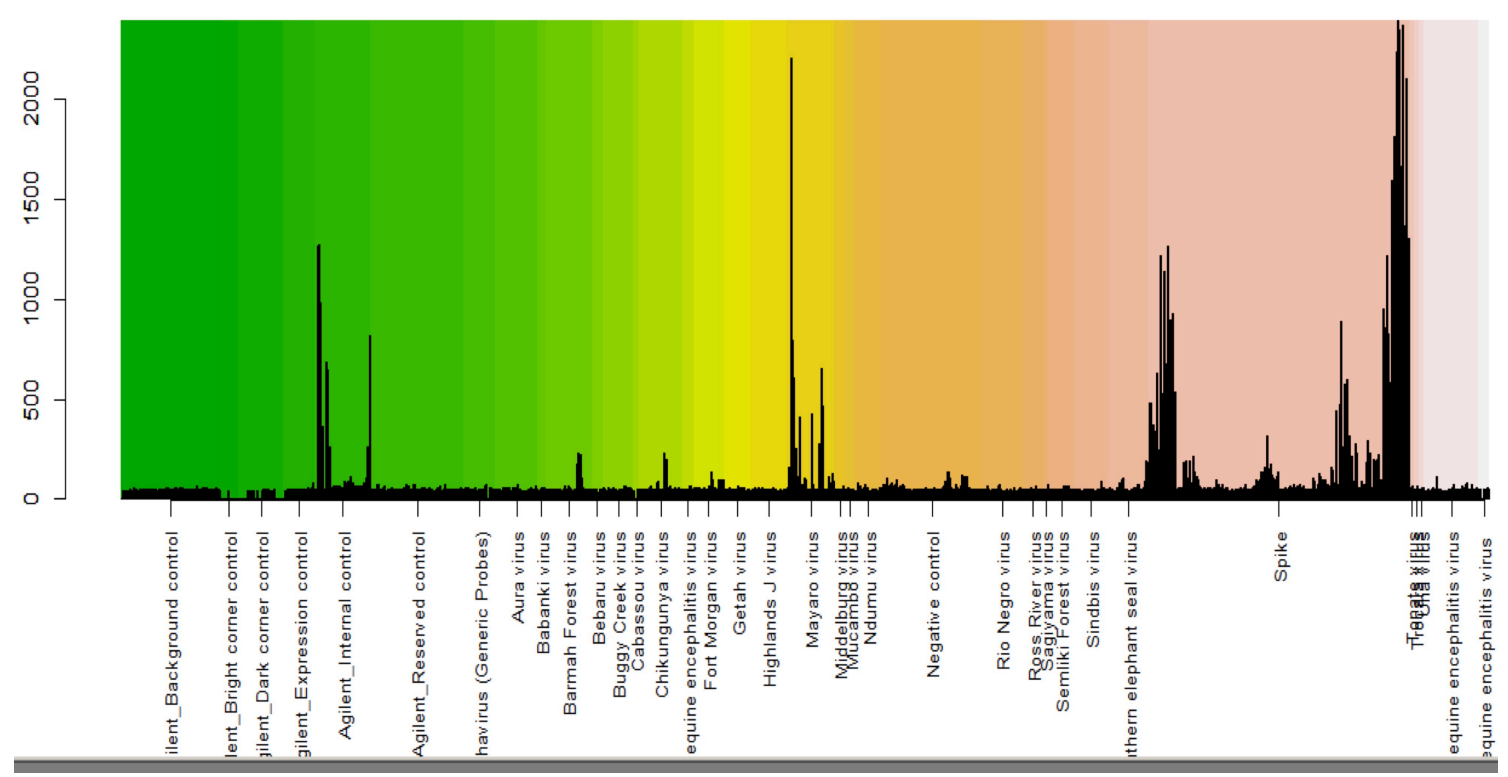

Figure 50. Visualization of probes fluorescence intensity of RoboArboVirusChi v3 slide hybridized with MAYV, SLEV, BUSQV and PIRYV. Data of virus species within the Alphavirus genus are shown. 
PMT_400_RoboArboChip_20.09.2013_1_2.8.1

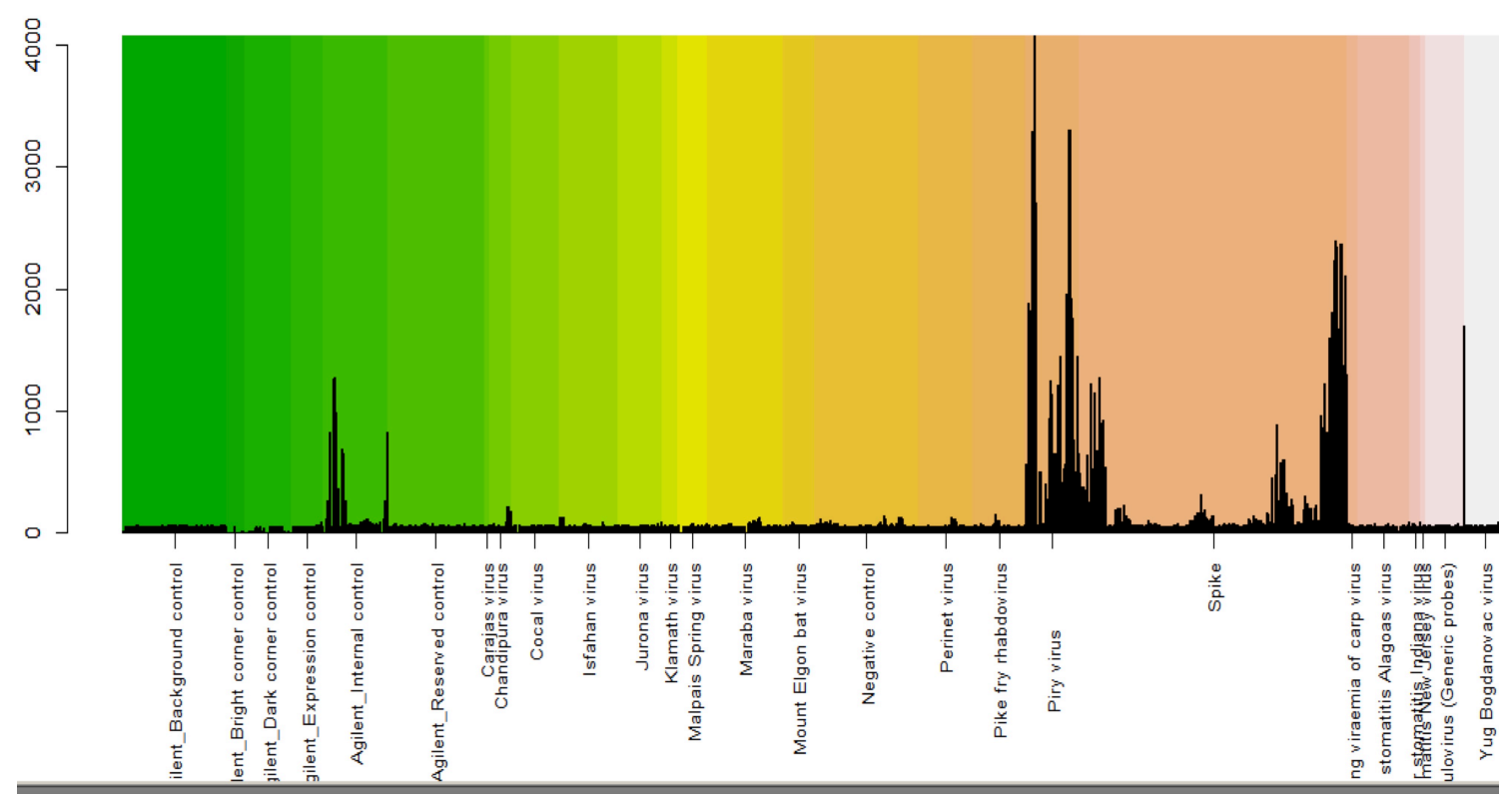

Figure 51. Visualization of probes fluorescence intensity of RoboArboVirusChi v3 slide hybridized with MAYV, SLEV, BUSQV and PIRYV. Data of virus species within the Vesiculovirus genus are shown.

Table 79. Significance analysis of array hybridized with a pool of MAYV, SLEV, BUSQV and PIRYV. The top 10 viruses with lowest $p$-values.

\begin{tabular}{cccc}
\hline Virus & No. of probes & $\boldsymbol{p}$-value & Average \\
Spike & 34 & $2,55 \mathrm{E}-15$ & 4,35 \\
Piry virus & 200 & $1,39 \mathrm{E}-13$ & 4,44 \\
Bussuquara virus & 40 & $2,04 \mathrm{E}-13$ & 3,50 \\
Myaro virus & 36 & $2,20 \mathrm{E}-13$ & 2,60 \\
NA & 37 & $4,54 \mathrm{E}-12$ & 3,18 \\
& NA & NA & NA \\
\hline
\end{tabular}

The visualizations of spots intensity are shown in Figures 53 and the significance analysis of the array hybridized with the four DENV serotypes is shown in Table 72. 
PMT_400_RoboArboChip_20.09.2013_1_7.8.1

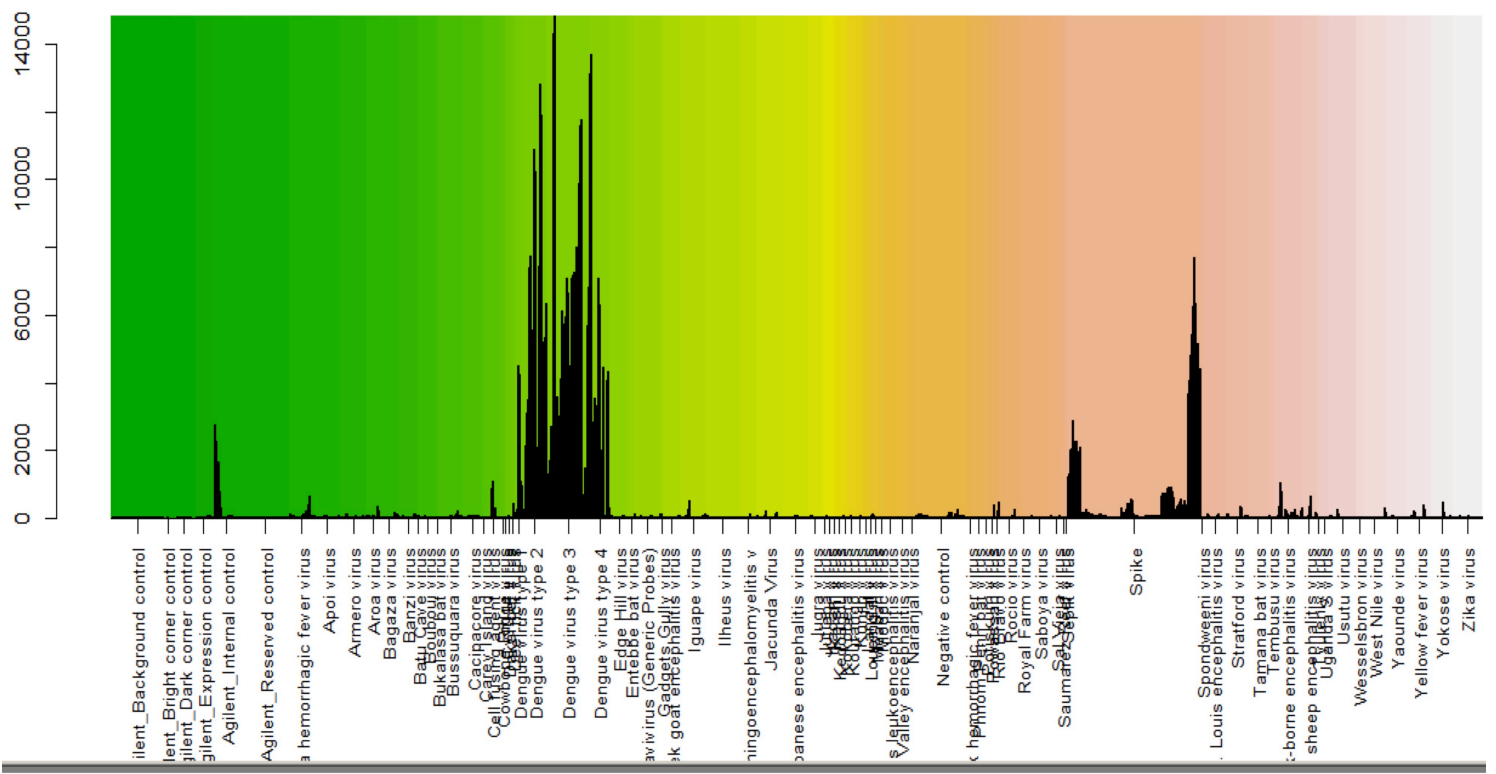

Figure 52. Visualization of probes fluorescence intensity of RoboArboVirusChi v3 slide hybridized with DENV-1, DENV-2, DENV-3 and DENV-4. Data of virus species within the Flavivirus genus are shown.

Table 80. Significance analysis of array hybridized with a pool of MAYV, SLEV, BUSQV and PIRYV. The top 10 viruses with lowest $p$-values.

\begin{tabular}{cccc}
\hline Virus & No. of probes & $\boldsymbol{p}$-value & Average \\
\hline Dengue virus type 3 & 39 & $8,23 \mathrm{E}-27$ & 6,03 \\
Spike & 200 & $3,23 \mathrm{E}-25$ & 6,40 \\
Dengue virus type 2 & 36 & $1,01 \mathrm{E}-22$ & 5,88 \\
Dengue virus type 1 & 36 & $2,34 \mathrm{E}-20$ & 5,26 \\
Dengue virus type 4 & 31 & $2,07 \mathrm{E}-13$ & 4,86 \\
\hline
\end{tabular}

The RoboArboVirusChip v3 was able to specifically detect all the viruses within the two pools. 


\subsection{Determination of sensitivity of the RoboArboVirusChip v3}

The sensitivity of the RoboArboVirusChip v3 was determined by using 10 foldserial dilutions of DENV-1 $\left(2.6 \times 10^{7}\right.$ RNA copies/mL), DENV-2 $\left(2.5 \times 10^{9}\right.$ RNA copies/mL), DENV-3 $\left(6.7 \times 10^{7}\right.$ RNA copies/mL $)$ and DENV-4 $\left(2.1 \times 10^{9}\right.$ RNA copies $/ \mathrm{mL}$ ). Microarray experiment was performed as mention above (Table 78).

Table 81. Determination of sensitivity of the RoboArboVirusChip v3 for DENV-1, DENV-2, DENV-3 and DENV-4.

\begin{tabular}{cccccc}
\hline Virus & $\begin{array}{c}\text { Titer } \\
\text { (RNA copies/mL) }\end{array}$ & $\boldsymbol{p}$-value & Average & Spike $\boldsymbol{p}$-value & Spike average \\
& & & & & \\
\hline DENV-1 & 26 & $1.58 \mathrm{E}-06$ & 1.619 & $6.77 \mathrm{E}-27$ & 7.610 \\
DENV-2 & 25 & $2.57 \mathrm{E}-07$ & 2.156 & $6.10 \mathrm{E}-29$ & 8.081 \\
& & & & & \\
DENV-3 & 67 & $1.23 \mathrm{E}-12$ & 4.333 & $3.76 \mathrm{E}-30$ & 8.006 \\
& & & & & \\
DENV-4 & 21 & $2.99 \mathrm{E}-21$ & 2.592 & $1.85 \mathrm{E}-54$ & 5.601 \\
\hline
\end{tabular}

\subsection{Analysis of clinical samples with the RoboArboVirusChip v3}

Serum samples collected form DENV infected $(n=4)$ and uninfected $(n=40)$ patients were used to determine the applicability of the RoboArboVirusChip v3 for detecting virus in serum samples. A pool of four serum samples from uninfected patients were analyzed per array, all of which showed a negative result in the microarray assay (Table 79). While all serum samples of DENV infected patients (DENV-1=1, DENV2=1, DENV-3, and DENV-4=1), analyzed in independent arrays, were specifically detected (Table 80). 
Table 82. Significance analysis of array hybridized with RNA of serum samples of DENV uninfected cases. The top 10 viruses with lowest $p$-values.

\begin{tabular}{|c|c|c|c|c|}
\hline Samples ID & Virus & No. of probes & $p$-value & Average \\
\hline \multirow[t]{2}{*}{$1,2,2664$ and 1328} & Spike & 200 & $2,11 \mathrm{E}-20$ & 1,09 \\
\hline & NA & NA & NA & NA \\
\hline \multirow[t]{2}{*}{$2671,1318,2666$ and 1390} & Spike & 200 & $8,14 \mathrm{E}-36$ & 2,75 \\
\hline & Agilent_Internal control & 36 & $3,57 \mathrm{E}-08$ & 2,51 \\
\hline & NA & NA & NA & NA \\
\hline $1334,1337,1323$ and 1239 & Spike & 200 & $1,22 \mathrm{E}-29$ & 2.06 \\
\hline & NA & NA & NA & NA \\
\hline 2082, 2272, 2076 and 2306 & Spike & 200 & $6.27 \mathrm{E}-31$ & 2.20 \\
\hline & NA & NA & NA & NA \\
\hline $2271,2091,2051$ and 2109 & Spike & 200 & 7.33E-50 & 3.94 \\
\hline \multirow{3}{*}{$2112,2238,2086$ and 2265} & NA & NA & NA & NA \\
\hline & Spike & 200 & $1.35 \mathrm{E}-41$ & 2.43 \\
\hline & NA & NA & NA & NA \\
\hline $2262,2075,2069$ and 2240 & Spike & 200 & $1.33 \mathrm{E}-17$ & 1.37 \\
\hline \multirow{3}{*}{$2290,2270,2289$ and 1223} & NA & NA & NA & NA \\
\hline & Spike & 200 & $1.88 \mathrm{E}-46$ & 3.71 \\
\hline & NA & NA & NA & NA \\
\hline $1298,1325,1847$ and 1651 & Spike & 200 & $2.71 \mathrm{E}-45$ & 3.61 \\
\hline \multirow{3}{*}{$2488,2510,2309$ and 2516} & NA & NA & NA & NA \\
\hline & Spike & 200 & $5.46 \mathrm{E}-27$ & 1.91 \\
\hline & NA & NA & NA & NA \\
\hline
\end{tabular}


Table 83. Significance analysis of array hybridized with RNA of serum samples of DENV infected cases. The top 10 viruses with lowest $p$-values.

\begin{tabular}{|c|c|c|c|c|}
\hline Samples ID & Virus & No. of probes & $p$-value & Average \\
\hline \multirow{4}{*}{2116} & Spike & 200 & $9,87 \mathrm{E}-60$ & 4,49 \\
\hline & Agilent_Internal control & 36 & 1,14E-06 & 2,58 \\
\hline & Dengue virus type 3 & 36 & 0,003032398 & 1,04 \\
\hline & NA & NA & NA & NA \\
\hline \multirow[t]{4}{*}{1111} & Spike & 200 & $2,24 \mathrm{E}-14$ & 2,12 \\
\hline & Agilent_Internal control & 36 & $7,65 \mathrm{E}-08$ & 3,07 \\
\hline & Dengue virus type 4 & 31 & $4,26 \mathrm{E}-07$ & 2,51 \\
\hline & NA & NA & NA & NA \\
\hline \multirow[t]{3}{*}{1112} & Dengue virus type 1 & 36 & $1,23424 \mathrm{E}-05$ & 2,42 \\
\hline & Spike & 200 & $6.27 \mathrm{E}-31$ & 2.20 \\
\hline & NA & NA & NA & NA \\
\hline \multirow[t]{3}{*}{1113} & Dengue virus type 1 & 36 & $2,43424 \mathrm{E}-06$ & 1,54 \\
\hline & Spike & 200 & $5.237 \mathrm{E}-25$ & 2.35 \\
\hline & NA & NA & NA & NA \\
\hline
\end{tabular}

\section{DISCUSSION}

The differential diagnosis of infectious disease is a great challenge in clinical medicine, public and veterinary health, especially during epidemic outbreaks. The initial sign and symptoms caused by roboviruses and arboviruses infecting humans are very similar, therefore specific laboratory test are necessary for the final diagnosis. In this study we have developed a microarray platform that can be used in the surveillance of all roboviruses and arboviruses with sequences deposited in the GenBank.

The early identification of viruses during epidemic outbreaks helps the heath authorities to implement the more appropriated disease containment strategies. Conventional methods of virus identification include immunoassays, PCRs and virus isolation; however these methods can detect only one or few viruses in a single assay, turning the final diagnosis laborious, time consuming and expensive when several assays are needed (Elnifro et al., 2000). The DNA microarray platform developed in this study can be used to screen up to 412 viruses in a single assay, allowing an early identification of an outbreak causative agent. We have evaluated this platform with 17 reference viruses and all of them were readily detected and identified by specific hybridization to 
the appropriate oligonucleotides probes. Unfortunately, the genus specific probes were not able to detect the virus at the genus level, suggesting this platform could be not use for new virus discovery.

The RoboArboVirusChip designed in this study contain up to 10 probes for 412 viruses with sequences deposited in the GenBank up to February 2012. However, new probes designed based on new sequences deposited in the GenBank for those viruses with less than 10 probes will be updated and tested in the future. To our knowledge, this is only DNA microarray platform containing probes aiming the specific identification of roboviruses and arboviruse. Although the DNA microarray platform called GreenechipVr was designed to detect all the vertebrate viruses (1710 viruses, including roboviruses and arboviruses) (Palacios, 2007), this platform covers viruses with sequences deposited in the GenBank up to 2007. For this reason, the RoboArboVirusChip covers an additional of 183 viruses when compared to the GreenechipVr. The viruses covered by the RoboArboVirusChip and not by the GreenechipVr belong to the following families: Arenaviridae (19 viruses), Bunyaviridae (123 viruses), Flaviviridae (7 viruses), Reoviridae (16 viruses), Rhabdoviridae (15 viruses) and Togaviridae (3 viruses). Therefore, our platform has a better capability to detect roboviruses and arboviruse than the GreenechipVr. In addition, GreenechipVr includes less than 10 probes for several roboviruses and arboviruses, suggesting that is less sensitive to detect those viruses when compared to the RoboArboVirusChip, which contain at least 10 probes for most of those viruses.

Although our platform is the only one targeting roboviruses and arboviruses, some studies in the literature describe the development of DNA microarray tools containing probes for arboviruses. For example, there are DNA microarray platforms designed to identify: Dengue virus serotypes (Putonti et al., 2006), seven flaviviruses pathogenic for human (Nordström et al., 2005), flaviviruses causing infections of the central nervous system (Korimbocus et al., 2005), and seven European bunyaviruses causing encephalitis or meningo-encephalitis (Hasib et al., 2011). In addition, the ArboChip3.0 was designed to detect 33 flaviviruses pathogenic for human (Grubaugh, Petz, et al., 2013), and then updated to the ArboChip5.1 version to detect 144 RNA viruses transmitted by mosquitoes from four arbovirus genera (Alphavirus, Flavivirus, Orthobunyavirus and Phlebovirus) (Grubaugh, Mcmenamy, et al., 2013). All those studies targeted less number of arboviruses when compared to our RoboArboVirusChip. 
In addition, our platform target all pathogenic and non-pathogenic arboviruses for human and livestocks. In some cases, non-pathogenic viruses easily can turn emergent viruses. For example, Rio Mamore virus was previously considered non-pathogenic for human but recently fatal Hantavirus Pulmonary Syndrome (HPS) cases have been reported in Peru, French Guiana and Brazilian Amazon regions associated with this virus (Casapía et al., 2012; Matheus et al., 2012; De Oliveira et al., 2014).

Other sutides in the literature describe the development of DNA microarray tools targeting roboviruses. In one such study, 47 probes targeting only Lassa virus were designed (Olschläger and Günther, 2012). Another study described a DNA microarray targeting the Centers for Disease Control and Prevention (CDC) category biothreat agents (Leski et al., 2009), including roboviruses of the families Arenaviridae: Lassa virus, Machupe virus, Guanarito virus and Junin virus; and Bunyaviridae: genus Huntavirus: Seoul virus, Hantaan virus, Puumala virus and Sinnombre virus. However, the RoboArboVirusChip described in this study includes probes for all the viruses mention in those previous studies and all roboviruses with sequences deposited in the GenBank, as we have mentioned above.

Dengue, the most important vector-borne virus disease, is caused by the Dengue virus (DENV), which belongs to the Flavivirus genus, Flaviviridae family. It has recently be estimated that approximately 390 million dengue infections occur per year, of which, 96 million manifest some level of disease severity (Bhatt et al., 2013). Infection with any of the four viral serotypes (DENV-1 to -4) can be asymptomatic or lead to disease with clinical symptoms ranging from an undifferentiated and self-limiting fever to a severe dengue disease, which are mostly characterized by plasma leakage and hypovolemic shock that in some cases can be fatal (Who, 2009). Secondary infection with a second virus serotype is a risk factor for the development of severe form of the disease (Halstead, 1970). Therefore, epidemiological surveillance is of great interest to the implement control of the spread of new introduced serotypes. The RoboArboVirusChip was able to clearly differentiate the four DENV serotypes, suggesting that it can be used in the surveillance of DENV serotypes circulation.

Co-infection with more than one virus type is a common event for arboviruses in hyper-endemic regions. Co-infection with more than one DENV serotypes and DENV/Chikungunya virus have been described in the literature (Figueiredo et al., 2011; Sulca et al., 2013; Cnops et al., 2014; Parreira et al., 2014). The microarray slide 
described in this study was able to clearly identify viruses contained in three different mixtures: four DENV serotypes, four different viruses of the same genus (Flavivirus genus: ROCV, SLEV, YFV and DENV-2) and four viruses from different families (Togaviridae [MAYV], Flaviviridae [SLEV and BUSQV] and Rhabdoviridae [PIRYV]). Therefore, the RoboArboVirusChip could be used to identify co-infection with different viruses.

The RoboArboVirusChip was able to detect a minimum of 21-67 RNA copies/mL of DENV-1 to -4 , which is similar to the sensitivity described by other DNA microarray platforms (Grubaugh, Mcmenamy, et al., 2013; Huang et al., 2013), and to the sensitivity of a real-time RT-PCR describes by our group and which has been used to detect DENV in serum and saliva samples (Dos Santos et al., 2008; Poloni et al., 2010; Muller et al., 2014). These data suggest that the RoboArboVirusChip could be use to analyze clinical samples, which was confirmed by the detection of DENV in four clinical samples.

Finally, we have searched for roboviruses and other arboviruses in serum of 40 DENV negative patients but no virus was detected. May be other viruses different from roboviruses and arboviruses or even other pathogens, mimicking dengue symptoms, were the causative agents of the diseases in those patients, that is why we did not detected any virus with the RoboArboVirusChip. The dengue negative cases were collected during an epidemic outbreak in 2006 in Ribeirao Preto. The peak of dengue occurred between April and June, which coincided with the appearance of influenza cases that can be confused with dengue (CVE, 2006). In this sense, in a study performed in Puerto Rico in 2009, 31 of 289 dengue suspected cases was confirmed with dengue and most of the other were infected with influenza virus $(n=136)$ (Zarocostas, 2009). Another study performed in Nicaragua in 2005-2009, analyzing 124 dengue suspected cases but negative by DNA microarray and new generation sequencing methods, detected mainly herpesviruses but not arbovirus or robovirus (Yozwiak et al., 2012). Although there is circulation of other arboviruses during dengue outbreaks, this event seems to be not common (Mondini et al., 2007; Terzian et al., 2011). 


\section{CONCLUSIONS}

1. A DNA microarray (RoboArboVirusChip) platform for detection of roboviruses and arboviruses at the species level was designed.

2. The RoboArboVirusChip successfully detected all reference viruses tested.

3. The chip was able to differentiate viruses in mixtures containing viruses of different families, same genus and different serotypes.

4. The chip showed sensitivity sufficient to detect viruses in clinical samples.

5. The RoboArboVirusChip was applicable to detect viruses in serum samples.

6. Permanent update of probes is needed since new sequences of viruses covered by the RoboArboVirusChip and sequences of new viruses are constantly been deposited in the GenBank. 


\section{REFERENCE}

ALLISON, A. B. et al. Characterization of Durham virus, a novel rhabdovirus that encodes both a C and SH protein. Virus Res, v. 155, n. 1, p. 112-22, Jan 2011. ISSN 1872-7492. Available at: < http://www.ncbi.nlm.nih.gov/pubmed/20863863 >.

AQUINO, V. H. et al. Molecular epidemiology of dengue type 3 virus in Brazil and Paraguay, 2002-2004. American Journal of Tropical Medicine and Hygiene, v. 75, n. 4, p. 710-715, OCT 2006 2006. ISSN 0002-9637.

ARMSTRONG, C. A. L., R. D. Experimental lymphocytic choriomeningitis of monkeys and mice produced by a virus encountered in studies of the 1933 St. Louis encephalitis epidemic.: Public Health Reports. 49: 1019-1027 p. 1934.

ATKINSON, B. et al. Rapid molecular detection of Lujo virus RNA. J Virol Methods, v. 195, p. 170-3, Jan 2014. ISSN 1879-0984. Available at: < http://www.ncbi.nlm.nih.gov/pubmed/24096270 >.

ATTOUI, $\mathrm{H}$. et al. Comparative sequence analysis of American, European and Asian isolates of viruses in the genus Coltivirus. J Gen Virol, v. 79 ( Pt 10), p. 2481-9, Oct 1998. ISSN 0022-1317. Available at: < http://www.ncbi.nlm.nih.gov/pubmed/9780055 >.

Micromonas pusilla reovirus: a new member of the family Reoviridae assigned to a novel proposed genus (Mimoreovirus). J Gen Virol, v. 87, n. Pt 5, p. 1375-83, May 2006. ISSN 0022-1317. Available at: < http://www.ncbi.nlm.nih.gov/pubmed/16603541 >.

Coltiviruses and seadornaviruses in North America, Europe, and Asia. Emerg Infect Dis, v. 11, n. 11 , p. 1673-9, Nov 2005. ISSN 1080-6040. Available at: < http://www.ncbi.nlm.nih.gov/pubmed/16318717 >.

Complete nucleotide sequence of Middelburg virus, isolated from the spleen of a horse with severe clinical disease in Zimbabwe. J Gen Virol, v. 88, n. Pt 11, p. 3078-88, Nov 2007. ISSN 0022-1317. Available at: < http://www.ncbi.nlm.nih.gov/pubmed/17947533 >.

AUGUSTE, A. J. et al. A newly isolated reovirus has the simplest genomic and structural organization of any reovirus. J Virol, v. 89, n. 1, p. 676-87, Jan 2015. ISSN 1098-5514. Available at: $\langle$ http://www.ncbi.nlm.nih.gov/pubmed/25355879 >.

BARBER, T. L.; WALTON, T. E.; LEWIS, K. J. Efficacy of trivalent inactivated encephalomyelitis virus vaccine in horses. Am J Vet Res, v. 39, n. 4, p. 621-5, Apr 1978. ISSN 0002-9645. Available at: < http://www.ncbi.nlm.nih.gov/pubmed/646197>.

BECK, A. S.; BARRETT, A. D. Current status and future prospects of yellow fever vaccines. Expert

Rev Vaccines, p. 1-14, Sep 2015. ISSN 1744-8395. Available at: < http://www.ncbi.nlm.nih.gov/pubmed/26366673 >.

BELAGANAHALLI, M. N. et al. Genetic characterization of the tick-borne orbiviruses. Viruses, v. 7, n. 5, p. 2185-209, May 2015. ISSN 1999-4915. Available at: < http://www.ncbi.nlm.nih.gov/pubmed/25928203 >. 
BELLOMO, C. M.; PIRES-MARCZESKI, F. C.; PADULA, P. J. Viral load of patients with hantavirus pulmonary syndrome in Argentina. J Med Virol, v. 87, n. 11, p. 1823-30, Nov 2015. ISSN 10969071. Available at: < http://www.ncbi.nlm.nih.gov/pubmed/26087934 >.

BHATT, S. et al. The global distribution and burden of dengue. Nature, v. 496, n. 7446, p. 504-7, Apr 2013. ISSN 1476-4687. Available at: < http://www.ncbi.nlm.nih.gov/pubmed/23563266 >.

BLACK, S. S. et al. Necrotizing panencephalitis in puppies infected with La Crosse virus. J Vet Diagn Invest, v. 6 , n. 2, p. 250-4, Apr 1994. ISSN 1040-6387. Available at: < http://www.ncbi.nlm.nih.gov/pubmed/8068759 >.

BLASDELL, K. R. et al. Koolpinyah and Yata viruses: two newly recognised ephemeroviruses from tropical regions of Australia and Africa. Vet Microbiol, v. 174, n. 3-4, p. 547-53, Dec 2014. ISSN 1873-2542. Available at: < http://www.ncbi.nlm.nih.gov/pubmed/25457369 >.

BLITVICH, B. J. et al. Orthobunyaviruses, a common cause of infection of livestock in the Yucatan peninsula of Mexico. Am J Trop Med Hyg, v. 87, n. 6, p. 1132-9, Dec 2012. ISSN 14761645. Available at: < http://www.ncbi.nlm.nih.gov/pubmed/23045250 >.

BODEWES, R. et al. Novel divergent rhabdovirus in feces of red fox, Spain. Emerg Infect Dis, v. 20 , n. 12, p. 2172-4, Dec 2014. ISSN 1080-6059. Available at: < http://www.ncbi.nlm.nih.gov/pubmed/25419624 >.

BRIESE, T.; CALISHER, C. H.; HIGGS, S. Viruses of the family Bunyaviridae: are all available isolates reassortants? Virology, v. 446, n. 1-2, p. 207-16, Nov 2013. ISSN 1096-0341. Available at: < http://www.ncbi.nlm.nih.gov/pubmed/24074583 >.

BRIESE, T. et al. Genetic detection and characterization of Lujo virus, a new hemorrhagic feverassociated arenavirus from southern Africa. PLoS Pathog, v. 5, n. 5, p. e1000455, May 2009. ISSN 1553-7374. Available at: < http://www.ncbi.nlm.nih.gov/pubmed/19478873 >.

BUCHMEIER MJ. Arenaviridae: the virus and their replication. . 6th. Fields Virology, 2007. 1792-1827.

BÖHLAND, S. K. A method for the rapid sequence-independent amplification of microdissected chromosomal material. 1992. 1322-1324.

CALISHER, C. H. et al. Rapid and specific serodiagnosis of western equine encephalitis virus infection in horses. Am J Vet Res, v. 47, n. 6, p. 1296-9, Jun 1986. ISSN 0002-9645. Available at: $<$ http://www.ncbi.nlm.nih.gov/pubmed/3729130 >.

CASAPÍA, M. et al. [Hantavirus pulmonary syndrome (Rio Mamore virus) in the Peruvian Amazon region]. Rev Peru Med Exp Salud Publica, v. 29, n. 3, p. 390-5, 2012 Jul-Sep 2012. ISSN 1726-4642. Available at: < http://www.ncbi.nlm.nih.gov/pubmed/23085803 >.

CHARREL, R. N. et al. Tick-borne virus diseases of human interest in Europe. Clin Microbiol Infect, v. 10, n. 12, p. 1040-55, Dec 2004. ISSN 1198-743X. Available at: < http://www.ncbi.nlm.nih.gov/pubmed/15606630 >.

CHARREL, R. N.; DE LAMBALLERIE, X. Zoonotic aspects of arenavirus infections. Vet Microbiol, v. 140, n. 3-4, p. 213-20, Jan 2010. ISSN 1873-2542. Available at: < http://www.ncbi.nlm.nih.gov/pubmed/19748747 >. 
CHARREL, R. N.; DE LAMBALLERIE, X.; EMONET, S. Phylogeny of the genus Arenavirus. Curr Opin Microbiol, v. 11 , n. 4, p. 362-8, Aug 2008. ISSN 1369-5274. Available at: < http://www.ncbi.nlm.nih.gov/pubmed/18602020 >.

CHAVES-CARBALLO, E. Carlos Finlay and yellow fever: triumph over adversity. Mil Med, v. 170, n. 10 , p. 881-5, Oct 2005. ISSN 0026-4075. Available at: < http://www.ncbi.nlm.nih.gov/pubmed/16435764 >.

CHENG, B. Y. et al. Arenavirus Genome Rearrangement for the Development of Live Attenuated Vaccines. J Virol, v. 89, n. 14, p. 7373-84, Jul 2015. ISSN 1098-5514. Available at: < http://www.ncbi.nlm.nih.gov/pubmed/25972555 >.

CHENG, R. H. et al. Nucleocapsid and glycoprotein organization in an enveloped virus. Cell, v. 80 , n. 4, p. 621-30, Feb 1995. ISSN 0092-8674. Available at: < http://www.ncbi.nlm.nih.gov/pubmed/7867069 >.

CHIONG, M. A. Dr. Carlos Finlay and yellow fever. CMAJ, v. 141, n. 11, p. 1126, Dec 1989. ISSN 0820-3946. Available at: < http://www.ncbi.nlm.nih.gov/pubmed/2684378 >.

$\mathrm{CJ}$, P. Arenaviridae. Lymphocytic choriomeningitis virus, Lassa virus, and the South American hemorrhagic fevers. In: . principles and practice of infectious diseases. MANDELL GL, B. J., DOLIN R, EDS. MANDELL, DOUGLAS AND BENNETT'S. Philadelphia:: Churchill Livingstone,: 1855-1862 p. 2000;.

CLETON, N. et al. Come fly with me: review of clinically important arboviruses for global travelers. J Clin Virol, v. 55, n. 3, p. 191-203, Nov 2012. ISSN 1873-5967. Available at: < http://www.ncbi.nlm.nih.gov/pubmed/22840968 >.

CNOPS, L. et al. First dengue co-infection in a Belgian traveler returning from Thailand, July 2013. J Clin Virol, v. 61, n. 4, p. 597-9, Dec 2014. ISSN 1873-5967. Available at: < http://www.ncbi.nlm.nih.gov/pubmed/25453334 >.

COSTARD, S. et al. African swine fever: how can global spread be prevented? Philos Trans R Soc Lond B Biol Sci, v. 364, n. 1530, p. 2683-96, Sep 2009. ISSN 1471-2970. Available at: < http://www.ncbi.nlm.nih.gov/pubmed/19687038 >.

COWLED, C. et al. Persistent and recrudescent infection in cattle following natural infection with Middle Point orbivirus. Arch Virol, v. 157, n. 6, p. 1161-5, Jun 2012. ISSN 1432-8798. Available at: < http://www.ncbi.nlm.nih.gov/pubmed/22415142 >.

CYBINSKI, D. H.; GARD, G. P. Isolation of a new rhabdovirus in Australia related to Tibrogargan virus. Aust J Biol Sci, v. 39, n. 3, p. 225-32, 1986. ISSN 0004-9417. Available at: < http://www.ncbi.nlm.nih.gov/pubmed/3548679 >.

DASH, A. P. et al. Emerging and re-emerging arboviral diseases in Southeast Asia. J Vector Borne Dis, v. 50, n. 2, p. 77-84, 2013 Apr-Jun 2013. ISSN 0972-9062. Available at: < http://www.ncbi.nlm.nih.gov/pubmed/23995308 >.

DAVIES, F. G. et al. The serological relationships of Nairobi sheep disease virus. J Comp Pathol, v. 88, n. 4, p. 519-23, Oct 1978. ISSN 0021-9975. Available at: < http://www.ncbi.nlm.nih.gov/pubmed/101557 >. 
DE OLIVEIRA, R. C. et al. Rio Mamoré virus and hantavirus pulmonary syndrome, Brazil. Emerg Infect Dis, v. 20, n. 9, p. 1568-70, Sep 2014. ISSN 1080-6059. Available at: < http://www.ncbi.nlm.nih.gov/pubmed/25152089 >.

DENNEHY, P. H. Rotavirus Infection: A Disease of the Past? Infect Dis Clin North Am, Sep 2015. ISSN 1557-9824. Available at: < http://www.ncbi.nlm.nih.gov/pubmed/26337738 >.

DESCLOUX, E. Risk of DENV vertical transmission during the perinatal period and through breastfeeding. NATHALIE SIGUR, L. A. A. E. H.: Journées Scientifiques de l'Institut Pasteur 2013.

DIXON, L. K. et al. African swine fever virus replication and genomics. Virus Res, v. 173, n. 1, p. 3-14, Apr 2013. ISSN 1872-7492. Available at: < http://www.ncbi.nlm.nih.gov/pubmed/23142553 >.

DOHERTY, R. L. Arthropod-borne viruses in Australia, 1973-1976. Aust J Exp Biol Med Sci, v. 55, n. 2, p. 103-30, Apr 1977. ISSN 0004-945X. Available at: < http://www.ncbi.nlm.nih.gov/pubmed/20071 >.

DOS SANTOS, H. W. et al. A simple one-step real-time RT-PCR for diagnosis of dengue virus infection. J Med Virol, v. 80, n. 8, p. 1426-33, Aug 2008. ISSN 1096-9071. Available at: < http://www.ncbi.nlm.nih.gov/pubmed/18551599 >.

DOWNS, W. G. et al. Tacaribe virus, a new agent isolated from Artibeus bats and mosquitoes in Trinidad, West Indies. Am J Trop Med Hyg, v. 12, p. 640-6, Jul 1963. ISSN 0002-9637. Available at: < http://www.ncbi.nlm.nih.gov/pubmed/22324073 >.

DROLET, B. S. et al. A Review of Knowledge Gaps and Tools for Orbivirus Research. Vector Borne Zoonotic Dis, v. 15, n. 6, p. 339-47, Jun 2015. ISSN 1557-7759. Available at: < http://www.ncbi.nlm.nih.gov/pubmed/26086555 >.

E.J. SAN DIEGO. Ninth Report of the International Committee on Taxonomy of Viruses. . ED: KING: Elsevier. ICTV 2011 Master Species List (<st1:stockticker w:st="on">MSL) version 22012.

EDWARDS, J. F. Cache Valley virus. Vet Clin North Am Food Anim Pract, v. 10, n. 3, p. 515-24, Nov 1994. ISSN 0749-0720. Available at: < http://www.ncbi.nlm.nih.gov/pubmed/7728634 >.

ELLIOTT, R. M. Orthobunyaviruses: recent genetic and structural insights. Nat Rev Microbiol, v. 12 , n. 10, p. 673-85, Oct 2014. ISSN 1740-1534. Available at: < http://www.ncbi.nlm.nih.gov/pubmed/25198140 >.

ELNIFRO, E. M. et al. Multiplex PCR: optimization and application in diagnostic virology. Clin Microbiol Rev, v. 13, n. 4, p. 559-70, Oct 2000. ISSN 0893-8512. Available at: < http://www.ncbi.nlm.nih.gov/pubmed/11023957 >.

EMMONS, R. W. et al. Main Drain virus as a cause of equine encephalomyelitis. J Am Vet Med Assoc, v. 183, n. 5, p. 555-8, Sep 1983. ISSN 0003-1488. Available at: < http://www.ncbi.nlm.nih.gov/pubmed/6413468 >.

ENRIA, D. A.; BRIGGILER, A. M.; SÁNCHEZ, Z. Treatment of Argentine hemorrhagic fever. Antiviral Res, v. 78, n. 1, p. 132-9, Apr 2008. ISSN 0166-3542. Available at: < http://www.ncbi.nlm.nih.gov/pubmed/18054395 >. 
ESCUTENAIRE, S.; PASTORET, P. P. Hantavirus infections. Rev Sci Tech, v. 19, n. 1, p. 64-78, Apr 2000. ISSN 0253-1933. Available at: < http://www.ncbi.nlm.nih.gov/pubmed/11189727 >.

EUSEBIO-COPE, A.; SUZUKI, N. Mycoreovirus genome rearrangements associated with RNA silencing deficiency. Nucleic Acids Res, v. 43, n. 7, p. 3802-13, Apr 2015. ISSN 1362-4962. Available at: < http://www.ncbi.nlm.nih.gov/pubmed/25800742 >.

FAN, Y. et al. Identification and genomic characterization of a novel fish reovirus, Hubei grass carp disease reovirus, isolated in 2009 in China. J Gen Virol, v. 94, n. Pt 10, p. 2266-77, Oct 2013. ISSN 1465-2099. Available at: < http://www.ncbi.nlm.nih.gov/pubmed/23851441 >.

FIGUEIREDO, R. M. et al. Co-infection of Dengue virus by serotypes 3 and 4 in patients from Amazonas, Brazil. Rev Inst Med Trop Sao Paulo, v. 53, n. 6, p. 321-3, 2011 Nov-Dec 2011. ISSN 1678-9946. Available at: < http://www.ncbi.nlm.nih.gov/pubmed/22183455 >.

FLUSIN, O. et al. Inhibition of Hazara nairovirus replication by small interfering RNAs and their combination with ribavirin. Virol J, v. 8, p. 249, 2011. ISSN 1743-422X. Available at: < http://www.ncbi.nlm.nih.gov/pubmed/21600011 >.

FRANZ, D. R. et al. Clinical recognition and management of patients exposed to biological warfare agents. JAMA, v. 278, n. 5, p. 399-411, Aug 1997. ISSN 0098-7484. Available at: < http://www.ncbi.nlm.nih.gov/pubmed/9244332 >.

FUKUNAGA, Y.; KUMANOMIDO, T.; KAMADA, M. Getah virus as an equine pathogen. Vet Clin North Am Equine Pract, v. 16, n. 3, p. 605-17, Dec 2000. ISSN 0749-0739. Available at: < http://www.ncbi.nlm.nih.gov/pubmed/11219353 >.

FULHORST, C. F. et al. Genetic diversity between and within the arenavirus species indigenous to western Venezuela. Virology, v. 378, n. 2, p. 205-13, Sep 2008. ISSN 1096-0341. Available at: < http://www.ncbi.nlm.nih.gov/pubmed/18586298 >.

GADD, T. et al. Characterization of perch rhabdovirus (PRV) in farmed grayling Thymallus thymallus. Dis Aquat Organ, v. 106, n. 2, p. 117-27, Oct 2013. ISSN 0177-5103. Available at: < http://www.ncbi.nlm.nih.gov/pubmed/24113245 >.

GAN, V. C.; LEO, Y. S. Current epidemiology and clinical practice in arboviral infections implications on blood supply in South-East Asia. ISBT Sci Ser, v. 9, n. 1, p. 262-267, Jul 2014. ISSN 1751-2816. Available at: < http://www.ncbi.nlm.nih.gov/pubmed/25210534 >.

GAO, X.; NASCl, R.; LIANG, G. The neglected arboviral infections in mainland China. PLoS NegI Trop Dis, v. 4, n. 4, p. e624, 2010. ISSN 1935-2735. Available at: < http://www.ncbi.nlm.nih.gov/pubmed/20436960 >.

GEGÚNDEZ, M. I.; LLEDÓ, L. [Infection due to Hantavirus and other rodent-borne viruses]. Enferm Infecc Microbiol Clin, v. 23, n. 8, p. 492-500, Oct 2005. ISSN 0213-005X. Available at: < http://www.ncbi.nlm.nih.gov/pubmed/16185565 >.

GHASEMI, M. et al. Caspian White Fish (Rutilus frisii kutum) as a host for Spring Viraemia of Carp Virus. Vet Microbiol, v. 170, n. 3-4, p. 408-13, Jun 2014. ISSN 1873-2542. Available at: < http://www.ncbi.nlm.nih.gov/pubmed/24685241 >. 
GRUBAUGH, N. D. et al. Multi-gene detection and identification of mosquito-borne RNA viruses using an oligonucleotide microarray. PLoS Negl Trop Dis, v. 7, n. 8, p. e2349, 2013. ISSN 19352735. Available at: < http://www.ncbi.nlm.nih.gov/pubmed/23967358 >.

Evaluation of a field-portable DNA microarray platform and nucleic acid amplification strategies for the detection of arboviruses, arthropods, and bloodmeals. Am J Trop Med Hyg, v. 88 , n. 2, p. 245-53, Feb 2013. ISSN 1476-1645. Available at: < http://www.ncbi.nlm.nih.gov/pubmed/23249687 >.

GUBALA, A. et al. Tibrogargan and Coastal Plains rhabdoviruses: genomic characterization, evolution of novel genes and seroprevalence in Australian livestock. J Gen Virol, v. 92, n. Pt 9, p. 2160-70, Sep 2011. ISSN 1465-2099. Available at: < http://www.ncbi.nlm.nih.gov/pubmed/21593274 >.

GUBLER, D. J. Human arbovirus infections worldwide. Ann N Y Acad Sci, v. 951, p. 13-24, Dec 2001. ISSN 0077-8923. Available at: < http://www.ncbi.nlm.nih.gov/pubmed/11797771 >.

HALSTEAD, S. Observations related to pathogensis of dengue hemorrhagic fever. VI. Hypotheses and discussion. Yale J Biol Med, v. 42, n. 5, p. 350-62, Apr 1970. ISSN 0044-0086. Available at: < http://www.ncbi.nlm.nih.gov/entrez/query.fcgi?cmd=Retrieve\&db=PubMed\&dopt=Citation\&lis t_uids $=5419208>$.

HANSON, R. P. The natural history of vesicular stomatitis. Bacteriol Rev, v. 16, n. 3, p. 179-204, Sep 1952. ISSN 0005-3678. Available at: < http://www.ncbi.nlm.nih.gov/pubmed/12987386 >.

HASIB, L. et al. Development of a flow-through [corrected] microarray based reverse transcriptase multiplex ligation-dependent probe amplification assay for the detection of European Bunyaviruses. [corrected]. Mol Biotechnol, v. 49, n. 2, p. 176-86, Oct 2011. ISSN 1559-0305. Available at: < http://www.ncbi.nlm.nih.gov/pubmed/21390485 >.

HEATH, S. E. et al. Equine encephalitis caused by snowshoe hare (California serogroup) virus. Can Vet J, v. 30, n. 8, p. 669-71, Aug 1989. ISSN 0008-5286. Available at: < http://www.ncbi.nlm.nih.gov/pubmed/17423397 >.

HEPOJOKI, J. et al. Arenavirus Coinfections Are Common in Snakes with Boid Inclusion Body Disease. J Virol, v. 89, n. 16, p. 8657-60, Aug 2015. ISSN 1098-5514. Available at: < http://www.ncbi.nlm.nih.gov/pubmed/26041290 >.

HESS, G. [The present epidemiological status of African swine fever]. Tierarztl Prax, v. 14, n. 2 , p. 231-5, 1986. ISSN 0303-6286. Available at: < http://www.ncbi.nlm.nih.gov/pubmed/3738896 $>$.

HETZEL, U. et al. Isolation, identification, and characterization of novel arenaviruses, the etiological agents of boid inclusion body disease. J Virol, v. 87, n. 20, p. 10918-35, Oct 2013. ISSN 1098-5514. Available at: < http://www.ncbi.nlm.nih.gov/pubmed/23926354 >.

Reply to "Updated phylogenetic analysis of arenaviruses detected in boid snakes". J Virol, v. 88, n. 2, p. 1401, Jan 2014. ISSN 1098-5514. Available at: < http://www.ncbi.nlm.nih.gov/pubmed/24379419 >. 
HICKS, D. J.; FOOKS, A. R.; JOHNSON, N. Developments in rabies vaccines. Clin Exp Immunol, v. 169, n. 3, p. 199-204, Sep 2012. ISSN 1365-2249. Available at: < http://www.ncbi.nlm.nih.gov/pubmed/22861358 >.

HILLS, S. et al. Control of Japanese encephalitis in Asia: the time is now. Expert Rev Anti Infect Ther, v. 12, n. 8, p. 901-4, Aug 2014. ISSN 1744-8336. Available at: < http://www.ncbi.nlm.nih.gov/pubmed/24927959 >.

HOKE, C. H. History of U.S. military contributions to the study of viral encephalitis. Mil Med, v. 170, n. 4 Suppl, p. 92-105, Apr 2005. ISSN 0026-4075. Available at: < http://www.ncbi.nlm.nih.gov/pubmed/15916288 >.

HOLLIDGE, B. S. et al. Orthobunyavirus entry into neurons and other mammalian cells occurs via clathrin-mediated endocytosis and requires trafficking into early endosomes. J Virol, v. 86, n. 15 , p. 7988-8001, Aug 2012. ISSN 1098-5514. Available at: < http://www.ncbi.nlm.nih.gov/pubmed/22623766 >.

HTTP://WWW.CDC.GOV/VHF/LASSA. Lassa Fever Confirmed in Death of U.S. Traveler Returning from Liberia 2015.

HTTPS://EARRAY.CHEM.AGILENT.COM/EARRAY/. Agilent Technologies eArray.

HTTPS://WWWN.CDC.GOV/ARBOCAT/VIRUSBROWSER.ASPX. Arbovirus Catalog- Virus Selection. Atlanta: Centers for Disease Control and Prevention.

HUANG, W. et al. An easy operating pathogen microarray (EOPM) platform for rapid screening of vertebrate pathogens. BMC Infect Dis, v. 13, p. 437, 2013. ISSN 1471-2334. Available at: < http://www.ncbi.nlm.nih.gov/pubmed/24053492 >.

HUANG, Y. J. et al. Flavivirus-mosquito interactions. Viruses, v. 6, n. 11, p. 4703-30, Nov 2014. ISSN 1999-4915. Available at: < http://www.ncbi.nlm.nih.gov/pubmed/25421894 >.

HUBÁLEK, Z.; RUDOLF, I.; NOWOTNY, N. Arboviruses pathogenic for domestic and wild animals. Adv Virus Res, v. 89 , p. 201-75, 2014. ISSN 1557-8399. Available at: < http://www.ncbi.nlm.nih.gov/pubmed/24751197 >.

JA, C. Pathology of fatal lymphocytic choriomeningitis virus infection in multiple organ transplant recipients from a common donor: Mod Pathol,: :163A-264A. p. 2005;.

JACKSON, A. O. et al. Biology of plant rhabdoviruses. Annu Rev Phytopathol, v. 43, p. 623-60, 2005. ISSN 0066-4286. Available at: < http://www.ncbi.nlm.nih.gov/pubmed/16078897 >.

JADI, R. S. et al. Development of an inactivated candidate vaccine against Chandipura virus (Rhabdoviridae: Vesiculovirus). Vaccine, v. 29, n. 28, p. 4613-7, Jun 2011. ISSN 1873-2518. Available at: < http://www.ncbi.nlm.nih.gov/pubmed/21549791 >.

JFST, R. Arboviruses isolated in the Evandro Chagas Institute, including some described for the first time in the Brazilian Amazon region, their known hosts, and their pathology for man. In: Rosa APAT, Vasconcelos PFC, Rosa JFST (eds). An overview of arbovirology in Brazil and neighbouring countries. Instituto Evandro Chagas, Belém: 19-31 p. 1998. 
$\mathrm{JI}, \mathrm{X}$. et al. Movement protein Pns6 of rice dwarf phytoreovirus has both ATPase and RNA binding activities. PLoS One, v. 6, n. 9, p. e24986, 2011. ISSN 1932-6203. Available at: < http://www.ncbi.nlm.nih.gov/pubmed/21949821 >.

JONES, K. E. et al. Global trends in emerging infectious diseases. Nature, v. 451, n. 7181, p. $990-$ 3, Feb 2008. ISSN 1476-4687. Available at: < http://www.ncbi.nlm.nih.gov/pubmed/18288193 $>$.

JONSSON, C. B.; FIGUEIREDO, L. T.; VAPALAHTI, O. A global perspective on hantavirus ecology, epidemiology, and disease. Clin Microbiol Rev, v. 23, n. 2, p. 412-41, Apr 2010. ISSN 1098-6618. Available at: <http://www.ncbi.nlm.nih.gov/pubmed/20375360 >.

JOSE, J.; SNYDER, J. E.; KUHN, R. J. A structural and functional perspective of alphavirus replication and assembly. Future Microbiol, v. 4, n. 7, p. 837-56, Sep 2009. ISSN 1746-0921. Available at: <http://www.ncbi.nlm.nih.gov/pubmed/19722838 >.

KAWAOKA Y. Family Orthomyxoviridae. In Virus Taxonomy: Eighth Report of the International Committee on Taxonomy of Viruses,. COX N. J., H. O., HONGO S., KAVERIN N., KLENK H. D., LAMB R. A., MCCAULEY J., PALESE P. San Diego:: Elsevier Academic Press: 681-693 p. 2005.

KEDMI, M. et al. The association of winds with the spread of EHDV in dairy cattle in Israel during an outbreak in 2006. Prev Vet Med, v. 96, n. 3-4, p. 152-60, Sep 2010. ISSN 1873-1716. Available at: < http://www.ncbi.nlm.nih.gov/pubmed/20619907 >.

KHAN, A.; KHAN, A. S. Hantaviruses: a tale of two hemispheres. Panminerva Med, v. 45, n. 1, p. 43-51, Mar 2003. ISSN 0031-0808. Available at: < http://www.ncbi.nlm.nih.gov/pubmed/12682619 >.

$\mathrm{KIM}, \mathrm{Y}$. H. et al. Development of inactivated trivalent vaccine for the teratogenic Aino, Akabane and Chuzan viruses. Biologicals, v. 39, n. 3, p. 152-7, May 2011. ISSN 1095-8320. Available at: < http://www.ncbi.nlm.nih.gov/pubmed/21411335 >.

KIRKLAND, P. D. Akabane and bovine ephemeral fever virus infections. Vet Clin North Am Food Anim Pract, v. 18, n. 3, p. 501-14, viii-ix, Nov 2002. ISSN 0749-0720. Available at: < http://www.ncbi.nlm.nih.gov/pubmed/12442580 >.

KLASCO, R. Colorado tick fever. Med Clin North Am, v. 86, n. 2, p. 435-40, ix, Mar 2002. ISSN 0025-7125. Available at: < http://www.ncbi.nlm.nih.gov/pubmed/11982311 >.

KORIMBOCUS, J. et al. DNA probe array for the simultaneous identification of herpesviruses, enteroviruses, and flaviviruses. J Clin Microbiol, v. 43, n. 8, p. 3779-87, Aug 2005. ISSN 00951137. Available at: < http://www.ncbi.nlm.nih.gov/pubmed/16081910 >.

KRUGER, D. H. et al. Hantaviruses-Globally emerging pathogens. J Clin Virol, Oct 2014. ISSN 1873-5967. Available at: < http://www.ncbi.nlm.nih.gov/pubmed/25453325 >.

KUHN, R. J. et al. Structure of dengue virus: implications for flavivirus organization, maturation, and fusion. Cell, v. 108, n. 5, p. 717-25, Mar 2002. ISSN 0092-8674. Available at: < http://www.ncbi.nlm.nih.gov/pubmed/11893341 >.

LADNER, J. T. et al. Genomic and phylogenetic characterization of viruses included in the Manzanilla and Oropouche species complexes of the genus Orthobunyavirus, family 
Bunyaviridae. J Gen Virol, v. 95, n. Pt 5, p. 1055-66, May 2014. ISSN 1465-2099. Available at: < http://www.ncbi.nlm.nih.gov/pubmed/24558222 >.

LANTEZ, V. et al. Comparative production analysis of three phlebovirus nucleoproteins under denaturing or non-denaturing conditions for crystallographic studies. PLoS Negl Trop Dis, v. 5, n. 1 p. e936, 2011. ISSN 1935-2735. Available at: < http://www.ncbi.nlm.nih.gov/pubmed/21245924 >.

LANYON, S. R.; REICHEL, M. P. Bovine viral diarrhoea virus ('pestivirus') in Australia: to control or not to control? Aust Vet J, v. 92, n. 8, p. 277-82, Aug 2014. ISSN 1751-0813. Available at: < http://www.ncbi.nlm.nih.gov/pubmed/24934714 >.

LAUCK, M. et al. Genome Sequence of Bivens Arm Virus, a Tibrovirus Belonging to the Species Tibrogargan virus (Mononegavirales: Rhabdoviridae). Genome Announc, v. 3, n. 2, 2015. ISSN 2169-8287. Available at:<http://www.ncbi.nlm.nih.gov/pubmed/25792044 >.

LEE, A. S.; BURDEINICK-KERR, R.; WHELAN, S. P. A genome-wide small interfering RNA screen identifies host factors required for vesicular stomatitis virus infection. J Virol, v. 88, n. 15, p. 8355-60, Aug 2014. ISSN 1098-5514. Available at: < http://www.ncbi.nlm.nih.gov/pubmed/24829348 >.

LEPARC-GOFFART, I.; EMONET, S. F. [An update on Lassa virus]. Med Trop (Mars), v. 71, n. 6, p. 541-5, Dec 2011. ISSN 0025-682X. Available at: < http://www.ncbi.nlm.nih.gov/pubmed/22393616 >.

LESKI, T. A. et al. Testing and validation of high density resequencing microarray for broad range biothreat agents detection. PLoS One, v. 4, n. 8, p. e6569, 2009. ISSN 1932-6203. Available at: <http://www.ncbi.nlm.nih.gov/pubmed/19668365 >.

LETCHWORTH, G. J.; RODRIGUEZ, L. L.; DEL CBARRERA, J. Vesicular stomatitis. Vet J, v. 157, n. 3, p. 239-60, May 1999. ISSN 1090-0233. Available at: < http://www.ncbi.nlm.nih.gov/pubmed/10328837 >.

LEYSSEN, P.; DE CLERCQ, E.; NEYTS, J. Molecular strategies to inhibit the replication of RNA viruses. Antiviral Res, v. 78, n. 1, p. 9-25, Apr 2008. ISSN 0166-3542. Available at: < http://www.ncbi.nlm.nih.gov/pubmed/18313769 >.

$\mathrm{LI}, \mathrm{Y}$. et al. Identification and genome characterization of Heliothis armigera cypovirus types 5 and 14 and Heliothis assulta cypovirus type 14. J Gen Virol, v. 87, n. Pt 2, p. 387-94, Feb 2006. ISSN 0022-1317. Available at: < http://www.ncbi.nlm.nih.gov/pubmed/16432026 >.

LISIEUX, T. et al. New arenavirus isolated in Brazil. Lancet, v. 343, n. 8894, p. 391-2, Feb 1994. ISSN 0140-6736. Available at: < http://www.ncbi.nlm.nih.gov/pubmed/7905555 >.

LIU, T. P. The effect of allatectomy on glycogen metabolism in the fat body of the female housefly, Musca domestica L. Comp Biochem Physiol B, v. 47, n. 1, p. 79-86, Jan 1974. ISSN 0305-0491. Available at: < http://www.ncbi.nlm.nih.gov/pubmed/4204049 >.

$\mathrm{LOH}$, J. et al. Detection of novel sequences related to african Swine Fever virus in human serum and sewage. J Virol, v. 83, n. 24, p. 13019-25, Dec 2009. ISSN 1098-5514. Available at: < http://www.ncbi.nlm.nih.gov/pubmed/19812170 >. 
LONGDON, B.; OBBARD, D. J.; JIGGINS, F. M. Sigma viruses from three species of Drosophila form a major new clade in the rhabdovirus phylogeny. Proc Biol Sci, v. 277, n. 1678, p. 35-44, Jan 2010. ISSN 1471-2954. Available at: < http://www.ncbi.nlm.nih.gov/pubmed/19812076 >.

LOWEN, A. C.; ELLIOTT, R. M. Mutational analyses of the nonconserved sequences in the Bunyamwera Orthobunyavirus S segment untranslated regions. J Virol, v. 79, n. 20, p. 1286170, Oct 2005. ISSN 0022-538X. Available at: < http://www.ncbi.nlm.nih.gov/pubmed/16188988 $>$.

MACLACHLAN, N. J. Bluetongue: history, global epidemiology, and pathogenesis. Prev Vet Med, v. 102, n. 2, p. 107-11, Nov 2011. ISSN 1873-1716. Available at: < http://www.ncbi.nlm.nih.gov/pubmed/21570141 >.

MACLACHLAN, N. J.; GUTHRIE, A. J. Re-emergence of bluetongue, African horse sickness, and other orbivirus diseases. Vet Res, v. 41, n. 6, p. 35, 2010 Nov-Dec 2010. ISSN 0928-4249. Available at: <http://www.ncbi.nlm.nih.gov/pubmed/20167199 >.

MANGALA PRASAD, V. et al. Rubella virus capsid protein structure and its role in virus assembly and infection. Proc Natl Acad Sci U S A, v. 110, n. 50, p. 20105-10, Dec 2013. ISSN 1091-6490. Available at: < http://www.ncbi.nlm.nih.gov/pubmed/24282305 >.

MATHEUS, S. et al. Complete genome sequence of a novel hantavirus variant of Rio Mamoré virus, Maripa virus, from French Guiana. J Virol, v. 86, n. 9, p. 5399, May 2012. ISSN 1098-5514. Available at: < http://www.ncbi.nlm.nih.gov/pubmed/22492924 >.

MCCORMICK, J. B. et al. A prospective study of the epidemiology and ecology of Lassa fever. J Infect Dis, v. 155, n. 3, p. 437-44, Mar 1987. ISSN 0022-1899. Available at: < http://www.ncbi.nlm.nih.gov/pubmed/3805771 >.

MELLOR, P. S.; HAMBLIN, C. African horse sickness. Vet Res, v. 35, n. 4, p. 445-66, 2004 Jul-Aug 2004. ISSN 0928-4249. Available at: < http://www.ncbi.nlm.nih.gov/pubmed/15236676 >.

MESLIN, F. X. Global aspects of emerging and potential zoonoses: a WHO perspective. Emerg Infect Dis, v. 3, n. 2, p. 223-8, 1997 Apr-Jun 1997. ISSN 1080-6040. Available at: < http://www.ncbi.nlm.nih.gov/pubmed/9204308 >.

MIYAZAKI, N. et al. Structural evolution of reoviridae revealed by oryzavirus in acquiring the second capsid shell. J Virol, v. 82, n. 22, p. 11344-53, Nov 2008. ISSN 1098-5514. Available at: < http://www.ncbi.nlm.nih.gov/pubmed/18787002 >.

MJ., B. Lethal snake viruses identified. University of California Irvine,: BBC News 2012.

MLERA, L.; MELIK, W.; BLOOM, M. E. The role of viral persistence in flavivirus biology. Pathog Dis, v. $71, \quad$ n. 2 , p. 137-63, Jul 2014. ISSN 2049-632X. Available at: < http://www.ncbi.nlm.nih.gov/pubmed/24737600 >.

MOHD JAAFAR, F. et al. Complete characterisation of the American grass carp reovirus genome (genus Aquareovirus: family Reoviridae) reveals an evolutionary link between aquareoviruses and coltiviruses. Virology, v. 373, n. 2, p. 310-21, Apr 2008. ISSN 0042-6822. Available at: < http://www.ncbi.nlm.nih.gov/pubmed/18191982 >. 
MONDINI, A. et al. Simultaneous infection by DENV-3 and SLEV in Brazil. J Clin Virol, v. 40, n. 1, p. 84-6, Sep 2007. ISSN 1386-6532. Available at: < http://www.ncbi.nlm.nih.gov/pubmed/17658293 >.

MUKHOPADHYAY, S.; KUHN, R. J.; ROSSMANN, M. G. A structural perspective of the flavivirus life cycle. Nat Rev Microbiol, v. 3, n. 1, p. 13-22, Jan 2005. ISSN 1740-1526. Available at: < http://www.ncbi.nlm.nih.gov/pubmed/15608696 >.

MULLER, V. D. et al. Phospholipase A2 Isolated from the Venom of Crotalus durissus terrificus Inactivates Dengue virus and Other Enveloped Viruses by Disrupting the Viral Envelope. PLoS One, v. 9, n. 11, p. e112351, 2014. ISSN 1932-6203. Available at: < http://www.ncbi.nlm.nih.gov/pubmed/25383618 >.

NANDI, S.; NEGI, B. S. Bovine ephemeral fever: a review. Comp Immunol Microbiol Infect Dis, v. 22 , n. 2, p. 81-91, Apr 1999. ISSN 0147-9571. Available at: < http://www.ncbi.nlm.nih.gov/pubmed/10051179 >.

NICHOL ST. Bunyaviridae. In:. 2005. 695-716.

NODA, Y. et al. Aino virus antigen in brain lesions of a naturally aborted bovine fetus. Vet Pathol, v. 35, n. 5, p. 409-11, Sep 1998. ISSN 0300-9858. Available at: < http://www.ncbi.nlm.nih.gov/pubmed/9754547 >.

NORDSTRÖM, $H$. et al. DNA microarray technique for detection and identification of seven flaviviruses pathogenic for man. J Med Virol, v. 77, n. 4, p. 528-40, Dec 2005. ISSN 0146-6615. Available at: < http://www.ncbi.nlm.nih.gov/pubmed/16254977 >.

O'BRIEN, V. A.; BROWN, C. R. Group size and nest spacing affect Buggy Creek virus (Togaviridae: Alphavirus) infection in nestling house sparrows. PLoS One, v. 6, n. 9, p. e25521, 2011. ISSN 1932-6203. Available at: < http://www.ncbi.nlm.nih.gov/pubmed/21966539 >.

OLIVE, M. M.; GOODMAN, S. M.; REYNES, J. M. The role of wild mammals in the maintenance of Rift Valley fever virus. J WildI Dis, v. 48, n. 2, p. 241-66, Apr 2012. ISSN 1943-3700. Available at: < http://www.ncbi.nlm.nih.gov/pubmed/22493102 >.

OLSCHLÄGER, S.; GÜNTHER, S. Rapid and specific detection of Lassa virus by reverse transcription-PCR coupled with oligonucleotide array hybridization. J Clin Microbiol, v. 50, n. 7, p. 2496-9, Jul 2012. ISSN 1098-660X. Available at: < http://www.ncbi.nlm.nih.gov/pubmed/22535985 >.

PALACIOS, G. Panmicrobial oligonucleotide array for diagnosis of infectious diseases. 2007. 73-81.

PALACIOS, G. et al. Panmicrobial oligonucleotide array for diagnosis of infectious diseases. Emerg Infect Dis, v. 13, n. 1, p. 73-81, Jan 2007. ISSN 1080-6040. Available at: < http://www.ncbi.nlm.nih.gov/entrez/query.fcgi?cmd=Retrieve\&db=PubMed\&dopt=Citation\&lis t_uids $=17370518>$.

PARREIRA, R. et al. Dengue virus serotype 4 and chikungunya virus coinfection in a traveller returning from Luanda, Angola, January 2014. Euro Surveill, v. 19, n. 10, 2014. ISSN 1560-7917. Available at: < http://www.ncbi.nlm.nih.gov/pubmed/24650864 >. 
PATON, D. J.; TAYLOR, G. Developing vaccines against foot-and-mouth disease and some other exotic viral diseases of livestock. Philos Trans R Soc Lond B Biol Sci, v. 366, n. 1579, p. 2774-81, Oct 2011. ISSN 1471-2970. Available at: < http://www.ncbi.nlm.nih.gov/pubmed/21893540 >.

PENRITH, M. L. et al. African swine fever virus eradication in Africa. Virus Res, v. 173, n. 1, p. 228-46, Apr 2013. ISSN 1872-7492. Available at: < http://www.ncbi.nlm.nih.gov/pubmed/23142552 >.

PHILLIPS, A. T. et al. Bioluminescent imaging and histopathologic characterization of WEEV neuroinvasion in outbred CD-1 mice. PLoS One, v. 8, n. 1, p. e53462, 2013. ISSN 1932-6203. Available at: < http://www.ncbi.nlm.nih.gov/pubmed/23301074 >.

POLONI, T. R. et al. Detection of dengue virus in saliva and urine by real time RT-PCR. Virology Journal, v. 7, JAN 272010 2010. ISSN 1743-422X.

PUTONTI, C. et al. Human-blind probes and primers for dengue virus identification. FEBS J, v. 273 , n. 2, p. 398-408, Jan 2006. ISSN 1742-464X. Available at: < http://www.ncbi.nlm.nih.gov/pubmed/16403026 >.

RADOSHITZKY, S. R. et al. Past, present, and future of arenavirus taxonomy. Arch Virol, v. 160, n. 7 , p. 1851-74, Jul 2015. ISSN 1432-8798. Available at: < http://www.ncbi.nlm.nih.gov/pubmed/25935216 >.

RATHBUN, J. Y. et al. Novel Arenavirus Entry Inhibitors Discovered by Using a Minigenome Rescue System for High-Throughput Drug Screening. J Virol, v. 89, n. 16, p. 8428-43, Aug 2015. ISSN 1098-5514. Available at: < http://www.ncbi.nlm.nih.gov/pubmed/26041296 >.

REEVES, W. C. Partners: serendipity in arbovirus research. J Vector Ecol, v. 26, n. 1, p. 1-6, Jun 2001. ISSN 1081-1710. Available at: < http://www.ncbi.nlm.nih.gov/pubmed/11469177 >.

REGENMORTEL, V. Virus Taxonomy: the Classification and Nomenclature of Viruses. Seventh Report of the International Committee on Taxonomy of Viruses. San Diego: Academic Press. V, M. H. 2000.

REICHERT, $M$. et al. Trade practices are main factors involved in the transmission of viral haemorrhagic septicaemia. J Fish Dis, v. 36, n. 2, p. 103-14, Feb 2013. ISSN 1365-2761. Available at: < http://www.ncbi.nlm.nih.gov/pubmed/23020691 >.

ROBIN, Y. et al. [Semliki forest virus and equine encephalomyelitis in Senegal (author's transI)]. Ann Microbiol (Paris), v. 125A, n. 2, p. 235-41, 1974 Feb-Mar 1974. ISSN 0300-5410. Available at: <http://www.ncbi.nlm.nih.gov/pubmed/4472890 >.

ROMERO, J. R.; SIMONSEN, K. A. Powassan encephalitis and Colorado tick fever. Infect Dis Clin North Am, v. 22, n. 3, p. 545-59, x, Sep 2008. ISSN 0891-5520. Available at: < http://www.ncbi.nlm.nih.gov/pubmed/18755390 >.

ROMERO-BREY, I.; BARTENSCHLAGER, R. Membranous replication factories induced by plusstrand RNA viruses. Viruses, v. 6, n. 7, p. 2826-57, Jul 2014. ISSN 1999-4915. Available at: < http://www.ncbi.nlm.nih.gov/pubmed/25054883 >.

ROSEN, L. The natural history of Japanese encephalitis virus. Annu Rev Microbiol, v. 40, p. 395414, 1986. ISSN 0066-4227. Available at: < http://www.ncbi.nlm.nih.gov/pubmed/2877613 >. 
RUSSELL, F. F. Permanent Value of Major Walter Reed's Work on Yellow Fever. Am J Public Health Nations Health, v. 24, n. 1, p. 1-7, Jan 1934. ISSN 0002-9572. Available at: < http://www.ncbi.nlm.nih.gov/pubmed/18013904 >.

SABIN, A. D. Karl Friedrich Meyer: May 19, 1884-April 27, 1974. Biogr Mem Natl Acad Sci, v. 52, p. 269-32, 1980. Available at: < http://www.ncbi.nlm.nih.gov/pubmed/11620787 >.

SALVATO, M. S. et al. Arenaviridae. In Virus Taxonomy, Ninth Report of the International Committee on Taxonomy of Viruses. KING, A. M. Q., ADAMS, M.J., CARSTENS, E.B., LEFKOWITZ, E.J., EDS. San Diego, CA, USA: Elsevier:: 715-723 p. 2012.

SAYLER, K. A. et al. Isolation of Tacaribe Virus, a Caribbean Arenavirus, from Host-Seeking Amblyomma americanum Ticks in Florida. PLoS One, v. 9, n. 12, p. e115769, 2014. ISSN 19326203. Available at: <http://www.ncbi.nlm.nih.gov/pubmed/25536075 >.

SCHLAFER, D. H.; MEBUS, C. A. Abortion in sows experimentally infected with African swine fever virus: clinical features. Am J Vet Res, v. 45, n. 7, p. 1353-60, Jul 1984. ISSN 0002-9645. Available at: < http://www.ncbi.nlm.nih.gov/pubmed/24049897 >.

SCHMALJOHN, C.; HJELLE, B. Hantaviruses: a global disease problem. Emerg Infect Dis, v. 3, n. 2, p. 95-104, 1997 Apr-Jun 1997. ISSN 1080-6040. Available at: < http://www.ncbi.nlm.nih.gov/pubmed/9204290 >.

SOO, H. M. et al. Molecular characterization of Fiji disease fijivirus genome segment 9. J Gen Virol, v. 79 ( Pt 12), p. 3155-61, Dec 1998. ISSN 0022-1317. Available at: < http://www.ncbi.nlm.nih.gov/pubmed/9880035 >.

STENGLEIN, M. D. et al. Identification, characterization, and in vitro culture of highly divergent arenaviruses from boa constrictors and annulated tree boas: candidate etiological agents for snake inclusion body disease. MBio, v. 3, n. 4, p. e00180-12, 2012. ISSN 2150-7511. Available at: $<$ http://www.ncbi.nlm.nih.gov/pubmed/22893382 >.

SUHRBIER, A.; JAFFAR-BANDJEE, M. C.; GASQUE, P. Arthritogenic alphaviruses--an overview. Nat Rev Rheumatol, v. 8, n. 7, p. 420-9, Jul 2012. ISSN 1759-4804. Available at: < http://www.ncbi.nlm.nih.gov/pubmed/22565316 >.

SULCA, J. et al. [Isolation of dengue virus serotype 1 and 3 from a coinfected patient using a modified shell vial culture]. Rev Peru Med Exp Salud Publica, v. 30, n. 2, p. 354-5, Apr 2013. ISSN 1726-4642. Available at: < http://www.ncbi.nlm.nih.gov/pubmed/23949533 >.

TER MEULEN, J. et al. Hunting of peridomestic rodents and consumption of their meat as possible risk factors for rodent-to-human transmission of Lassa virus in the Republic of Guinea. Am J Trop Med Hyg, v. 55, n. 6, p. 661-6, Dec 1996. ISSN 0002-9637. Available at: < http://www.ncbi.nlm.nih.gov/pubmed/9025695 >.

TERZIAN, A. C. et al. Detection of Saint Louis encephalitis virus in Dengue-suspected cases during a dengue 3 outbreak. Vector Borne Zoonotic Dis, v. 11, n. 3, p. 291-300, Mar 2011. ISSN 1557-7759. Available at: < http://www.ncbi.nlm.nih.gov/pubmed/20645866 >.

TESH, R. B. The genus Phlebovirus and its vectors. Annu Rev Entomol, v. 33, p. 169-81, 1988. ISSN 0066-4170. Available at: < http://www.ncbi.nlm.nih.gov/pubmed/2829707 >. 
THIMMASANDRA NARAYANAPPA, A. et al. A novel pathogenic Mammalian orthoreovirus from diarrheic pigs and Swine blood meal in the United States. MBio, v. 6, n. 3, p. e00593-15, 2015. ISSN 2150-7511. Available at: < http://www.ncbi.nlm.nih.gov/pubmed/25991685 >.

THOMSON, G. R. The epidemiology of African swine fever: the role of free-living hosts in Africa. Onderstepoort J Vet Res, v. 52, n. 3, p. 201-9, Sep 1985. ISSN 0030-2465. Available at: < http://www.ncbi.nlm.nih.gov/pubmed/3911134 >.

TOMORI, O.; FAGBAMI, A.; KEMP, G. Kotonkan virus: experiment infection of white Fulani calves. Bull Epizoot Dis Afr, v. 22, n. 3, p. 195-200, Sep 1974. ISSN 0007-487X. Available at: < http://www.ncbi.nlm.nih.gov/pubmed/4478981 >.

URBANO, P.; URBANO, F. G. The Reoviridae family. Comp Immunol Microbiol Infect Dis, v. 17, n. 3-4, p. 151-61, 1994 Aug-Nov 1994. ISSN 0147-9571. Available at: < http://www.ncbi.nlm.nih.gov/pubmed/8001342 >.

UREN, M. F. et al. Effective vaccination of cattle using the virion $G$ protein of bovine ephemeral fever virus as an antigen. Vaccine, v. 12, n. 9, p. 845-50, Jul 1994. ISSN 0264-410X. Available at: $<$ http://www.ncbi.nlm.nih.gov/pubmed/7975863 >.

VAN EEDEN, C.; ZAAYMAN, D.; VENTER, M. A sensitive nested real-time RT-PCR for the detection of Shuni virus. J Virol Methods, v. 195, p. 100-5, Jan 2014. ISSN 1879-0984. Available at: < http://www.ncbi.nlm.nih.gov/pubmed/24134941 >.

VERWOERD, D. W. et al. Structure of the bluetongue virus capsid. J Virol, v. 10, n. 4, p. 783-94, Oct 1972. ISSN 0022-538X. Available at: < http://www.ncbi.nlm.nih.gov/pubmed/4117349 >.

VITULLO, A. D.; HODARA, V. L.; MERANI, M. S. Effect of persistent infection with Junin virus on growth and reproduction of its natural reservoir, Calomys musculinus. Am J Trop Med Hyg, v. 37, n. 3, p. 663-9, Nov 1987. ISSN 0002-9637. Available at: < http://www.ncbi.nlm.nih.gov/pubmed/2825553 >.

VITULLO, A. D.; MERANI, M. S. Is vertical transmission sufficient to maintain Junin virus in nature? J Gen Virol, v. 69 ( Pt 6), p. 1437-40, Jun 1988. ISSN 0022-1317. Available at: < http://www.ncbi.nlm.nih.gov/pubmed/2838581 >.

WATSON, M. et al. DetectiV: visualization, normalization and significance testing for pathogendetection microarray data. Genome Biol, v. 8, n. 9, p. R190, 2007. ISSN 1465-6914. Available at: $<$ http://www.ncbi.nlm.nih.gov/pubmed/17868443 >.

WEAVER, S. C. Vector biology in viral pathogenesis. In: Nathanson, N. (Ed.), Viral Pathogenesis. . New York,: Lippincott-Raven,: 329-352. p. 1997.

WEAVER, S. C.; BARRETT, A. D. Transmission cycles, host range, evolution and emergence of arboviral disease. Nat Rev Microbiol, v. 2, n. 10, p. 789-801, Oct 2004. ISSN 1740-1526. Available at: < http://www.ncbi.nlm.nih.gov/pubmed/15378043 >.

WEAVER, S. C. et al. Recombinational history and molecular evolution of western equine encephalomyelitis complex alphaviruses. J Virol, v. 71, n. 1, p. 613-23, Jan 1997. ISSN 0022538X. Available at: < http://www.ncbi.nlm.nih.gov/pubmed/8985391 >. 
WEAVER, S. C.; REISEN, W. K. Present and future arboviral threats. Antiviral Res, v. 85, n. 2, p. 328-45, Feb 2010. ISSN 1872-9096. Available at: < http://www.ncbi.nlm.nih.gov/pubmed/19857523 >.

WHO. Dengue: guidelines for diagnosis, treatment, prevention and control. Geneva: World Health Organization 2009.

WU, X. D. et al. [A review of research on Schmallenberg virus]. Bing Du Xue Bao, v. 30, n. 6, p. 694-703, Nov 2014. ISSN 1000-8721. Available at: < http://www.ncbi.nlm.nih.gov/pubmed/25868286 >.

YOZWIAK, N. L. et al. Virus identification in unknown tropical febrile illness cases using deep sequencing. PLoS Negl Trop Dis, v. 6, n. 2, p. e1485, 2012. ISSN 1935-2735. Available at: < http://www.ncbi.nlm.nih.gov/pubmed/22347512 >.

YUN, N. E.; WALKER, D. H. Pathogenesis of Lassa fever. Viruses, v. 4, n. 10, p. 2031-48, Oct 2012. ISSN 1999-4915. Available at: < http://www.ncbi.nlm.nih.gov/pubmed/23202452 >.

ZABEREZHNYĬ, A. D. et al. [African swine fever in Russian Federation]. Vopr Virusol, v. 57, n. 5, p. 4-10, 2012 Sep-Oct 2012. ISSN 0507-4088. Available at: < http://www.ncbi.nlm.nih.gov/pubmed/23248852 >.

ZACKS, M. A.; PAESSLER, S. Encephalitic alphaviruses. Vet Microbiol, v. 140, n. 3-4, p. 281-6, Jan 2010. ISSN 1873-2542. Available at: < http://www.ncbi.nlm.nih.gov/pubmed/19775836>.

ZAPATA, J. C.; SALVATO, M. S. Arenavirus variations due to host-specific adaptation. Viruses, v. 5, n. 1, p. 241-78, Jan 2013. ISSN 1999-4915. Available at: < http://www.ncbi.nlm.nih.gov/pubmed/23344562 >.

ZAROCOSTAS, J. World Health Organization declares A (H1N1) influenza pandemic. BMJ, v. 338, p. b2425, 2009. ISSN 1756-1833. Available at: < http://www.ncbi.nlm.nih.gov/pubmed/19525308 >.

ZEIER, M. et al. New ecological aspects of hantavirus infection: a change of a paradigm and a challenge of prevention--a review. Virus Genes, v. 30, n. 2, p. 157-80, Mar 2005. ISSN 09208569. Available at: < http://www.ncbi.nlm.nih.gov/pubmed/15744574 >. 


\section{Appendix}

Supplementary Table 1. Viruses and probes inlcuded in the RoboArbovirusChip.

\begin{tabular}{|c|c|c|c|c|c|}
\hline $\mathbf{N}^{\circ}$ & Virus & Genera & Family & $\begin{array}{l}\text { No. of } \\
\text { Sequences }\end{array}$ & $\begin{array}{l}\text { No. of } \\
\text { Probes }\end{array}$ \\
\hline 1 & Abu Hammad virus & Nairovirus & Bunyaviridae & 1 & 5 \\
\hline 2 & Abu Mina virus & Nairovirus & Bunyaviridae & 1 & 5 \\
\hline 3 & Adelaide River virus & Ephemerovirus & Rhabdoviridae & 1 & 11 \\
\hline 4 & African horsesickness virus & Orbivirus & Reoviridae & 57 & 124 \\
\hline 5 & African swine fever virus & Asfivirus & Asfarviridae & 100 & 17 \\
\hline 6 & Aguacate virus & Phlebovirus & Bunyaviridae & 3 & 15 \\
\hline 7 & Aino virus & Orthobunyavirus & Bunyaviridae & 8 & 15 \\
\hline 8 & Akabane virus & Orthobunyavirus & Bunyaviridae & 11 & 14 \\
\hline 9 & Alenquer virus & Phlebovirus & Bunyaviridae & 3 & 19 \\
\hline 10 & Alkhurma hemorrhagic fever virus & Flavivirus & Flaviviridae & 1 & 10 \\
\hline 11 & Allpahuayo virus & Arenavirus & Arenaviridae & 3 & 10 \\
\hline 12 & Altai virus & Hantavirus & Bunyaviridae & 1 & 5 \\
\hline 13 & Alto Paraguay hantavirus & Hantavirus & Bunyaviridae & 2 & 10 \\
\hline 14 & Amapari virus & Arenavirus & Arenaviridae & 2 & 10 \\
\hline 15 & Amur virus & Hantavirus & Bunyaviridae & 12 & 15 \\
\hline 16 & ANAJ Hantavirus & Hantavirus & Bunyaviridae & 1 & 4 \\
\hline 17 & Andes virus & Hantavirus & Bunyaviridae & 3 & 16 \\
\hline 18 & Anhembi virus & Orthobunyavirus & Bunyaviridae & 3 & 15 \\
\hline 19 & Anopheles A virus & Orthobunyavirus & Bunyaviridae & 1 & 5 \\
\hline 20 & Anopheles B virus & Orthobunyavirus & Bunyaviridae & 1 & 6 \\
\hline 21 & Apeu virus & Orthobunyavirus & Bunyaviridae & 4 & 16 \\
\hline 22 & Apoi virus & Flavivirus & Flaviviridae & 1 & 10 \\
\hline 23 & Araraquara virus & Hantavírus & Bunyaviridae & 2 & 10 \\
\hline 24 & Araucaria virus & Hantavirus & Bunyaviridae & 9 & 5 \\
\hline 25 & Arbia virus & Phlebovirus & Bunyaviridae & 1 & 19 \\
\hline 26 & Arenavirus $\mathrm{H}$ & Arenavirus & Arenaviridae & 2 & 7 \\
\hline 27 & Ariquemes virus & Phlebovirus & Bunyaviridae & 3 & 15 \\
\hline 28 & Armero virus & Phlebovirus & Bunyaviridae & 3 & 13 \\
\hline
\end{tabular}




\begin{tabular}{|c|c|c|c|c|c|}
\hline 29 & Aroa virus & Flavivirus & Flaviviridae & 1 & 7 \\
\hline 30 & Artybash virus & Hantavirus & Bunyaviridae & 2 & 9 \\
\hline 31 & Arumowot virus & Phlebovirus & Bunyaviridae & 3 & 15 \\
\hline 32 & Asama virus & Hantavirus & Bunyaviridae & 7 & 15 \\
\hline 33 & Ash River virus & Hantavirus & Bunyaviridae & 2 & 10 \\
\hline 34 & Aura virus & Alphavirus & Togaviridae & 1 & 10 \\
\hline 35 & Babanki virus & Alphavirus & Togaviridae & 1 & 2 \\
\hline 36 & Bagaza virus & Flavivirus & Flaviviridae & 2 & 9 \\
\hline 37 & Bandia virus & Nairovirus & Bunyaviridae & 1 & 2 \\
\hline 38 & Banna virus & Seadornavirus & Reoviridae & 17 & 38 \\
\hline 39 & Banzi virus & Flavivirus & Flaviviridae & 1 & 10 \\
\hline 40 & Barmah Forest virus & Alphavirus & Togaviridae & 1 & 9 \\
\hline 41 & Batai virus & Orthobunyavirus & Bunyaviridae & 5 & 7 \\
\hline 42 & Batama virus & Orthobunyavirus & Bunyaviridae & 1 & 2 \\
\hline 43 & Batu Cave virus & Flavivirus & Flaviviridae & 1 & 3 \\
\hline 44 & Bayou virus & Hantavírus & Bunyaviridae & 2 & 6 \\
\hline 45 & Bear Canyon virus & Arenavírus & Arenaviridae & 3 & 9 \\
\hline 46 & Bebaru virus & Alphavirus & Togaviridae & 1 & 2 \\
\hline 47 & Belterra virus & Phlebovirus & Bunyaviridae & 3 & 11 \\
\hline 48 & Bermejo virus & Hantavírus & Bunyaviridae & 2 & 10 \\
\hline 49 & Berrimah virus & Ephemerovirus & Rhabdoviridae & 1 & 9 \\
\hline 50 & Bhanja virus & Phlebovirus & Bunyaviridae & 3 & 12 \\
\hline 51 & Big brushy tank virus & Arenavirus & Arenaviridae & 4 & 16 \\
\hline 52 & Birao virus & Orthobunyavirus & Bunyaviridae & 2 & 10 \\
\hline 53 & Black Creek Canal virus & Hantavírus & Bunyaviridae & 4 & 5 \\
\hline 54 & Black Mesa virus & Arenavírus & Arenaviridae & 2 & 8 \\
\hline 55 & Blue River virus & Hantavírus & Bunyaviridae & 1 & 5 \\
\hline 56 & Bluetongue virus & Orbivirus & Reoviridae & 298 & 364 \\
\hline 57 & Boraceia virus & Orthobunyavirus & Bunyaviridae & 1 & 4 \\
\hline 58 & Bouboui virus & Flavivirus & Flaviviridae & 1 & 8 \\
\hline 59 & Bovine ephemeral fever virus & Ephemerovirus & Rhabdoviridae & 2 & 10 \\
\hline 60 & Bozo virus & Orthobunyavirus & Bunyaviridae & 2 & 4 \\
\hline
\end{tabular}




\begin{tabular}{|c|c|}
\hline 61 & Broadhaven virus \\
\hline 62 & Buenaventura virus \\
\hline 63 & Buggy Creek virus \\
\hline 64 & Bujaru virus \\
\hline 65 & Bukalasa bat virus \\
\hline 66 & Bunyamwera virus \\
\hline 67 & Bussuquara virus \\
\hline 68 & Bwamba virus \\
\hline 69 & Cabassou virus \\
\hline 70 & Cacao virus \\
\hline 71 & Cache Valley virus \\
\hline 72 & Cachoeira Porteira virus \\
\hline 73 & Cacipacore virus \\
\hline 74 & California encephalitis virus \\
\hline 75 & Calovo virus \\
\hline 76 & Camp Ripley virus \\
\hline 77 & Candiru virus \\
\hline 78 & Cano - Delgadito virus \\
\hline 79 & Cao Bang virus \\
\hline 80 & Carajas virus \\
\hline 81 & Caraparu virus \\
\hline 82 & Carey Island virus \\
\hline 83 & Carrizal virus \\
\hline 84 & Castelo dos Sonhos virus \\
\hline 85 & Catacamas virus \\
\hline 86 & Catarina virus \\
\hline 87 & Catch-me-cave virus \\
\hline 88 & Cell fusing agent virus \\
\hline 89 & Chagres virus \\
\hline 90 & Chandipura virus \\
\hline 91 & Chandiru virus \\
\hline 92 & Chapare virus \\
\hline
\end{tabular}

\begin{tabular}{|c|c|c|c|}
\hline Orbivirus & Reoviridae & 1 & 5 \\
\hline Phlebovirus & Bunyaviridae & 3 & 5 \\
\hline Alphavirus & Togaviridae & 1 & 8 \\
\hline Phlebovirus & Bunyaviridae & 1 & 2 \\
\hline Flavivirus & Flaviviridae & 1 & 1 \\
\hline Orthobunyavirus & Bunyaviridae & 4 & 13 \\
\hline Flavivirus & Flaviviridae & 1 & 10 \\
\hline Orthobunyavirus & Bunyaviridae & 1 & 2 \\
\hline Alphavirus & Togaviridae & 2 & 1 \\
\hline Phlebovirus & Bunyaviridae & 1 & 2 \\
\hline Orthobunyavirus & Bunyaviridae & 7 & 14 \\
\hline Orthobunyavirus & Bunyaviridae & 3 & 14 \\
\hline Flavivirus & Flaviviridae & 3 & 10 \\
\hline Orthobunyavirus & Bunyaviridae & 4 & 11 \\
\hline Orthobunyavirus & Bunyaviridae & 1 & 5 \\
\hline Hantavírus & Bunyaviridae & 6 & 11 \\
\hline Phlebovirus & Bunyaviridae & 3 & 8 \\
\hline Hantavírus & Bunyaviridae & 2 & 7 \\
\hline Hantavírus & Bunyaviridae & 3 & 14 \\
\hline Vesiculovirus & Rhabdoviridae & 1 & 1 \\
\hline Orthobunyavirus & Bunyaviridae & 4 & 12 \\
\hline Flavivirus & Flaviviridae & 1 & 1 \\
\hline Hantavírus & Bunyaviridae & 3 & 13 \\
\hline Hantavírus & Bunyaviridae & 8 & 4 \\
\hline Hantavírus & Bunyaviridae & 2 & 10 \\
\hline Arenavírus & Arenaviridae & 4 & 16 \\
\hline Phlebovirus & Bunyaviridae & 1 & 4 \\
\hline Flavivirus & Flaviviridae & 5 & 8 \\
\hline Phlebovirus & Bunyaviridae & 3 & 15 \\
\hline Vesiculovirus & Rhabdoviridae & 2 & 4 \\
\hline Phlebovirus & Bunyaviridae & 3 & 15 \\
\hline Arenavírus & Arenaviridae & 2 & \\
\hline
\end{tabular}




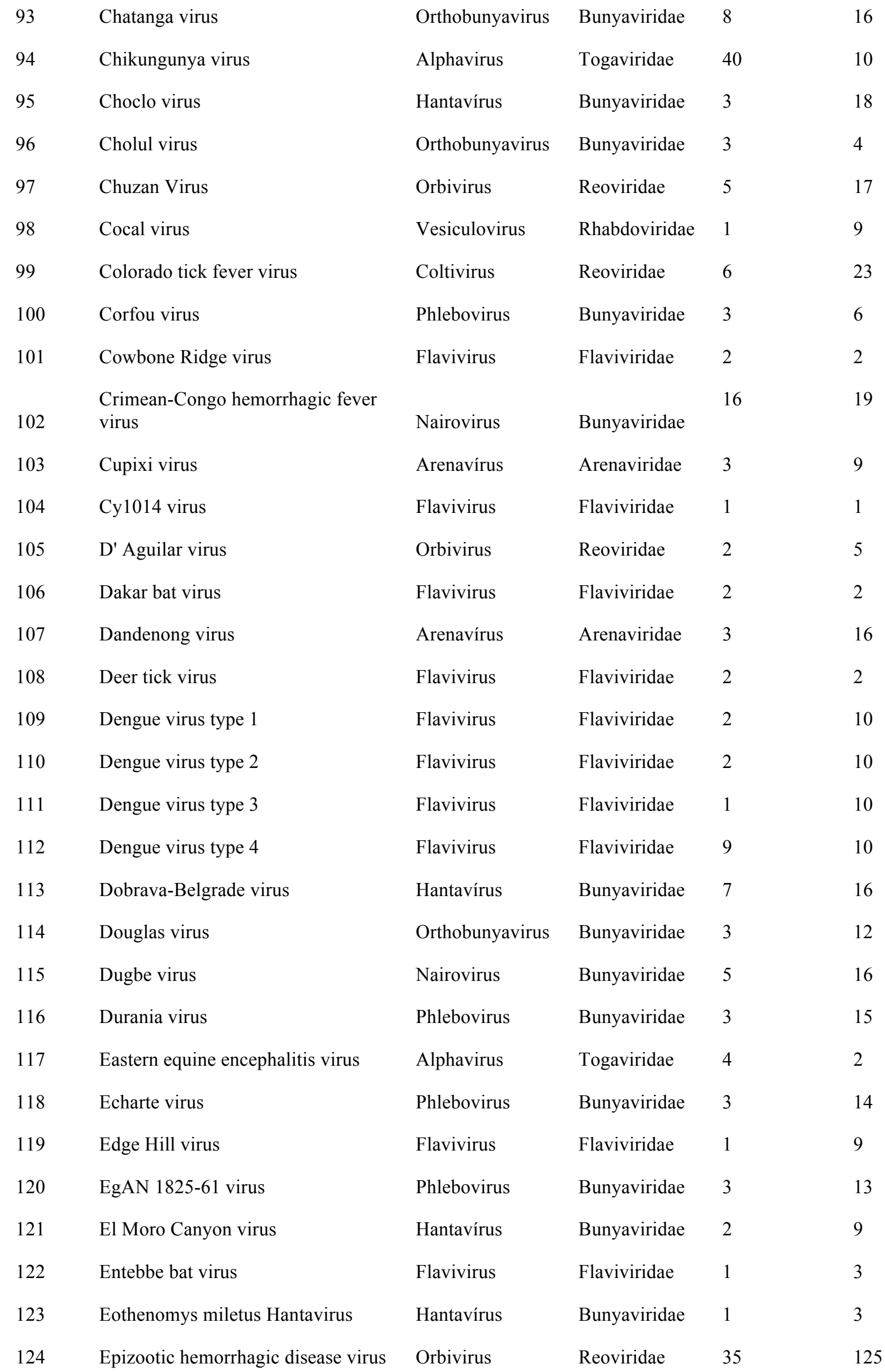




\begin{tabular}{|c|c|}
\hline 125 & Equine encephalosis virus \\
\hline 126 & Erve virus \\
\hline 127 & Eyach virus \\
\hline 128 & Farallon virus \\
\hline 129 & Flexal virus \\
\hline 130 & Fort Morgan virus \\
\hline 131 & Fort Sherman virus \\
\hline 132 & Four Corners Hantavirus \\
\hline 133 & Frijoles virus \\
\hline 134 & Gabek Forest virus \\
\hline 135 & Gadgets Gully virus \\
\hline 136 & Gbagroube virus \\
\hline 137 & Germiston virus \\
\hline 138 & Getah virus \\
\hline 139 & Granada virus \\
\hline 140 & Great Island virus \\
\hline 141 & Greek goat encephalitis virus \\
\hline 142 & Guanarito virus \\
\hline 143 & Guaroa virus \\
\hline 144 & Gumbo Limbo virus \\
\hline 145 & Hantaan virus \\
\hline 146 & Hazara virus \\
\hline 147 & Heartland virus \\
\hline 148 & Highlands $\mathrm{J}$ virus \\
\hline 149 & HoJo virus \\
\hline 150 & Hokkaido virus \\
\hline 151 & Huitzilac virus \\
\hline 152 & I612045 virus \\
\hline 153 & Iaco virus \\
\hline 154 & Icoaraci virus \\
\hline 155 & Iguape virus \\
\hline 156 & Ilesha virus \\
\hline
\end{tabular}

\begin{tabular}{|c|c|c|}
\hline Orbivirus & Reoviridae & 10 \\
\hline Nairovirus & Bunyaviridae & 1 \\
\hline Coltivirus & Reoviridae & 6 \\
\hline Nairovirus & Bunyaviridae & 1 \\
\hline Arenavírus & Arenaviridae & 2 \\
\hline Alphavirus & Togaviridae & 1 \\
\hline Orthobunyavirus & Bunyaviridae & 3 \\
\hline Hantavírus & Bunyaviridae & 3 \\
\hline Phlebovirus & Bunyaviridae & 3 \\
\hline Phlebovirus & Bunyaviridae & 1 \\
\hline Flavivirus & Flaviviridae & 2 \\
\hline Arenavírus & Arenaviridae & 5 \\
\hline Orthobunyavirus & Bunyaviridae & 2 \\
\hline Alphavirus & Togaviridae & 36 \\
\hline Phlebovirus & Bunyaviridae & 1 \\
\hline Orbivirus & Reoviridae & 3 \\
\hline Flavivirus & Flaviviridae & 1 \\
\hline Arenavírus & Arenaviridae & 4 \\
\hline Orthobunyavirus & Bunyaviridae & 3 \\
\hline Orthobunyavirus & Bunyaviridae & 1 \\
\hline Hantavírus & Bunyaviridae & 12 \\
\hline Nairovirus & Bunyaviridae & 3 \\
\hline Phlebovirus & Bunyaviridae & 6 \\
\hline Alphavirus & Togaviridae & 29 \\
\hline Hantavírus & Bunyaviridae & 3 \\
\hline Hantavírus & Bunyaviridae & 1 \\
\hline Hantavírus & Bunyaviridae & 3 \\
\hline Orthobunyavirus & Bunyaviridae & 5 \\
\hline Orthobunyavirus & Bunyaviridae & 3 \\
\hline Phlebovirus & Bunyaviridae & 3 \\
\hline Flavivirus & Flaviviridae & 1 \\
\hline Orthobunyavirus & Bunyaviridae & 3 \\
\hline
\end{tabular}




\begin{tabular}{|c|c|}
\hline 157 & Ilheus virus \\
\hline 158 & Imjin virus \\
\hline 159 & Ingwavuma virus \\
\hline 160 & Inkoo virus \\
\hline 161 & Ippy virus \\
\hline 162 & Isfahan virus \\
\hline 163 & Isla Vista virus \\
\hline 164 & $\begin{array}{l}\text { Israel turkey } \\
\text { meningoencephalomyelitis virus }\end{array}$ \\
\hline 165 & Itaituba virus \\
\hline 166 & Itaporanga virus \\
\hline 167 & Itaqui virus \\
\hline 168 & Ixcanal virus \\
\hline 169 & Jabora virus \\
\hline 170 & Jacunda Virus \\
\hline 171 & Jamestown Canyan virus \\
\hline 172 & Japanese encephalitis virus \\
\hline 173 & Jeju virus \\
\hline 174 & Jerry Slough virus \\
\hline 175 & Joa virus \\
\hline 176 & Jugra virus \\
\hline 177 & Junin virus \\
\hline 178 & Jurona virus \\
\hline 179 & Jutiapa virus \\
\hline 180 & Kadam virus \\
\hline 181 & Kadipiro virus \\
\hline 182 & Kaeng Khoi virus \\
\hline 183 & Kairi virus \\
\hline 184 & Karimabad virus \\
\hline 185 & Karshi virus \\
\hline 186 & Kedougou virus \\
\hline 187 & Kemerovo virus \\
\hline 188 & Kenkeme virus \\
\hline
\end{tabular}

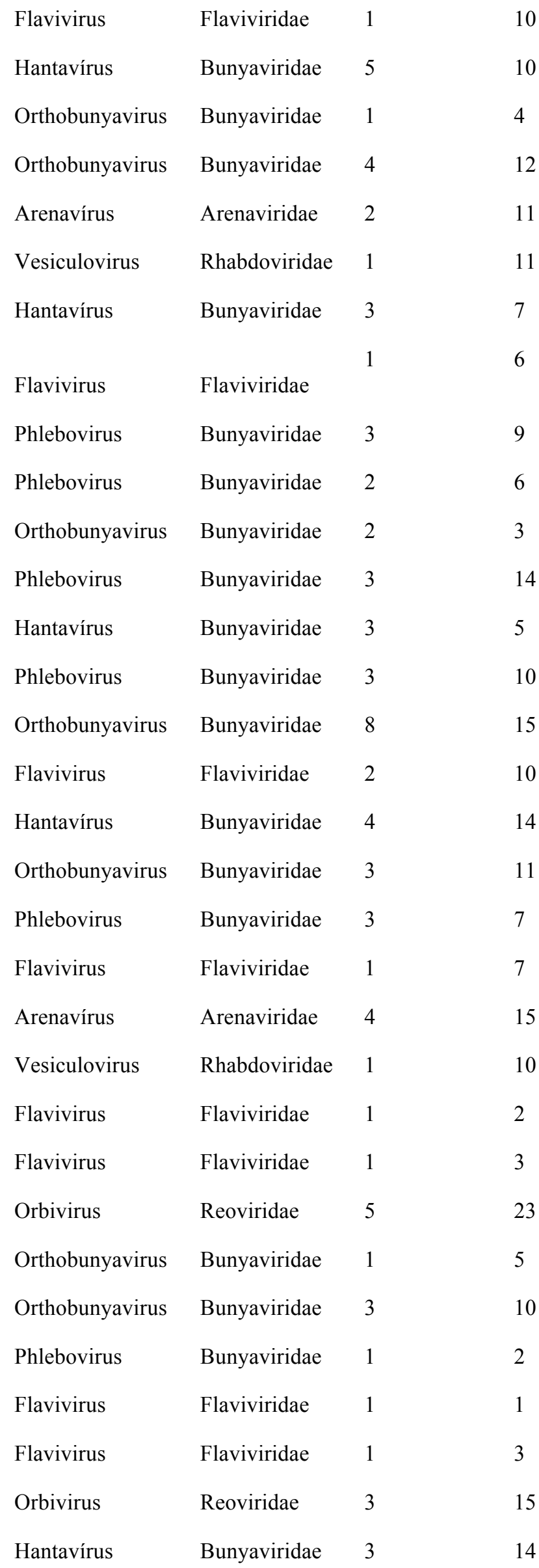




\begin{tabular}{|c|c|c|c|c|c|}
\hline 189 & Keystone virus & Orthobunyavirus & Bunyaviridae & 2 & 7 \\
\hline 190 & Khabarovsk & Hantavírus & Bunyaviridae & 1 & 5 \\
\hline 191 & Kimberley virus & Ephemerovirus & Rhabdoviridae & 1 & 12 \\
\hline 192 & Klamath virus & Vesiculovirus & Rhabdoviridae & 1 & 4 \\
\hline 193 & Kodoko virus & Arenavírus & Arenaviridae & 2 & 5 \\
\hline 194 & Kokobera virus & Flavivirus & Flaviviridae & 1 & 2 \\
\hline 195 & Koutango virus & Flavivirus & Flaviviridae & 1 & 3 \\
\hline 196 & Kunjin virus & Flavivirus & Flaviviridae & 1 & 3 \\
\hline 197 & Kupe virus & Nairovirus & Bunyaviridae & 3 & 16 \\
\hline 198 & La Crosse virus & Orthobunyavirus & Bunyaviridae & 9 & 16 \\
\hline 199 & Laguna Negra virus & Hantavírus & Bunyaviridae & 20 & 10 \\
\hline 200 & Langat virus & Flavivirus & Flaviviridae & 1 & 2 \\
\hline 201 & Lassa virus & Arenavírus & Arenaviridae & 4 & 6 \\
\hline 202 & Latino virus & Arenavírus & Arenaviridae & 2 & 7 \\
\hline 203 & Leanyer virus & Orthobunyavirus & Bunyaviridae & 3 & 14 \\
\hline 204 & Lechiguanas virus & Hantavírus & Bunyaviridae & 2 & 4 \\
\hline 205 & Liao ning virus & Seadornavirus & Reoviridae & 3 & 22 \\
\hline 206 & Lipovnik virus & Orbivirus & Reoviridae & 2 & 10 \\
\hline 207 & Lokern virus & Orthobunyavirus & Bunyaviridae & 1 & 5 \\
\hline 208 & Louping ill virus & Flavivirus & Flaviviridae & 1 & 1 \\
\hline 209 & Lujo virus & Arenavírus & Arenaviridae & 6 & 14 \\
\hline 210 & Lumbo virus & Orthobunyavirus & Bunyaviridae & 2 & 6 \\
\hline 211 & Luna virus & Arenavírus & Arenaviridae & 6 & 16 \\
\hline 212 & Lunk virus & Arenavírus & Arenaviridae & 4 & 15 \\
\hline 213 & Lymphocytic choriomeningitis virus & Arenavírus & Arenaviridae & 2 & 16 \\
\hline 214 & M'Poko virus & Orthobunyavirus & Bunyaviridae & 1 & 1 \\
\hline 215 & Macaua virus & Orthobunyavirus & Bunyaviridae & 3 & 15 \\
\hline 216 & Machupo virus & Arenavírus & Arenaviridae & 6 & 13 \\
\hline 217 & Maciel virus & Hantavírus & Bunyaviridae & 2 & 9 \\
\hline 218 & Madrid virus & Orthobunyavirus & Bunyaviridae & 1 & 2 \\
\hline 219 & Maguari virus & Orthobunyavirus & Bunyaviridae & 4 & 8 \\
\hline 220 & Main Drain virus & Orthobunyavirus & Bunyaviridae & 3 & 8 \\
\hline
\end{tabular}




\begin{tabular}{|c|c|}
\hline 221 & Malakal virus \\
\hline 222 & Maldonado virus \\
\hline 223 & Malpais Spring virus \\
\hline 224 & Maporal virus \\
\hline 225 & Maraba virus \\
\hline 226 & Maripa Hantavirus \\
\hline 227 & Marituba virus \\
\hline 228 & Massilia virus \\
\hline 229 & Mayaro virus \\
\hline 230 & Meaban virus \\
\hline 231 & Melao virus \\
\hline 232 & Menekre virus \\
\hline 233 & Merino Walk virus \\
\hline 234 & Middelburg virus \\
\hline 235 & Mobala virus \\
\hline 236 & Modoc virus \\
\hline 237 & $\begin{array}{l}\text { Montana myotis leukoencephalitis } \\
\text { virus }\end{array}$ \\
\hline 238 & Montano virus \\
\hline 239 & Mopia virus \\
\hline 240 & Morogoro virus \\
\hline 241 & Morro Bay virus \\
\hline 242 & Morumbi virus \\
\hline 243 & Mount Elgon bat virus \\
\hline 244 & Mucambo virus \\
\hline 245 & Mucura virus \\
\hline 246 & Muju virus \\
\hline 247 & Muleshoe virus \\
\hline 248 & Munguba virus \\
\hline 249 & Murray Valley encephalitis virus \\
\hline 250 & Murutucu virus \\
\hline 251 & Nairobi sheep disease virus \\
\hline 252 & Naranjal virus \\
\hline
\end{tabular}

\begin{tabular}{|c|c|c|c|}
\hline Ephemerovirus & Rhabdoviridae & 2 & 10 \\
\hline Phlebovirus & Bunyaviridae & 3 & 15 \\
\hline Vesiculovirus & Rhabdoviridae & 1 & 6 \\
\hline Hantavírus & Bunyaviridae & 3 & 14 \\
\hline Vesiculovirus & Rhabdoviridae & 1 & 14 \\
\hline Hantavírus & Bunyaviridae & 3 & 14 \\
\hline Orthobunyavirus & Bunyaviridae & 3 & 4 \\
\hline Phlebovirus & Bunyaviridae & 3 & 15 \\
\hline Alphavirus & Togaviridae & 53 & 12 \\
\hline Flavivirus & Flaviviridae & 2 & 3 \\
\hline Orthobunyavirus & Bunyaviridae & 4 & 9 \\
\hline Arenavírus & Arenaviridae & 4 & 13 \\
\hline Arenavírus & Arenaviridae & 2 & 15 \\
\hline Alphavirus & Togaviridae & 2 & 2 \\
\hline Arenavírus & Arenaviridae & 2 & 14 \\
\hline Flavivirus & Flaviviridae & 2 & 2 \\
\hline & & 1 & 5 \\
\hline Flavivirus & Flaviviridae & & \\
\hline Hantavírus & Bunyaviridae & 20 & 15 \\
\hline Arenavírus & Arenaviridae & 7 & 12 \\
\hline Arenavírus & Arenaviridae & 2 & 16 \\
\hline Orthobunyavirus & Bunyaviridae & 1 & 5 \\
\hline Phlebovirus & Bunyaviridae & 3 & 9 \\
\hline Vesiculovirus & Rhabdoviridae & 1 & 8 \\
\hline Alphavirus & Togaviridae & 25 & 2 \\
\hline Phlebovirus & Bunyaviridae & 3 & 11 \\
\hline Hantavírus & Bunyaviridae & 3 & 6 \\
\hline Hantavírus & Bunyaviridae & 1 & \\
\hline Phlebovirus & Bunyaviridae & 3 & 15 \\
\hline Flavivirus & Flaviviridae & 2 & 4 \\
\hline Orthobunyavirus & Bunyaviridae & 2 & 9 \\
\hline Nairovrus & Bunyaviridae & 5 & 10 \\
\hline Flavivirus & Flaviviridae & 2 & \\
\hline
\end{tabular}




\begin{tabular}{|c|c|}
\hline 253 & Ndumu virus \\
\hline 254 & Neembucu Hantavirus \\
\hline 255 & Nepuyo virus \\
\hline 256 & Newfound Gap Hantavirus \\
\hline 257 & New York virus \\
\hline 258 & Ngari virus \\
\hline 259 & Nique virus \\
\hline 260 & Nola virus \\
\hline 261 & North American arenavirus \\
\hline 262 & Northway virus \\
\hline 263 & Nova virus \\
\hline 264 & Ntaya virus \\
\hline 265 & Nyabira virus \\
\hline 266 & Nyando virus \\
\hline 267 & Odrenisrou virus \\
\hline 268 & Oliveros virus \\
\hline 269 & Omsk hemorrhagic fever virus \\
\hline 270 & Oran virus \\
\hline 271 & Oriboca virus \\
\hline 272 & Oriximina virus \\
\hline 273 & Orogrande virus \\
\hline 274 & Oropouche virus \\
\hline 275 & Oxbow virus \\
\hline 276 & Oyo virus \\
\hline 277 & Palma virus \\
\hline 278 & Pampa virus \\
\hline 279 & Paraná virus \\
\hline 280 & Pata virus \\
\hline 281 & Peaton \\
\hline 282 & Pergamino virus \\
\hline 283 & Perinet virus \\
\hline 284 & Phnom Penh bat virus \\
\hline
\end{tabular}

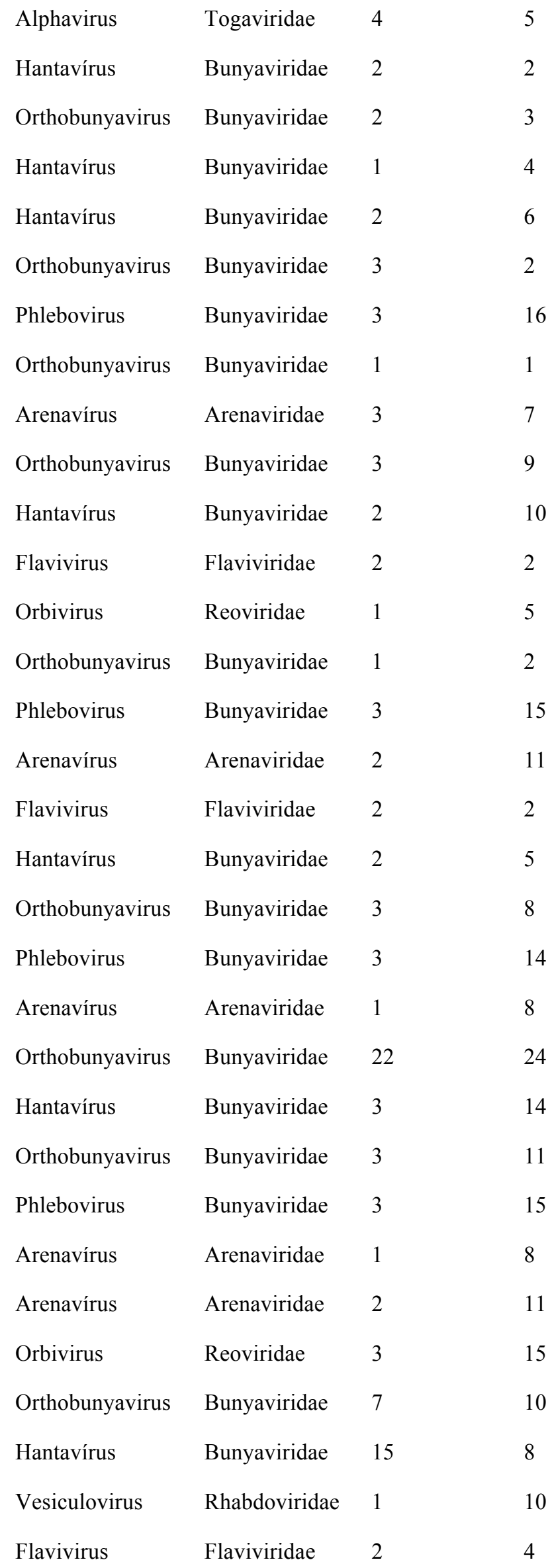




\begin{tabular}{|c|c|}
\hline 285 & Pichinde virus \\
\hline 286 & Pike fry rhabdovirus \\
\hline 287 & Pirital virus \\
\hline 288 & Piry virus \\
\hline 289 & Playa de Oro Hantavirus \\
\hline 290 & Playas virus \\
\hline 291 & Pongola virus \\
\hline 292 & Potiskum virus \\
\hline 293 & Powassan virus \\
\hline 294 & Precarious point virus \\
\hline 295 & Prospect Hill virus \\
\hline 296 & Punique virus \\
\hline 297 & Punta Salinas virus \\
\hline 298 & Punta Toro virus \\
\hline 299 & Puumala virus \\
\hline 300 & Qalyub virus \\
\hline 301 & Qiandao Lake virus \\
\hline 302 & Raza virus \\
\hline 303 & Restan virus \\
\hline 304 & Rift Valley fever virus \\
\hline 305 & Rio Bravo virus \\
\hline 306 & Rio Grande virus \\
\hline 307 & Rio Mamore virus \\
\hline 308 & Rio Negro virus \\
\hline 309 & Rio Segundo virus \\
\hline 310 & Rocio virus \\
\hline 311 & Rockport virus \\
\hline 312 & Ross River virus \\
\hline 313 & Royal Farm virus \\
\hline 314 & Saaremaa virus \\
\hline 315 & Sabiá virus \\
\hline 316 & Saboya virus \\
\hline
\end{tabular}

\begin{tabular}{|c|c|c|}
\hline Arenavírus & Arenaviridae & 5 \\
\hline Vesiculovirus & Rhabdoviridae & 1 \\
\hline Arenavírus & Arenaviridae & 3 \\
\hline Vesiculovirus & Rhabdoviridae & 3 \\
\hline Hantavírus & Bunyaviridae & 3 \\
\hline Orthobunyavirus & Bunyaviridae & 1 \\
\hline Orthobunyavirus & Bunyaviridae & 1 \\
\hline Flavivirus & Flaviviridae & 1 \\
\hline Flavivirus & Flaviviridae & 1 \\
\hline Phlebovirus & Bunyaviridae & 3 \\
\hline Hantavírus & Bunyaviridae & 3 \\
\hline Phlebovirus & Bunyaviridae & 3 \\
\hline Nairovirus & Bunyaviridae & 1 \\
\hline Phlebovirus & Bunyaviridae & 4 \\
\hline Hantavírus & Bunyaviridae & 6 \\
\hline Nairovirus & Bunyaviridae & 1 \\
\hline Hantavírus & Bunyaviridae & 3 \\
\hline Nairovirus & Bunyaviridae & 1 \\
\hline Orthobunyavirus & Bunyaviridae & 2 \\
\hline Phlebovirus & Bunyaviridae & 101 \\
\hline Flavivirus & Flaviviridae & 1 \\
\hline Phlebovirus & Bunyaviridae & 1 \\
\hline Hantavírus & Bunyaviridae & 3 \\
\hline Alphavirus & Togaviridae & 2 \\
\hline Hantavírus & Bunyaviridae & 1 \\
\hline Flavivirus & Flaviviridae & 2 \\
\hline Hantavírus & Bunyaviridae & 7 \\
\hline Alphavirus & Togaviridae & 4 \\
\hline Flavivirus & Flaviviridae & 1 \\
\hline Hantavírus & Bunyaviridae & 4 \\
\hline Arenavírus & Arenaviridae & 3 \\
\hline Flavivirus & Flaviviridae & 1 \\
\hline
\end{tabular}




\begin{tabular}{|c|c|}
\hline 317 & Sagiyama virus \\
\hline 318 & Saint Croix River virus \\
\hline 319 & Sal Vieja virus \\
\hline 320 & Salehabad virus \\
\hline 321 & Salobo virus \\
\hline 322 & San Angelo virus \\
\hline 323 & San Perlita virus \\
\hline 324 & Sandfly fever Naples virus \\
\hline 325 & Sandfly fever sicilian virus \\
\hline 326 & Sandfly Sicilian Turkey virus \\
\hline 327 & Sangassou virus \\
\hline 328 & Sango virus \\
\hline 329 & Sapporo rat virus \\
\hline 330 & Sathuperi virus \\
\hline 331 & Saumarez Reef virus \\
\hline 332 & Schmallenberg virus \\
\hline 333 & Seewis virus \\
\hline 334 & Semliki Forest virus \\
\hline 335 & Seoul virus \\
\hline 336 & Sepik virus \\
\hline 337 & Serang virus \\
\hline 338 & Serra do Navio virus \\
\hline 339 & Serra Norte virus \\
\hline 340 & Shamonda virus \\
\hline 341 & Shokwe virus \\
\hline 342 & Shuni virus \\
\hline 343 & Simbu virus \\
\hline 344 & Sin Nombre virus \\
\hline 345 & Sindbis virus \\
\hline 346 & Skinner Tank virus \\
\hline 347 & Snowshoe Hare virus \\
\hline 348 & Soochong virus \\
\hline
\end{tabular}

\begin{tabular}{|c|c|c|c|}
\hline Alphavirus & Togaviridae & 2 & 1 \\
\hline Orbivirus & Reoviridae & 2 & 8 \\
\hline Flavivirus & Flaviviridae & 3 & 4 \\
\hline Phlebovirus & Bunyaviridae & 1 & 3 \\
\hline Phlebovirus & Bunyaviridae & 3 & 9 \\
\hline Orthobunyavirus & Bunyaviridae & 2 & 9 \\
\hline Flavivirus & Flaviviridae & 1 & 1 \\
\hline Phlebovirus & Bunyaviridae & 5 & 7 \\
\hline Phlebovirus & Bunyaviridae & 8 & 4 \\
\hline Phlebovirus & Bunyaviridae & 3 & 11 \\
\hline Hantavírus & Bunyaviridae & 4 & 15 \\
\hline Orthobunyavirus & Bunyaviridae & 2 & 10 \\
\hline Hantavírus & Bunyaviridae & 2 & 2 \\
\hline Orthobunyavirus & Bunyaviridae & 3 & 8 \\
\hline Flavivirus & Flaviviridae & 1 & 1 \\
\hline Orthobunyavirus & Bunyaviridae & 3 & 10 \\
\hline Hantavírus & Bunyaviridae & 3 & 12 \\
\hline Alphavirus & Togaviridae & 11 & 5 \\
\hline Hantavírus & Bunyaviridae & 6 & 13 \\
\hline Flavivirus & Flaviviridae & 1 & 1 \\
\hline Hantavírus & Bunyaviridae & 3 & 12 \\
\hline Orthobunyavirus & Bunyaviridae & 3 & 10 \\
\hline Phlebovirus & Bunyaviridae & 3 & 14 \\
\hline Orthobunyavirus & Bunyaviridae & 4 & 10 \\
\hline Orthobunyavirus & Bunyaviridae & 2 & 2 \\
\hline Orthobunyavirus & Bunyaviridae & 1 & 4 \\
\hline Orthobunyavirus & Bunyaviridae & 1 & 1 \\
\hline Hantavírus & Bunyaviridae & 3 & 7 \\
\hline Alphavirus & Togaviridae & 60 & 7 \\
\hline Arenavírus & Arenaviridae & 2 & 15 \\
\hline Orthobunyavirus & Bunyaviridae & 3 & 7 \\
\hline Hantavírus & Bunyaviridae & 10 & 15 \\
\hline
\end{tabular}




\begin{tabular}{|c|c|}
\hline 349 & Sororoca virus \\
\hline 350 & South River virus \\
\hline 351 & Southern elephant seal virus \\
\hline 352 & Spondweeni virus \\
\hline 353 & Spring viraemia of carp virus \\
\hline 354 & St. Louis encephalitis virus \\
\hline 355 & Stratford virus \\
\hline 356 & Tacaiuma virus \\
\hline 357 & Tacaribe virus \\
\hline 358 & Tahyna \\
\hline 359 & Tamana bat virus \\
\hline 360 & Tamiami virus \\
\hline 361 & Tanganya virus \\
\hline 362 & Tehran virus \\
\hline 363 & Tembusu virus \\
\hline 364 & Tensaw virus \\
\hline 365 & Tete virus \\
\hline 366 & Thailand virus \\
\hline 367 & Thottapalayam virus \\
\hline 368 & Tick-borne encephalitis virus \\
\hline 369 & Tillamook virus \\
\hline 370 & Tilligerry virus \\
\hline 371 & Tinaroo virus \\
\hline 372 & Tlacotalpan virus \\
\hline 373 & Tonate virus \\
\hline 374 & Tonto creek virus \\
\hline 375 & Topografov virus \\
\hline 376 & Toscana virus \\
\hline 377 & Tribec virus \\
\hline 378 & Trivittatus virus \\
\hline 379 & Trocara virus \\
\hline 380 & Tucunduba virus \\
\hline
\end{tabular}

\begin{tabular}{|c|c|c|c|}
\hline Orthobunyavirus & Bunyaviridae & 3 & 14 \\
\hline Orthobunyavirus & Bunyaviridae & 3 & 8 \\
\hline Alphavirus & Togaviridae & 2 & 5 \\
\hline Flavivirus & Flaviviridae & 1 & 1 \\
\hline Vesiculovirus & Rhabdoviridae & 1 & 2 \\
\hline Flavivirus & Flaviviridae & 8 & 10 \\
\hline Flavivirus & Flaviviridae & 1 & 8 \\
\hline Orthobunyavirus & Bunyaviridae & 1 & 2 \\
\hline Arenavírus & Arenaviridae & 2 & 14 \\
\hline Orthobunyavirus & Bunyaviridae & 4 & 16 \\
\hline Flavivirus & Flaviviridae & 1 & 8 \\
\hline Arenavírus & Arenaviridae & 2 & 13 \\
\hline Hantavírus & Bunyaviridae & 2 & 10 \\
\hline Phlebovirus & Bunyaviridae & 3 & 7 \\
\hline Flavivirus & Flaviviridae & 5 & 2 \\
\hline Orthobunyavirus & Bunyaviridae & 3 & 5 \\
\hline Orthobunyavirus & Bunyaviridae & 1 & 5 \\
\hline Hantavírus & Bunyaviridae & 8 & 7 \\
\hline Hantavírus & Bunyaviridae & 3 & 10 \\
\hline Flavivirus & Flaviviridae & 40 & 10 \\
\hline Nairovirus & Bunyaviridae & 1 & 2 \\
\hline Orbivirus & Reoviridae & 3 & 15 \\
\hline Orthobunyavirus & Bunyaviridae & 3 & 9 \\
\hline Orthobunyavirus & Bunyaviridae & 2 & 1 \\
\hline Alphavirus & Togaviridae & 2 & 1 \\
\hline Arenavírus & Arenaviridae & 4 & 16 \\
\hline Hantavírus & Bunyaviridae & 3 & 14 \\
\hline Phlebovirus & Bunyaviridae & 7 & 1 \\
\hline Orbivirus & Reoviridae & 3 & 1 \\
\hline Orthobunyavirus & Bunyaviridae & 4 & 13 \\
\hline Alphavirus & Togaviridae & 2 & \\
\hline Orthobunyavirus & Bunyaviridae & 3 & \\
\hline
\end{tabular}




\begin{tabular}{|c|c|}
\hline 381 & Tula virus \\
\hline 382 & Tunari virus \\
\hline 383 & Turkish sheep encephalitis virus \\
\hline 384 & Turuna virus \\
\hline 385 & Tyuleniy virus \\
\hline 386 & Uganda $\mathrm{S}$ virus \\
\hline 387 & Umatilla virus \\
\hline 388 & Umbre virus \\
\hline 389 & Una virus \\
\hline 390 & Uriurana virus \\
\hline 391 & Ussuri virus \\
\hline 392 & Usutu virus \\
\hline 393 & Utique virus \\
\hline 394 & Uukuniemi virus \\
\hline 395 & Venezuelan equine encephalitis virus \\
\hline 396 & Vesicular stomatitis Alagoas virus \\
\hline 397 & Vesicular stomatitis Indiana virus \\
\hline 398 & $\begin{array}{l}\text { Vesicular stomatitis New Jersey } \\
\text { virus }\end{array}$ \\
\hline 399 & Vinces virus \\
\hline 400 & Weldona virus \\
\hline 401 & Wesselsbron virus \\
\hline 402 & West Nile virus \\
\hline 403 & Western equine encephalitis virus \\
\hline 404 & Whitewater virus \\
\hline 405 & Wyeomyia virus \\
\hline 406 & Xingu virus \\
\hline 407 & Yaounde virus \\
\hline 408 & Yellow fever virus \\
\hline 409 & Yokose virus \\
\hline 410 & Yug Bogdanovac virus \\
\hline 411 & Yunnan Orbivirus \\
\hline 412 & Zika virus \\
\hline
\end{tabular}

\begin{tabular}{|c|c|c|}
\hline Hantavírus & Bunyaviridae & 6 \\
\hline Hantavírus & Bunyaviridae & 3 \\
\hline Flavivirus & Flaviviridae & 1 \\
\hline Phlebovirus & Bunyaviridae & 3 \\
\hline Flavivirus & Flaviviridae & 1 \\
\hline Flavivirus & Flaviviridae & 1 \\
\hline Orbivirus & Reoviridae & 3 \\
\hline Orthobunyavirus & Bunyaviridae & 8 \\
\hline Alphavirus & Togaviridae & 1 \\
\hline Phlebovirus & Bunyaviridae & 3 \\
\hline Hantavírus & Bunyaviridae & 4 \\
\hline Flavivirus & Flaviviridae & 7 \\
\hline Phlebovirus & Bunyaviridae & 3 \\
\hline Phlebovirus & Bunyaviridae & 3 \\
\hline Alphavirus & Togaviridae & 57 \\
\hline Vesiculovirus & Rhabdoviridae & 1 \\
\hline Vesiculovirus & Rhabdoviridae & 1 \\
\hline & & 1 \\
\hline Vesiculovirus & Rhabdoviridae & \\
\hline Orthobunyavirus & Bunyaviridae & 2 \\
\hline Orthobunyavirus & Bunyaviridae & 1 \\
\hline Flavivirus & Flaviviridae & 1 \\
\hline Flavivirus & Flaviviridae & 3 \\
\hline Alphavirus & Togaviridae & 36 \\
\hline Arenavírus & Arenaviridae & 2 \\
\hline Orthobunyavirus & Bunyaviridae & 3 \\
\hline Orthobunyavirus & Bunyaviridae & 2 \\
\hline Flavivirus & Flaviviridae & 1 \\
\hline Flavivirus & Flaviviridae & 3 \\
\hline Flavivirus & Flaviviridae & 1 \\
\hline Vesiculovirus & Rhabdoviridae & 1 \\
\hline Orbivirus & Reoviridae & 3 \\
\hline Flavivirus & Flaviviridae & 1 \\
\hline
\end{tabular}


